AN ANALYSIS OF THE RELATIONS AMONG ELEMENTS OF CLIMATE, SURFACE PROPERTIES, AND GEOMORPHOLOGY

\author{
Technical Report No. 11 \\ Project NR 389-042 \\ Office of Naval Research
}

by

Mark A. Melton

Department of Geology

Columbia University

New York 27, N. Y.

1957 

Department of Geology

Columbia University

New York 27, N. Y.

\title{
AN ANALYSIS OF THE RELATIONS AMONG ELEMENTS OF CLIMATE, SURFACE PROPERTIES, AND GEOMORPHOLOGY
}

\author{
Technical Report No. 11 \\ Project NR 389-042 \\ Office of Naval Research
}

by

Mark A. Melton

The research reported in this document has been made possible through support and sponsorship by the United States Department of the Navy, Office of Naval Research, Geography Branch, under Project NR 389-042, Contract N6 ONR 271-30, Task Order 30. Reproduction in whole or in part is permitted for any purpose of the United States Government. 
Lithoprinted in U.S.A.

EDWARDS BROTHERS, INC.

Ann Arbor, Michigan 


\section{Contents}

Abstract ............................. vi

Introduction and Acknowledgments $\ldots \ldots \ldots \ldots \ldots \ldots \ldots \ldots \ldots \ldots \ldots \ldots \ldots$

Methods of Map Analysis and Definitions of Terms ................. 1

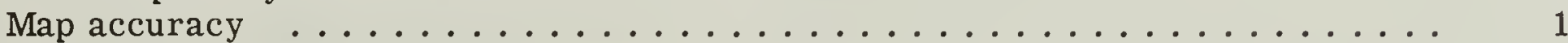

Methods of obtaining quantitative data from maps $\ldots \ldots \ldots \ldots \ldots \ldots \ldots$

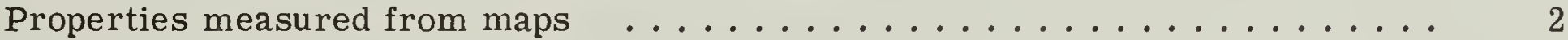

Derived quantities $\ldots \ldots \ldots \ldots \ldots \ldots \ldots \ldots \ldots \ldots$

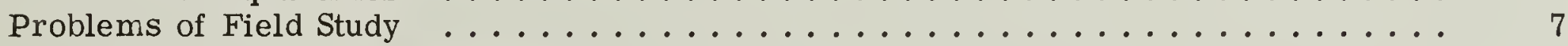

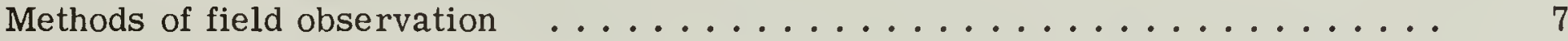

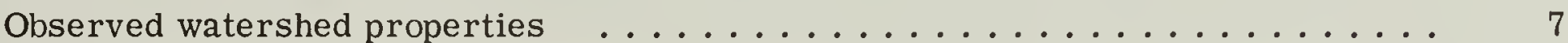

General plan of field measurements $\ldots \ldots \ldots \ldots \ldots \ldots \ldots \ldots$

Measured properties $\ldots \ldots \ldots \ldots \ldots \ldots \ldots \ldots \ldots \ldots \ldots \ldots$

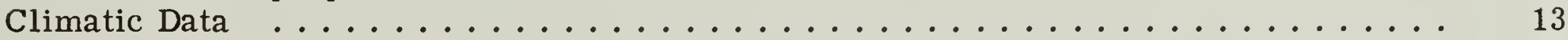

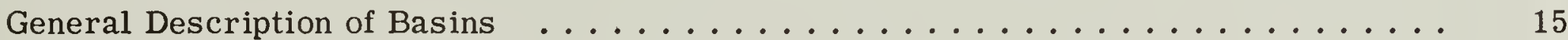

Basins in Arizona $\ldots \ldots \ldots \ldots \ldots \ldots \ldots \ldots \ldots \ldots \ldots \ldots \ldots$

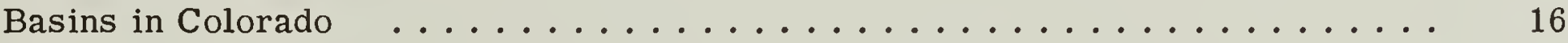

Basins in New Mexico .......................... 18

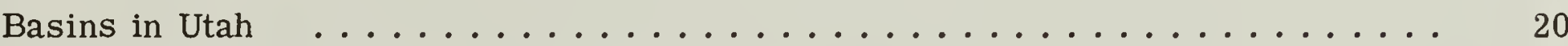

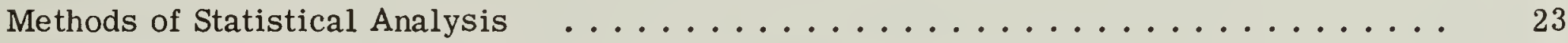

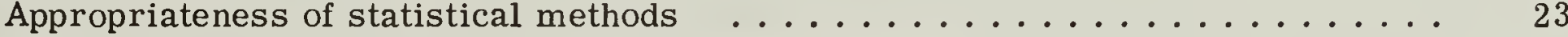

Regression and correlation analysis of paired variables $\ldots \ldots \ldots \ldots \ldots \ldots$

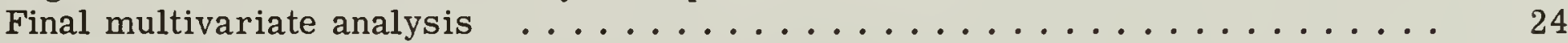

Inferences Drawn from Results of Statistical Tests . . . . . . . . . . . . . 27

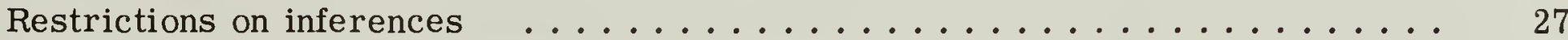

Results of analysis of variance and covariance tests $\ldots \ldots \ldots \ldots \ldots \ldots \ldots$

Results of simple correlation and regression analyses $\ldots \ldots \ldots \ldots \ldots \ldots$

Relations among planimetric properties of basins ............... . . 30

Relation of valley-side slopes to other basin characteristics . . . . . . . . . . 30

Texture of topography as affected by climatic and mantle characteristics . . . . 33

Generalizations on investigative procedures $\ldots \ldots \ldots \ldots \ldots \ldots \ldots \ldots \ldots$

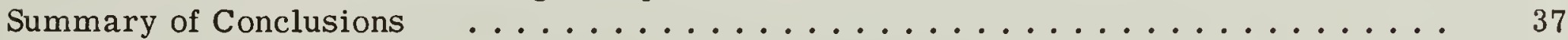

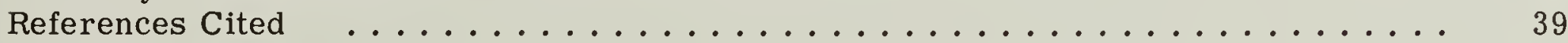

Appendices

I Derivations of relations among geometrical elements of valleys $\ldots \ldots \ldots \ldots$

II Index maps of study areas $\ldots \ldots \ldots \ldots \ldots \ldots \ldots \ldots \ldots \ldots \ldots . \ldots \ldots$

III Derivation of relation between diameter of imprint and volume of imprint,

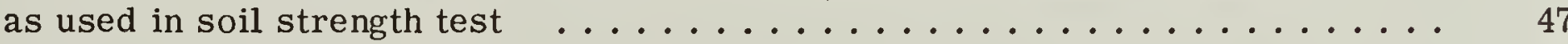

IV Maps and drainage nets of study areas . . . . . . . . . . . . . . . 49

$\mathrm{V}$ Two-variable correlation and regression analyses

A. Correlation tables of relations analyzed by grouped-data methods . . . . 63

B. Scatter plots and regressions of selected relations; ungrouped data ... 71

VI A. Analyses of variance $\ldots \ldots \ldots \ldots \ldots \ldots \ldots \ldots \ldots \ldots \ldots$

B. Determination of the effect of gullying and trenching on drainage density,

bII Solution of normal equations relating drainage density to soil properties and climate elements by the Doolittle method $\ldots \ldots \ldots \ldots \ldots \ldots$ 
Digitized by the Internet Archive in 2020 with funding from Columbia University Libraries 


\section{Illustrations}

Figures $\quad \underline{\text { Page }}$

1. Inflection angle as measured on various forms of first-order channels. . . . . . . 3

2. Relations among valley-side slope, inflection angle, channel gradient, and dihedral angle between valley sides for an idealized channel. . . . . . . . . 6

3. Infiltrometer assembly diagram. . . . . . . . . . . . . . . . . 9

4. Conversion of discharge (percent of flow) to infiltration rate (inches per hour)

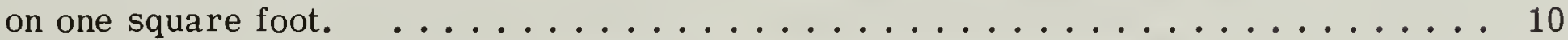

5. Principle of measuring soil strength by dropping a spherical weight. . . . . . . 10

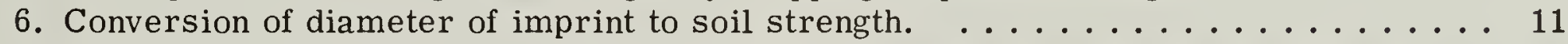

7. Relation of P-E index to elevation for Arizona, Colorado, New Mexico, and Utah. . . 14

8. Hypothetical channels illustrating influence of infiltration capacity, interflow,

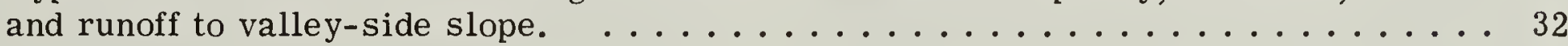

Tables

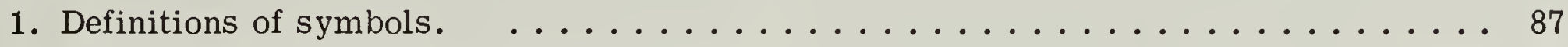

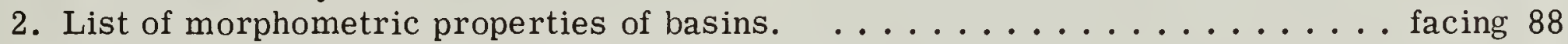

3. Vegetation characteristics of each basin. ................. 89

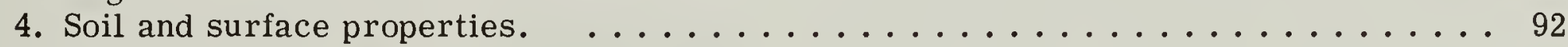

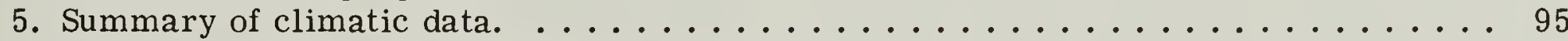

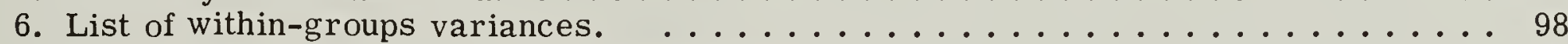

7. Individual infiltration-capacity measurements. . . . . . . . . . . . . 99 


\section{Abstract}

Landform morphometry is related to causative factors of climate, mantle characteristics, vegetation density, and lithology. Drainage basins analyzed are in mature fluvial development, free from obvious structural influence, and in climates ranging from arid to humid. Over 80 basins in Arizona, Colorado, New Mexico, and Utah were inspected in the field; 22 were subjected to detailed field investigations.

Morphometric properties of all basins were measured from recent 1: 24,000 topographic maps, or special drainage maps, and show great ranges: valley-side slope has a four-fold range, drainage density and basin relief about 100-fold, and basin area 5,000-fold.

Climate was measured by the Thornthwaite precipitation-effectiveness (P-E) index, and the intensity of average five-year, one-hour rains. Lithologies distinguished are shale, clastic rocks, schist, limestone, granitic rocks, and acid volcanic rocks, assumed to indicate roughly the proportion of clay in residual soils. Mantle and cover characteristics are summarized by relative infiltration capacity, wet and dry soil strength, percentage of bare area, and surface roughness.

Validity of statistical inferences is affected by sampling procedures, which were mainly nonrandom. Analysis-of-variance tests show that shale and schist produce high drainage densities, whereas granitic, clastic, and acid volcanic rocks produce low densities, with no significant differences among these three. Shale and schist have low infiltration capacity, whereas clastic and granitic rocks produce high values. Valley-side slopes are greatest in shale and limestone, and lowest in schist, on the average, subject to differences in erosional history.

Drainage density averaged highest in basins having gullied slopes, intermediate in unmodified basins, and lowest in basins with trenched main channels. Differences were not judged significant, even with adjustment for infiltration, though low power renders the test inconclusive.
Using punched cards, variables were analyzed in pairs for significant correlations and regressions. Texture of topography decreases exponentially with valley-side slope. Relative relief and ruggedness number corrected for order increase exponentially with slopes. Texture questionably varies inversely with relative relief.

High correlations exist among channel frequency, drainage density, and frequency and density of first-order channels. It is inferred that average channel-segment length of any order varies inversely with the total channel length, for areas of the same size but differing drainage densities. Average first-order channel length is a constant proportion of average channel length of all orders, and is inversely proportional to total channel length.

Multiple correlation analyses show that valleyside slopes and drainage density are related to climate, and to properties of mantle and vegetal cover, as measured in the field. Slopes increase with infiltration capacity and $\mathrm{P}-\mathrm{E}$ index, but vary inversely with wet soil strength and runoff intensity-frequency. Greater runoff produces lower valley-side slopes. Climate enters further by the increase of infiltration capacity with $\mathrm{P}-\mathrm{E}$ index. Greater infiltration permits interflow, reducing the ratio of slope runoff to channel flow. Channels are deepened with less opportunity for erosion of slopes, producing steep slopes.

Drainage density varies with percent bare area and runoff frequency-intensity, but inversely with $\mathrm{P}-\mathrm{E}$ index and infiltration capacity, fitting theoretical observations of Gilbert, Davis, and Johnson, and confirming Horton's infiltration theory of erosion. Primary controls of topographic texture are lithology and climate, which act through the agency of secondary surface properties. Accidental changes in these secondary controls, unrelated to climatic changes, will quickly alter the drainage density to another value than that expected from consideration of climate and lithology alone. 


\section{Introduction and Acknowledgements}

Climatic influence on topographic form properties of fluvially dissected landscapes has long been recognized by geologists and geographers. Although considerable literature exists on this subject, three vital procedures are lacking in early studies: (1) Isolation of climatic elements and effects. Climate was usually referred to as "arid" or "humid," in regard to moisture; "hot," "temperate," or "cold," in regard to temperature. (2) Investigation of relative importance of processes. Knowledge of process was largely taken for granted emphasis being placed on historical interpretation and classification. (3) Expression of laws in quantitative terms. Research was largely of a qualitative nature because it was thought that features of the landscape are so variable that mathematical treatment would be impracticable. Attempts at quantitative application of principles were resticted to simple cases.

Recently, however, a number of geomorphologists have recognized the availability of mathematical tools capable of coping with the variability, or chance element, in landforms. Their approach has been chiefly to examine in detail the variations in properties of areas similar in major characteristics and history. If it can be shown that these variations are too great to be of random nature, then they must be the result of some basic differences in rate or intensity of operation of process. In these recent studies, climate has been for the most part of secondary interest.

The main purpose of this study is to provide a foundation for further research into the effects of availability of moisture to vegetal cover, and of rainstorm intensity and frequency on processes of landform evolution. Consideration is given to properties of the surface mantle as they are affected by climate, and in turn as they affect processes. Because action of the processes is too slow to be observed during a short time, relative rates are inferred from measurements of the landforms themselves.

The factors influencing topographic texture and average slope can be considered as fundamental in control of the fluvial landscape. The controls most often mentioned in descriptive treatments of the subject are "climate," "rock permeability," and "rock strength." Structural properties of the rock such as jointing, initial or available relief, stage in the erosional cycle, and condition of the surface soil are frequently mentioned as well (Thornbury,
1954, p. 128). Factors influencing the steepness and mode of retreat of slopes in fluvially-controlled landscapes have received much attention in testing Walther Penck's ideas of slope development.

Gilbert (1877, p. 109-118) analyzed the processes of slope and channel equilibrium as effected by running water. He reasoned that fluvially eroded areas in arid regions are "degraded" at a rate limited by the slowness of the production of fine waste material; removal by transport is rapid once waste has formed. Thus, differences in rock texture are accentuated in arid regions. Greater availability of water hastens the rate of production of waste material, and likewise increases the rapidity of transport. But the greater vegetal cover in humid regions slows transportation and is generally effective in causing an accumulation of waste. Thus, differences in rock texture are obscured by accumulated waste in humid regions. A climate intermediate between arid and humid, Gilbert concluded, must produce the most rapid and effective erosion.

In badlands areas, declivities decrease as the amount of water flowing over them increases, and slopes are greater "in proportion as they are near divides, unless they are very near divides" (Gilbert, 1877, p. 117). The convexity of hilltops evidently puzzled Gilbert at the time he wrote the report on the Henry Mountains, and his solution to the problem, as indicated later, was the agency of creep (Gilbert, 1909, p. 344-350). Little has been added to the qualitative knowledge of slope equilibrium since Gilbert's publications; quantitative study of these processes described has only just begun.

Walther Penck (1953, p. 119-120, and 130-133) evidently believed that the same landforms can appear under all climates, though developing at different rates. Climatic differences may change the relationship of mass-wasting to transportation, but they do not produce any fundamental change in the denudational forms. Slope gradients depend only on the intensity of erosion; so if all slopes in a region are of the same steepness, it is an expression of the fact that erosion has acted upon them with the same intensity. It follows from this, according to Penck, that gradients are determined by endogenetic factors, and less so by rock hardness. The form of slope profiles reflects changes in endogenetic rates. old highlands, separated from a former base-level of erosion by a topographic break, invariably display concave slopes. Convex and straight slopes are associated with zones of intense recent erosion. 
Where the mean slope gradient corresponds to the maximum gradient for the rock concerned, convex slopes are replaced by straight profiles; these find their "purest expression in the steep relief of mountains which escaped Pleistocene glaciation, whether these are covered with tropical virgin forest or belong to arid regions" (Penck, 1953, p. 132). Penck's views of relation of slope form to endogenetic factors have largely been discredited in universal application. It is possible that qualifications may have originally been present in his book that have been lost in translation, so great is the mass of verbiage.

The first truly quantitative approach to the subject of the control of topographic texture was by hydrologists. Robert E. Horton (1945, p. 283, 285) defined the terms drainage density, the total length of channels divided by the area drained, and stream frequency, the number of channel segments divided by the area drained, showing that together they determine the fineness of topography. He concluded, perhaps erroneously, that areas with low drainage density are poorly drained, and areas with high drainage density are well drained. Horton emphasized the importance of surface characteristics in determining drainage density, particularly infiltration capacity, and resistance of the surface to erosion (1933, p. 260, and 1945, p. 284).

Forest and range conservationists, working under the U.S. Department of Agriculture, have obtained much-needed quantitative information on infiltration and erosion rates related to land use, type of soil and cover, and distribution of rain during storms (Dortignac, 1951; Love and Johnson, 1952; Love and Dunford, 1952; Love, 1953; Anderson, 1954). Of special importance to geomorphologists are studies of rainfall-runoff proportions, in cases of known accelerated erosion, in both forested and grazed watersheds. Schumm (1955) has demonstrated that sediment loss from basins can be related to form properties within the basin, and to infiltration capacity of the soil.

A. N. Strahler has emphasized the use of statistical methods in quantitative investigations, rather than deductive analysis (1950, 1954a). Recently he has used the $\mathrm{Pi}$ Theorem and dimensional analys is in combining factors that rationally can be said to contribute to the main causes determining drainage density (Strahler, 1956b). Dimensionless numbers were derived that have the property of independence of size of corresponding units of the drainage basins considered. Thus, if drainage density can rationally be said to depend upon (1) the average rate of flow stated in volume per unit of area of basin, (2) an erosion proportionality factor, (3) the height of the basin above its mouth, (4) density of surface material, (5) viscosity of water, and (6) the acceleration of gravity, then these quantities can be arranged into four dimensionless numbers. These are (1) ruggedness number (product of drainage density and relief of basin), (2) Froude number, (3) Reynolds number, and (4) Horton number (product of erosion proportionality factor and the average volume rate of flow per unit area). Full evaluation of the relations among all these quantities would take many years of research. The present study treats only portions of these relations that are inherent in expression of relief, strength of surface material, average rate of runoff, measures of roughness, and extent of cover.

Generalizing from these discussions, there seems to be agreement on factors influencing slope development and equilibrium, and drainage density. Considerable disagreement exists as to which factors are dominant in effect and which are secondary. Where topographic features and related quantities are measurable, it is generally not known whether these quantities are related by simple proportion, by power functions, by exponential functions, or by other transcendental functions. The writer has endeavored to advance the understanding of these fundamental questions by using (1) form measurements from topographic maps, (2) simple field measurements of soil properties and characteristics of vegetal cover, (3) analysis of climate elements, and (4) combination of numerical data by statistical analysis. Correlation analysis, in particular, allows separation of major, minor, and definitely unrelated effects.

This investigation formed part of a quantitative study of erosional landforms sponsored through Columbia University by the Geography Branch of the Office of Naval Research as Project Number NR 389-042, under Contract N60NR 271, Task Order 30.

The writer is indebted to Professor A. N. Strahler for guidance in planning and carrying out field and map research. Professor Howard Levene of the Department of Mathematical Statistics of Columbia University advised on a method of analysis of variance and critically read the text. Mr. Gary Gordon of Mt. Vernon, Iowa, assisted in the field during two months of the summer of 1955. Sara Melton assisted during two field seasons, and helped in preparing the manuscript. Styron Douthit and Steven Haines of the University of Oklahoma aided in preparation of the illustrations. 


\section{Methods of Map Analysis and Definitions of Terms}

Geologists familiar with quantitative landform analysis will understand most of the terms used here, although some are original. To avoid misunderstanding, all terms and symbols are defined in Table 1, which gives units and dimensions of all quantities. Map data is included from 3 fifth-order basins, 22 fourth-order basins, and 83 third-order basins. Field measurements are given for 1 fifthorder basin, 19 fourth-order basins, and 9 thirdorder basins. These are divided into 58 third-order basins for analysis. The remaining basins were inspected briefly to determine the general condition of the vegetal cover, rock type, and condition of channels.

\section{MAP ACCURACY}

The amount of usable, reliable information contained on topographic maps increases with the accuracy of the map. Because maps differ in accuracy depending on scale and contour interval, and on the method by which they were made, it is important in comparative studies that data be obtained from maps of comparable relative accuracy. Otherwise, comparisons between areas differing in some respect will be in error.

Only tho se maps published by the U. S. Geological Survey at the scale 1:24,000, and compiled from aerial photographs, have been used in this study, with three exceptions: (1) maps of the Nederland, Black Hawk, and Morrison quadrangles in Colorado, were published at the scale $1: 24,000$, but were made by plane-table surveys in 1942 and 1938, before photogrammetric methods were in use by the U. S. Geological Survey. The drainage nets of the basins studied in these areas were drawn from aerial photographs obtained from the U.S. Forest Service, by using a KEK Stereoscopic Plotter.* Considerable revision in the drainage nets of basins in those areas was necessary. (2) A small badlands area in the Chinle shale, north of Cameron, Arizona, is not included in any quadrangle map, and could not be adequately shown at the scale 1:24,000. Two small drainage basins in the badlands were mapped at 1 inch to 50 feet by E. D. Koons, S. A. Schumm, and A. N. Strahler, in the summer of 1953. When examined by the writer, two years later, two small channels had become obliterated and

* Manufactured by Kail and Associates, Denver, Colorado. were removed from the drainage net; otherwise, the map was extremely accurate. (3) An area of badlands in the Saguaro National Monument, southeast of Tucson, Arizona, is covered only by the 1904 Tucson Quadrangle, at the scale 1:125,000. In order to use the area in the study, a fifth-order basin was mapped at 1 inch to 100 feet with plane table and alidade by the writer and assistant, in December, 1955. The drainage nets mapped in these three areas are believed comparable in accuracy to the drainage nets shown on photogrammetric maps of other areas.

In all basins in which field measurements were taken, the drainage net was drawn on the map to correspond with the existing channels.* It was found that in most maps a high percentage of the first-order channels is represented by the smallest cusps in contour lines. In a few areas (e.g. Spring Creek basin, Springville Quadrangle, Utah), the smallest cusps represent only irregularities in the surface, not persistent drainage lines. In other areas (e.g. Quartz Hill basin, Paxton Springs Quadrangle, N. M.), the smallest cusps in the contour lines represent second or third-order channels. In many basins shallow gullies established on the valley sides are not shown by the contour lines. In accordance with these considerations, about $95 \%$ of the basins studied needed at least minor corrections of the drainage net as shown on the contour map. (See Appendix IV for photo-copies of portions of maps, showing drainage nets of all basins studied.)

\section{METHODS OF OBTAINING QUANTITATIVE DATA FROM MAPS}

Many of the basins studied are rather small, as shown on the original maps. In measuring features

*Horton (1945) used stream with the same meaning that channel has here and in previous reports by $A$. N. Strahler (1950, 1952a, 1953), V. C. Miller (1953), K. G. Smith (1953), S. A. Schumm (1954) and D. R. Coates (1955). The term channel means a permanent, clearly defined trench or trough clearly showing evidence of scour by channel flow and bounded by valley sides sloping toward the channel axis. Excluded by this definition are ephemeral or seasonal rills cut in otherwise smooth slopes which do not contribute runoff to the rill and which have no clearly defined watershed and drainage divide. Channel is preferred since emphasis is placed on the depression in which water flows, rather than a stream of water itself. Most channels studied here would be classed as ephemeral or intermittent streams. 
in these basins, the percentage of error can be reduced by enlarging the maps photographically; measurements on the prints can then be made with greater relative precision. The maps of all basins studied in detail in the field were enlarged two to eight times, depending upon original size. Prints were made by a Photostat machine, or by making full-sized negatives on large sheets of film and printing directly on blue-line paper. The prints were air dried. Distortion of the image was present in almost all cases, but by marking several oneinch intervals with various orientations on the original and measuring the corresponding interval on the enlarged print, it was established that differential shrinkage caused slight variation in scale. In two perpendicular directions, parallel to the edges of the print, the greatest difference in scale was $1.6 \%$.

Measurements of length were made from the enlarged maps by means of a Dietzgen Map Measure, No. 1719B, scaled to $1 / 32$ inch, and on which measurements can be estimated to the nearest $1 / 64$ inch. Hence, on an enlarged map with scale of about 10 inches per mile, measured lengths can justifiably be recorded to the nearest 0.01 mile.

Area measurements were made with a Keuffel and Esser Compensating Polar Planimeter, Model 4242. Highly consistent results were obtained in repeated measurements of the same outline. Reversing the position of the pole with respect to the tracer head eliminated a small systematic error. Deviations greater than 0.02 square inches are unusual in individual area measurements, hence, on a map with scale 100 square inches per square mile, it is justifiable to record measurements to the nearest 0.001 square mile.

\section{PROPERTIES MEASURED FROM MAPS}

Of all the information that can be obtained from maps by measurement, two general categories may be distinguished: (a) quantities measured (or counted) directly, with no more computation than multiplication by a scale factor, and (b) quantities that must be computed from direct measurements because they cannot in themselves be measured. The first category includes length and area measurements, numbers of items obtained by enumeration, and certain angular measurements. Lowercase Roman letters are used as notation for properties of length, area, or number; lower-case Greek letters for angular measurements. To develop a satisfactory notation for the numerous morphometric properties, full use of upper and lower-case letters, and of subscripts, is necessary. Subscript notation must be systematic and consistent. Subscripts are appended to letter symbols to distinguish measurements of the same kind that are made on features differing in some way, such as $\mathrm{n}_{1}$, number of first-order channels, $\mathrm{n}_{2}$, number of second-order channels, and so forth. The notation inherited by geomorphologists and now employed by hydrologists is remarkably poor in the use of subscripts. The principal objection is that the same symbol, for instance F, is used for such different quantities as force and frequency, with the difference indicated by a subscript. The writer has followed a conservative practice in using subscripts only to denote the order of the feature upon which the measurement is taken, such as $\mathrm{n}_{1}$, number of first-order channels, and $l_{1}$, total length of first-order channels.

Channel order states the relative magnitude of a segment of stream channel in a hierarchy determined by arrangement of tributaries with respect to the main trunk. The system of ordering channel segments proposed by Horton (1945) and modified by Strahler (1952b, footnote, p. 1120) is followed here. The smallest permanent channels, those having no tributaries, are designated firstorder channels. At the junction of two first-order channels, a second-order channel begins; at the junction of two second-order channels, a thirdorder channel begins, and so forth. A channel of any given order can directly receive tributaries of all lesser orders. The trunk stream, or master stream, through which all discharge passes has the highest order. The area drained by a channel of order $u$, down to its junction with another channel of order equal to or greater than $u$, is designated a basin of order $u$.

Because of the way in which channel ordering is defined, it is possible to state the minimum possible number of channels of each order in a basin of a given order. Thus, for a second-order channel, at least two first-order channels must be present; for a third-order channel, at least two second-order channels and four first-order channels are needed, for a fourth-order channel, two third-order channels, four second-order channels, and eight first-order channels a re needed. In general, in a basin of order $u_{o}$ the minimum number of channel segments of order $u$, is

$$
\dot{\mathrm{n}}_{\mathrm{u}}=2^{\mathrm{u}_{\mathrm{o}}-\mathrm{u}}
$$

The minimum total number of segments of all orders is

$$
\sum_{\mathrm{u}=1}^{\mathrm{u}_{\mathrm{o}}} \dot{\mathrm{n}}_{\mathrm{u}}=\sum_{\mathrm{u}=1}^{\mathrm{u}_{\mathrm{o}}} 2^{\mathrm{u}_{\mathrm{o}}-\mathrm{u}}
$$

Basin area, or planimetric area, $a$, is the area in square miles of the outline of the watershed of a channel as projected onto the horizontal map plane. This area is commonly used to calculate the total amount of water entering the system 


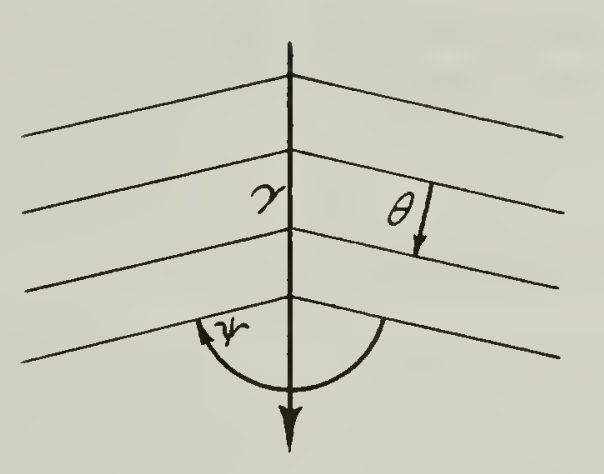

(a)

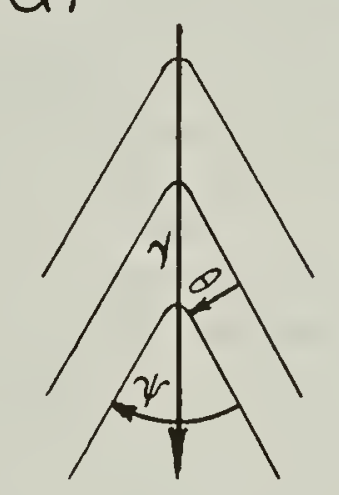

(C)

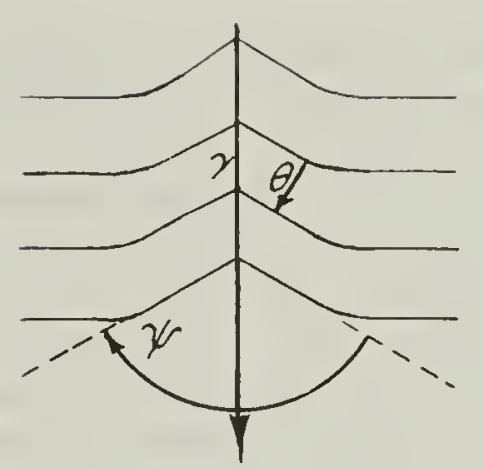

(b)

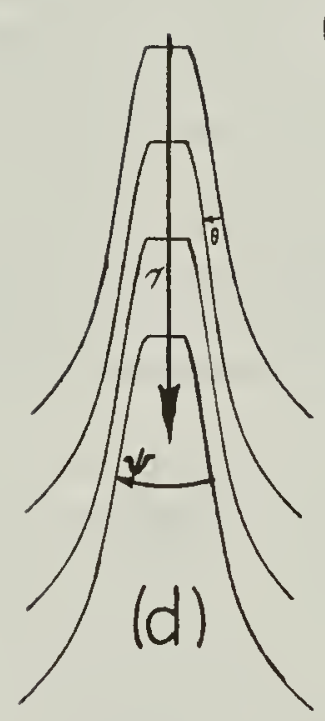

Figure 1. Inflection angle as measured on various forms of first-order channels.

during a rain. Basin area is a fundamental dimensional property in the majority of the quantitative expressions of drainage-basin characteristics.

Basin perimeter is the length along the major divide as projected onto the horizontal plane of the map. The symbol used here for the perimeter is $\mathrm{p}$; the unit of measure is miles. The perimeter is a linear measure of the size of the basin, and is largely independent of the texture of the topography. It is used in conjunction with basin area to give a measure of the departure of the basin from a true circle (see basin circularity), and in conjunction with the relief to give a measure of general steepness of the basin (see relative relief).

Basin relief is the vertical distance between the mouth of the basin and the highest point in the basin, which in the basins in this study is always located on the major divide. The symbol for relief is $r$; the unit of measurement is feet. In order to find the relief, it is usually necessary to interpolate between contour lines at the mouth and highest point. This is done to the nearest one-fourth contour interval, since it is desirable to avoid the rigorous but clumsy expression of $r$ given with a possible range of two contour intervals.

Total length of channel segments of each order within the basin were measured and recorded uncorrected for gradient, in units of miles. The symbol used for the total length of channel segments or order $u$ is $l_{u} *^{*}$ The mean length of channel segments of order $u$ is $\frac{1}{n_{u}}$, where $n_{u}$ is the number of segments of order $u$, and is represented by the symbol $\bar{l}_{u}$. The total length of channels of all orders in a basin is $\sum 1_{u}$.

Inflection angle of contour lines is the angle which a contour line makes with itself where it depicts a channel and is given the symbol $\psi$. The inflection angle has apparently not previously been studied. In this study, the minimum inflection angle of each first-order stream was measured from a map by use of protractor and straightedge. Figure 1 shows several common forms of first-order channels, as delineated by contour lines, and the inflection angle for each is illustrated.

It is obvious that geometrically the gradient of a channel can vary from zero up to the angle of slope of the adjacent valley sides, but no steeper. Increasing difference between the channel gradient and the slope of the adjacent valley sides produces a more acute inflection angle. Thus, the inflection

* Confusion may arise because of the identity of form of the letter 1 and numeral 1 . In this notation all subscripts refer to order number, hence a subscript 1 always means the numeral one. The letter 1 is always followed by a subscript denoting channel order. Therefore, 1 appearing without a subscript always means one. 
angles of first-order channels are usually greater than of higher order channels. In Figure 1 a, the channel gradient is nearly the same as the slope of the valley side, and gives a broadly obtuse inflection angle. In Figure $1 \mathrm{~b}$, the gradient is somewhat less than the slope of the adjacent valley sides, and the inflection angle is acute; in Figure $1 \mathrm{c}$, the channel gradient is much less than the adjacent valley-side slopes, and the inflection angle is even more acute. As valleys are deepened the angle of inflection, as shown on a map of the channel, may be expected to become more acute. Thus, the evolution of a first-order basin, initiated by a small gully having as its gradient the slope of the surface upon which it formed, to a mature basin form in which channel gradient is considerably lower than the slope of the adjacent valley sides, might be traced by changes in the inflection angle.

New tributaries to existing channels tend to develop perpendicular to the contour line, so as to have the steepest possible slope. The projection of the new tributary on a map makes an angle with the main channel equal to the complement of the angle which the contour line makes with the main channel. Main channels which have highly acute inflection angles will tend to develop tributaries entering at nearly right angles. The relation between angle of entry (axil angle*), valley-side slope, and channel gradient was found by Horton to be

$$
\cos \xi=\frac{\tan \gamma}{\tan \theta}
$$

where $\xi$ is the axil angle, $\gamma$ the channel gradient, and $\Theta$ the valley-side slope (Horton, 1945, p. 349). This equation can be derived from equation 19 in Appendix I, by setting

$$
\frac{\psi}{2}=90-\xi
$$

The relations among channel gradient, valleyside slope, dihedral angle between valley-sides, and the inflection angle can be expressed in geometric laws, and the derivation of these laws is given in Appendix I.

The measurements of inflection angles of firstorder channels taken in this study are biased by the habit or convention of indicating small streams adopted by the individual cartographer. It is therefore advisable in future studies to take inflectionangle measurements on small channels in the field. Reliable results from map measurements might be obtained for second or third-order channels, but

*Axil angle has been used by botanists for 150 years to denote the upper angle between the main stem and a branch. Its use in this sense is analogous. no more than a general indication of the inflection angles can be obtained from map measurement of first-order channels.

\section{DERIVED QUANTITIES}

Derived quantities are those that must be obtained by calculation from the properties measured or counted directly from maps. The accuracy of the derived quantities depends directly on the accuracy of measured quantities, and their frequency distributions depend on the distributions of all the measured items involved in their calculation. A greater amount of freedom is involved in their estimation. For these reasons it is desirable to distinguish between measured and derived quantities. Upper-case Roman letters are used here as symbols for derived quantities, except that derived angular quantities are represented by lower-case Greek letters.

Drainage density, $\mathrm{D}$, is the ratio of the total length of channels of all orders in a basin to the area of the basin, $\frac{\Sigma l_{u}}{a}$, and is therefore the number of miles of channel maintained by a square mile of drainage area (Horton, 1945, p. 283). Drainage density is a numerical expression of the fineness of texture of the basin, but because a particular value is usually nearly constant over an area of homogeneous lithology, climate, and stage of development, it is independent of the basin size. Drainage density has the dimension of inverse of length, and is a useful indicator of scale of size of planimetric units in a fluvially controlled landscape.

Density of first-order channel segments, $D_{1}$, is the total length of first-order channel segments in a basin of some larger order, divided by the area of the entire basin, $\frac{l_{1}}{a}$. It is useful in determining whether a drainage density higher in one area than in another is due to a greater length from headward growth of the first-order channels.

Channel frequency, $F$, is the ratio of the total number of channel segments of all orders in a basin to the area of the basin, $\frac{\Sigma \mathrm{n}_{\mathrm{u}}}{\mathrm{a}}$ (Horton, 1945, p. 285). It is a supplementary measure of the fineness of texture of the topography, but may be independent of drainage density because it depends only on number of channel segments, not on the lengths.

Frequency of first-order channels, $F_{1}$, is the total number of first-order channels divided by the area of the entire basin, $\frac{\mathrm{n}_{1}}{\mathrm{a}} \cdot$ This measure is useful in determining whether a drainage density 
higher in one area than in another has resulted from growth of new channels, or simply a lengthening of existing channels.

Ruggedness number, $\mathrm{H}$, is the product of drainage density and relief of basin, both in the same units: $H=\frac{D \cdot r}{5280}$ or $H=\frac{\sum l_{u} \cdot r}{5280 a}$ (Strahler, $1954 \mathrm{c}$ ). It is a dimensionless number, since $D$ has the dimension $\left[L^{-1}\right]$, and $r$ has the dimension $[L]$. Areas of low absolute relief, but high drainage density are as rugged, when their small size is considered, as areas with great relief but low drainage density. Areas that are geometrically similar in planimetric and relief features will have the same value of the ruggedness number.

Relative relief, $R$, which is a measure of the general steepness of the basin from summit to mouth, can be measured in a variety of ways. Schumm (1954, p. 22) defined relief ratio as "the ratio between the total relief of a basin. . and the longest dimension of the basin parallel to the principal drainage line. This relief ratio is a dimensionless height-length ratio and is equal to the tangent of the angle formed by two planes intersecting at the mouth of the basin; one representing the horizontal, the other passing through the highest point of the basin." In oddly shaped basins, or basins with the highest point at some place other than at the position farthest removed from the mouth, there is a question as to what should be taken as the length measurement, and the interpretation of the relief ratio as the tangent of the angle between two planes is not appropriate.

For this study relative relief, $R$, is defined as the ratio of the basin relief, expressed in units of miles, to the length of perimeter: $R=\frac{100 \mathrm{r}}{5280 \mathrm{p}}$. The advantage of this measure over relief ratio is that both relief and perimeter had been measured for other purposes; the position of the highest point of the basin with respect to the mouth does not affect the measure. A rational relation between the measure of relief used here and Schumm's relief ratio can be developed by assuming various shapes for the basin.

Ratio of channel lengths to basin perimeter, $P$, is a dimensionless measure of fineness of topographic texture relative to bas in size. Two basins of different sizes, but with geometrically similar planimetric properties, will have different values of drainage density, but identical values of the channel-perimeter ratio.

Basin circularity, $C$, measures the degree to which a basin approximates a circle in planimetric outline. Circularity is defined as the area of the basin divided by the area of the circle with equal perimeter (Miller, 1953, p. 8). The circle can be defined uniquely as that plane figure in which the greatest area is bound by the shortest possible perimeter. Therefore, if the area of any irregular figure, such as a drainage-basin outline, be divided by the area of the circle having the same perimeter, the quotient will be a number between zero and one. The measure is ambiguous, though, as it does not discriminate between departures from perfect circularity due to irregularities in gross outline, or to crenulations in the perimeter.

$$
\text { Bifurcation ratio, } \mathrm{B}_{\mathrm{u}: \mathrm{u}+1}=\frac{\mathrm{n}_{\mathrm{u}}}{\mathrm{n}_{\mathrm{u}+1}} \text {, is the ratio }
$$
between the number of channel segments of a given order and the number of channel segments of the next higher order. According to Horton's law of stream numbers, values of $B$ tend to be the same for all values of $u$ within a given basin (Horton, 1945, p. 286). The value of $B$ characteristic of all orders within the basin is the slope of the regression line when numbers of channel segments are plotted on semi-log paper against order number (Strahler, 1954 b, p. 345).

Length ratio, $L_{u: u-1}=\frac{\bar{l}_{u}}{\bar{I}_{u-1}}$, is the ratio of the mean lengths of channels of a given order, to the mean length of channels of the next lower order. According to Horton's law of stream lengths, the mean channel length for each order increases as an exponential function of channel order (Horton, 1945 , p. 286). Whether the values of $\mathrm{L}_{\mathrm{u}: \mathrm{u}-1}$ for $\mathrm{a}$ basin are constant within a basin, or change systematically with order is a question that must be answered by statistical analys is.

Maximum valley-side slope, $\theta$, is the slope in degrees of the valley side at its steepest point along an orthogonal profile. This definition assumes that short, oversteepened sections of the valley side near channels, that are the obvious result of recent rejuvenation, are not included in the profile. It is not likely that such sections of slope would be included in map measurements, but it is necessary to exclude them from the definition, as valley-side slopes are also measured in the field (see maximum valley-side slopes under Measured Properties). The measure is obtained from a map by computing the horizontal distance between two contour lines that are separated vertically by say, 100 feet, and converting the tangent to the angle in degrees. Depending on the variability of slopes within the basin, 15 to 75 slope readings are needed to give an adequate estimation of the mean value.

The importance of the valley-side slopes instudies of erosion lies in the fact that the energy available for erosion in foot-pounds per pound of water per linear foot is equal to the sine of the slope.

Dihedral angle between valley sides, $\zeta$, measured in degrees, is the angle between the valley sides measured perpendicular to the stream. It 
cannot be measured easily either in the field or from the map, but it can be calculated. Figure 2 is an illustration of the dihedral angle, inflection angle, gradient, and valley-side slope. Appendix I gives the geometrical relation among the quantities $\Theta, \Psi, \zeta$, and $\gamma$.

Gradient of stream channel, $\gamma$, expressed in degrees, can be obtained from the map by measuring the distance along the channel between two or more contour lines. This quantity is of great importance in the equilibrium of the basin, since it is related to rates of transport, runoff, and celerity of flood crests.

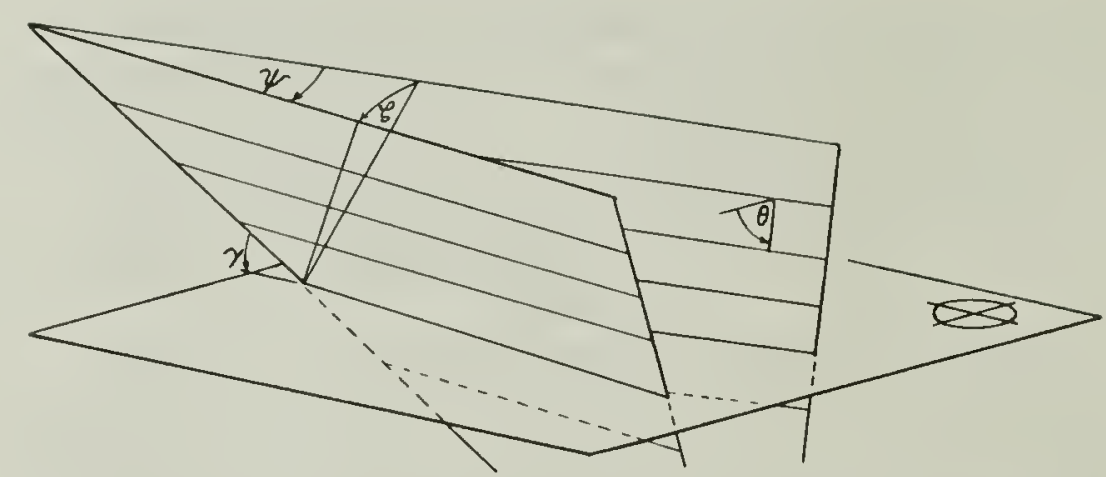

Figure 2. Relations among valley-side slope, inflection angle, channel gradient, and dihedral angle between valley sides for an idealized channel. 


\section{Problems of Field Study}

\section{METHODS OF FIELD OBSERVATION}

Field investigations were carried out (1) to observe the accuracy of the map, particularly in regard to the extent of the drainage net, and (2) to obtain measurements of characteristics of the soil and vegetal cover that are believed to influence morphometric properties of the basin.

At representative points within each basin several stations were established at which a series of measurements and observations was made. In large basins about 10 stations per square mile were established; in small basins the density increased to 200 stations per square mile. To estimate the number of measurements required to detect a difference of a specified amount in some property of interest, among a number of areas, a prior knowledge of the standard deviation of the property is necessary. Estimates of the standard deviations of the properties studied in the field, excepting maximum valley-side slopes, were not available at the beginning of the study. Without such estimates it is impossible to judge in advance the necessary number of readings within each basin, or the number of basins, needed to detect differences in means of the properties studied. It was assumed, however, that for a given property, greater variability would exist among the means for all basins than among readings within the basins; analysis of the data proves this assumption to be correct (Table 6). Therefore, the emphasis was placed on gathering data from a large number of basins, and fewer measurements were taken within each basin.

A major problem in the field study of each area was to decide which linear depressions should be included as channels, and which should be omitted. The crux of the problem is in the identification of the smallest "finger-tip," or first-order channels, because the channels of higher order present no difficulty once all first-order channels are drawn on the map. First-order channels can be defined as the smallest permanent depressions found in a connected drainage system, whose form is maintained indefinitely against agents tending to obliterate it, by the action of water flowing in a concentrated stream. However, any definition depending on the knowledge of the behavior of the depression through several years, or seasons, is unusable in studies in which observations are made in each basin during a single, relatively brief period. For the purposes of field identification, true, functional, erosional, first-order channels are defined as linear depressions having the following characteristics:

(1) Water entering the depressions is forced to flow in a concentrated stream, and under no conditions can become sheetflow.

(2) At its lower end the depression (a) joins another similar depression of equal or greater size, (b) disperses onto an alluvial fan or cone, or (c) ends at a sinkhole or other localized area of recognizably great permeability.

(3) Erosion and/or creep have produced (a) graded valley sides that lead down to the depression, and have orientations noticeably different from the hillside adjoining the area drained by the depression. The gradient of the depression in this case is lower than the slope of the adjacent surfaces (Gilbert, 1877 , p. 115). Or (b) the depression is steepsided with rectangular or trapezoidal crosssection, its depth being on the order of ten times the maximum micro-relief on the older unmodified surfaces near the depression.

This definition excludes steep-gradient, grassy swales through which water might, after a mild rain, pass in the form of sheetflow. However, perhaps such channels need not be excluded from consideration as higher order channels, uncommon though they may be.

\section{OBSERVED WATERSHED PROPERTIES}

Vegetation: The typical vegetation assemblages with their elevations and exposures were noted in each basin (Table 3). Identifications of species were made from Southwestern Trees (Little, 1950). Certain species of trees and bushes provide a basis from which inferences about the climate of the basin can be drawn (Little, 1950; Costello, 19?). Estimation of the precipitation-effectiveness index for each basin was obtained from a regression line for precipitation-effectiveness against elevation and confirmed by field data. For instance, the saguaro cactus, creosote bush, and paloverde of the desert or Lower Sonoran Life Zone indicate a precipitation-effectiveness index of less than 15; the shrub live oak and cliffrose of the chaparral or Upper Sonoran Life Zone indicates a P-E index of 
35 to 40 , and the Engelmann spruce and alpine fir of the Hudsonian Life Zone indicate a P-E index of 90 to 120 (see Climatic Data).

Lithology: Basins were selected for study partly on the basis of similarity of lithology throughout. In a few instances, basins were found to have areas of rock differing from that of the major part of the basin. In addition, in four basins the rocks lie in near-horizontal, alternating weak and strong layers, consisting of sandstone, limestone, and shale, or lava and pumice. Descriptions of the lithology prevailing in each basin are given in the general description of basins. If consistent structural planes are present throughout the area, their strike and dip are noted also.

Percentage of basin lying within each type of cover: Each basin studied in the field was divided into portions covered by forest and bushes, grassland, and bare soil or rock. The percent of total area lying within each type of cover was then estimated, either from aerial photographs, or from a vantage point providing a general view of the entire basin. It was found that on those maps with green overprint representing vegetative cover, there was often little correspondence with the actual cover. Data are given in the general description of each basin.

Range evaluation: Many of the basins studied in the field were being grazed at the time the field work was done, or had recently been grazed. The extent of grazing was estimated from observation of the general length of grass stubble. A simple count of animal density is inadequate; for instance, near Tucson, three animals per square mile result in considerably over-grazed range, whereas in the Colorado Front Range, many more animals can be supported without serious over-grazing. Data for each basin are given in the general description of basins.

Presence of gullies: It is assumed here that gullies usually signify readjustment of the drainage pattern to a changed environment. Where numerous gullies were present, excluding those few caused by some factor not affecting the entire basin, note was made of whether they were primarily on the valley slopes or in the channels. In a single case extensive gullying was found in both situations. It seems likely that channel trenching and gullying on the upland slopes may be due to opposite causes.

The surface characteristics of the mantle of the basins may have changed greatly with the advent of human activity. Grazing, logging, burning, and mining activities leave very apparent effects. Grazing can drastically reduce the amount of cover, and even moderate grazing lowers the infiltration capacity of the soil. Watershed management studies in the Colorado Front Range, on granitic soils similar to the majority of those studied here, and in ponderosa pine forest, show that heavy grazing more than doubles the amount of erosion per unit area, for each inch of runoff (Love, 1953, p. 214). It could therefore be contended that measurement of surface characteristics, including vegetal cover, as they are now will not reflect the condition of the basin when it was developed, and are therefore valueless. All evidence available to the writer indicates that increase of drainage density, brought about by lowered resistance to erosion, concentration of runoff, decreased infiltration rate, disruption of plant cover, etc., occur very soon after the change of conditions. New gullies on slopes below a new road, or in areas of recently-burned forest are convincing evidence of the rapidity of the change. Gullies in slopes are included in the drainage net and it is therefore considered likely that measurements of surface properties do bear relation to the extent of channels. Part of the difficulty is in the assumption inherent in the objection. Basins were not developed then left unchanging and static for the next surface geologist to study, but must reflect by continual development the changes in climate and environment within the basin.

Perhaps there is more reason to believe that degree of slope will not be influenced immediately by changes in surface properties, as time is required to accomplish the regrading of a slope. Erosion of a large amount of material is necessary to change the average basin slope even a degree or two. Since rates of creep are not well-known, supporting evidence for this view is needed.

\section{GENERAL PLAN OF FIELD MEASUREMENTS}

At each station established in a basin, a series of measurements was repeated in as nearly the same manner as possible from basin to basin. All measurements should have been taken at randomly located points, but unfortunately, it was impossible to do this consistently. In cobbly and bouldery soils it was often difficult to locate places on which several of the measurements could be made. In other areas, such as the Chinle-shale badlands, where full randomization would be relatively easy, it was less important due to the high degree of homogeneity of the area.

\section{MEASURED PROPERTIES}

Infiltration capacity: The present study did not include a general investigation into the factors influencing the infiltration capacity of the soil. The infiltration capacity measurements were taken solely with the intention of obtaining comparative data, not necessarily the actual rate of infiltration during a rain.

The infiltrometer used in this study was. designed 
by the writer to be portable, light in weight, and conservative in use of water. These requirements were important because in many areas it was necessary to carry the apparatus and water over rugged terrain.

The principle of measurement is simple: water from a tank is drawn through a metering device, an adjustable valve, a sprinkler, and distributed by inspection evenly over a plat of soil one square foot in area at the maximum rate of infiltration. Discharge is measured by the meter in ounces per minute, and is converted to inches (depth) per hour over an area of one square foot. The apparatus is mounted on a standard surveying tripod, and weighs 45 pounds when full of water (Figure 3 ). The reservoir tank holds $21 / 2$ gallons, and will supply enough water for two to five tests, depending on the length of run, and the infiltration capacity of the soil.

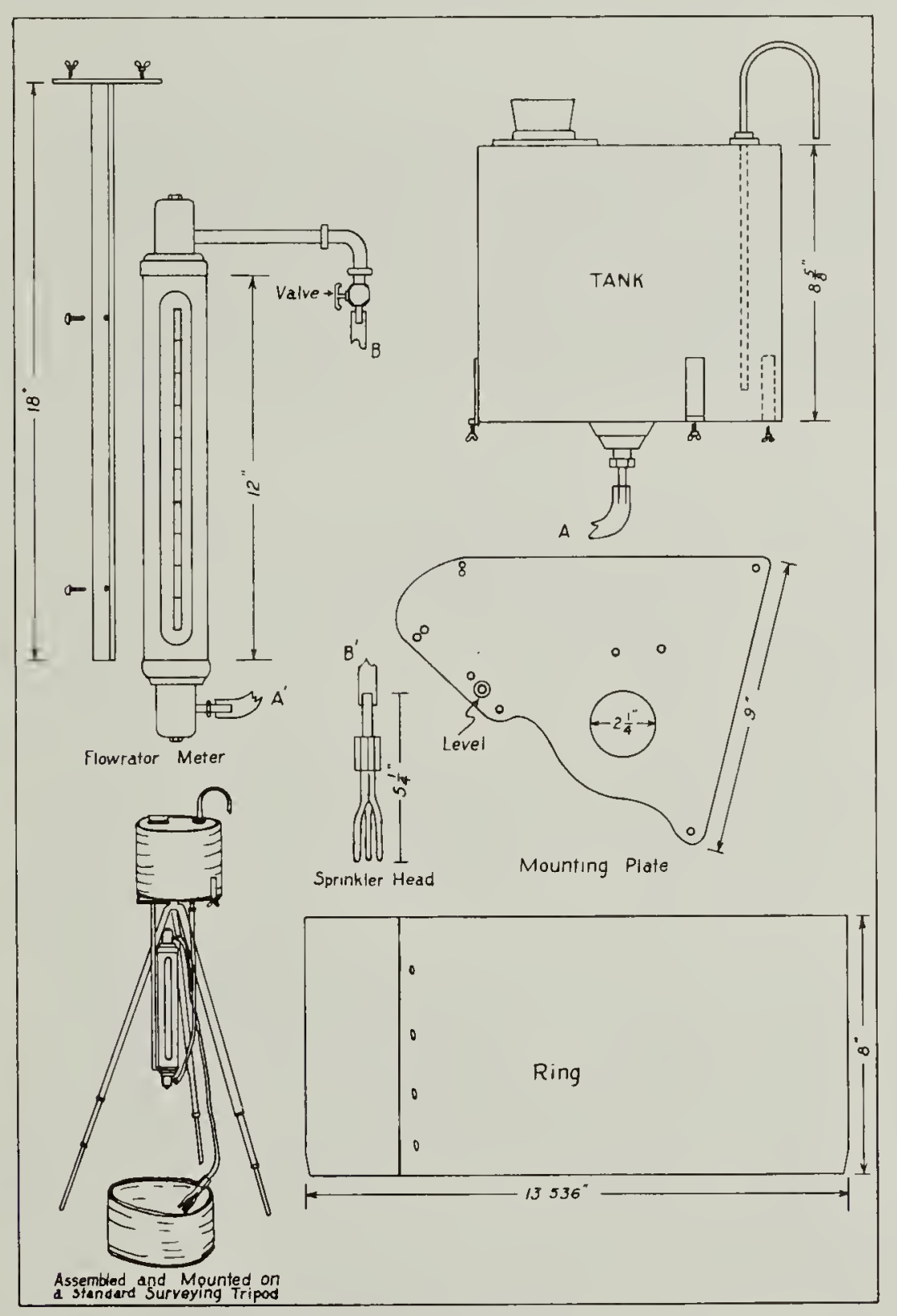

Figure 3. Infiltrometer assembly diagram.

The one square-foot area is bounded by a stainless steel ring with a sharpened lower edge, that can be driven into the ground. Doubtless a double- ring arrangement, with water filling an outside ring to lessen the amount of lateral flow, would be desirable were accuracy the main consideration. The added weight of another ring and the necessarily greater quantity of water, would reduce the distance which the instrument could be carried during a day's work. The infiltrometer used in this study is definitely a reconnaissance instrument, and cannot compare in accuracy with more elaborate equipment.

The tank containing the water is made of stainless steel, and is built on the principle of the Mariotte bottle (Westphal, 1952, Zweiter Teil, p. 15). The tank can be closed air tight by a rubber stopper; the only air entering the tank comes through a copper tube extending down almost to the bottom of the tank. Thus, the only free surface is at the bottom of the tube, and once the air has started bubbling out of the tube into the tank, the pressure-head is measured from the end of the tube. Therefore, throughout the course of the test, though the level of the water decreases, the hydrostatic head remains the same. This is necessary because the measuring instrument is accurate under constant head. Once a definite rate of flow has been established, it is not necessary to make repeated changes in the valve setting, as would be the case were the head continuously decreasing.

The measuring device is a Flowrator, ${ }^{*}$ which is basically a tapered glass tube with a metal float fitting closely within the tube. For protection, a pressed steel cover surrounds the tube and supports the pipe connections. Water flows upward through the tube; as the discharge increases the frictional force of the water on the float increases, and an upward acceleration is imparted. Higher in the tube, the diameter of the opening and the area of discharge are greater; the velocity of water flowing around the float is less, and hence the frictional force is less. The float therefore seeks a level at which its weight is exactly balanced by the upward force of the moving water, and this position is a measure of the discharge. The maximum discharge possible is 11.2 ounces per minute or 8.4 inches per hour. Figure 4 gives the conversion graph from percent of total flow to inches per hour over one square foot. After leaving the Flowrator, the water passes down through a sprinkler and is distributed evenly over the area within the ring.

The surface of the test area is prepared by removing loose leaves, twigs, accumulated pine duff and needles, leaving only grass on the largely mineral soil. At the beginning of a test, the discharge is set at $75 \%$ of the maximum, 8.4 ounces per minute, or 6.3 inches per hour. If the soil is dry, it will take 15 to 180 seconds to saturate the surface

* Manufactured by Fisher and Porter Company, Hatboro, Pennsylvania. 


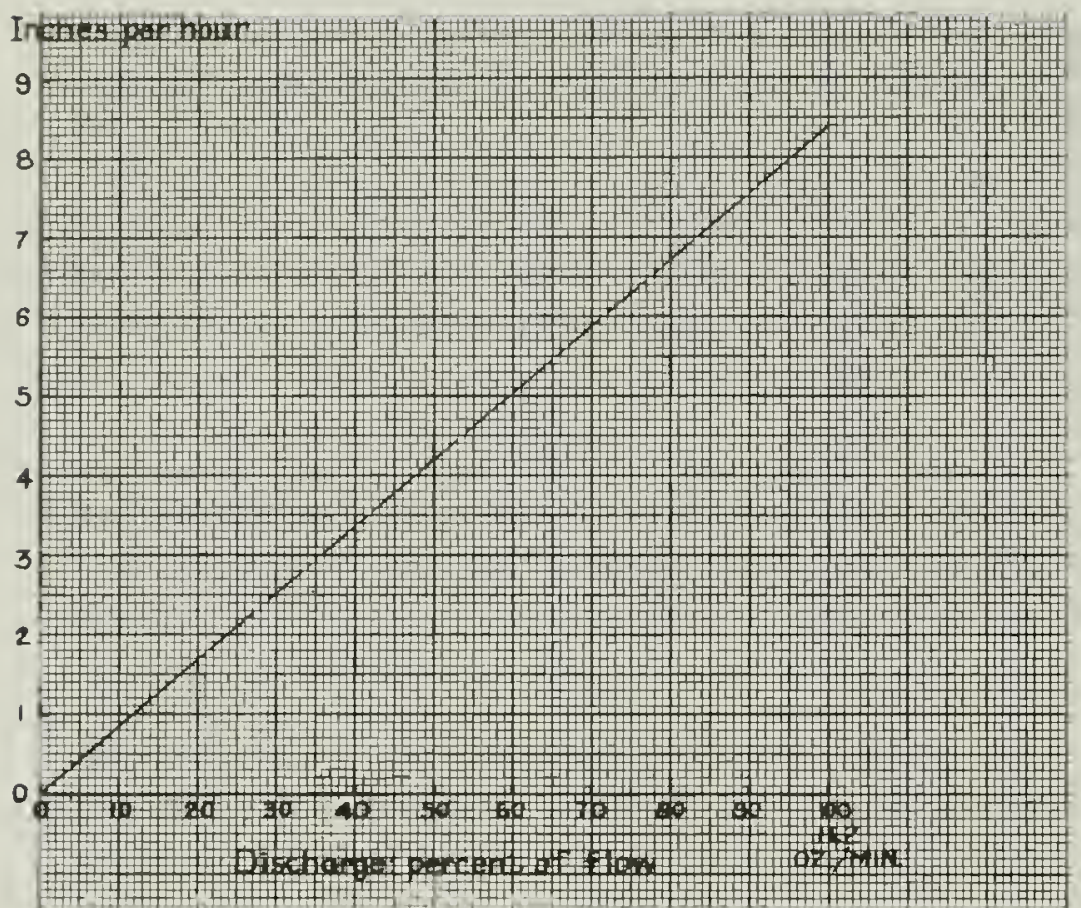

Figure 4. Conversion graph: percent of total flow $(100 \%=$ 11.2 ounces per minute) to inches per hour over an area of one square foot.

and to form excess.* The time at which the excess forms is recorded, and the discharge is decreased. Some practice is required to adjust the discharge to match the infiltration rate, and at best it takes one minute to determine if the machine is adjusted correctly. On most poorly-developed, gravelly soils, during the first 15 minutes of the test, the rate of infiltration decreases rather rapidly. Thereafter, the rate is fairly constant, though it may decrease slowly if considerable clay is present in the soil. It is usually possible to adjust the instrument to within $1 \%$ of flow after 20 to 25 minutes have elapsed, giving an adjustment error on 0.084 inches per hour, and the rate of infiltration usually changes little thereafter. The "instantaneous" rates for $3,5,10,15,20,25,30$ and sometimes 40 and 50 minutes were recorded. The final, stable rate (usually the minimum rate) was taken as the infiltration capacity (Horton, 1942, p. 480). The values of infiltration capacity obtained with this instrument are probably higher than the actual value prevailing during a hard, general rain, since no allowance is made for the lateral flow of water when it passes below the edge of the ring.

*L. D. Love (personal communication, 1955) and others believe that because of wetting difficulties, most reliable results may be obtained on pre-wetted plats that have drained 12 to 24 hours. The writer encountered wetting difficulties commonly in soils with a deep pine-needle deposit. In a few cases a small amount of detergent was added to the water, and this usually shortened the time needed to saturate the surface. Too few trials were made to determine whether this altered the final infiltration capacity.
A greater source of error, however, may be the disturbance of the soil structure caused by pounding in the ring, thereby opening up fissures not otherwise present. The values obtained are believed to be consistent within themselves, since values of infiltration capacity vary greatly between areas of different rock type, and less so within areas of similar type.

Soil strength, s, is measured under instantaneous impact of a 12 pound iron shot, dropped a standardized distance, to impart 60 foot pounds of energy normal to the ground surface. This distance is 5 feet for horizontal surfaces, and 5 feet divided by the cosine of the slope on sloping surfaces. Satisfactory results can be obtained on slopes up to 35 degrees. The volume of the imprint of the shot divided into 60 foot-pounds gives a measure of strength in pounds per square foot.

$$
\frac{60 \mathrm{ft} .-\mathrm{lbs} .}{\mathrm{x} \mathrm{ft.}{ }^{3}}=\frac{60}{\mathrm{x}} \text { lbs. per ft. }{ }^{2}
$$

The volume of the imprint can be obtained from a graph relating diameter of the base of a spherical segment to volume. The diameter of the imprint is easily measured. Appendix III gives the derivation of the relation between the diameter of imprint and volume of imprint. Figure 5 illustrates the method; Figure 6 is a graph relating diameter of imprint directly to strength of soil.

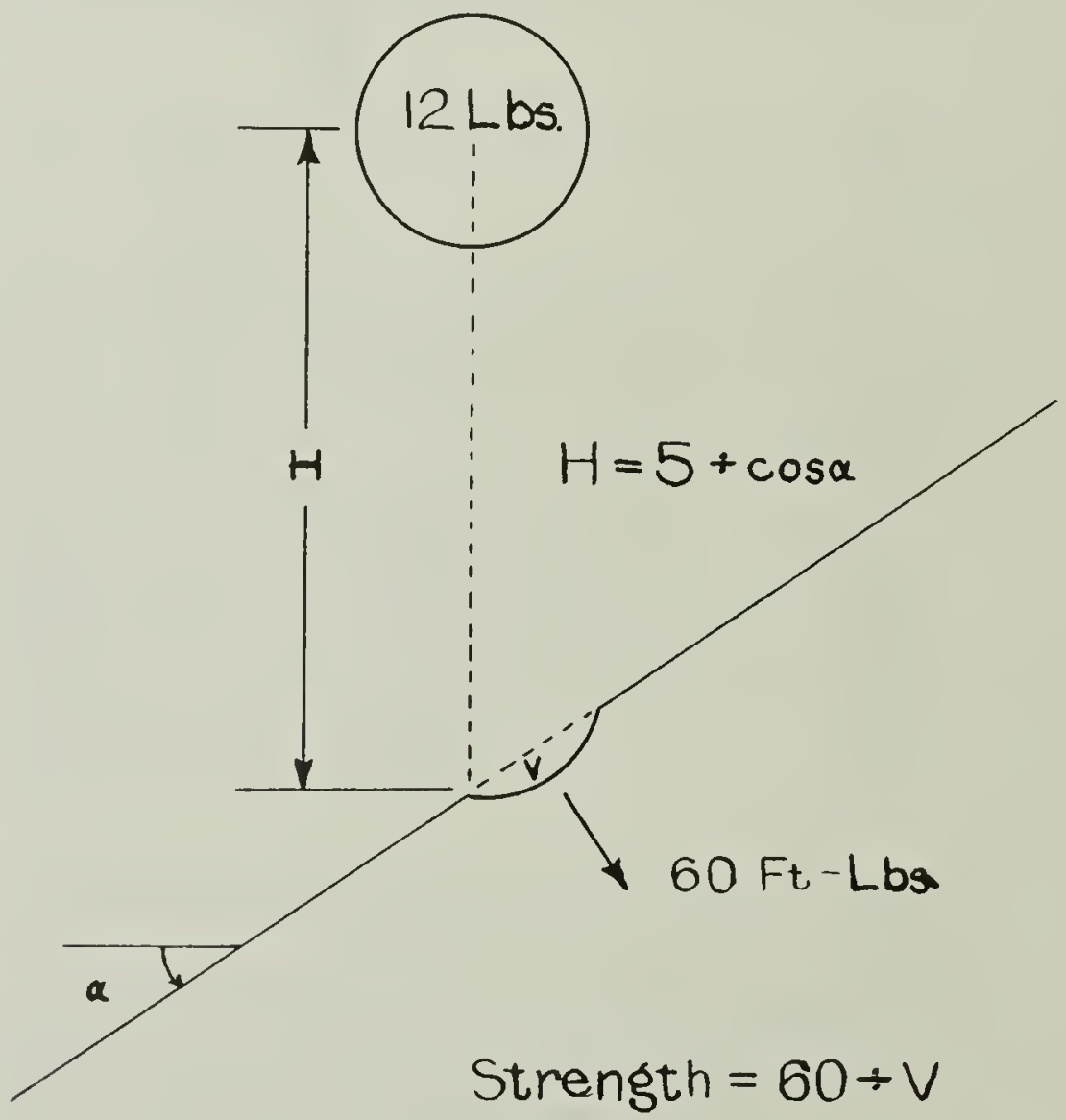

Figure 5. Principle of measuring soil strength by dropping a spherical weight a standardized distance and measuring the volume of imprint. 


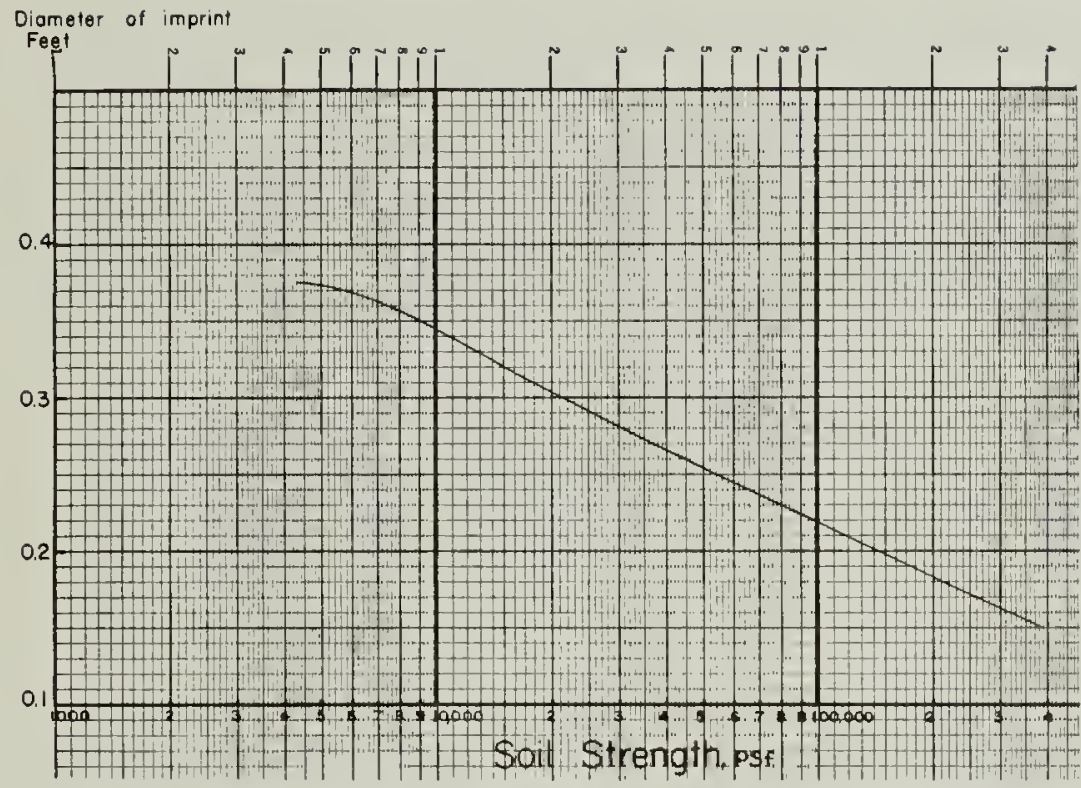

Figure 6. Conversion of diameter of imprint of 12-1b. shot, diameter $=0.378 \mathrm{ft}$, to soil strength, whendropped the distance necessary to impart $60 \mathrm{ft}$.-1bs. normal to the soil surface.

To standardize the moisture conditions under which the strength tests were made, two or three repetitions of the test were made on the soaked plat of ground used in the infiltration test to obtain a value of the strength of the soil approximating its condition after a hard rain. In addition, three or four tests were made in the surrounding area on the soil in its natural condition. In most areas the soil was extremely dry; only in a few cases was it damp.

It would have been desirable to randomize all measurements of strength. However, the measurement of wet soil strength was necessarily limited to the area selected for infiltration measurements, which were in turn limited by the stoniness of the ground. Randomization over dry surfaces would produce tests on cobbles, logs, etc., and the results would not be indicative of soil strength. The measurements were probably not systematically biased, as there was no way of estimating the strength of the point directly under the shot prior to making the test.

Size-distribution of soil was described at each station within the infiltrometer ring by the visual and manual methods developed by the Department of Soil Mechanics at Columbia University (Burmister, 1952, p. 48). The average soil description for test plats within each basin is given in Table 4.

Percent bare area was obtained by measuring the exposed, bare, mineral soil with a steel measuring tape extended for 50 feet over the ground in a randomly oriented direction. The ground at each foot mark on the tape was inspected, and if bare of all cover, such as grass, fallen leaves, twigs, limbs, cobbles, or larger rock fragments, it was given a count of one. For each foot mark lying above a section of ground that was covered in any way, the count was zero. Upon counting through 50 feet, the number of foot marks lying above bare ground was multiplied by two to give an expression in percent of total area.

The direction of traverse and point of origin were randomized by throwing a geologic hammer in the air with a spinning motion, and extending the tape in the direction in which the pick pointed upon landing. Two such readings were made at each station. The average of the results for each basin are given in Table 3 .

Roughness, or number and size of rock fragments lying loose on the surface, or partially buried, was found by counting and measuring all fragments $1 / 2$ inch or greater in mid-diameter within a circle with a radius of one foot. The center of the circle was located by selecting a number of feet between 9 and 100 from a table of random numbers; an orientation was found by throwing a geologic hammer into the air in the same manner as described above for percent bare area. Fragments were measured to the nearest $1 / 16$ inch by small calipers. The distance which a buried fragment extended above the ground was recorded. One circle was measured at each station. The roughness number, $M$, is the average total length of diameters of pebbles in each circle for the entire basin. $M$ is then

$$
M=\frac{\sum_{i=1}^{N} f_{i} m_{i}}{N}=\frac{\sum_{i=1}^{N} \sum_{j=1}^{f_{i}} x_{i j}}{N}
$$

where $f_{i}$ is the number of rock fragments in the $i$ 'th circle of one foot radius, $m_{i}$ is the average middiameter of rock fragments in the i'th circle, $x_{i j}$ is the diameter of the $j$ 'th pebble in the $i$ 'th circle, and $\mathrm{N}$ is the number of circles measured in each basin. The roughness number increases rapidly with increasing number of loose fragments, and also with increasing average size of rock fragments. Among the basins studied, those having a large number of smaller fragments indicate greater roughness than basins with a small number of larger fragments.

Maximum valley-side slopes, $\theta$, were measured in the field with an Abney hand level, calibrated to read to $1 / 2^{\circ}$. Within each basin, about 40 measurements were usually taken, which would provide sufficient probability of detecting differences of $11 / 2^{\circ}$ or $2^{\circ}$ in the means of two basins when the standard deviation is about $4^{\circ}$. The mean slopes of all basins for which data were taken are given in Table 2 .

In measuring slopes, the writer walked along the valley side near the upper limit of the steepest portion of the slope, with an assistant near the foot of the slope. At fairly regular intervals, slope and 
orientation readings were recorded. In basins in which trenching or rejuvenation of the channel was apparent, the short, steep slope near the channel was ignored, and the long slope on the main valley side was measured.

In large basins, those of one square mile or greater area, a system of randomized sampling that will still allow rapid measurement is needed. In such cases a tendency to ignore slopes of lower angle, and take too many readings on steep slopes would bias the mean. In smaller basins, where several readings are taken on each valley side, bias is less likely because a greater percent of the area is sampled. 


\section{Climatic Data}

. . . little essential advance can be made in the investigation of rainfall by continuation of readings at arbitrarily selected localities which happen to be centers of population. Intensive study of rainfall for a relatively short period at car efully selected critical localities would advance our knowledge far more than the continuation for many years of routine readings at sporadically located stations. (Turnage and Mallery, 1941, from Introduction, by Forest Shreve).

Since 1941 there has been no advance in systematic collection of weather records, especially temperature data, in mountainous regions. In compiling climatic data for this study, considerable reliance was placed on records (some of only a few years duration) obtained from high mining camps in the Colorado Front Range (1860 to 1915), from ranches in New Mexico and Arizona, and from Forest Service ranger stations and fire lookouts. Perforce, much of the data is from the years before 1930, and obtained from Bulletin W, Climatic Summary of the United States (U. S. Weather Bureau, Department of Agriculture, 1933). Although the Weather Bureau under the Department of Commerce has placed emphasis on improving techniques of forecasting, there is a great need for research into the effects of topography, exposure, and elevation on precipitation amounts and intensities, temperature, and snow accumulation, in connection with hydrologic studies for flood control, erosion problems, forest and range management, and other conservation programs. This need is being met partially by utilization of weather records of Forest Service Experimental Stations, and by regional studies such as those prepared by the Hydrologic Services Division, U. S. Weather Bureau (U. S. Weather Bureau Technical Paper No. 24, 1954, Parts I and II). But these summaries would be greatly improved were adequate mountain weather data available.

The data secured consist of average monthly precipitation, monthly average of mean daily temperature, average number of days per year with .01 inches or more precipitation, and elevation of the station. In addition, the depth of precipitation of the average five-year, one-hour storm for the general region was obtained from Technical Paper No. 24, Part II (U. S. Weather Bureau, 1954). Data are presented by state, section, and station in Table 5 .

The Thornthwaite Precipitation-Effectiveness Index, or P-E index, is a measure of the availability of moisture to vegetation, and depends on the amount and distribution of precipitation and evaporation; the latter in turn depends on variations of temperature and wind movement (Thornthwaite, 1931). The exact rational formula is

$$
\hat{\mathrm{I}}=10 \sum_{12} \frac{\mathrm{P}}{\mathrm{E}},
$$

where $P$ is the average precipitation for each month, and $\mathrm{E}$ is the average evaporation for each month. The index, I, is therefore a dimensionless ratio. An empirical formula that is an approximation to I, when no evaporation data are available, is

$$
I=115 \sum_{12}\left(\frac{\mathrm{P}}{\mathrm{T}-10}\right)^{1.11}
$$

where $\mathrm{T}$ is the monthly average daily temperature.

Thornthwaite divided the range of values of I as follows:

$\begin{array}{cr}\text { Characteristic vegetation } & \text { P-E Index } \\ \text { Rain forest } & \geq 128 \\ \text { Forest } & 64-127 \\ \text { Grassland } & 32-63 \\ \text { Steppe } & 16-31 \\ \text { Desert } & \leq 15\end{array}$

The P-E index for each station for which sufficient data are available, or for which temperatures can be estimated by interpolation from nearby stations, is provided in Table 5 .

In the areas of the West for which data were obtained, the precipitation increases with elevation, above a lower limit, and temperature decreases (Turnage and Mallery, 1941). Within a limited area, the P-E indices, when plotted against elevation, show a significant linear increase. The points on the graphs deviate from linearity in Colorado and Utah for elevations greater than 10,000 feet and 8,000 feet respectively. The graphs obtained were then used to estimate the mean P-E index for each basin. Ignored are the differences of precipitation effectiveness on north and south-facing hillsides, the effect of nearby mountains, and the situation of the station. The value of I is, therefore, only approximate. However, the results agree well with 
known vegetation in the basins. Figure 7 shows graphs of $\mathrm{P}-\mathrm{E}$ index against elevation.*

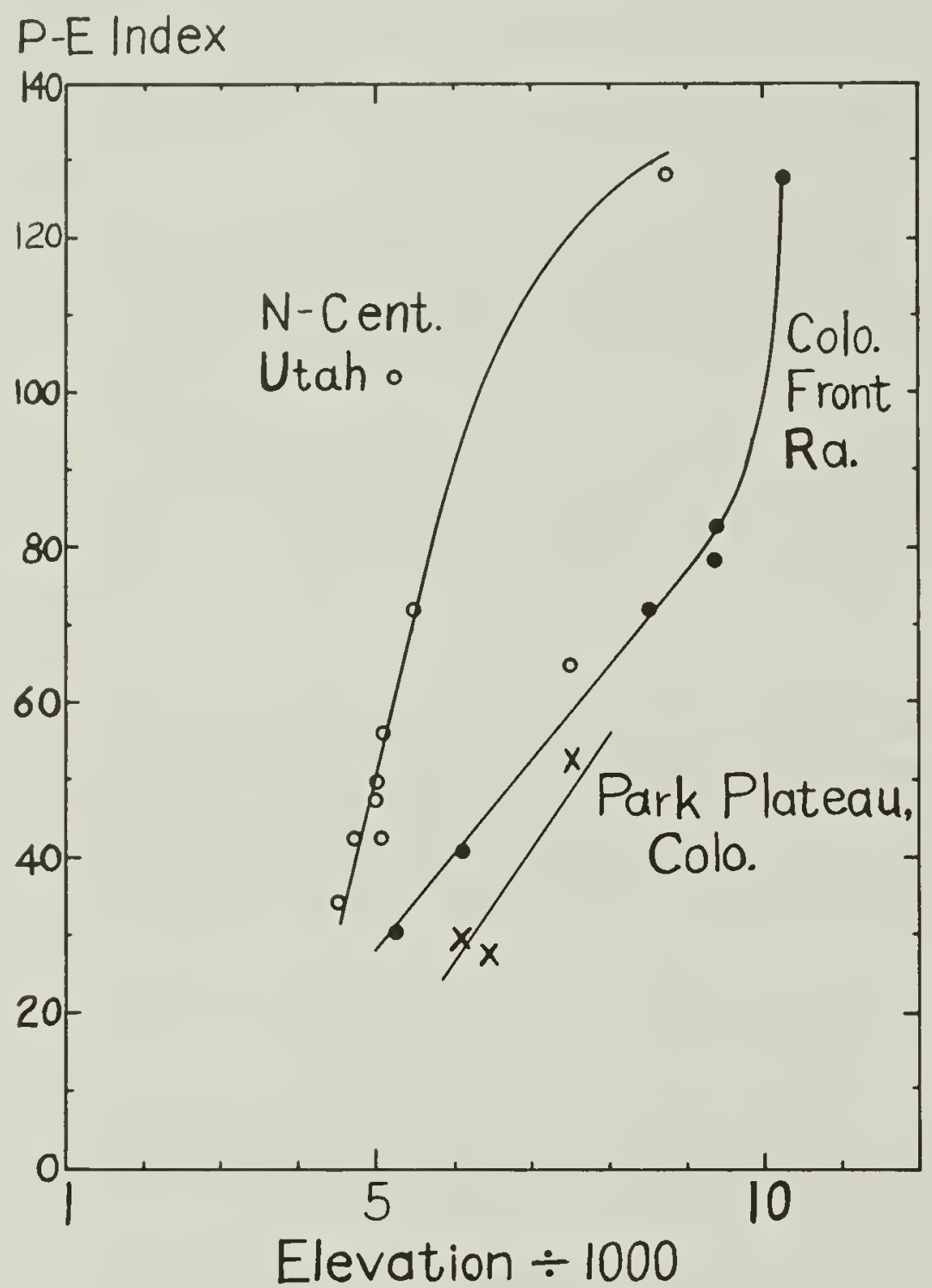

Figure 7 (a)

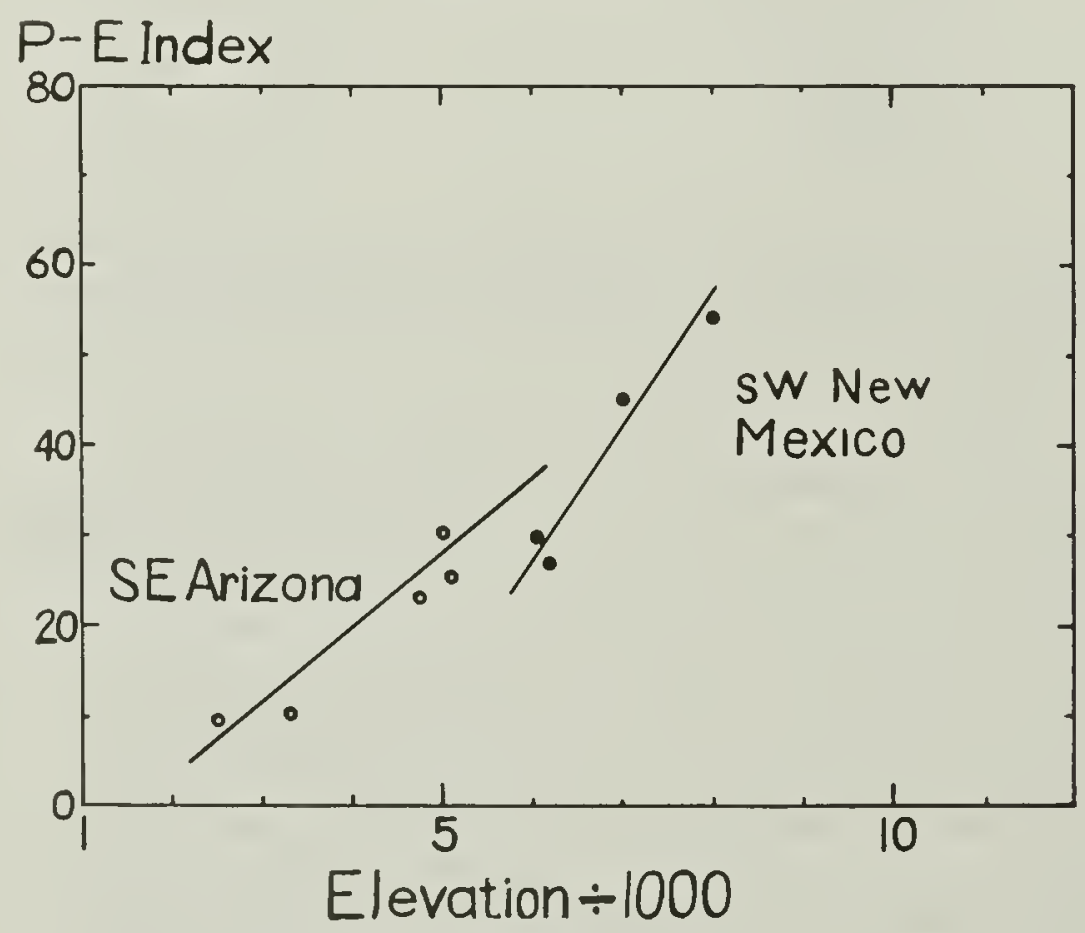

Figure 7 (b)

*Lines or curves fitted by eye only.

\section{P-E Index}

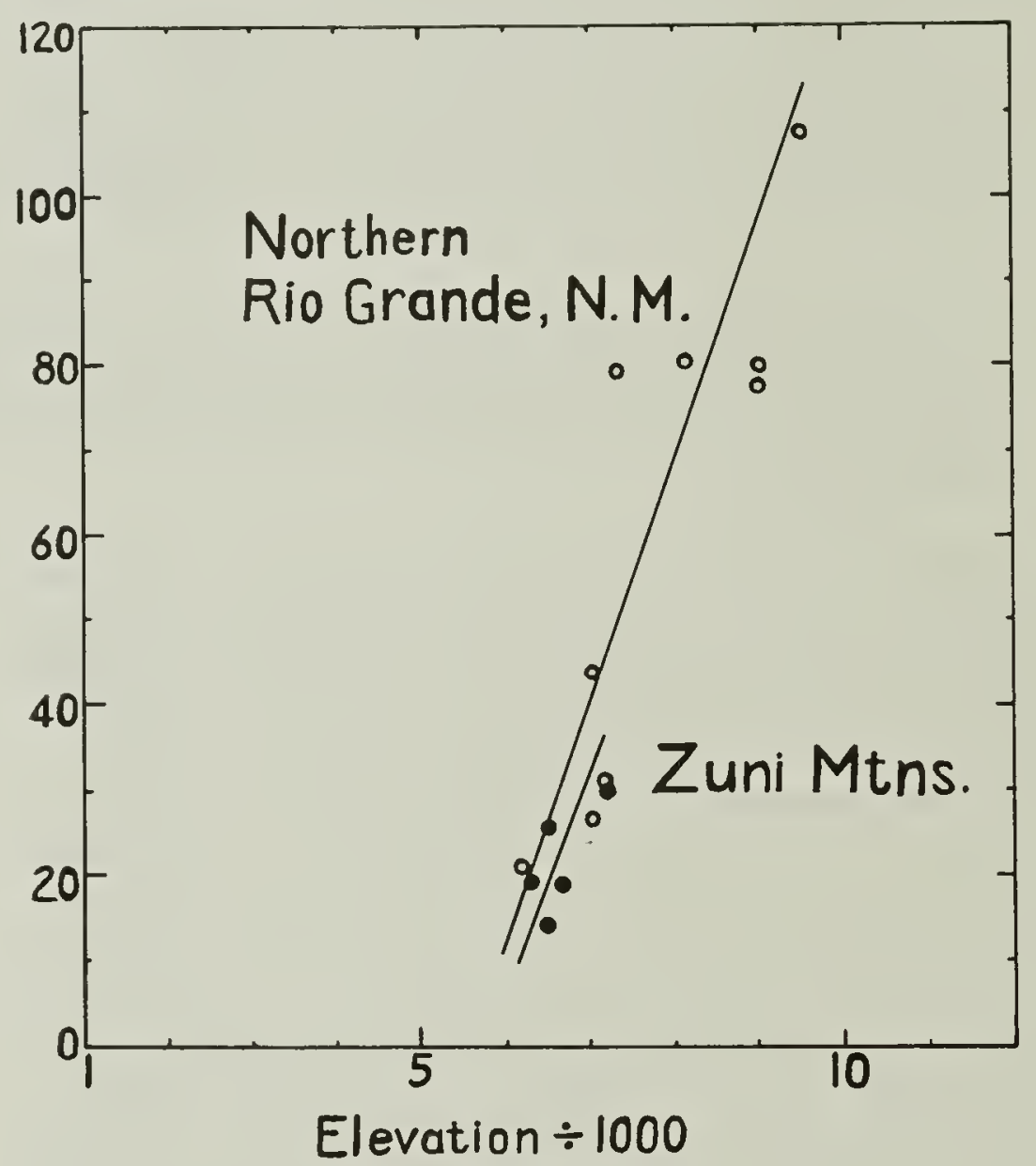

Figure 7 (c)

Figure 7. Variation of precipitation-effectiveness index with elevation;

(a) in Park Park Plateau and Front Range, Colo. and Wasatch Mtns., Utah,

(b) in southeastern Arizona and southwestern New Mexico,

(c) in north-central and west-central New Mexico.

Intensity-duration-frequency relations are expressed by the amount of rain received from a storm of one hour duration expected to occur once in five years. The information was obtained from Technical Paper 24, Part II (U. S. Weather Bureau, 1954 , p. 6-8), by multiplying the two-year one-hour amounts as given on isopleth maps, by 1.4 which is the ratio of the amounts for the two return periods in the western United States.

Season of maximum rainfall is secured directly from the tabulated amounts of precipitation for each month.

Ratio of mean January precipitation to $1 / 12$ mean annual precipitation is obtained directly from the values for mean annual precipitation, and mean January precipitation. The measure is important because of the greater effectiveness of rain for erosion when the vegetal cover is least extensive as it is in this winter month. The calculated value was found to be within the range of the value given by the map in Climatic Atlas of the United States (Visher, 1954, p. 204). 


\section{General Description of Basins}

This section treats general aspects of each basin. Obtained largely from map and field inspection, the description is provided for reference only; no effort is made to discuss the contribution of the information on each basin in regard to the conclusions. Location, physiographic province and section, type of surroundings, grazing history and range evaluation, lithology and structure, presence of gullying, type and extent of cover, and other features are best explained verbally, since most of the information is non-numerical. Climatologic data are included in the form of estimated precipitation-effectiveness index, and the distribution of rainfall by months. The basins are listed alphabetically by state and quadrangle in which they are located. Maps of all basins are given in Appendix IV.

\section{BASINS IN ARIZONA}

Chinle Badlands, Cameron, including two major basins in this locality, are covered by a special map made in August, 1953, by E. D. Koons, S. A. Schumm, and A. N. Strahler, at the scale one inch to 50 feet (1:600). The topography is "micro-relief," that is, an area of fully-developed, mature topography, relatively rugged, but composed of extremely small sized units. The area is located at the edge of the Navajo section of the Colorado Plateau, in the Painted Desert. The lithology is the blue-gray Chinle shale, in thickly platy laminae of silt and clay, and fine sand, containing nodules of gypsum and thin plates of iron-stained chalcedony. Beds are essentially flat-lying. No vegetation whatsoever is present anywhere in these basins. The surface layer of soft, unstable sand and clay, one to four inches thick, with numerous drying cracks, has been produced from the original shale by swelling of the clay during rains, and partial desiccation. Any disturbance of the surface produces a cascade of the crust material, exposing a spot of bare, unaltered shale, and burying the foot of the slope more deeply. (See also, Schumm, 1954, p. 80).

The nearest weather station at Tuba City, about 18 miles north, is probably in a meteorologically similar area. Of the yearly rainfall, $46 \%$ occurs in the months July through October. The region is definitely desertic, with a P-E index of 12.8 .

Finley and Adams Canyon, and Sycamore Canyon (Harshaw Quadrangle): Four fourth-order basins are included in this section. Field work was not detailed; only infiltration measurements were taken in these areas. The basins lie in the Patagonia Mountains, in the Basin and Range province, Mexican Highland section. Underlying the basins is a granite complex that is deeply weathered in places, with many residual boulders and dikes standing in relief. No gullying is present. Vegetation varies from oak chaparral on south-facing slopes, to oak woodland and pinon-juniper on the north-facing and higher slopes. Grass is plentiful in open areas and is ungrazed. About $85 \%$ of the area is in forest and bushes, $12 \%$ to $14 \%$ is grassland, and the remaining is bare soil or rock. The P-E index is estimated at 40 to 65 , depending on elevation and exposure. The nearest source of weather records is Nogales, 14 miles southwest, where $68 \%$ of the yearly precipitation is in July through October.

Tributary Basins to Harshaw Creek on Red Mountain (Mt. Hughes Quadrangle), located in Secs. $16,17,20,21$, Twp. 22 S., Ra. 16 E., are one fourthorder basin and two third-order basins. Red Mountain is very near the boundary between the Sonoran Desert and Mexican Highland sections of the Basin and Range province, and stands prominently 2,300 feet above the Sonoita Creek valley. The rock is wholly igneous; a thick series of mineralized felsite overlies prophyritic basalt. Cliffs form easily in both series, and slide rock slopes are common. Several mine drifts are present, but none are active.

The main cover in the basins is oak chaparral and brush, grading downward into semi-desert shrub and grassland, and upward into pinon-juniper woodland, and near the top of Red Mountain on northfacing slopes, larger Arizona white oak. An estimated $50 \%$ of the area is in brush and chaparral, $30 \%$ is grassland, and $20 \%$ bare rock. The grassland area is grazed lightly, and the range appeared to be in fair to good condition.

The P-E index is estimated to be 35 to 45 , depending on elevation and orientation. The nearest weather station is at Patagonia, three miles distant. There, $63 \%$ of the yearly precipitation occurs in the months July through October.

Whipple Basin (Prescott Quadrangle) is a fourthorder basin in the northwest quarter of Sec. 26, Twp. 14 N., Ra. 2 W., at the north boundary of the Whipple Military Reservation, in the Mexican Highland section, Basin and Range province. The basin lies in an extensive structural valley, three miles 
from the north end of the Bradshaw Mountains. The immediate relief in the area is low, not more than 250 feet. The rock is biotite granite, not greatly weathered where exposed, and overlain by thin well-indurated bouldery alluvium. The cover is estimated to be $67 \%$ grassland, $30 \%$ trees and bushes, and $3 \%$ bare rock. Grazing is moderate, and the range is in fair condition. Few new gullies have formed on the hillsides, and the channels show rejuvenation, but are not trenched.

Prescott, about two miles to the southwest, probably has very nearly the same climate. The $\mathrm{P}-\mathrm{E}$ index is 40 , and the months of greatest precipitation are July, August, September, December, January, and February, with $74 \%$ of the annual precipitation occurring in those six months.

Hog Canyon Basin (Sonoita Quadrangle) is a fourth-order basin tributary to Hog Canyon, and extends across Sec. 20, Twp. 20 S., Ra. 16 E. The area is in a dissected alluvial fan on the east flank of the Santa Rita mountains, in the Mexican Highland section, Basin and Range province. The immediate relief is 500 feet, but the mountains rise sharply to the west to a height of 4,600 feet above the basin, doubtless causing increased precipitation from maritime tropical air masses from the south and southeast. South-facing slopes are almost entirely grassland, while the north-facing slopes have only small grassland areas. About $55 \%$ of the basin is grassland, $45 \%$ is oak woodland, and less than $1 \%$ is bare. Grazing is light; the range is fair to good, with much long bunch grass remaining. Gullies are present in some small channels and in many places extend into fresh slopes.

The nearest weather records are from the Crown $\mathrm{C}$ ranch, one mile east, where precipitation data are available. The P-E index is estimated to be 35 to 40 , depending on exposure. Greatest precipitation is in the months July through October, when $62 \%$ of the annual rainfall occurs.

Basins in Saguaro National Monument (Tucson Quadrangle, 1904): Two fourth-order basins near the west boundary of the Monument and one-half mile north of the headquarters, were mapped by the writer and assistant in December, 1955, on a scale 100 feet to the inch $(1: 1,200)$. The area is in the Sonoran Desert section, Basin and Range province. The basins are in an area of low relief, a dissected pediment, near the foot of the Tanque Verde Mountains. Rock type is mainly chlorite and sericite schist, with injected fine-grained granite. Attitude of the planes of schistosity is variable, but the strike averages $\mathrm{N} 10^{\circ} \mathrm{E}$, dip $25^{\circ}$ to $45^{\circ} \mathrm{W}$. About $60 \%$ to $70 \%$ of the area is bare soil and rock, the remainder is covered by saguaro "forest." The prickly pear is over-grazed, with three animals (horses) per square mile, and the range is very poor. As the result of over-grazing and disturbance of the surface by the animals' hooves, numerous gullies have become established on the hillsides, and a few small channels deepened. Main channels are broad and filled with sand and gravel.

The climate data for this area were taken from Tucson Magnetic Observatory and the old Vail and Pantano records. The P-E index is estimated at 15. Of the annual rainfall, $52 \%$ is in the months July through October.

\section{BASINS IN COLORADO}

Dory Hill Basin and Mesa Gulch (Black Hawk Quadrangle) are two fourth-order basins in Secs. 32, 33, Twp. 2 S., Ra. 72 W., and Secs. 4, 5, 8, 9, Twp. 3 S., Ra. 72 W., in the Colorado Front Range, Southern Rocky Mountains province. The basins lie in a dissected pediment or other old erosion surface of moderate relief, sloping eastward. The immediate relief is 1,500 feet. Higher mountains near the Continental Divide, 10 to 15 miles to the west, reach heights of 4,500 feet above the basin level.

The rock underlying the basins is granite-gneiss and schist, with a probable general northward dip. About $60 \%$ of the area is grassland and is grazed, $35 \%$ to $37 \%$ is in forest, the remainder is bare. The estimated P-E index is 76 to 80 , according to the nearest records taken from Frances weather station at nearly the same elevation. The months March through July receive $54 \%$ of the mean annual precipitation, though rainfall is distributed rather evenly throughout the year.

Cabrini Gulch (Morrison Quadrangle) is a small third-order basin below the Mother Cabrini Shrine, off Highway 40, in the southeast corner of Sec. 16, Twp. 4 S., Ra. 70 W., and is tributary to Mt. Vernon Canyon. It is about a mile west of the mountain front, in the Colorado Front Range, Southern Rocky Mountains province. The rock underlying the basin is hard, black, biotite-hornblende schist, with infrequent veinlets of feldspathic material. About $95 \%$ of the basin is grassland, the remainder is covered by small trees and bushes. Grazing is moderate to heavy, and the range is fair. The main channel of the basin is gullied to a depth of 20 feet near the mouth and less than one foot near the head. A single gully. in the slopes was caused by concentration of runoff from the road which passes across the top of the basin. The P-E index is estimated at 46 on the basis of elevation alone, although this figure may be high, considering that a large percentage of the basin faces south. The months of greatest rainfall are April through August, when $61 \%$ of the yearly precipitation occurs.

Green Mountain Basin (Morrison Quadrangle) is a small third-order basin on the southeast end of Green Mountain, in the center of Sec. 19, Twp. 4 S., 
Ra. 69 W., near the western boundary of the Colorado Piedmont section, Great Plains province, about two miles east of the mounta in front. Underlying the basin is a coarse, bouldery conglomerate (the Green Mountain conglomerate) of alluvial origin, consisting of igneous and metamorphic rock fragments. Below the conglomerate is a partially consolidated, greenish-brown crossbedded sand. The mountain is a remnant of Tertiary alluvium, protected by the resistant conglomerate. An exposure of granite cobbles reveals partial disintegration to a depth of two and one half feet. Almost all cobbles have a caliche coating on the under sides.

About $95 \%$ of the area is grassland, $3 \%$ to $4 \%$ has small trees and brush, and the remainder is bare. The basin is moderately grazed, and the range is fair to good. The main channel, about 8 feet deep, is trenched and has a trapezoidal cross-section. The smaller channels, higher in the basin, are gullied less deeply and have V-shaped cross-sections.

The P-E index is estimated at 38 to 44 . The precipitation is assumed to be the same as that of Morrison, 3 miles southwest, where $61 \%$ of the annual precipitation occurs in the months of April through August.

Delonde Gulch (Nederland Quadrangle) is a fourth-order basin in Secs. 3 and 4, Twp. 1 S., Ra. 73 W., in the Colorado Front Range. The immediate area has about 1,800 feet of relief, while six or seven miles west the peaks of the Continental Divide rise to heights of 4,000 feet above the basin. The rock in the area is granite-gneiss and schist, disordered, but with a general northward dip. Considerable mining was done immediately west of the basin until the late 1930's, though no mines were seen in the basin itself. More recently logging has become the major activity, but its eventual extent cannot be predicted. Forest covers nearly $100 \%$ of the basin. The estimated $\mathrm{P}-\mathrm{E}$ index is 84 , and the precipitation is heaviest in the months of March through August, according to the nearest weather records, at Gold Hill.

Hicks Gulch (Nederland Quadrangle) is two miles south of Delonde Gulch, in Secs. 15, 16, 17, Twp. 1 S., Ra. 73 W., at about the same elevation, and is very similar to it, except as described below. Many inactive mine drifts are present in Hicks Gulch. To provide timber for mines, most of the large limber pines in the upper part of the basin were logged 35 to 50 years ago. The basin is grazed lightly, and the range is good to excellent in the grasslands. Aerial photographs show about $75 \%$ of the basin covered by forest and bushes, $20 \%$ to $23 \%$ by grass, and the remainder bare. There are no gullies, but rejuvenation of the main channel is evident by the steep-walled inner channel which becomes considerably deeper toward the mouth. In each of the two main tributaries, small levee-like features extend along the channel for nearly a quarter of a mile, and are probably the result of a late Pleistocene earth-flow or solifluction episode. The basin was probably never glaciated, since no spur trimming or other alteration of the valley, and no cirque or nivation cirque is present. The broad, poorly-drained upland in the highest part of the basin was affected greatly by periglacial phenomena, such as frost heaving, and even now soil moisture may be frozen a few feet below the surface during much of the year. The P-E index is estimated to be 79 to 85 , depending on elevation and exposure.

Moon Gulch (Nederland Quadrangle) is in Secs. 2, 3, 10, 11, Twp. 2 S., Ra. 73 W., about four miles SSE of Hicks Gulch, at about the same elevation. Underlying the basin is the same granite-gneiss and schist as in the two basins farther north in this quadrangle, and the planes of schistosity have a general northward dip. The greater height of the southern part of the basin is due to the presence of a fine-grained granite stock, resistant to erosion. Around this stock are numerous inactive mine excavations. Considerable portions of the basin have been burned over, some rather recently, and are gullied extensively. About $50 \%$ of the bas in area is in forest cover, $35 \%$ burned, and the remainder is grassland. The grasslands are primarily moderately grazed meadows near the main channel, and the range is in good to excellent condition; elsewhere the range is poor, and not grazed. The main channel has produced a broad floodplain, bounded by terraces of 20 to 30 feet in height. The floodplain narrows rapidly upstream, and is not apparent more than a mile above the mouth.

The P-E index is estimated to be 78 to 85 , depending on elevation and exposure. According to the nearest records of the Silver Lake weather station, the months with greatest precipitation are March through July, when $54 \%$ of the annual amount occurs.

Tributaries to Saruche Canyon and Gallinas Creek (Starkville Quadrangle) comprise two basins, one third-order and one fourth-order, in the Park Plateau, Raton section, Great Plains province. The tributary to Gallinas Creek lies in Secs. 27, 34, Twp. 34 S., Ra. 64 W.; the tributary to Saruche Canyon lies partially in the southwest quarter of Sec. 32, Twp. 34 S., Ra. 64 W. The rock is alternating thick-bedded sandstone and thinner shale, and coal strata. The beds are flat-lying, and cliffs are common on the sandstone. Considerable coal mining operations are carried on in the area, though not in these basins. The estimated P-E index is 48 . The nearest source of weather records is Madrid, 10 miles northwest, where $66 \%$ of the annual precipitation occurs during the period April through August. 


\section{BASINS IN NEW MEXICO}

Cottonwood Canyon (Allie Canyon Quadrangle) lies mainly in Secs. 1, 2, 3, Twp. 16 S., Ra. 12 W., in the Mexican Highland section, Basin and Range province. This area was not included in the field study. The P-E index is 38 , estimated from the elevation. Weather data are available from the Mimbres Ranger Station, one mile away. The greatest rainfall occurs in July through September, when $52 \%$ of the annual precipitation occurs.

Tributaries to Sapillo Creek (Allie Canyon Quadrangle) are two, small, fourth-order basins in Secs. 20, 21, 29, Twp. 15 S., Ra. 12 W., in the Mexican Highland section, Basin and Range province. These areas were not visited for field study. The estimated $\mathrm{P}-\mathrm{E}$ index is 40 , and the rainfall characteristics are assumed to be the same as above for the Mimbres Ranger Station, six miles to the southeast.

Sawmill Canyon and Tributaries (Big Burro Mountains Quadrangle) are three fourth-order basins in Secs. 11, 12, 13, Twp. 20 S., Ra. 16 W., and Secs. 6, 7, 18, Twp. 15 W., Ra. 20 S., in the Mexican Highland section, Basin and Range province. They extend over a large portion of the Big Burro Mountains, where the area has a relief of 2,300 feet. The Big Burro Mountains are an isolated granite mass, which is structurally complex, containing many dikes of fine to coarse texture ranging in composition from granitic to ultramafic. Wherever exposed, the granite is deeply and thoroughly weathered. Forest of pines and oak brush covers about $40 \%$ of the area, the remainder has sparse bunch grass or is completely bare, and the range is poor. Much gullying has occurred on the slopes, and some in the small channels. The estimated P-E index is 40 to 55 , varying with exposure and elevation. From the daily weather records kept for seven years at the Smithsonian Institution Astrophysical Observatory sunspot laboratory (Tyrone Station) on top of Jacks Mountain, near the head of these basins, the P-E index was 54. Greatest precipitation is from July through September, and a lesser maximum in December through February; $74 \%$ of the yearly precipitation occurs during those months.

Walnut Creek (Big Burro Mountains Quadrangle) is in the northeast quarter of Sec. 7, Twp. $20 \mathrm{~S}$., Ra. 15 W., on the northeast slope of the Big Burro Mountains. These two third-order basins differ from Sawmill Canyon in their greater relative relief and abundance of vegetation; forest covers about $85 \%$ of the area, the remainder is bare. The estimated $\mathrm{P}-\mathrm{E}$ index is 50 to 55 . In other respects these basins are essentially like the others in the Big Burro Mountains.

Paso del Norte Basin (Bland Quadrangle) occupies half of Sec. 2, Twp. 18 N., Ra. 4 E., and is near the boundary between the Southern Rocky Mountains province and the Mexican Highland section of the Basin and Range province. It is on the edge of the Jemez Caldera, and lies in an area of volcanic dacite, basalt, and pumice beds, dipping southeastward. Immediately to the north and west, the Sierra de los Valles drops 700 feet into the Valle Grande, which is the caldera proper. Elsewhere along the Sierra, peaks reach elevations of 10,200 feet. Almost $100 \%$ of the basin is forest covered. The estimated P-E index is 98. The nearest weather station is Los Alamos. July and August are the months of maximum rainfall, when $35 \%$ of the yearly precipitation occurs.

Peters Dome Basin (Bland Quadrangle) is a fourth-order tributary of Capulin Canyon immediately east of Sec. 20, Twp. 18 N., Ra. 5 E., in the San Miguel Mountains, in the Mexican Highland section, Basin and Range province. The rocks are nearly horizontal, alternating basalt and pumice. Though on all sides of the basin the basalt forms cliffs 800 to 900 feet in height, the basin itself is free of larger cliffs; only near its mouth has it begun to erode into the main cliff-forming layer. Forest and bushes, partially burned 50 to 75 years ago, cover about $94 \%$ of the basin; $4 \%$ is grassland, and the remainder is bare. The basin is poor range and is not grazed; however, it does serve as a main stock drive-way for herds from the west. No gullies are present. The estimated P-E index is 65 to 75 , depending on elevation and exposure. The nearest source of weather records of the same elevation is 10 miles northeast at Los Alamos; distribution of precipitation is probably the same as for Paso del Norte basin.

Cerro Pavo Basin (Cerro del Grant Quadrangle) is a large third-order basin in Secs. 7, 18, 19, Twp. 21 N., Ra. 4 E., in the southernmost end of the Southern Rocky Mountains province. The bas in lies atop a high lava-capped mesa, which falls away with considerable relief to the west, north, and east, and rises southward to the smooth, forested peaks of the north rim of the Jemez Caldera. Underlying the basin is gray to pink dacite or rhyolite porphyry, with occasional interbedded scoria, all essentially flat-lying. About $80 \%$ of the basin is forest covered; the remainder is grassland. The range, grazed by sheep and cattle, is fair to good in the meadows near the main channels. No gullies are present, and small channels are poorly defined. The P-E index is 110 , estimated from the elevation. The distribution of rainfall is assumed to be similar to that of Capulin Ranger Station, where the months of greatest rainfall are May through September, when $74 \%$ of the annual precipitation occurs.

Basins in Hurley East Quadrangle are located in Secs. 15, 22, 23, Twp. 18 S., Ra. 12 W., northeast of the mining town of Hurley. These three third-order and one fourth-order basins were not 
visited in the field. A published geologic map (Paige, 1916) shows that Tertiary basalt and andesite, overlying gravel and tuff, form the higher parts of the basins. The P-E index is 31 to 35 , estimated from elevation only. The nearest source of rainfall data, Ft. Bayard, records that $54 \%$ of the yearly precipitation is in the months July through September.

Hairpin Basin (Jarosa Quadrangle) is a small third-order basin in Secs. 1, 2, Twp. 21 N., Ra. 2 E., and is in the southernmost part of the Southern Rocky Mountains province. The main rock type is thickly-bedded red sandstone, essentially horizontal, cropping out in low cliffs on south-facing slopes. About $90 \%$ of the area is covered by brush and forest, $5 \%$ is grassland, and $5 \%$ is bare soil and rock. The basin is moderately grazed, and the range on north-facing slopes is good to fair. The only gullies present are those formed as a result of recent road building. The P-E index is 72 , estimated from the elevation. Capulin Ranger Station is the nearest source of weather data; there, $74 \%$ of the annual precipitation occurs in May through September.

Poleo Basin (Jarosa Quadrangle) is a fourthorder basin in Secs. 27, 28, Twp. 22 N., Ra. 2 E., in the southernmost part of the Rocky Mountains province, near the northern limit of the plateau comprising the San Pedro Mountains. The topograpy drops rapidly northward into the Rio Puerco Valley. The rock types are reddish, coarse-to-conglomeratic arkosic sandstone, gray quartzose sandstone, crinoidal limestone, and shale. In the greater part of the area, the beds are flat-lying, but dip eastward $10^{\circ}$ to $20^{\circ}$ in the higher western part of the basin. Trees and brush cover an estimated $96 \%$ of the area, grass $1 \%$, and the remainder is bare soil and rock. Grazing is light to moderate; the range is poor. Gullies are present in the main channel and one of the main tributaries. They are V-shaped, one to eight feet deep, cut in alluvium, but not bedrock. The estimated $\mathrm{P}-\mathrm{E}$ index is 77 , and rainfall distribution is assumed to be the same as for Capulin Ranger Station.

Quartz Hill Basin (Paxton Springs Quadrangle) is a fifth-order basin in Secs. 19, 20, 29, 30, Twp. 10 N., Ra. 11 W., on the eastern flank of the Zuni Mountains, in the Datil section of the Colorado Plateau province. The rock underlying the entire basin is a gneissic granite, with occasional septlike layers of muscovite-chlorite schist, dipping steeply southwestward. Of several mines present, only one is still active. The granite is deeply weathered in most places, especially at the eastern end of the basin where remnants of arkose originally deposited directly on the granite are found. The greater decomposition here can be attributed to pre-arkose weathering. Trees and bushes cover an estimated $80 \%$ of the basin, grass $15 \%$, and $5 \%$ is bare soil and rock. The area is grazed moderately to heavily; range is poor to fair. The few gullies present are in the smallest channels. The $\mathrm{P}-\mathrm{E}$ index is 44 , estimated from the elevation. The distribution of rainfall is assumed to be similar to that of El Morro National Monument, 18 miles west, and San Rafael, 15 miles northeast. The months of greatest precipitation are July through September, when $48 \%$ of the annual rainfall occurs.

Camino Basin (Santa Fe Quadrangle) is a small fourth-order bas in located in the northeast quarter of Sec. 28, Twp. 17 N., Ra. 9 E., in the Mexican Highland section of the Basin and Range province, in the valley of the Santa Fe River. The lithology is the Santa Fe formation, indurated sand and gravel of alluvial origin. About $15 \%$ of the basin is covered by trees and bushes, $30 \%$ by bunch grass, and $55 \%$ is bare. Grazing is very heavy, mainly by sheep and goats, resulting in very poor range conditions. The main channels are gullied, with vertical sides. The $\mathrm{P}-\mathrm{E}$ index is between that for Santa Fe Airport and Santa Fe City, or about 23. The distribution of rainfall is assumed to be about the same as that of Santa Fe City, where $44 \%$ of the annual precipitation is in July through September.

Tano Basin (Santa Fe Quadrangle) is a fourthorder basin essentially like Camino Basin in lithology. It lies north of the city of Santa Fe proper, but within the city limits, and is a tributary to Arroyo de los Frijoles. Trees and bushes cover $80 \%$ of the basin area; grass $4 \%$, and $16 \%$ is bare. The range is very poor to fair, and has probably been grazed in the recent past, though not immediately prior to the time of field study. Most of the channels are trenched, and gullies have become established on the slopes. The main channel is deepened to 15 feet near its head, but is not gullied toward the mouth; there, a broad, sandy channel is present. All gully sides are nearly vertical; the bottoms are usually flat. The $\mathrm{P}-\mathrm{E}$ index is estimated at 33 , somewhat above that of Santa Fe. The distribution of precipitation is the same as for Camino Basin.

Cedro Peak Basin (Sedillo Quadrangle) is a fourth-order basin in Secs. 25, 36, Twp. 10 N., Ra. 5 E., in the Mexican Highland section, Bas in and Range province, in the northernmost extension of the Manzano Mountains. The rock is the Pennsylvanian Magdalena formation, composed of limestone, feldspathic sandstone, breccia, and thin shale beds. An anticlinal axis passes north-south through the western part of the basin, from which beds dip gently northeast and northwest. About $97 \%$ of the basin is forest covered, $2 \%$ is grassland, and the remainder is bare. Grazing is light and the range is generally very poor, with only small areas of fair range. The main channel is gullied near its mouth to a depth of five feet. All other channels show signs of intense recent scour, down to, but not into bedrock, but are not actually gullied. Slopes give evidence of recent 
sheet-wash or rill erosion, but have very few gullies. A single gully has become established down a ridge crest, erosion having occurred along a trail. The P-E index is estimated to be 36 to 40 , depending on elevation and exposure. The distribution of rainfall is assumed to be the same as for the Tijeras Ranger Station, three miles northwest, where during the months of May, July, August, and September $47 \%$ of the annual precipitation occurs.

Tributaries to Bear Canyon (Twin Sisters Quadrangle) are three fourth-order basins in Secs. 13, 14, 23, 24, Twp. 16 S., Ra. $13 \mathrm{~W}$., in the Mexican Highland section, Basin and Range province. The area is a rugged, dissected section of lavas, mainly andesite and basalt (Paige, 1916), alternating with gravels and tuffs; the lava beds form prominent steps in the hillside. The area was not visited in the field. The estimated P-E index is 60 . The nearest source of weather records is Pinos Altos, where $50 \%$ of the yearly precipitation occurs during July, August, and September.

Little Cherry Creek (Twin Sisters Quadrangle) is a fifth-order basin in Secs. 15, 16, 19, 20, 21, 22, Twp. 16 S., Ra. 13, W., in the Mexican Highland section of the Basin and Range province. The estimated $\mathrm{P}-\mathrm{E}$ index is 51 . In other respects, the basin is similar to the others in Twin Sisters quadrangle. The basin was not inspected in the field.

Mill Creek (Twin Sisters Quadrangle) is a fourthorder basin similar to the two preceding ones, excepting the P-E index, which is estimated at 45.

Wilson Creek Basins (Twin Sisters Quadrangle) are four fourth-order basins similar to the three other areas in Twin Sisters quadrangle, except that the estimated P-E index is 51 . Forest covers $100 \%$ of the basin.

\section{BASINS IN UTAH}

Dry Hollow (Lehi Quadrangle) is a fourth-order basin in Secs. 20, 21, Twp. 4 S., Ra. 1 E., on the south side of the Traverse Mountains, five miles from the foot of the Wasatch Front, in the Great Basin section, Basin and Range province. The Traverse Mountains have not been affected by Recent uplift, as have the Wasatch Mountains, resulting in less rugged topography (Marsell, 1953, p. 20). The prevailing rock type is hard buff quartzite. The soil contains considerable clay that is probably weathered from limestone and/or lava, though these lithologies are not seen in the basin. Trees and brush cover $60 \%$ of the area, grass $35 \%$, and $5 \%$ is bare. The range which is generally poor, is heavily over-grazed in places by sheep and cattle. While a few small tributaries are gullied, the main channel is not and is indistinct in most places. The tributaries usually end in alluvial cones, and do not directly join the main channel. The entire surface of the basin is covered by quartzite fragments, which cause instability of the slopes on the steep hillsides. The estimated P-E index is 48 to 52 , depending on elevation. The distribution of precipitation is probably nearly the same as that of Alpine, five miles east, where except for four dry months, June through September, rain is distributed evenly throughout the year. Only $21 \%$ of the annual precipitation occurs in those months.

Hog Hollow (Lehi Quadrangle) is a fifth-order basin similar to Dry Hollow, but is nearer the Wasatch Front. The surface of the basin shows considerable andesitic lava and much less quartzite. A greater percentage of this area is covered by trees and bushes than in Dry Hollow. The estimated $\mathrm{P}-\mathrm{E}$ index is 51 to 55 , depending on elevation. The distribution of rainfall is the same as for Alpine, which is $11 / 2$ miles southeast.

Maple Hollow and Mercer Hollow (Lehi Quadrangle) are two fourth-order bas ins located in Secs. 15 and 16, 21, respectively, Twp. 4 S., Ra. 1 E., and are similar to the two preceding areas in this quadrangle, with a greater amount of lava cropping out than in Dry Hollow. The estimated $\mathrm{P}-\mathrm{E}$ index is 50 to 53 , depending on elevation. The distribution of precipitation is assumed to be the same as above for Alpine.

Pole Canyon (Spanish Fork Peak Quadrangle) is a large fifth-order basin in Secs. 13, 14, 15, 22, 23, 24, 27, Twp. 9 S., Ra. 3 E., in the Wasatch Mountains of the Middle Rocky Mountains province. Almost continual uplift during the late Pleistocene and Recent has caused rejuvenation, and accounts for the great ruggedness of the area. The main lithologies are limestone and quartzite. Forest covers almost the entire area. The estimated P-E index is 70 to 80 , depending on elevation. The distribution of precipitation is assumed to be similar to that of Thistle, where the rainfall is fairly evenly distributed throughout the year, with slight maxima in January and March, and a minimum in June and July.

Deadmans Hollow (Springville Quadrangle) is a small third-order basin in Secs. 1 and 36, Twps. 7 and $8 \mathrm{~S}$., Ra. 3 E., in the Wasatch Mountains of the Middle Rocky Mountains province. Uplift has caused rejuvenation and rugged topography. The main rock type is buff quartzite and sandstone. Trees and brush cover about $20 \%$ of the area, the remainder has sparse bunch grass or is completely bare. The estimated P-E index is 45 to 50 , depending on elevation. The distribution of rainfall is probably the same as for Provo Bench station, where the occurrence of precipitation is fairly even throughout the year, with a slight maximum in May, and a minimum in June and July.

Spring Creek (Springville Quadrangle) is a fourthorder basin in Secs. 24, 25, 26, Twp. 7 S., Ra. 3 E., in the Wasatch Mountains of the Middle Rocky Mountains province. Uplift of the mountain range 
has caused rejuvenation and rugged topography in the area. The main rock type is gray limestone and buff quartzite. Trees and bushes cover $85 \%$ of the basin, grass nearly $15 \%$, while only a negligible part is bare. Cattle graze the basin heavily near the roads and the main channel; the range is poor to fair. The main channel is gullied to a depth of 3 feet near its head and 20 feet at the mouth. The P-E index is estimated at 70 to 75 , depending on elevation. The distribution of rainfall is probably the same as above for Provo Bench station.
Tributary to Hobble Creek (Springville Quadrangle) is a small third-order basin in Secs. 36 and 1, Twps. 7 S. and 8 S., Ra. 3 E. The basin is similar to Deadmans Hollow. The main lithology is buff sandstone, quartzite, and gray limestone. The basin is grazed heavily, and the range is poor to fair. A few new gullies are present on the bas in slopes, but old channels are not gullied. The estimated $\mathrm{P}-\mathrm{E}$ index is 55 to 60 . Precipitation distribution is the same as for Provo Bench station, the nearest source of weather data. 



\section{Methods of Statistical Analysis}

\section{APPROPRIATENESS OF STATISTICAL METHODS}

The important assumptions inherent in statistical procedures are becoming well-known. Departures in practice from rigid adherence to the conditions imposed by those assumptions will produce more-or-less serious effects on validity of conclusions drawn from the results of a test. In this study, the attempt was made to comply with sound statistical methods, but some wide departures exist.

Normality of parent populations is fundamental in the parametric methods of analysis used here. The number and size of samples taken in any single category of measurement within a given environment are insufficient to allow detection of moderate departures from normality. One exception is maximum valley-side slope, which other investigators have found to be normally distributed within a drainage basin (Strahler, 1950, p. 681-685); this is also true of all areas studied here. Another exception is the drainage density of subordinate basins within a single larger basin, or within the same rock type; these distributions do not appear to be significantly different from normal, although total samples are small. Miller (1953, p. 14) rendered symmetrical the distribution of areas of first-order basins by logarithmic transformation.

Sample means tend to be normally distributed, regardless of the parent distribution, when samples are large, and the parent populations have finite variances (Dixon and Massey, 1951, p. 52). Most data used here are sample means, and for that reason are expected to be approximately normally distributed. The analysis of variance and similar tests, are remarkably robust to departures from normality (Box, 1953, p. 318) for tests on means. The question of normality is therefore probably of less importance, for the purposes of this study, than other factors.

Objective sampling is the sine qua non of all statistical methods; this requirement of statistics imposes restrictions on the methods of obtaining data suitable for analysis. Choice of sampling methods is the area of greatest divergence from conventional methods used in geology. Practicing statisticians have long realized the difficulty in obtaining unbiased samples of a population when there is freedom of choice in selecting the observations to be recorded. The training of a geologist is at least in part that of learning to observe in a manner that assumes a bias toward representation of the true situation, thus reducing variability in measurements and allowing treatment by nonstatistical methods. In the statistical approach, it must be assumed that the true characteristics of the universe are unknown and can best be estimated from random samples. Attempts to obtain data close to some value arrived at by "judgment," "insight," or "experience," will nearly always result in biased samples, and failure of the method of analysis. In this study, samples were taken both by random and non-random methods, and results are accordingly subject to qualification.

Study areas were chosen after cursory examination showed them to be satisfactory in accessibility, absence of cliffs, low in roughness, and in the mature stage of development. No effort was made to select by random methods sample basins in all types of rock; the majority are in granite and coarse clastic sediments, and few in shale or limestone. Measurements within basins were largely on areas selected to be representative and, as noted above, certain measurements would mean little on areas differing greatly from the average of the entire basin. Selecting measurement sites in a manner to reduce the variance of the observations may not bias the observed mean. However, if analysis of variance is used to test for significance of differences among means of a measurement in several basins, too many significant results will be obtained if inferences are made about the entire population instead of the portion that was measured. This is because the error attributable to a single measurement will occur in the denominator of the $F$ ratio, and will cause it to exceed the critical value too frequently. In regression analysis, selection in independent variables probably does not seriously affect the value of correlation and regression coefficient unless either extreme or intermediate values are eliminated. In this case, as extreme values were frequently rejected, the indicated correlation will be too low. Selection in the dependent variables has greater effect. If the selection tends to reduce the variability of the dependent variable, the indicated correlation will be too high (Ezekiel, 1930, p. 266-267).

Additivity and linearity of effects is an important assumption in multiple regression analysis, when several variables are examined for their influence on another. The plane of best fit through a set of points can always be found, and in cases presented here it is used only where the dependent 
variable is linear when plotted against each independent variable.* It is not definitely known whether or not effects of rock type, vegetal cover, and climatic elements on morphologic properties are additive. However, as will be seen in considering effects of these factors on valley-side slope and drainage density, non-linear two-variable plots obtained were rectified by taking logarithms, indicating either multiplicative effects or non-linear variables.

Multiple regression and correlation can be used where $\mathrm{Y}$ is a dependent random variable and $\mathrm{X}_{1}$, $\mathrm{X}_{2}, \ldots \mathrm{X}_{\mathrm{n}}$ are independent random variables whose values are known, and not subject to errors in measurement or observation. In the cases to be considered here, values of all variables were obtained by measurement in the field, from maps, or by meterological observation, and hence are estimates subject to at least some observational error. The effect of introducing observational error into the independent variables is to reauce the indicated correlation and regression coefficient. The regression is $\mathrm{Y}$ on estimated $\mathrm{X}_{1}, \ldots \mathrm{X}_{\mathrm{n}}$, rather than on true $X_{1}, \ldots X_{n}$ (Ezekiel, 1930, p. 225; Professor Howard Levene, Personal Communication). The combined influence of selection, tending to increase indicated correlation and regression coefficients, and introduction of error into the $\mathrm{X}_{\mathrm{i}}$, tending to reduce the coefficients, is complex, and the effects on the conclusions drawn in this study are not known.

The theoretical considerations discussed in the previous paragraphs are of great importance in confirming hypotheses by statistical methods, when research and experimentation have been properly controlled, when properties of experimental material are well-known, and when only a few variables are considered at one time. The research in this study is primarily investigative, and it is the writer's opinion that it is probably sound scientific practice to lean toward declaring too many relations or differences to be significant, rather than risk failing to detect a truly significant relation. It should be understood that the hypotheses thus proposed are not considered to be definitely confirmed until rigorous investigation has produced sustaining evidence.

\section{REGRESSION AND CORRELATION ANALYSIS OF PAIRED VARIABLES}

Preliminary analysis of grouped data: The data of greatest interest and promise were grouped into

\footnotetext{
* In view of the differences in opinion prevalent on the effects, say, of increased rainfall on texture of topography, when modifications of intensity-frequency relations, soil properties, vegetal cover, and stream regimen are considered, the question of non-additivity of effects should be the subject of further research.
}

classes and transferred to punch cards.* The data thus recorded were:

\section{Morphometric properties}

Drainage density

Density of first-order channels

Channel frequency

Frequency of firstorder channels

Ratio of channel length to perimeter

Valley-wall slope

Ruggedness number

Length of perimeter

Inflection angle

Relative relief

Basin order

\section{Properties of soil and cover}

Infiltration capacity Percent bare area Soil strength (wet) Roughness number Cover

Rock type

Life zones

\section{$\underline{\text { Climatic properties }}$}

5-year 1-hour rainfall $\mathrm{P}-\mathrm{E}$ index
The information available for each basin was recorded on two series of punch cards. Fourth and fifth-order basins were divided into third-order basins, with one card for each. Cards were then easily sorted into classes to obtain frequencies in each cell in a two-way table. Usual methods of analysis of grouped data yielded correlation and regression coefficients with comparative speed. Of the total number of properties investigated, those proving to be significantly correlated were considered for further analysis.

Correlation analysis of grouped data is limited by several considerations: (1) because of grouping, the estimated standard errors tend to be too large, and the correlation coefficient too small. It is necessary to have a considerable number of cells in the correlation table, and this requirement is limited by the number of holes in the cards. (2) The correlation table is difficult to interpret as to linearity, degree of correlation, importance of extreme values, etc. (Croxton, 1953, p. 136). Despite these objections, the method of correlation using grouped data on punched cards proved valuable in facilitating rapid analysis. Appendix $\mathrm{V}$ gives the correlation tables and the correlation coefficients obtained, for a number of important relations.

\section{FINAL MULTIVARIATE ANALYSIS}

Certain of the significant relations discovered from analysis of grouped data were further analyzed by ungrouped methods, in order to find the statement of most linear function giving the best fit and lowest scatter. The final results of these are given in part B of Appendix V. These relations

*Keysort cards, manufactured by The McBee Company, Athens, Ohio. 
are valid as they are, but their usefulness can be increased if combined with other measurements. Several combinations of logarithmic and arithmetic scales were tried for each pair of variables.

Multivariate correlation analysis is a method of analyzing the effect of several independent variables on the variation of a dependent variable. This method is necessary in determining whether each independent variable acts independently of the others, or if an apparent significant cor relation obtained on a two-variable analysis is actually due to their both being correlated with a third variable. Where all aspects of an experiment are not easily controlled and all possible combinations of factors are not found, multiple correlation and regression analysis will be of greater use in quantitative geomorphology, than the standard experimental designs employing the analys is of variance. (See analysis of covariance.)

The methods used in analyzing two to four variables are usually presented fully in elementary statistics textbooks. The amount of calculation needed to prepare a multiple correlation study increases as some power of the number of variables considered. In this study, the final analysis consists of determination of the effects on a dependent variable (drainage density), of five independent va riables (infiltration capacity, P-E index, etc.). No explicit solution of normal equations for this many variables is available. The normal equations were first expressed in matrix form, the inverse matrix found by the Doolittle method, and the inverse then used to obtain the desired solutions. (See Anderson and Bancroft, 1952, p. 168, and Ezekiel, 1950, pp. 168, 363, 367). The full solution is given in Appendix VII.

Correlation analysis of six variables, to yield stable solutions, usually requires more values on each variable than are used here. In this study, however, each of the 23 values used represents more actual measurements averaged to obtain it. Drainage density represents the average stream length per unit of area, and was obtained from ten to 300 individual measurements of stream length; each $\mathrm{P}-\mathrm{E}$ index is obtained from 12 paired values; infiltration capacity is an average of four to 11 readings; percent bare area is the average of two to 20 measurements; roughness number is measured from hundreds of rock fragments. Much better results would probably be obtained by using the original, unaveraged figures, as the gain in degrees of freedom would be considerable in most cases. Unfortunately, to do this would mean duplicating values of the dependent variable. Therefore, the value of the drainage density would have to be repeated as many times as there are infiltration readings in the basin, and there would be no real gain in degrees of freedom. A solution would be the use of analysis of variance with unequal replication in each cell, but this is unfeasible because all combinations of the five independent variables are not found.

Analysis of variance is a technique of determining the significance of difference among several means drawn from distinct environments. This study treats the effect of rock type on several morphometric and soil-cover properties of the basins in each type. A simple one-way classification is used, and six rock categories are distinguished. Where significant differences are found to exist among the means, Scheffé's method of judging contrasts is used to test specific pairs or groups of means for significant differences (Scheffé, 1953, p. 87). The analysis of variance tables are presented in Appendix VI, and contrasts are analyzed, where appropriate.

The analysis of covariance is essentially similar to the analysis of variance, with the addition that an associated measurement is made for each item, in order to determine how much of the differences in the means of the primary measurements is the result of variation in the related variable. The means are adjusted to what they would be were the associated measure the same for each. Then, if signigicant differences are present, these are due to the differences in the main variable of classification (Dixon and Massey, 1951, p. 173). One aim of the study was to determine if a consistent difference in drainage density could be shown to exist among basins with gullied slopes, trenched channels, and no gullies. Infiltration capacity was the associated measurement, and variations in drainage density due to differences in infiltration capacity were removed. The analysis of covariance table is given in Appendix VI B, and the results discussed in the conclusions section. 



\section{Inferences Drawn From Results of Statistical Tests}

\section{RESTRICTIONS ON INFERENCES}

Certain restrictions must be placed on the conclusions because of the nature of the statistical methods used. Perhaps most important is the influence of subjective sampling on the values of the correlation coefficients obtained in the analys is. This influence may be great, but little can be said of it before much more detailed work is done on limited aspects of this general study. Rather high values for the critical level (e.g. .05, or .10) were used, so that by chance alone, one would expect some of the differences or the correlations to be sufficiently great to be judged significant erroneously.

\section{RESULTS OF ANALYSIS OF VARIANCE AND COVARIANCE TESTS}

Rock type and drainage density: The type of rock has an apparent influence on drainage density, according to the high value obtained for $F$ in the following analysis of variance table:

\begin{tabular}{|c|c|c|c|c|}
\hline $\begin{array}{l}\text { Source of } \\
\text { Variation }\end{array}$ & S. S. & d.f. & M. S. & $F$ \\
\hline \multirow{2}{*}{$\begin{array}{l}\text { Among rock } \\
\text { types } \\
\text { Within rock } \\
\text { types }\end{array}$} & 57,371 & 5 & 11,474 & 56.7 \\
\hline & 12,140 & 60 & 202.3 & ..... \\
\hline Total & 69,511 & 65 & 1,069 & ..... \\
\hline
\end{tabular}

Six categories of lithology are distinguished: clastic (sandstone and alluvium), shale, limestone, schist, granite (includes gneiss), and acid volcanic (includes pumice). Inspection of the means of $\mathrm{D}$ for each rock type shows that some are decidedly different from others (Appendix VI A). The estimated effect of each lithology on $D$ is:

$\begin{array}{lllc}\text { Shale: } & 150.5 & \text { Schist: } & 37.9 \\ \text { Clastic: } & -7.8 & \text { Granitic: } & -3.86 \\ \text { Limestone: } & -12.5 & \text { Acid volcanic: } & -12.28\end{array}$

These values are probably meaningless, and it should be noted that they do not add to zero, as the sample size was different in each case. The important point is that shale and schist have average drainage density well above the mean, whereas limestone and acid volcanic rocks are well below the mean.

Scheffé's method of judging contrasts was used to find which of the means produce the significant results (Scheffé, 1953). Significant differences in drainage density exist between the average for shale and schist, the two lithologies with the highest values, and the average for granitic, clastic, volcanic, and limestone, and also between the average for shale and the average for schist. No significant difference in drainage density was found among granitic, volcanic, clastic, or limestone (see Appen$\operatorname{dix}$ VI A).

It is apparent that rock type has perceptible effect on drainage density under the general mountaintype climate in this study. However, the sampling of shale and limestone basins is poor, and all basins from both these lithologies are taken from areas with extremes of other conditions. For instance, all the shale basins lie in a very dry climate. The limestone basins are in the Wasatch Range, and were subjected to late Pleistocene uplift and rejuvenation. Tests of differing rock types within the same general climatic type, and in areas with identical histories by Miller (1953, p. 24, and Table 1) show the importance of lithology in determining drainage density in a humid climate. Further such studies may show that elimination of variation due to climate and differing geologic histories will reduce the error variance enough to allow detection of a significant difference among granite, clastic rocks, and acid volcanic rocks, that in this study show no differences.

Rock type and infiltration capacity: Individual infiltration capacity readings (not basin averages) were tested against rock type. The rock types distinguished are the same as for drainage density. The analysis of variance table is:

\begin{tabular}{crrrr}
\hline $\begin{array}{c}\text { Source of } \\
\text { Variation }\end{array}$ & S. S. & d.f. & M. S. & F \\
\hline $\begin{array}{l}\text { Among rock types } \\
\text { Within rock types }\end{array}$ & $\begin{array}{r}67.89 \\
249.4\end{array}$ & $\begin{array}{r}5 \\
135\end{array}$ & $\begin{array}{r}13.58 \\
1.85\end{array}$ & 7.43 \\
\hline Total & 317.3 & 140 & 2.27 & \\
\hline$F_{.001}(5,135)=4.10$ & & & &
\end{tabular}


The value of $\mathrm{F}$ is significant, and indicates that differences in infiltration-capacity means exist among the various rock types. Examination of the rock-type means (Appendix VI A) shows that some differ more widely from the grand mean than others. The estimated effect of each lithology on infiltration capacity is:

$\begin{array}{lrlr}\text { Shale: } & -1.43 & \text { Schist: } & -1.00 \\ \text { Clastic: } & -0.53 & \text { Granitic: } & 0.81 \\ \text { Limestone: } & 0.52 & \text { Acid volcanic: } & -0.31\end{array}$

Much reliance cannot be placed on these values. It is significant, perhaps, that shale and schist have infiltration capacities below the mean, whereas they have drainage densities well above the mean. Limestone and granitic rocks have infiltration capacities above the mean, but drainage density below the mean. Acid volcanic rocks probably have infiltration capacity not significantly different from the mean, though drainage density below the mean, and thus act somewhat anomalously.

The high value of $F$ is the result of the high infiltration rates on granitic and limestone lithologies. The contrast (granitic and limestone) vs. (clastic and volcanic) is significant at .05. Also, the contrast (clastic and volcanic) vs. (shale and schist), formed from the groups with the lowest infiltration rates, was judged not significant at .05 (see Appendix VI A).

The question arises as to whether lithology affects values of drainage density other than through the value of the infiltration capacity. A possible method of approach may be through an experiment using analysis of covariance, correcting values of drainage density for differences in infiltration capacity, and selecting basins with the same general climate and history, but from different lithologies. The data obtained in this study are inadequate to attempt this analysis.

Rock type and valley-side slopes: The individual slope measurements within each area studied were arranged into groups corresponding to rock type, without regard to basin. The estimated effect of each lithology on valley-slide slope is:

$\begin{array}{llll}\text { Shale: } & 7.9 & \text { Schist: } & -4.4 \\ \text { Clastic: } & 1.5 & \text { Granitic: } & -1.3 \\ \text { Limestone: } & 9.1 & \text { Acid Volcanic: } & -3.9\end{array}$

Limestone is well above the general mean, probably because the only samples are from basins in the Wasatch Mountains which have undergone late Pleistocene rejuvenation. Shale is also high, perhaps because of the aridity of the region sampled. Schist and acid volcanic rocks are low. To test whether these differences are significant, an analysis-of-variance test was made:

\begin{tabular}{|c|c|c|c|c|}
\hline $\begin{array}{l}\text { Source of } \\
\text { Variation }\end{array}$ & S. S. & d. f. & M. S. & $\mathrm{F}$ \\
\hline $\begin{array}{l}\text { Among rock } \\
\text { types }\end{array}$ & $11,983.48$ & 5 & 2396.69 & 18.99 \\
\hline types & $110,298.35$ & 874 & 126.19 & ........ \\
\hline Total & $122,281.83$ & 879 & .......... & ........ \\
\hline
\end{tabular}

$\mathrm{F}_{.001}(5,874)=4.10$

The value of $\mathrm{F}$ obtained is significant at .001, and the evidence points to the conclusion that rock type affects valley-side slopes.

Because the average slopes on shale and limestone are $10^{\circ}$ greater than on the other lithologies, it is reasonably suspected that the high values are the result of some other factors, specifically aridity and rejuvenation, that become manifest through the poor sampling of shale and limestone basins, mentioned above. Therefore, the contrast (clastic and granitic) vs. (schist and volcanic) was analyzed, and was found to be significant at .05 . It can be stated that lithology probably does influence valleyside slopes (see Appendix VI A).

Infiltration capacity, drainage density, and gullies: Basins for which infiltration-capacity readings are available were grouped according to whether they had gullied slopes, trenched channels, or unmodified drainage lines. Infiltration capacity was used as a supplementary measurement to adjust the drainage densities of the basins. The purpose of the test was to determine: (1) whether basins with gullies show consistently higher drainage densities than basins with trenched channels or unmodified drainage lines, when variation due to infiltration capacity is removed; (2) whether basins with gullied slopes show consistently lower infiltration capacity. The analysis of covariance table is:

\begin{tabular}{lrrrrrrrr}
\hline $\begin{array}{l}\text { Source of } \\
\text { Variation }\end{array}$ & d.f. & $\sum x^{2}$ & $\sum x y$ & $\sum y^{2}$ & d.f. & $\Sigma y^{\prime 2}$ & M.S. \\
\hline $\begin{array}{l}\text { Among } \\
\text { means }\end{array}$ & 2 & 1.4 & -.74 & .42 & 2 & .50 & .25 \\
$\begin{array}{c}\text { Within } \\
\text { groups }\end{array}$ & 20 & 10.5 & -12.03 & 24.44 & 19 & 10.68 & .56 \\
\hline Total & 22 & 11.9 & -12.77 & 24.86 & 21 & 11.18 & \\
\hline
\end{tabular}

For $X, F=1.33$; for $Y, F=0.17$; for $Y^{\prime}, F=0.45$, where $\mathrm{X}$ is infiltration capacity, $\mathrm{Y}$ unadjusted drainage density, and $Y^{\prime}$ the drainage density adjusted for differences in infiltration capacity. The critical value of $\mathrm{F}_{.05}(2,20)$ is 3.49 , and for $\mathrm{F}_{.05}(2,19)$ is 3.52. None of the values of $F$ obtained is significant. Though there is an increase in $\mathrm{F}$ from $\mathrm{Y}$ to 
$\mathrm{Y}^{\prime}$, it is not enough to exceed the critical value. As can be seen from the effects (see also Appendix VI B):

$$
\begin{gathered}
\text { Effects of gullying } \\
\text { on } \log _{e} D
\end{gathered}
$$

$$
\begin{gathered}
\text { Effects of gullying } \\
\text { on infiltration } \\
\text { capacity }
\end{gathered}
$$

\section{Channels}

trenched:

Slopes gullied: $\quad 0.167$

No gullies

\section{Channels} trenched: Slopes gullied: $\quad-0.28$ No gullies: $\quad 0.27$

The mean drainage density for gullied basins is higher than for trenched unmodified basins, and the mean infiltration capacity is lower than for the other classes; basins with trenched channels have lower drainage density than either gullied basins or untrenched and ungullied basins. However these differences are not great enough to be judged significant at .05 considering the amount of variability in the samples. These results fit theoretical considerations, and that may be reason to believe that with larger samples, and restricted sampling, the results would prove significant.

There is present a significant decrease in withingroups mean square (variance) when the effect due to differences in infiltration is removed. The unadjusted mean square is $24.44 / 20=1.22$, and the adjusted mean square is $0.56 ; F=1.22 / 0.56=$ 2.18 , which is greater than the critical value for .05. This indicates that a significant effect of infiltration capacity on drainage density is present.

\section{RESULTS OF SIMPLE CORRELATION AND REGRESSION ANALYSES}

Relations among morphometric properties of relief: Preliminary analys is with punched cards indicated that significant correlations exist among many of the morphometric properties of the basins studied. The correlation tables thus obtained are given in Appendix V A. Among properties involving relief, it was found that maximum valley-side slopes are correlated positively with relative relief and ruggedness number; slopes are negatively correlated with channel frequency and drainage density.

A scatter plot of valley-side slope (ordinate) against ruggedness number (abcissa) showed that a large number of points representing third-order basins lay above the average line, and points representing fifth-order basins lay consistently below the average, indicating that the ruggedness number was affected by the greater absolute relief of fifthorder basins. For purposes of estimating valleyside slopes, a better fit is obtained by decreasing the value of $\mathrm{H}$ by an amount depending on the basin order. This procedure can be explained by considering a model area having uniform drainage density throughout, and with uniform valley-side slopes, for all orders of basins. Then the absolute relief within a basin will normally be greater for basins of higher orders, simply because they are larger. Whereas the drainage density remains constant for all sizes and orders, the ruggedness number will increase with order. Therefore, to obtain the best relation with valley-side slope, which is constant, the value of $\mathrm{H}$ obtained for each basin should be divided by some number that increases with order, so that a constant for the area is obtained. In this case the order itself was used, though some function of the order number might give better results, perhaps $\mathrm{u}^{2}$ or $\mathrm{u}^{1 / 2}$. The plots of $\theta$ against $\log \frac{\mathrm{H}}{\mathrm{u}}$ and $\log \mathrm{R}$ are given in Appendix $\mathrm{V}$ A. The relation of valley-side slopes with these variables is considered below in connection with climate and soil properties.

The correlations of $\theta$ with $\log F$ and $\log \mathrm{D}$ indicate that an inverse relationship exists between slope steepness and topographic texture (Appendix $\mathrm{V} \mathrm{A}$ ) The absolute value of the correlation coefficient of $\Theta$ with $\log D(-.43)$ is greater than for $\theta$ with $\log F(-.34)$, indicating that perhaps part of the decrease in texture with increasing valleyside slopes is the result of foreshortening of steeper channels by projection onto the map. Foreshortening should not affect the number of channel segments, and as channel frequency is negatively correlated with $\theta$, the decrease in fineness is probably real. A possible mathematical model fitting this would have valley-side slopes inversely proportional to the logarithm of both drainage density and channel frequency. Conversely, topographic texture would vary as a negative exponent of average valley-side slope.

In addition, $D$ and $F$ are negatively correlated with $R$, as would be expected, since $R$ is highly correlated with $\theta$ (Appendix V A). Because correlation is low, it is not possible to determine which type of function gives the best linear scatter plot.

Which of the morphometric properties, among $\mathrm{D}, \mathrm{F}, \mathrm{R}$, and $\theta$ can be considered as controlling factors, if any are, is not definitely known. A plausible hypothesis is that $\mathrm{R}$ and either $\mathrm{F}$ or $\mathrm{D}$, or both, are relatively independent. $\mathrm{D}$ and $\mathrm{F}$ depend on rock type and climate, and $R$ probably depends greatly on past diastrophic history, Then $\Theta$ and $\mathrm{H}$ or $\frac{\mathrm{H}}{\mathrm{u}}$ are dependent. $\log \frac{\mathrm{H}}{\mathrm{u}}$ is correlated positively with $\log R,(r=.666, b=0.237)$, as expected, suggesting the mathematical model that ruggedness number corrected for basin order varies about as the one-fourth power of relative relief. 


\section{RELATIONS AMONG PLANIMETRIC PROPER- TIES OF BASINS}

Simple correlation of two variables by grouped data showed that high correlations exist among logarithms of $\mathrm{D}, \mathrm{D}_{1}, \mathrm{~F}$, and $\mathrm{F}_{1}$. Three power functions were obtained as the regression lines relating these properties:

(1) $\log _{e} \mathrm{D}$ vs. $\log _{10} F: r=.94 ; b=0.83$, $\frac{\mathrm{b}}{\mathrm{M}}=1.92 ; * \mathrm{~F}=0.60 \mathrm{D}^{1.92}$.

(2) $\log _{e} D_{1}$ vs. $\log _{e} D: r=.88 ; b=0.921$;

$$
\mathrm{D}_{1}=0.758 \mathrm{D}^{0.921} \text {. }
$$

(3) $\log F_{1}$ vs. $\log F: r=.97 ; b=.975 ;$

$$
\mathrm{F}_{1}=.99 \mathrm{~F} \cdot 975 \text {. }
$$

A test of significance of $b$ in equation (1) above shows that it is not significantly different from $.857(.40>\mathrm{P}>.30)$, and $2.303 \cdot \mathrm{b}$ is not significantly different from 2.00, when logarithms are removed. The relation $\mathrm{F}=\mathrm{kD}^{2}$ can therefore be used as a mathematical model. With increasingly fine textured topography, $\mathrm{F}$ increases proportionally to $\mathrm{D}^{2}$, showing that the increase in total length of drainage lines is due to an increase in number of channel segments, and not to longer segments of each order. An increase in drainage density is then, according to this hypothesis, a change of scale of topography, resulting in smaller basins and shorter channel segments of each order. If a model is considered in which the area of a certain basin is constant, that is, erosion is not allowed to enlarge the initial drainage area by extending the major divide, then the equation $F=\mathrm{kD}^{2}$ can be transformed into $\overline{\mathrm{l}}_{\mathrm{u}}=\frac{\mathrm{a}}{\mathrm{k} \sum \mathrm{l}_{\mathrm{u}}}$, with the restriction that increases of $\Sigma 1_{\mathrm{u}}$ are due solely to increases in $\mathrm{D}$. Then the average channel lengths of all orders are inversely proportional to the total length of channels at a given instant, during the time that the increase in $\mathrm{D}$ is taking place. $t$

The exponents of D and F; in equation (2) and (3) respectively, are not significantly different from 1.00. This suggests that the density of firstorder channels increases linearly with the total drainage density, and the frequency of first-order channels increases linearly with the total channel frequency; $D_{1}=k_{1} D$, and $F_{1}=k_{2} F$. These equations can be transformed into $1_{1}=\mathrm{k}_{1} \Sigma \mathrm{l}_{\mathrm{u}}$, and $\mathrm{n}_{1}=\mathrm{k}_{2} \Sigma \mathrm{n}_{\mathrm{u}}$, where increases in $\Sigma \mathrm{l}_{\mathrm{u}}$ and $\Sigma \mathrm{n}_{\mathrm{u}}$ are restricted to increases in fineness of topographic texture. Combining these two model equations gives

$* \frac{1}{\mathrm{M}}=2.303=\log _{\mathrm{e}} 10$.

$\dagger$ The same may be said of the relations among several basins of the same planimetric size, but differing in drainage density.
$\overline{\mathrm{I}}_{1}=\mathrm{k}_{3} \overline{\mathrm{I}}_{\mathrm{u}} *$ According to this hypothesis, the average length of first-order channels is a constant proportion of the average length of channels of all orders; the model implies then, combining with the first equation obtained, that average length of firstorder channels is inversely proportional to the total length of channel, when the latter increases during an increase of drainage density, $\overline{\mathrm{l}}_{1}=\frac{\mathrm{k} 4}{\sum \mathrm{l}_{\mathrm{u}}}$, if area is constant. A corollary of this hypothesis is that the average maximum length which firstorder channels attain before bifurcating is less in areas of high drainage density than in areas of low density (Schumm, 1954, p. 16).

The values which the constants of proportionality assume in the model equations stated above are abstract, fundamental properties of basins, and probably are influenced by many of the governing agents in basin regimen. These quantities should be of great interest for further investigation.

\section{RELATION OF VALLEY-SIDE SLOPES TO OTHER BASIN CHARACTERISTICS}

The effects of seven variables on slope values are dealt with as simple two-variable correlation and regression relations, and also combined in multiple correlation coefficients. The variables are (logarithms taken where necessary for linear plot, $\mathrm{Y}$ vs. $\mathrm{X}_{\mathrm{i}}$ ):

$\mathrm{X}_{1}$ wet soil strength/1000

$\mathrm{X}_{2}$ infiltration capacity

$\mathrm{X}_{3}$ Log Ruggedness number/order

$\mathrm{X}_{4} \log (\mathrm{P}-\mathrm{E})$

$\mathrm{X}_{5}$ Log relative relief

$\mathrm{X}_{6}$ Roughness number

$\mathrm{X}_{7}$ 5-year, 1 -hour rain +5

$\mathrm{Y}$ Average maximum valley-side slope.

The simple, two-variable correlation coefficients obtained from analysis of both grouped and ungrouped data are given in Appendix $\mathrm{V}$ and below:

$$
\begin{aligned}
& r_{Y 1}=-.423 ; \hat{\theta}=-.756 \frac{\mathrm{s}}{1000}+28.26 ; \mathrm{s}_{Y . X}=7.4 \\
& \mathrm{r}_{Y 2}=.746 ; \hat{\theta}=1.312 \mathrm{f}+20.7 ; \mathrm{s}_{Y . X}=4.9 \\
& r_{Y 3}=.777 ; \hat{\theta}=23.71 \log \frac{\mathrm{H}}{\mathrm{u}}+30.84 ; \mathrm{s}_{Y . X}=4.6 \\
& r_{Y 4}=.289 ; \hat{\theta}=9.90 \log (\mathrm{P}-\mathrm{E})+10.8 ; \mathrm{s}_{Y} . \mathrm{X}=7.0 \\
& \mathrm{r}_{Y 5}=.625 ; \hat{\theta}=18.69 \log \mathrm{R}+13.1 ; \mathrm{s}_{Y . X}=5.7
\end{aligned}
$$

* True for third and fourth-order basins; experimentally verified since writing. 
$\mathrm{r}_{\mathrm{Y} 6}=\frac{-.356 ; \hat{\mathrm{O}}=-.091 \mathrm{M}}{\text { (not significant) }}+25.46 ; \mathrm{s}_{\mathrm{Y} . \mathrm{X}}=7.6$

$\mathrm{r}_{\mathrm{Y} 7}=-.472 ; \hat{\theta}-4.36 q+40.96 ; \mathrm{s}_{\mathrm{Y} . \mathrm{X}}=7.2$

$\mathrm{r}_{35}=.666 \quad \mathrm{r}_{27}=-.918 \quad \mathrm{r}_{24}=.750$

$\mathrm{r}_{23}=.386 \quad \mathrm{r}_{12}=-.0946$.

Multiple correlation coefficients of three variables were obtained:*

$\mathrm{R}_{\mathrm{Y} \cdot 23}=.916 ; \quad \mathrm{R}_{\mathrm{Y} \cdot 24}=.851 ; \quad \mathrm{R}_{\mathrm{Y} \cdot 27}=.918$.

Three-variable partial correlation coefficients were found by combining the simple correlation coefficients:

$\mathrm{r}_{\mathrm{Y} 3.5}=.620$

$\mathrm{r}_{\mathrm{Y} 3.2}=.797$

$\mathrm{r}_{\mathrm{Y} 1.2}=-.532$

$\mathrm{r}_{\mathrm{Y} 5.3}=.230$

$\mathrm{r}_{\mathrm{Y} 7.2}=.804$

$\mathrm{r}_{\mathrm{Y} 4.2}=-.614$

$\mathrm{r}_{\mathrm{Y} 2.3}=.769$

$\mathrm{r}_{\mathrm{Y} 2.7}=.893$

$\mathrm{r}_{\mathrm{Y} 2.4}=.836$

These coefficients are not part of a complete multiple correlation study. They are used only as estimates of the population correlation coefficients. Thus, some of the coefficients calculated from larger samples are judged significant though smaller than $r_{Y 6}$ which is not significant.

The only variable not judged significant is the roughness number. However, the negative value of the regression coefficient obtained is consistent with a theory to be developed below to explain the inverse relation between slope angle and wet soil strength; both roughness and strength depend on the soil texture and adequate sampling should detect a positive relation between them.

The highest correlations were found between $\theta$ and $\log \frac{H}{\mathrm{u}}$, also $\Theta$ and $\mathrm{f}$. These have lowest standard error of estimate, that being on the order of the usual standard deviation of measurements within individual basins. $\log \frac{\mathrm{H}}{\mathrm{u}}$ alone explains $\dagger 60.4 \%$ of the variation in $\Theta ; \mathrm{f}$ alone explains $55.6 \%$. The third highest correlation was found to be with log $\mathrm{R}$, agreeing with previous findings (Schumm, 1954,

*The computation of multiple correlation coefficients was restricted here because not all intercorrelations among the $\mathrm{X}_{\mathrm{i}}$ were computed. The multiple coefficients chosen for presentation show the importance of the influence of infiltration capacity, log ruggedness number/ order, $\log (\mathrm{P}-\mathrm{E})$ index, and runoff intensity on valleyside slopes. These four variables are furthermore of greatest interest in this study, summarizing hydrologic, diastrophic, and climatic factors.

$\dagger$ †y "explains," it is meant that knowledge of $\mathrm{X}$ enables us to predict $\mathrm{Y}$ with error equal to $\left(1-\mathrm{r}^{2}\right)$ of previous error. Above, $60.4=100 \mathrm{r}^{2}$, etc. p. 23, and fig. 15). Log $\mathrm{R}$ alone explains $39.1 \%$ of the variation in $\Theta$. When expressed in degrees, valley-side slope varies proportionally to the logarithm of the relative relief, the logarithm of ruggedness number corrected for order, and infiltration capacity. The lowest correlation was found with $\log (\mathrm{P}-\mathrm{E})$, but it was judged significant because it was based on a large sample.

Three multiple correlation coefficients were calculated from the simple coefficients (Croxton, 1953, p. 172). The values obtained were rather high, showing that a large portion of the variation in the valleyside slopes is explained by consideration of only two independent variables. For instance, infiltration capacity, and the five-year, one-hour rainfall amount minus the infiltration capacity plus five (q) (which take into account infiltration and the relation of infiltration to average intensity of rain storms), together explain $84.3 \%$ of the variation in the valleyside slope.* Infiltration capacity and $\frac{\mathrm{H}}{\mathrm{u}}$ together explain $83.8 \%$ of the variation; infiltration capacity and $\log (\mathrm{P}-\mathrm{E})$ together explain $72.4 \%$ of the variation in $\Theta$.

Nine of the possible partial correlation coefficients were computed, and excepting $\mathrm{r}_{\mathrm{Y} 5.3}$, all are significantly different from zero. This means that $\log \mathrm{R}$ does not improve the estimation of $\theta$ when $\log \frac{\mathrm{H}}{\mathrm{u}}$ is already used. However, consideration of $\log \frac{H}{u}$ when $\log R$ is already used does significantly improve the estimation of $\Theta$. Consideration of $q$, when $f$ is already taken into account, explains about $64.4 \%$ of the variation in $\Theta$ unexplained by $\mathrm{f}$ alone. In this connection, a correlation exists between $\mathrm{f}$ and $\log (\mathrm{P}-\mathrm{E}),\left(\mathrm{r}_{24}=.750\right)$, a relation well known, and probably best explained by the increased amounts of humus and bacteria in soils with moister environments.

The results of greatest interest here are the relations between $\Theta$ and $\mathrm{f}$, and $\Theta$ and $\mathrm{q}$. It is apparent that greater average amounts and intensities of runoff are associated with lower slopes. Conversely, areas with high infiltration capacity have low runoff, and ceteris paribus, low rates of slope erosion; valley-side slopes in these areas tend to become and remain steep. In discussing a continuous downslope profile, Gilbert $(1877$, p. 117) stated that the declivity of slope is inversely proportional to the amount of water flowing over it, an observation that

* The multiple correlation coefficient and predicted slope values obtained from the use of infiltration capacity (f) and 5-year, 1-hour rainfall amount (P) as independent variables would be identical with those obtained from any two independent linear combinations of $f$ and $P$, such as $f$ and $q=(P-f+5)$, used here. The reason for using $q$ is that it has physical meaning, viz., the intensity of runoff expected every five years from a one-hour rain. 
appears to hold in general. Furthermore, these data show that the relation between slope and $f$ or $q$ is arithmetically linear:

$$
\theta=a_{1}-k_{1} q ; \quad \theta=a_{2}+k_{2} f \text {. }
$$

The following working hypothesis is proposed: where infiltration capacity is low, greater erosion accompanies greater runoff, and channels are eroded slowly in relation to the adjacent slopes, because much debris from the slopes is brought down into them. As a result, the slopes are lowered more rapidly than the channels, and the angle of slope declines. With higher infiltration capacity, little runoff occurs, and the valley-side slopes are not eroded so rapidly as in the previous case. Concentration of the runoff in channels greatly increases its eroding efficiency. An increment of water to channel flow comes by interflow (subsurface), and this addition serves to increase erosion in the channels, but the water thus added did not have the opportunity to erode the valley sides. Thus when the channel below a segment of slope is deepened, a proportionate amount of erosion has not occurred on the slope above. The tendency is thus to remove the support of the surface of the valley side afforded by the toe, thereby allowing an acceleration of creep, and consequent steepening. The quantity of interflow is affected by the structure of the soil, and is favored by shallow soils, with presence of parent rock or other im-

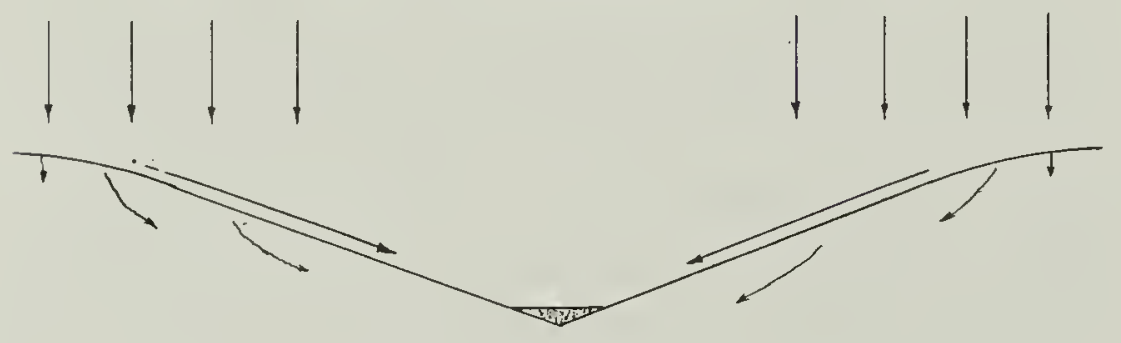

A

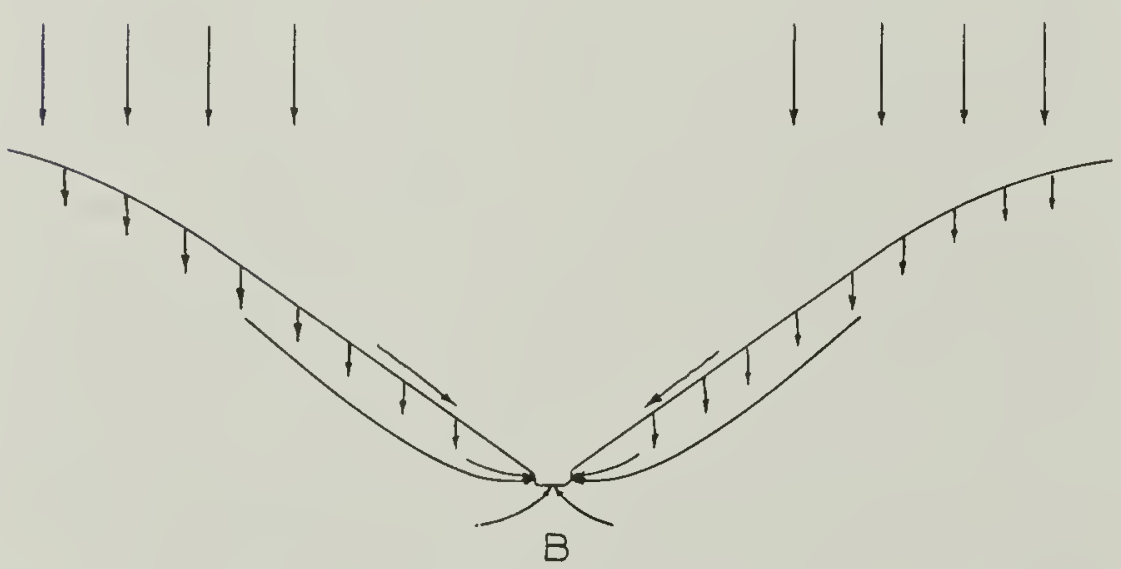

Figure 8. Hypothetical channels (A) with low infiltration capacity, high runoff and erosion rates, low interflow, debris-laden channel and low valley-side slopes; (B) with high infiltration capacity, low runoff and erosion rates, high interflow, eroded channel, and high valley-side slopes. permeable layer a short distance below the surface of the ground. This would be the case in much of the semiarid and arid west (Linsley, Kohler, and Paulhus, 1949, p. 388).

Climatic conditions enter further, because as the average rainfall intensity increases, the average amount and intensity of runoff increases. Furthermore, greater P-E index tends to increase infiltration capacity, thus producing steeper slopes.

The effect of soil strength on the average valley side slope maintained in an area of mature topography could be deduced from several reasonable premises, but the results would conflict unless the quantitative importance of all pertinent variables is known. A theory will be constructed that is consistent with the results obtained by statistical analysis of the measurements made in this study, but confirmation of the theory depends on further hydrologic research. We know (1) that $\Theta$ varies inversely with $S_{w}$ (wet soil strength), because $\mathrm{r}_{\mathrm{Y} 1}=-.423$ is significantly less than zero; $(2)$ that the correlation between $\theta$ and $S_{w}$ is improved when the effect of infiltration capacity is removed $\left(r_{Y 1.2}=-.532\right) ;(3)$ that wet soil strength is greater for coarser soils (confirmed by a one-way analysisof-variance test, not reproduced here). Excluding cliffs from consideration, the effect of soil strength must be through erosive processes rather than stability, because weaker soils tend to be stable at lower slope angles, in opposition to (1) above.

Analysis of covariance of the data in Table 4 gives the following table:

d.f. $\Sigma x^{2} \quad \sum x y \quad \sum y^{2} \quad$ d.f. $\Sigma y^{\prime 2} \quad$ M. S.

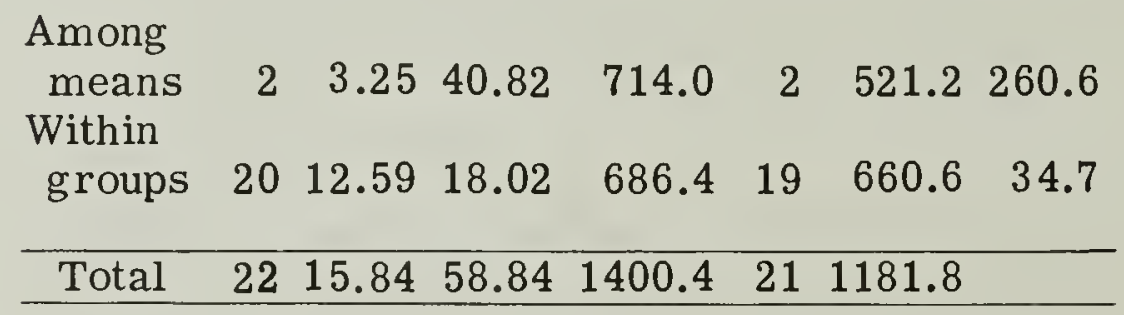

where $X=f, Y=\Theta$. The above was obtained by grouping $\theta$ and $f$ into three classes depending on soil texture. Fine-grained soils give high values of $\theta$, and coarse-grained soils give low values of $\theta$. The F-ratio for slope means unadjusted for infiltration capacity is 10.4 (significant at .001), and the $\mathrm{F}$-ratio for slope means after adjustment for infiltration capacity is 7.52 (significant at .01). Therefore, soil texture influences valley-side slope through some agency other than infiltration capacity alone. The correlation between $\theta$ and $S_{w}$ is probably due to this agency.

In the following proposal of a theory to explain the inverse relation between $\theta$ and $S_{w}$, it is assumed (1) that the hypothetical areas under consideration have identical climates, (2) that the bed rock near the surface is essentially homogeneous 
and does not differ greatly in mechanical composition from the top soil layer, and (3) that the area does not lie down-stream from a source of debris of contrasting caliber to that produced within the area.

In an area of low $S_{w}$, silt and clay predominate in the soil, and gravel is absent. Debris brought into the channels by runoff from the slopes remains in suspension and is immediately transported out of the area. Consequently, the channels remain free from bed load and are subject to immediate erosion by the concentrated stream of water. While runoff lasts, the channels are continually deepened and/or widened, and are not refilled as discharge wanessilt and especially clay remaining in suspension even in low velocities. Because of the greater efficiency for erosion of the concentrated stream over slope wash, the channels are lowered faster than the slopes, the toes of the slopes are removed, and the adjacent slopes are steepened until a steady state is achieved through a reduction of the rate of erosion in the channels relative to the rate of erosion of the slopes. The self-limiting mechanis $m$ is the result of increased erosion and creep on the steepened slopes, causing channel gradient to be lowered to that value necessary to transport the small quantity of fine-caliber bed load. In such areas, at steady state the slope orthogonals will intersect the channel at high angles, and the inflection angles will be acute.

In an area of high $S_{w}$ gravel predominates in the soil. Slope runoff sweeps debris into the subjacent channel where coarse material accumulates as bed load. Assuming a case in which valley-side slopes are initially steeper than equilibrium requires (e.g. where channels are trenched or rejuvenated), the greater declivity of the slopes permits movement of gravel and cobbles by rolling and sliding under relatively low down-slope discharges, but in the channel, higher velocities and discharges are required for transportation because the down-stream gravitational component is low. Down-cutting of the bed-rock channel cannot occur until the bed load is removed, and except where the channel is supplied by ground water, the bed load is replenished by material brought down from the slopes whenever sufficient discharge occurs to transport all of the bed load already present. Thus, channel downcutting is a relatively rare event, but the slopes can be eroded frequently. As channel discharge wanes, after a runoff-producing rain, any depressions that had formed in the channel are refilled by removal of debris from suspension. Erosion of the slope toes by lateral corrasion can occur at the outside of sharp channel bends, with consequent local steepening of the cut bank slope, but a compensating lowering of opposite slopes results in no quantitatively important change over the basin as a whole
(Strahler, 1950, pp. 812, 813). The slopes are therefore lowered at a greater rate than the channels, and reach a steady state at some relatively low angle, when the down-slope component of gravity is so adjusted as to allow only that amount of coarse debris to enter the channel which can be transported by stream flow. The channel gradient necessary to transport the large amount of coarse bed load is relatively steep; thus the angle between slope orthogonals and channel will be very acute, and the inflection angles obtuse.

In extreme cases, if the amount of debris supplied to the channels is quite great, it seems probable that the channel will aggrade rapidly and assume a braiding habit. The slope toes along the entire course of the channel may then be cut by lateral corrasion and the slopes be maintained at a steep angle until the maximum breadth possible for the drainage area has been attained. Basins with this environment were not included in the areas studied.

The mechanism proposed above for determining the relative rates of slope and channel erosion, i.e. the abundance of bed load, is the same as that proposed to explain the relation of slope angles to infiltration rates. However, areas most favorable for the accumulation of bed load because of low infiltration capacity-high runoff intensity are usually least favorable for the production of coarse debris because of the prevalence of silt and clay. Therefore, the effect of infiltration capacity is generally opposite the effect of debris availability, though both depend on soil texture and act through the same mechanism. This explains the indicated increased correlation between $\theta$ and $S_{w}$ when the effect of infiltration capacity is removed. Infiltration capacity depends also on climate, so the net effect of soil texture cannot be judged qualitatively except perhaps in extreme cases. The equilibrium valleyside slopes for given conditions of climate, infiltration capacity, soil texture, etc. are best estimated quantitatively by use of regression formulas.

Much further investigation is necessary before definite hypotheses can be formulated to include more than a few of the variables at one time for the entire environmental conditions of soil, climate, history, structure, and slope.

\section{TEXTURE OF TOPOGRAPHY AS AFFECTED BY CLIMATIC AND MANTLE CHARACTERISTICS}

Information from 23 basins subjected to full field investigation was arranged for multiple regression and correlation analysis. Drainage density (log D) 
was the dependent variable, with the following independent variables:*

$\mathrm{X}_{1}: \log (\mathrm{P}-\mathrm{E})$

$\mathrm{X}_{2}: \log$ infiltration

$\mathrm{X}_{3}$ : percent bare area $/ 100$

$\mathrm{X}_{4}: \log$ roughness number

$\mathrm{X}_{5}: \log \mathrm{q}$.

The estiniating equation found by simultaneous solution of the five normal equations is given in Appendix VII and below:

$Y=4.82-1.40 X_{1}-0.859 X_{2}+0.0904$

$X_{3}-0.074 X_{4}-1.59 X_{5}$.

The standard error of estimate is $0.122 \overline{4}$. The simple correlation coefficients are:

$\begin{array}{llll}r_{Y 1}=-.943 & r_{12}=.808 & r_{24}=-.150 \\ r_{Y 2}=-.793 & r_{13}=-.903 & r_{25}=-.906 \\ r_{Y 3}=.900 & r_{14}=-.318 & r_{34}=.241 \\ r_{Y 4}=.161 & r_{15}=-.748 & r_{35}=.689 \\ r_{Y 5}=.658 & r_{23}=-.848 & r_{45}=.266\end{array}$

The multiple correlation coefficient is $R_{Y .12345}=$ 0.965 , and thus $93.2 \%$ of the variation in $\mathrm{D}$ is explained by including only climatic and surface properties. If the effects of certain morphologic features, such as $R$ or $\Theta$ were considered in addition, possibly a greater amount of variation would be explained. An analysis of variance test for the

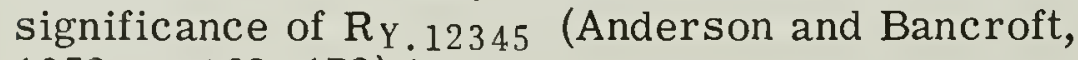
1952 , p. 163,172$)$ is:

\begin{tabular}{lrrlc}
\hline $\begin{array}{l}\text { Source of } \\
\text { Variation }\end{array}$ & d.f. & S. S. & M. S. & F \\
\hline & & & & \\
Regression & 5 & 4.489 & 0.898 & 46.29 \\
$\begin{array}{l}\text { Error } \\
\quad 17\end{array}$ & .329 & 0.0194 & \\
\hline$\quad$ Total & 22 & 4.818 & 0.219 & $\ldots . .$. \\
\hline
\end{tabular}

$R_{Y .12345}$ is significant at .001.

\footnotetext{
* These particular independent variables are used because they summarize the climatic, hydrologic, and surface properties that determine the topographic texture of a region. From two-variable plots, it was found that $\log \mathrm{D}$ is a linear function of the logarithms of $\mathrm{f}, \mathrm{M}$, and $\mathrm{q}$, so the $\log$ transformation is used for these. Log $\mathrm{D}$ is linear with $\mathrm{b} / 100$, and therefore the logarithmic transformation was not used for it.
}

Multiple correlation coefficients involving only $\log (\mathrm{P}-\mathrm{E}), \log \mathrm{f}$, and $\log \mathrm{q}$ are:

$$
\begin{aligned}
& R_{Y .15}=.946 \\
& R_{Y .125}=.960
\end{aligned}
$$

Selected partial correlation coefficients are:*

a) Three variables:

$$
\begin{array}{ll}
r_{Y 1.2}=-.842 & r_{13.2}=-.698 \\
r_{Y 1.3}=-.969 & r_{15.2}=-.064(\text { N.S. }) \\
r_{Y 1.5}=-.902 & r_{35.2}=-.353(\text { N.S.) } \\
r_{Y 2.1}=-.158 \text { (N.S.) } \dagger & r_{24.1}=.191 \text { (N.S.) } \\
r_{Y 3.1}=.341 \text { (N.S.) } & \\
r_{Y 3.2}=.704 & \\
r_{Y 4.1}=-.440 & \\
r_{Y 5.1}=-.214(\text { N.S. }) & \\
r_{Y 5.2}=-.234 \text { (N.S.) } &
\end{array}
$$

b) Four variables:

$$
\begin{aligned}
& r_{Y 1.23}=-.689 \quad r_{15.23}=-.463 \\
& r_{Y 1.25}=-.883 \\
& r_{Y 2.15}=-.518 \\
& r_{Y 3.12}=.306(\text { N.S. }) \\
& r_{Y 4.12}=-.424(.10) \\
& r_{Y 5.12}=-.533 \\
& r_{Y 5.23}=.0223 \text { (N.S.) }
\end{aligned}
$$

c) Five variables:

$$
\begin{aligned}
& r_{Y 1.325}=-.766 \\
& r_{Y 3.125}=.0139 \text { (N.S.) }
\end{aligned}
$$

The following inferences may be made from the quantities tabulated and presented above:

1. Log $D=Y$ shows significant correlations with (1) $\log (\mathrm{P}-\mathrm{E})$ index, (2) $\log$ percent bare area/ 100 , (3) log infiltration capacity, and (4) log runoff intensity, in decreasing order of importance as determined from the simple correlation coefficients. $\mathrm{Log}$ roughness number alone appears to have no correlation with $\mathrm{Y}$. These variables, together, explain all but $6.8 \%$ of the variation in $Y$, and we may state that the climatic, hydrologic, and surface properties of an area are of overwhelming impor-

* The partial correlation coefficients presented were chosen mainly to clarify the relative importance of the $\mathrm{P}-\mathrm{E}$ index, infiltration capacity, and runoff intensity in determining drainage density.

$\dagger(N . S$.$) denotes not significant at .10; (.10)$ denotes significant at .10 but not .05 ; all other s significant at .05 or less. 
tance in determining topographic texture. Furthermore, their influences can be detected by relatively simple methods of field measurements.

2. The value of $R_{Y .125}$ indicates that of the $93.2 \%$ of the variation in $\mathrm{Y}$ explained by consideration of all five independent variables, $92 \%$ is explained by $\mathrm{X}_{1}, \mathrm{X}_{2}$, and $\mathrm{X}_{5}$; percent bare area and surface roughness are very minor influences, when the others are already considered (note also, $\mathrm{r}_{\mathrm{Y} 3.125}=$ .0139).

3. The regression coefficients, which are partial derivatives of $\mathrm{Y}$ with respect to each independent variable, with the others held constant, gives the following decreasing order of importance to the independent variables: (1) log runoff intensity, (2) $\log (\mathrm{P}-\mathrm{E})$ index, (3) log infiltration capacity, (4) log percent bare area/100, and (5) log roughness number. The discrepancy in order of importance results in part from intercorrelations among the independent variables, and in part from the scale of the measures.

4. The partial correlation coefficients indicate that when $\mathrm{X}_{1}$ is already considered, the only variable that is significant is $\mathrm{X}_{4}$ (roughness). If this is not a spurious result, then when the P-E index is held constant, drainage density is inversely related to roughness. (Or, areas of greater roughness are associated with lower drainage density.) It should be noted that $\mathrm{X}_{4}$ shows the lowest simple correlation with $\mathrm{X}_{1}$ of all the independent variables. Conversely, when the effects of $\mathrm{X}_{2}, \mathrm{x}_{3}, \mathrm{x}_{5}, \mathrm{x}_{2}$ and $\mathrm{X}_{3}, \mathrm{X}_{2}$ and $\mathrm{X}_{5}$, and $\mathrm{X}_{2}, \mathrm{X}_{3}$, and $\mathrm{X}_{5}$ are removed, $\mathrm{X}_{1}$ still has a significant correlation with drainage density. The conclusion drawn is that the P-E index influences drainage density through the agencies of infiltration capacity, amount of cover, and runoff intensity, but probably not through surface roughness. In addition, the P-E index influences drainage density by other mechanisms, not explained here.

5. The infiltration capacity of an area is determined by the P-E index of the region, the surface cover, and by the type of rock from which the soil was developed. The amount of surface cover is determined by the P-E index also. The runoff intensity depends on average rainfall intensity (a function of the same factors that determine P-E index), infiltration capacity, and hence on surface cover and the P-E index. In equilibrium conditions, the drainage density will attain and stay at a value dependent on all these variables, and others not considered here. However, if say, the infiltration capacity and percent bare area were changed by fire, grazing, cultivation, etc., to values not in agreement with the P-E index, a change in drainage density would result, and the new value would no longer agree with that expected from consideration of the P-E index alone.

\section{GENERALIZATIONS ON INVESTIGATIVE PROCEDURES}

The following; are generalizations which seem appropriate concerning the philosophy of the investigation as a whole:

1. It has been shown that when various properties of drainage basins are analyzed, occurrences are found that would not reasonably be expected to result from operation of chance, or sampling error alone.

2. It was proposed that these non-chance occurrences represent in some manner true laws of nature, hence mathematical models were suggested consistent with what is known about these laws from sampling and statistical analysis.

3 . It is the nature of statistical laws, such as obtained, that a single observation contrary to the supposed law will not refute it, as the element of random error is always present in any observation or measurement, and is here presumed to exist in nature when a large system is considered.

4. Because it is impossible to consider all aspects of the environment of a drainage system, or any physical system whatsoever, we will never know that all factors influencing observations are included in the analysis. It seems most unlikely that enough factors could ever be considered at once to predict, completely without error, the lengths, gradients, and positions of all channels in a basin; adherence to the notion that perfect prediction could be obtained by finite extension of purely analytical differential equations is then rather useless. A better point of view is to acknowledge that some natural agencies operate in a manner that cannot be predicted except by the use of probability theory, and then build a theory based on statistical mechanics rather than on CartesianNewtonian mechanics.

5. Some of the non-random occurrences, the correlations obtained above, may reflect the agency of cause and effect. However, because of the complexity of the interconnections of causative factors and the presence of random error, simple cause and effect-meaning relations of forces, motions, and bodies-seems inappropriate, and instead a complex feedback among cause-like agencies and effect-like agencies seems more pertinent (in this case, properties of climate, lithology, history, vegetation, mantle, and form), when the totality of environment is included.

6. This does not mean that physical laws of cause and effect do not operate, or that methods of analysis by differential equations cannot be applied. Simple mechanical models of a natural system are satisfactory only in those very small parts limited both in time and physical boundaries. 


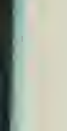

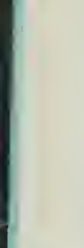

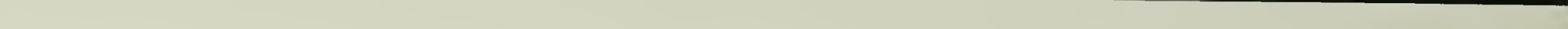
.

- 


\section{Summary of Conclusions}

The topographic texture and average valleyside slopes of fluvially-controlled landscapes are related to the causative and determinative factors of climate and lithology. However, it is difficult, or even meaningless, to consider isolated elements of the environment of a drainage basin in connection with these geometric properties of the basin because the geologic and climatic elements act in complex ways, through the agencies of vegetal growth, soil formation, runoff and erosion, infiltration, and soil creep. Thus in this study, as many elements as practicable were analyzed concurrently.

Drainage density is a negative power function of the P-E index, a measure of the availability of moisture to vegetation, but also depends on the percentage of bare area, infiltration capacity, soil strength, and intensity of runoff. These in turn depend on the P-E index and are the agents by which climate influences drainage density. Lithology influences drainage density by determining the amount of clay in the soil (though this depends also on the climate), and so affects the infiltration capacity and soil strength. Perhaps, also, lithology indirectly affects climate, because in the areas studied moist climates are confined to mountainous regions, and thus are found primarily on resistant rocks. Lastly, recency of uplift influences drainage density and valley-side slopes because areas of great immediate relief have large relief ratios and generally coarse texture. To develop fine texture in such an area would require impossibly steep slopes for equilibrium conditions.

The valley-side slopes of drainage basins vary with lithology, being steepest on shale and perhaps limestone, and gentlest on schist and acid volcanic lithologies. Steep slopes are associated with large relief ratio, high infiltration rate, low wet soil strength, low runoff intensity, and high P-E index. This suggests that steep slopes are produced and maintained in areas favoring channel deepening over slope erosion. In such areas, water passing into the soil by infiltration has no opportunity to erode the slope and contribute detritus to the channel load, but emerges directly into the channel and is immediately available for channel erosion. Thus, basins with steep slopes should be expected, on the average, to have low drainage density. This relation was found in the correlation analysis of the two variables. 


\section{References Cited}

Anderson, H. W. (1954) Suspended sediment discharge as related to streamflow, topography, soil, and land use. Am. Geophys. Union, Tr., vol. 35 , p. 268-281.

Anderson, R. L. and Bancroft, L. A. (1952) Statistical theory in research. McGraw-Hill Book Co., Inc., New York, N. Y., 399 pp.

Box, G. E. P. (1953) Non-normality and tests on variance. Biometrika, vol. 40, p. 318.

Burmister, D. M. (1952) Soil mechanics, vol. I. Columbia University Press, New York, 153 pp.

Coates, D. R. (1955) Quantitative geomorphology of small drainage basins of southern Indiana. Department of Geology, Columbia University, New York, Technical Report No. 10, Office of Naval Research Contract N60NR 271-30.

Costello, D. F. (19 ?) Vegetation zones in Colorado. Publication of Rocky Mountain Forest and Range Experiment Station, Ft. Collins, Colo., $10 \mathrm{pp}$.

Croxton, F. E. (1953) Elementary statistics with applications in medicine. Prentice-Hall, Inc., New York, $376 \mathrm{pp}$.

Dixon, W. J. and Massey, F. J., Jr. (1951) Introduction to statistical analysis. McGraw-Hill Book Co., Inc., New York, 370 pp.

Dortignac, E. J. (1951) Design and operation of Rocky Mountain infiltrometer. Station Paper No. 5, Rocky Mountain Forest and Range Experiment Station, Ft. Collins, Colo., 68 pp.

Ezekiel, Mordecai (1930) Methods of correlation analysis. John Wiley and Sons, Inc., New York, $427 \mathrm{pp}$.

Gilbert, G. K. (1877) Report on the geology of the Henry Mountains. U. S. Geographical and Geological Survey of the Rocky Mountain Region, $170 \mathrm{pp}$.

(1909) The convexity of hilltops. Jour. Geol., vol. 17, p. 344-350.

Horton, R. E. (1933) The role of infiltration in the hydrologic cycle. Am. Geophys. Union, Tr., vol. 14 , p. 446-460.

(1942) Remarks on hydrologic terminology. Am. Geophys. Union, Tr., vol. 23, p. 479-482. (1945) Erosional development of streams and their drainage basins; hydrophysical approach to quantitative morphology. Bull. Geol. Soc. America, vol. 56, p. 275-370.

Linsley, R. K. Jr., Kohler, M. A., and Paulhus, J. L. H. (1949) Applied hydrology. McGraw-Hill Book Co., Inc., New York, 689 pp.
Little, E. L. Jr. (1950) Southwestern trees, a guide to the native species of New Mexico and Arizona. Agriculture Handbook No. 9, U. S. Dept of Agriculture, $109 \mathrm{pp}$.

Love, L. D. and Johnson, W. M. (1952) The Manitou Experimental Forest, its work and aims. Station Paper No. 7, Rocky Mounta in Forest and Range Experiment Station, Fort Collins, Colo., 23 pp. and Dunford, E. G. (1952) The Fraser Experimental Forest, its work and aims. Station Paper No. 8, Rocky Mountain Forest and Range Experiment Station, Fort Collins, Colo., 27 pp. (1953) Watershed management experiments in the Colorado Front Range. Jour. Soil and Water Conservation, vol. 8, p. 213-218.

Marsell, R. E. (1953) Geology of the central Wasatch Mountains near Salt Lake City. The Compass, vol. 31 , No. 1, 22 pp.

Miller, V. C. (1953) A quantitative geomorphic study of drainage basin characteristics in the Clinch Mountain area, Virginia, and Tennessee. Department of Geology, Columbia University, New York, Technical Report No. 3, Office of Naval Research Contract N60NR 271-30.

Olmsted, J. M. H. (1947) Solid analytic geometry. Appleton-Century-Crofts, Inc., New York, 257 pp.

Paige, Sydney (1916) Silver City folio. U. S. G. S. Folio 199, U. S. Geological Survey, Washington, D. C., 19 pp.

Penck, Walther (1953) Morphological analysis of land forms. Translated by Hella Czech and K. C. Boswell, St. Martin's Press Inc., New York, $429 \mathrm{pp}$.

Scheffé , H. (1953) A method of judging all contrasts in the analysis of variance. Biometrika, vol. 40, p. 87-104.

Schumm, S. A. (1954) Evolution of drainage systems and slopes in badlands at Perth Amboy, New Jersey. Department of Geology, Columbia University, New York, Technical Report No. 8, Office of Naval Research Contract N60NR 271-30.

(1955) The relation of drainage basin relief to sediment loss. Publication no. 36 de l'Association Internationale d'Hydrologie, Extrait, p. 216-219.

Smith, K. G. (1953) Erosional processes and landforms in Badlands National Monument, South Dakota. Department of Geology, Columbia University, New York, Technical Report No. 4, Office of Naval Research Contract N60NR 271-30. 
Strahler, A. N. (1950) Equilibrium theory of erosional slopes approached by frequency distribution analysis. Amer. Jour. Sci., vol. 248, p. 673-696, 800-814.

(1952a) Dynamic basis of geomorphology. Bull. Geol. Soc. America, vol. 63, p. 923938.

(1952b) Hypsometric (area-altitude) analysis of erosional topography. Bull. Geol. Soc. America, vol. 63, p. 1117-1142.

(1953) Revisions of Horton's quantitative factors in erosional terrain. Unpublished paper read before Hydrology Section of Am. Geophys. Union, Washington, D. C., 1953.

(1954a) Statistical analysis in geomorphic research. Jour. Geol., vol. 62, p. 1-25.

(1954b) Quantitative geomorphology of erosional landscapes. Comptes Rendus de la dixneuvieme Session, Section XIII, p. 341-354.

(1955) Accelerated land erosion as a drainage density transformation. (Abstract) Program of G. S. A. Annual Meeting, 1955, p. 99 A. (1956a) Quantitative slope analysis. Bull. Geol. Soc. Amer., vol. 67, p. 571-596. (1956b) The nature of induced erosion and aggradation. p. 621-638 of Wenner-Gren International Symposium on Man's Role in Chang- ing the Face of the Earth. University of Chicago Press, Chicago Ill.

Thornbury, William D. (1954) Principles of geomorphology. John Wiley and Sons, Inc., New York, $618 \mathrm{pp}$.

Thornthwaite, C. W. (1931) The climates of North America according to a new classification. Geographical Review, vol. 21, p. 633-655.

Turnage, W. V. and Mallery, T. D. (1941) An analysis of rainfall in the Sonoran desert and adjacent territory. Carnegie Inst. Washington, Publ. 529, 45 pp.

U. S. Dept. of Agriculture (1941) Climate and man, yea rbook of agriculture. Washington, D. C., $1248 \mathrm{pp}$.

U. S. Weather Bureau (1933) Bulletin W, Climatic summary of the United States. Washington, D. C. Hydrologic Services Div. (1954) Rainfall intensities for local drainage design in the United States. Part I: West of the 115th meridian; Part II, Between $105^{\circ} \mathrm{W}$. and $115^{\circ} \mathrm{W}$. Technical Paper No. 24, Washington, D. C.

Visher, S. S. (1954) Climatic atlas of the United States, Harvard University Press, Cambridge, 403 pp.

Westphal, Wilhelm H. (1952) Physikalisches Wor terbuch, Zweiter Teil. Springer-Verlag, Berlin, $795 \mathrm{pp}$. 


\section{Appendix I}

\section{DERIVATION OF RELATIONS AMONG GEOME- TRICAL ELEMENTS OF VALLEYS}

Valley-side slopes, inflection angle, and channel gradient are related by laws governing lines and planes, assuming that the valley sides are planar, and therefore meet in a straight line that is the channel. Consider the contour map (a) showing a portion of a basin with valley sides $\pi_{1}$ and $\pi_{2}$, with unequal slopes $\Theta_{1}$ and $\Theta_{2}$, intersecting in a line (channel) $\Lambda_{3}$. The projection of the channel, $\Lambda_{3}$, on the map plane is taken as the $\mathrm{Y}$ axis, the $\mathrm{Z}$ axis is vertical, and the $\mathrm{X}$ axis is perpendicular to the YZ plane, as shown in (a). If $r_{1}$ and $r_{2}$ are drawn in the $X Y$ plane from a point 0 on the $\mathrm{Y}$ axis perpendicular to a contour line, say 200 , on each side of the valley, two right triangles are formed, $\mathrm{ABO}$ and $\mathrm{ACO}$, and the following relations are true:

$$
\begin{aligned}
& \epsilon_{1}=90-\xi_{1} \\
& \epsilon_{2}=90-\xi_{2} \\
& \Psi=\epsilon_{1}+\epsilon_{2}=180-\left(\xi_{1}+\xi_{2}\right),
\end{aligned}
$$

where $\epsilon_{1}, \epsilon_{2}$ are the angles the contour line makes with the projected channel (Y axis), and $\xi_{1}, \xi_{2}$ are the acute angles which $r_{1}$ and $r_{2}$ make with the $Y$ axis (axil angles), and $\Psi$ is the inflection angle of the contour line.

If a perpendicular to $\pi_{1}, \rho_{2}$ be drawn, as in figure (b),

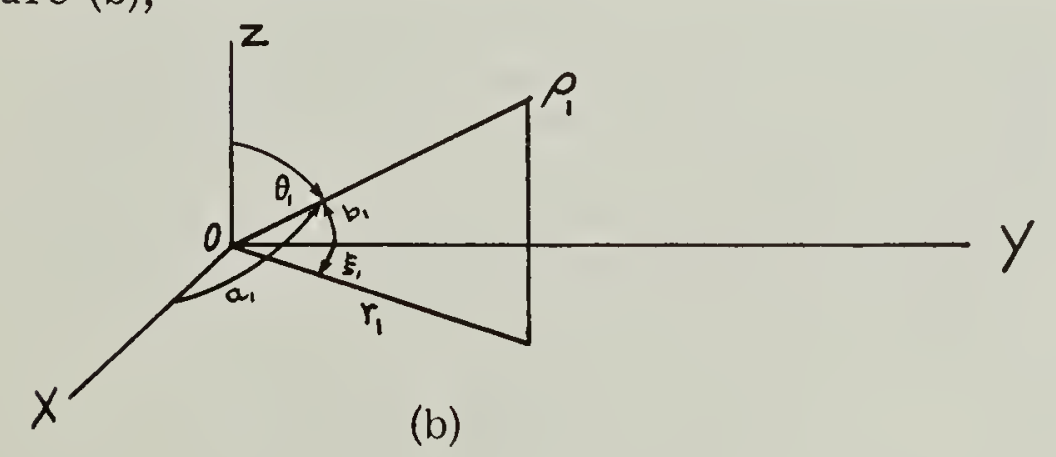

$\Theta_{1}$, the slope of $\pi_{1}$, is the angle between $\rho_{1}$ and the $\mathrm{Z}$ axis, $\mathrm{r}_{1}$ is the projection of $\rho_{1}$ on the XY plane, and $\xi_{1}$ is the angle between $\mathrm{r}_{1}$ and the $\mathrm{Y}$ axis. If $a_{1}$ and $b_{1}$ are the angles between $\rho_{1}$ and the $\mathrm{X}$ and $\mathrm{Y}$ axes respectively, then:

$$
\begin{aligned}
& \cos a_{1}=\lambda_{1}=\sin \theta_{1} \sin \xi_{1}, \\
& \cos b_{1}=\mu_{1}=\sin \theta_{1} \cos \xi_{1}, \\
& \cos \theta_{1}=\nu_{1}=\cos \theta_{1} .
\end{aligned}
$$

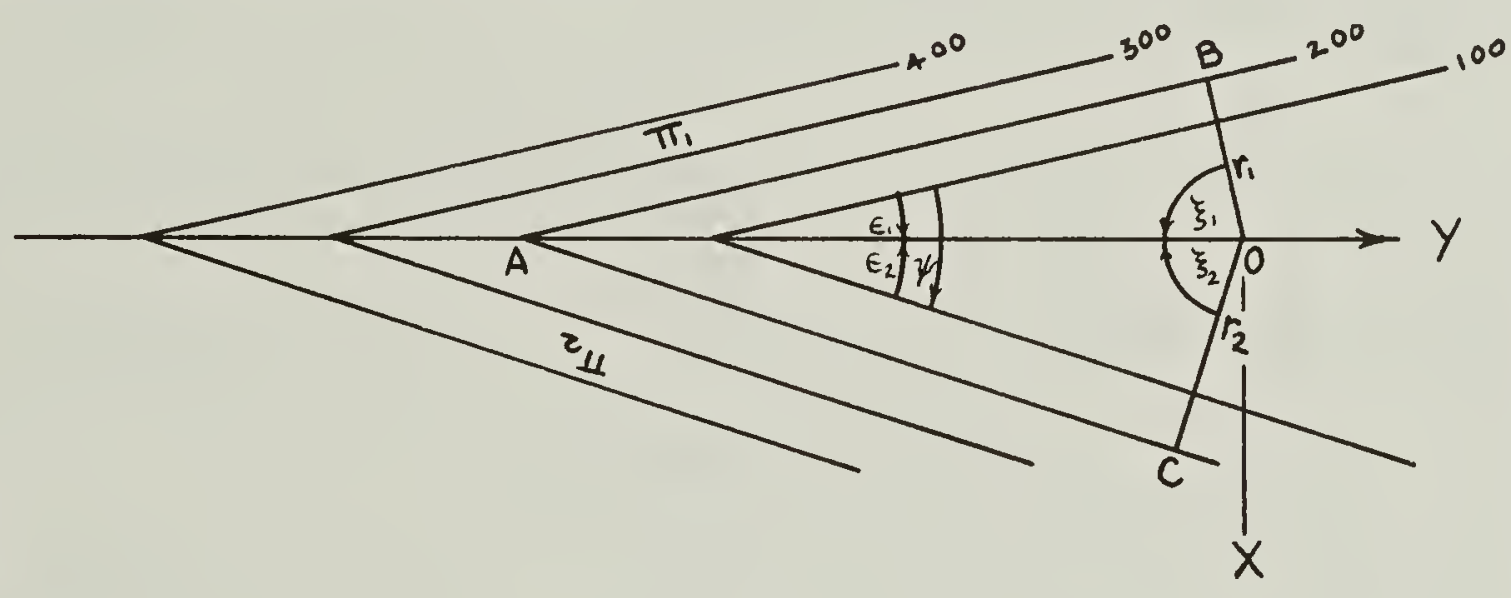

(a)

$\lambda_{1}, \mu_{1}$, and $\nu_{1}$, are the direction cosines of $\pi_{1}$.

If similarly th' perpendicular, $\rho_{2}$, to $\pi_{2}$ is drawn, as shown in figure (c), the projection of $\rho_{2}$ on the XY plane is $r_{2}$, angle $a_{2}$ is between $\rho_{2}$ and the negative end of the $\mathrm{X}$ axis, angle $\mathrm{b}_{2}$ is between $\rho_{2}$ and the $\mathrm{Y}$ axis, and angle $\mathrm{O}_{2}$ is between $\rho_{2}$ and the $\mathrm{Z}$ axis. By geometry, the direction cosines of $\pi_{2}$ are:

$$
\begin{aligned}
& \lambda_{2}=-\sin \theta_{2} \sin \xi_{2}, \\
& \mu_{2}=\sin \theta_{2} \cos \xi_{2}, \\
& \nu_{2}=\cos \theta_{2} .
\end{aligned}
$$

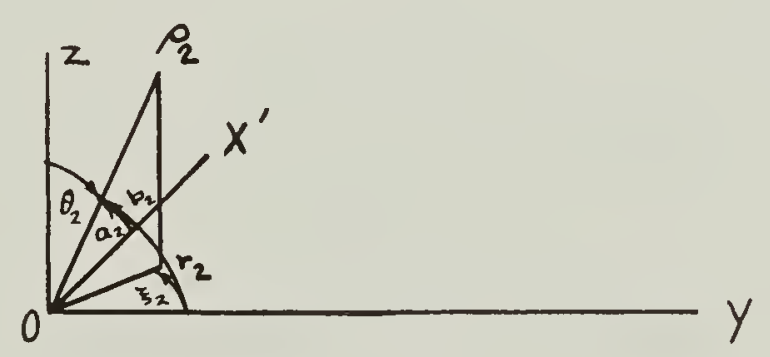

(c)

By (1) it is possible to eliminate $\xi_{1}$ and $\xi_{2}$ from the direction cosines, and obtain expressions in $\epsilon_{1}$ and $\epsilon_{2}, \Theta_{1}$ and $\theta_{2}$. For $\pi_{1}$ :

$$
\begin{aligned}
& \lambda_{1}=\sin \theta_{1} \cos \epsilon_{1}, \\
& \mu_{1}=\sin \theta_{1} \sin \epsilon_{1}, \\
& \nu_{1}=\cos \theta_{1}
\end{aligned}
$$


and for $\pi_{2}$ :

$$
\begin{aligned}
& \lambda_{2}=-\sin \theta_{2} \cos \epsilon_{2}, \\
& \mu_{2}=\sin \theta_{2} \sin \epsilon_{2}, \\
& \nu_{2}=\cos \theta_{2} .
\end{aligned}
$$

$\Lambda_{3}$, the intersection of $\pi_{1}$ and $\pi_{2}$ must lie in the $\mathrm{YZ}$ plane, because by definition the $\mathrm{Y}$ axis is the projection of $\Lambda_{3}$. The direction cosines of the $\mathrm{YZ}$ plane are:

$$
\begin{aligned}
& \lambda_{\mathrm{YZ}}=1 \\
& \mu_{\mathrm{YZ}}=0 \\
& \nu_{\mathrm{YZ}}=0 .
\end{aligned}
$$

Since $\Lambda_{3}$ is perpendicular to both $\rho_{1}$ and the $\mathrm{X}$ axis, then the direction numbers of $\Lambda_{3}$ can be found by evaluating the determinants:

$$
1_{3}=\left|\begin{array}{ll}
\mu_{1} & \nu_{1} \\
\mu_{\mathrm{YZ}} & \nu_{\mathrm{YZ}}
\end{array}\right|=\left|\begin{array}{ll}
\mu_{1} & \nu_{1} \\
0 & 0
\end{array}\right|=0
$$

(8) $\mathrm{m}_{3^{i}}=\left|\begin{array}{cc}\nu_{1} & \lambda_{1} \\ \nu_{\mathrm{YZ}} & \lambda_{\mathrm{YZ}}\end{array}\right|=\left|\begin{array}{cc}\cos \theta_{1} & \sin \theta_{1} \cos \epsilon_{1} \\ 0 & 1\end{array}\right|=\cos \theta_{1}$,

(9) $\mathrm{n}_{3}=\left|\begin{array}{cc}\lambda_{1} & \mu_{1} \\ \lambda_{\mathrm{YZ}} & \mu_{\mathrm{YZ}}\end{array}\right|=\left|\begin{array}{cc}\sin \theta_{1} \cos \epsilon_{1} & \sin \theta_{1} \sin \epsilon_{1} \\ 1 & 0\end{array}\right|$

$$
=-\sin \Theta_{1} \sin \epsilon_{1}
$$

(Olmsted, 1947, p. 23).

The direction cosines of $\Lambda_{3}$ are:

(10) $\lambda_{3}=0$

$$
\begin{gathered}
\frac{\cos \theta_{1}}{ \pm\left(\cos ^{2} \theta_{1}+\sin ^{2} \theta_{1} \sin ^{2} \epsilon_{1}\right)^{1 / 2}} \\
\frac{-\sin \theta_{1} \sin \epsilon_{1}}{ \pm\left(\cos ^{2} \theta_{1}+\sin ^{2} \theta_{1} \sin ^{2} \epsilon_{1}\right)^{1 / 2}}
\end{gathered}
$$

Since $\mu_{3}$ is the cosine of the angle between $\Lambda_{3}$ and the $\mathrm{Y}$ axis, $\cos ^{-1} \mu_{3}$ is the gradient of the channel, $\gamma$.

$$
\cos \gamma=\mu_{3}=\frac{\cos \Theta_{1}}{ \pm\left(\cos ^{2} \Theta_{1}+\sin ^{2} \Theta_{1} \sin ^{2} \epsilon_{1}\right)^{1 / 2}}
$$

Squaring and simplifying,

$$
\begin{aligned}
& \cos ^{2} \gamma=\frac{\cos ^{2} \theta_{1}}{\cos ^{2} \Theta_{1}+\sin ^{2} \Theta_{1} \sin ^{2} \epsilon_{1}}, \\
& \ldots \ldots \ldots \ldots \ldots \ldots \ldots \ldots \ldots \ldots \ldots \ldots \ldots \ldots \ldots \cot ^{2} \Theta_{1} \frac{\sin ^{2} \gamma}{\cos ^{2} \gamma} \\
& \sin ^{2} \epsilon=\ldots \\
& \sin \epsilon_{1}= \pm \frac{\tan \gamma}{\tan \theta_{1}} .
\end{aligned}
$$

The direction numbers of $\Lambda_{3}$ can also be expressed in terms of the direction cosines of $\pi_{2}$ and the YZ plane, and by analogy:

$$
\sin \epsilon_{2}= \pm \frac{\tan \gamma}{\tan \theta_{2}} \text {. }
$$

Assuming that $\epsilon_{1}$ and $\epsilon_{2}$. will always be acute, which is invariably true of natural channels, only the positive signs can be used in (14) and (15). From (14):

$$
\tan \epsilon_{1}=\frac{\tan \gamma}{\tan \Theta_{1} \cos \epsilon_{1}},
$$

and from (15)

$$
\tan \epsilon_{2}=\frac{\tan \gamma}{\tan \Theta_{2}} \frac{\gamma}{\cos \epsilon_{2}},
$$

Adding (16) and (17), and solving for $\tan \gamma$,

$$
\tan \epsilon_{1}+\tan \epsilon_{2}=\frac{\tan \gamma}{\tan \Theta_{1} \cos \epsilon_{1}}+\frac{\tan \gamma}{\tan \Theta_{2} \cos \epsilon_{2}}
$$

$$
\begin{aligned}
& \tan \gamma=\frac{\left(\tan \epsilon_{1}+\tan \epsilon_{2}\right) \tan \Theta_{1} \tan \theta_{2} \cos \epsilon_{1} \cos \epsilon_{2}}{\tan \Theta_{2} \cos \epsilon_{2}+\tan \theta_{1} \cos \epsilon_{1}} \\
& \text { (18) } \quad \tan \gamma=\frac{\tan \epsilon_{1}+\tan \epsilon_{2}}{\frac{\cot \Theta_{1}}{\cos \epsilon_{1}}+\frac{\cot \Theta_{2}}{\cos \epsilon_{2}}} .
\end{aligned}
$$

Equation (18) is the general expression of the relations among channel gradient, valley-side slopes, and the components of the inflection angle $\epsilon_{1}$ and $\epsilon_{2}$, where $\epsilon_{1}+\epsilon_{2}=\Psi$.

In the special case where $\theta_{1}=\theta_{2}$, that is, the two valley sides have the same slope, $\epsilon_{1}=\epsilon_{2}=1 / 2$ $\Psi$, and (18) can be simplified to:

$$
\tan \gamma=\sin \frac{\Psi}{2} \tan \theta
$$


If $\zeta$ is the dihedral angle between the planes $\pi_{1}$ and $\pi_{2}$, the relation among $\zeta, \epsilon_{1}, \epsilon_{2}, \Theta_{1}$, and $\mathrm{\theta}_{2}$ is easily obtained. By a theorem in solid analytic geometry,

(20)

$$
\cos \zeta=\lambda_{1} \lambda_{2}+\mu_{1} \mu_{2}+\nu_{1} \nu_{2},
$$

where $\lambda, \mu$, and $\nu$ are the direction cosines of the planes. From (4) and (5),

$$
\begin{aligned}
\cos \zeta= & -\sin \theta_{1} \sin \theta_{2} \cos \epsilon_{1} \cos \epsilon_{2}+\sin \\
& \Theta_{1} \sin \theta_{2} \sin \epsilon_{1} \sin \epsilon_{2}+\cos \theta_{1} \cos \theta_{2} .
\end{aligned}
$$

By collecting terms and converting to functions of $\epsilon_{1}+\epsilon_{2}$, and $\Theta_{1}+\Theta_{2}$, the following expression is obtained:

$$
\begin{aligned}
\cos \zeta= & \cos \left(\Theta_{1}+\Theta_{2}\right) \cdot \cos ^{2} 1 / 2\left(\epsilon_{1}+\epsilon_{2}\right)+\cos \left(\Theta_{1}-\Theta_{2}\right) . \\
& \sin ^{2}{ }_{1 / 2}\left(\epsilon_{1}+\epsilon_{2}\right) ;
\end{aligned}
$$

or

(21)

$$
\begin{aligned}
\cos \zeta= & \cos \left(\Theta_{1}+\theta_{2}\right) \cdot \cos ^{2} \frac{1}{2} \Psi+\cos \left(\Theta_{1}-\theta_{2}\right) \cdot \\
& \sin ^{2} 1 / 2 \Psi .
\end{aligned}
$$

In the case that $\theta_{1}=\theta_{2},(21)$ can be simplified to 


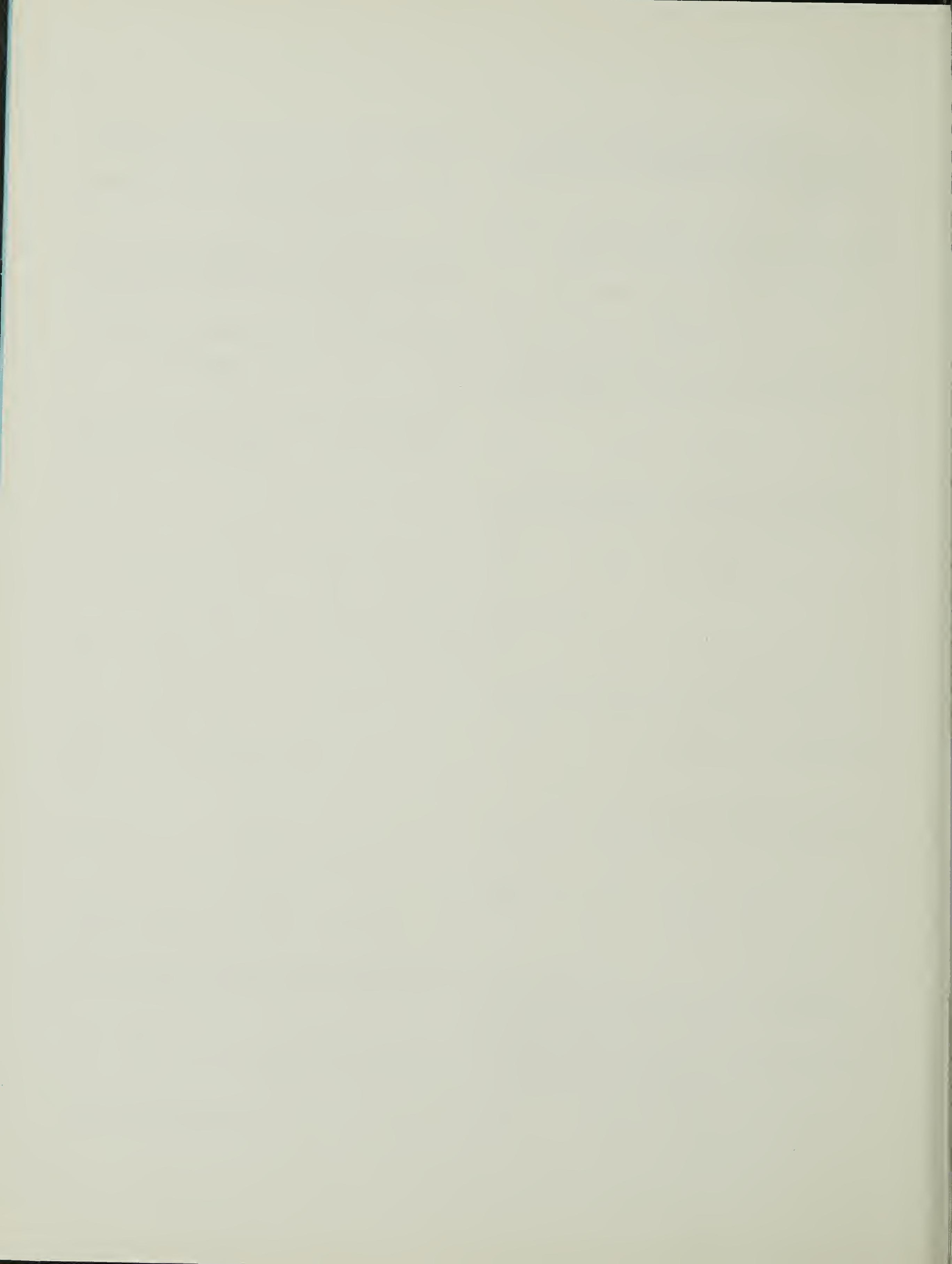




\section{Appendix II}

\section{INDEX OF STUDY AREAS}

The quadrangles listed below correspond to numbered squares within each state, as given on the index maps.

\section{Arizona}

1. Chinle Badlands (Special Map)

2. Prescott

3. Saguaro National Monument (Special Map)

4. Sonoita

5. Mt. Hughes

6. Harshaw

\section{Colorado}
1. Nederland
2. Black Hawk
3. Morrison
4. Starkville

New Mexico

1. Jarosa

2. Cerro del Grant

3. Bland

4. Santa Fe

5. Paxton Springs

6. Sedillo

7. Twin Sisters

8. Allie Canyon

9. Hurley East

10. Big Burro Mountains

Utah

1. Lehi

2. Springville

3. Spanish Fork Peak 
46

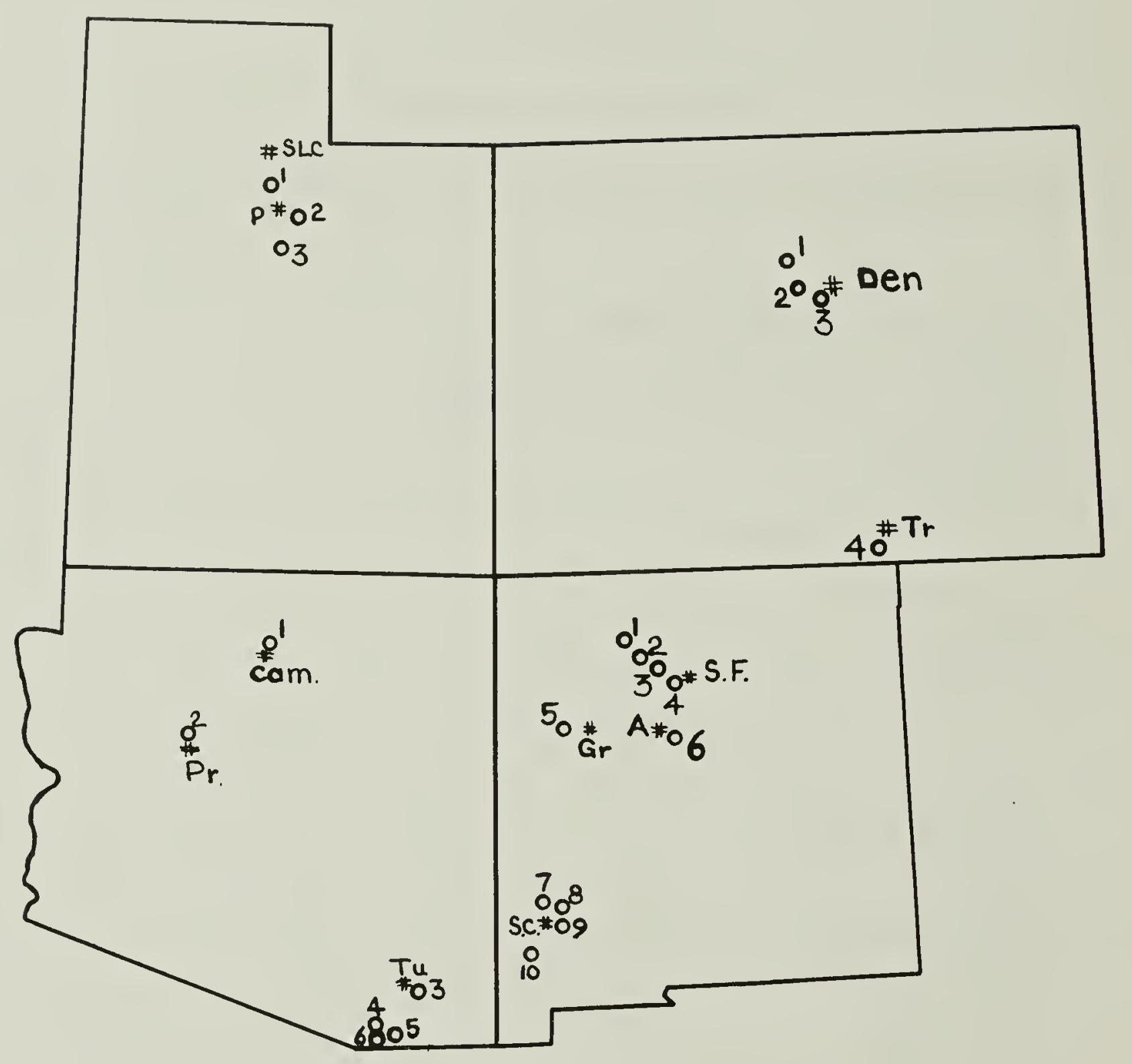

INDEX MAP OF STUDY AREAS 


\section{Appendix III}

\section{DERIVATION OF RELATION BETWEEN DIAME- TER OF IMPRINT AND VOLUME OF IMPRINT, AS USED IN SOIL STRENGTH TEST}

The imprint of the shot on a planar surface is a spherical segment with depth $h$, diameter $d$, and volume $V$. The radius of the shot, $r$, is 0.188 feet. An expression for $\mathrm{V}$ in $\mathrm{r}$ and $\mathrm{d}$ must be found.

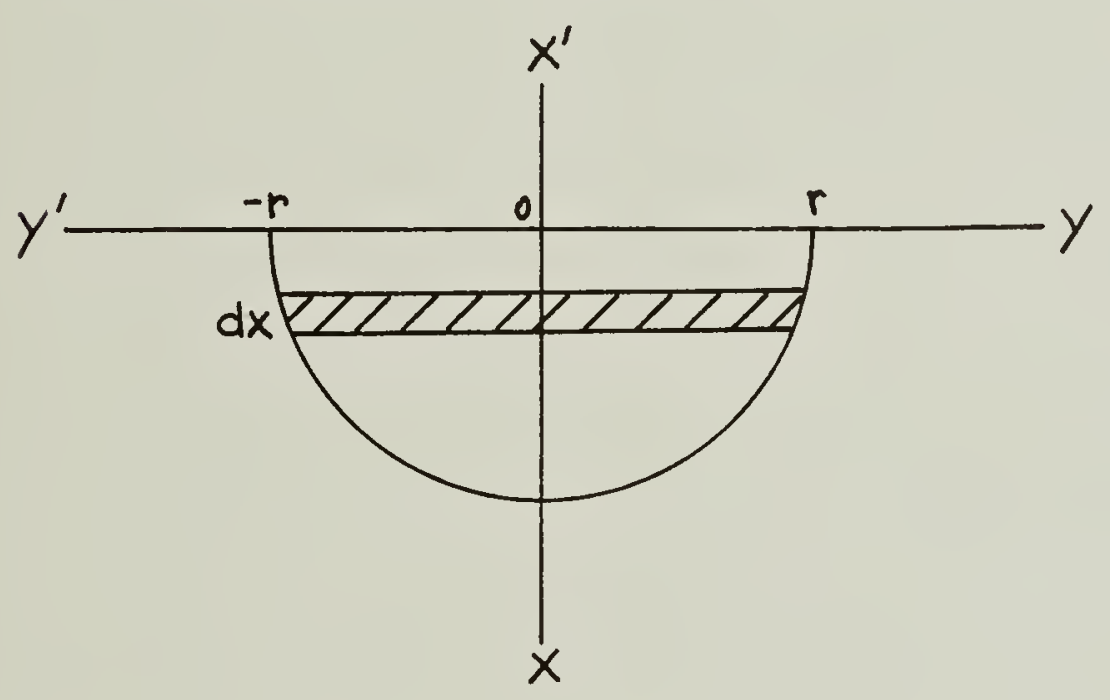

$$
X=+\left(r^{2}-y^{2}\right)^{1 / 2}
$$

(a)

Figure (a) is a semi-circle with a center at 0 , and radius $r$. Since only the portion in the positive side of the $\mathrm{Y}$ axis is considered, its equation is

(1)

$$
\mathrm{X}=+\left(\mathrm{r}^{2}-\mathrm{y}^{2}\right)^{1 / 2}
$$

For a circle,

$$
d X=-\frac{y d y}{x}=-\frac{y d y}{\left(r^{2}-y^{2}\right)^{1 / 2}}
$$

and the element of volume, $d V$, is

$$
d V=\pi y^{2} d x=-\frac{\pi y^{3}}{\left(r^{2}-y^{2}\right)^{1 / 2}},
$$

since a sphere is being considered, which is obtained by rotating the circle about the $\mathrm{X}$ axis. By integration,

$$
V=-\pi \int_{y_{1}}^{0} \frac{y^{3}}{\left(r^{2}-y^{2}\right)^{1 / 2}} d y
$$

is the volume of a segment below a line at $\mathrm{X}_{1}$, with a radius of base $\pm y_{I}$. The integration of (4) is easily done: let $\mathrm{u}=\mathrm{r}^{2}-\mathrm{y}^{2}$; then $\mathrm{y}^{2}=\mathrm{r}^{2}-\mathrm{u}$, and $d u=-2 \ddot{y} d y$.

$$
I=\frac{\pi}{2} \int y^{2}\left(r^{2}-y^{2}\right)^{-1 / 2}(-2 y d y)=\frac{\pi}{2} \int\left(r^{2}-u\right) u^{-1 / 2} d u \text {. }
$$

By usual methods:

$$
I=\pi\left(r^{2} u^{1 / 2}-1 / 3 u^{3 / 2}\right)+C,
$$

and converting back to y's

$$
I=\pi\left[r^{2}\left(r^{2}-y^{2}\right)^{1 / 2}-1 / 3\left(r^{2}-y^{2}\right)^{3 / 2}\right]+C .
$$

Then from (4),

$$
\begin{aligned}
V & =\left.\pi\left[\mathrm{r}^{2}\left(\mathrm{r}^{2}-\mathrm{y}^{2}\right)^{1 / 2}-1 / 3\left(\mathrm{r}^{2}-\mathrm{y}^{2}\right)^{3 / 2}\right]\right|_{\mathrm{y}_{1}} ^{0} \\
& =\pi\left\{2 / 3 \mathrm{r}^{3}-\left[\mathrm{r}^{2}\left(\mathrm{r}^{2}-\mathrm{y}_{\mathrm{l}}^{2}\right)^{1 / 2}-1 / 3\left(\mathrm{r}^{2}-\mathrm{y}_{1}^{2}\right)^{3 / 2}\right]\right\}
\end{aligned}
$$

or

(7) $\quad \mathrm{V}=2 / 3 \pi \mathrm{r}^{3}-\pi \mathrm{r}^{2}\left(\mathrm{r}^{2}-\mathrm{y} \frac{2}{1}\right)^{1 / 2}+\frac{\pi}{3}\left(\mathrm{r}^{2}-\mathrm{y}^{2}\right)^{3 / 2}$.

Since the relation between diameter and volume of the imprint is the main concern, let

$$
\begin{aligned}
& \mathrm{d}=2 \mathrm{y}, \\
& \mathrm{y}=\frac{\mathrm{d}}{2}
\end{aligned}
$$

then

(8) $\quad V=2 / 3 \pi r^{3}-\pi r^{2}\left(r^{2}-\frac{d^{2}}{4}\right)^{1 / 2}+\frac{\pi}{3}\left(r^{2}-\frac{d^{2}}{4}\right)^{3 / 2}$.

For the particular shot used, $r=0.188$ feet, and (8) becomes 
48

(9) $\quad \mathrm{V}=0.0138-0.1107\left(.0352-\frac{\mathrm{d}^{2}}{4}\right)^{1 / 2}+$ $+1.047\left(.0352-\frac{d^{2}}{4}\right)^{3 / 2}$

In the soil strength test, the strength, $\mathrm{S}$ is
(10)

$$
S=\frac{60}{V}
$$

Equation (9) can be used to construct a graph of $\mathrm{S}$ in terms of d. (See Figure 6). 
Appendix IV

MAPS AND DRAINAGE NETS OF STUDY AREAS 


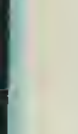




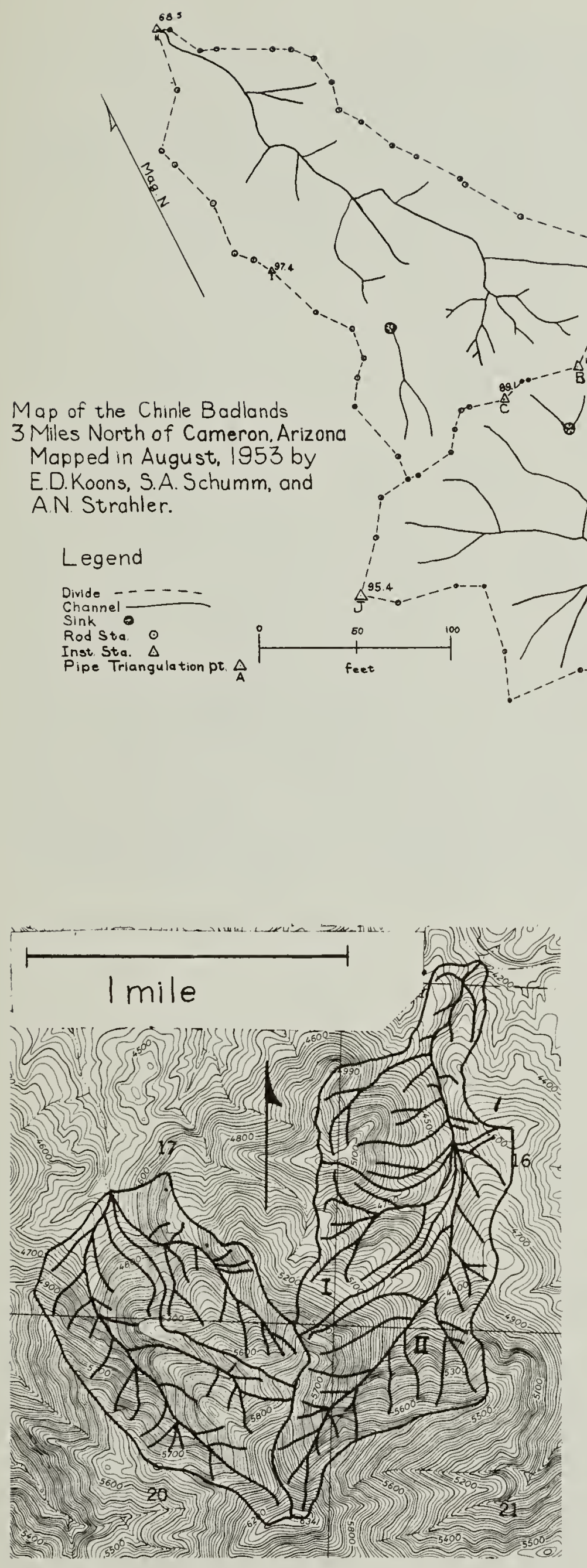

Mt. Hughes Quadrangle, Arizona

Tributaries to Harshaw Creek

$\mathrm{S} 1 / 217, \mathrm{~T} 22 \mathrm{~S}, \mathrm{R} 16 \mathrm{E}$ (Fourth order) NE $1 / 420, T 22 \mathrm{~S}, \mathrm{R} 16 \mathrm{E}$ (Third order) W $1 / 216$, T $22 \mathrm{~S}, \mathrm{R} 16 \mathrm{E}$ (Fourth order)

Near Cameron, Arizona

Chinle Badlands, North (Fourth order)

Chinle Badlands, South (Third order)

ap of the Chinle Badland Mapped in August, 1953 by E.D.Koons, S.A. Schumm, and

Legend

Rod Sta.

Rinst Sta. $\triangle$ (n......

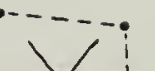




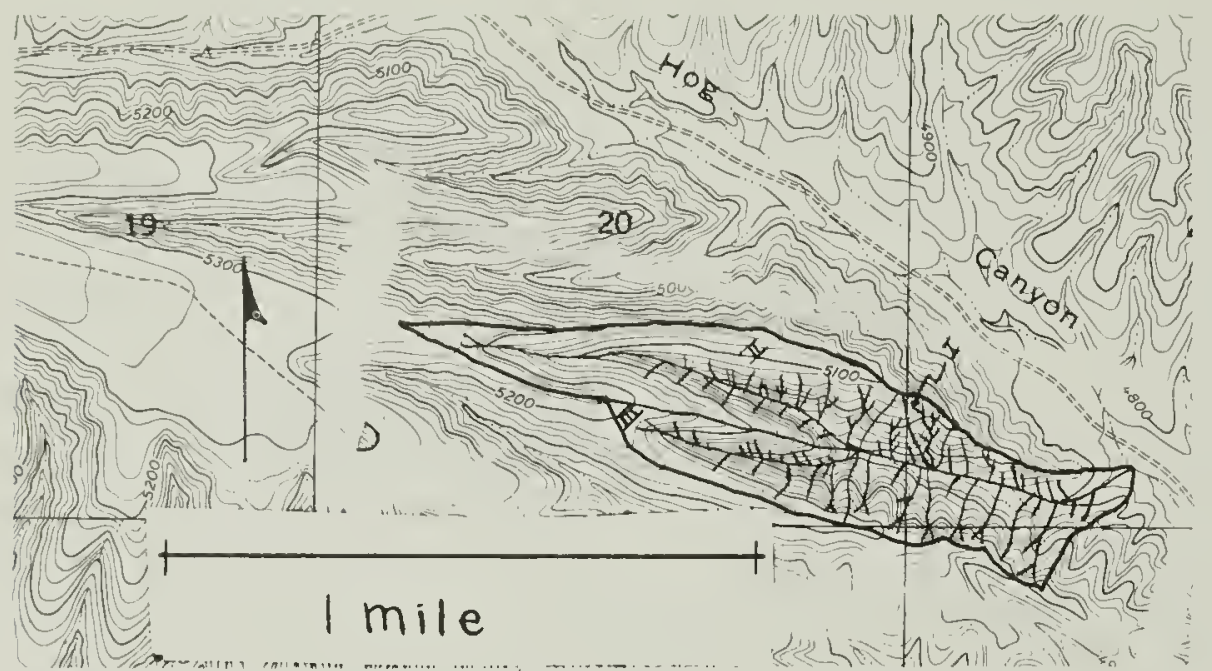

Sonoita Quadrangle, Arizona

Hog Canyon (Fourth order)

Prescott Quadrangle, Arizona

Whipple Basin (Fourth order)
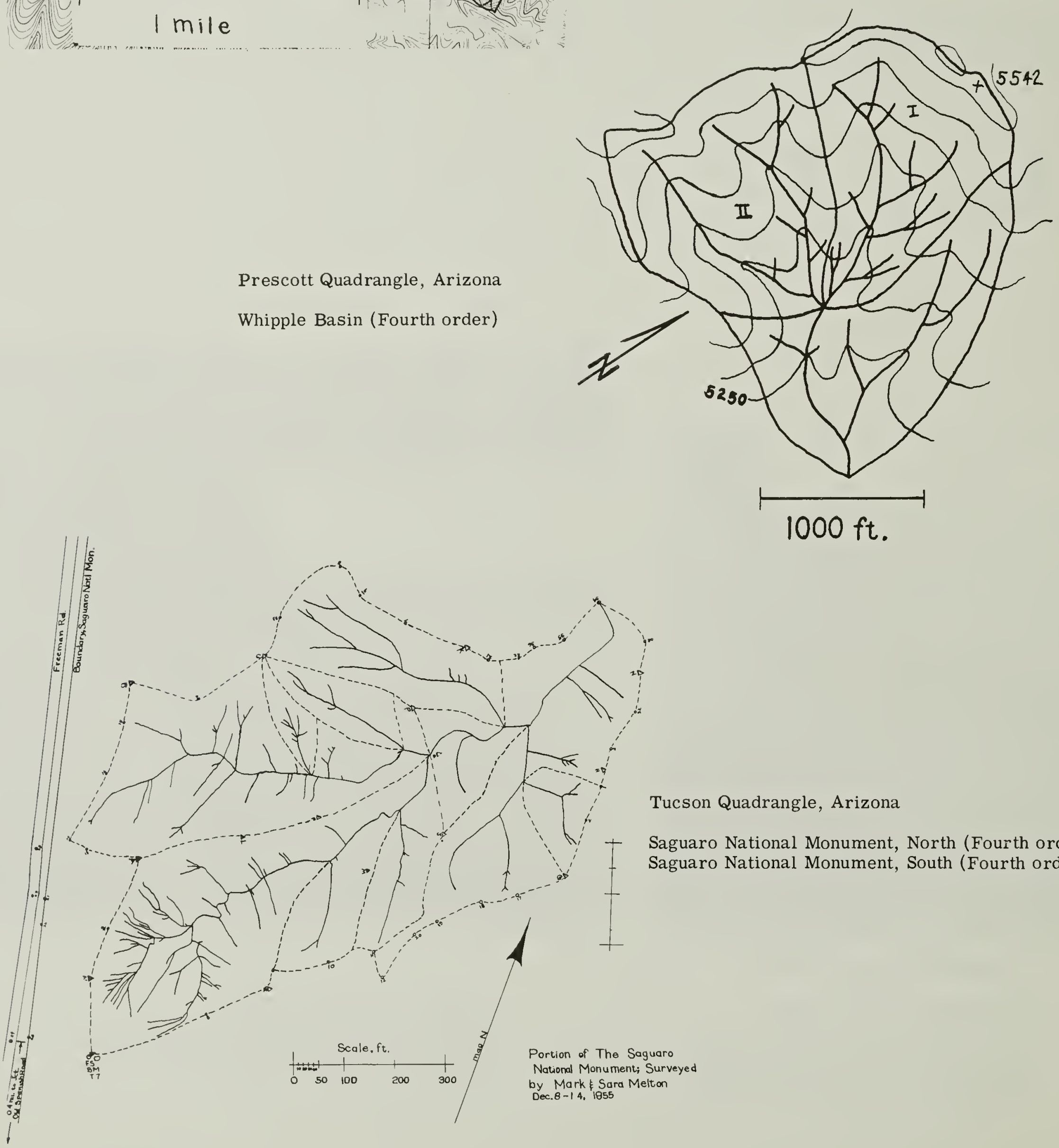

Tucson Quadrangle, Arizona

Saguaro National Monument, North (Fourth order) aguaro National Monument, South (Fourth order) 


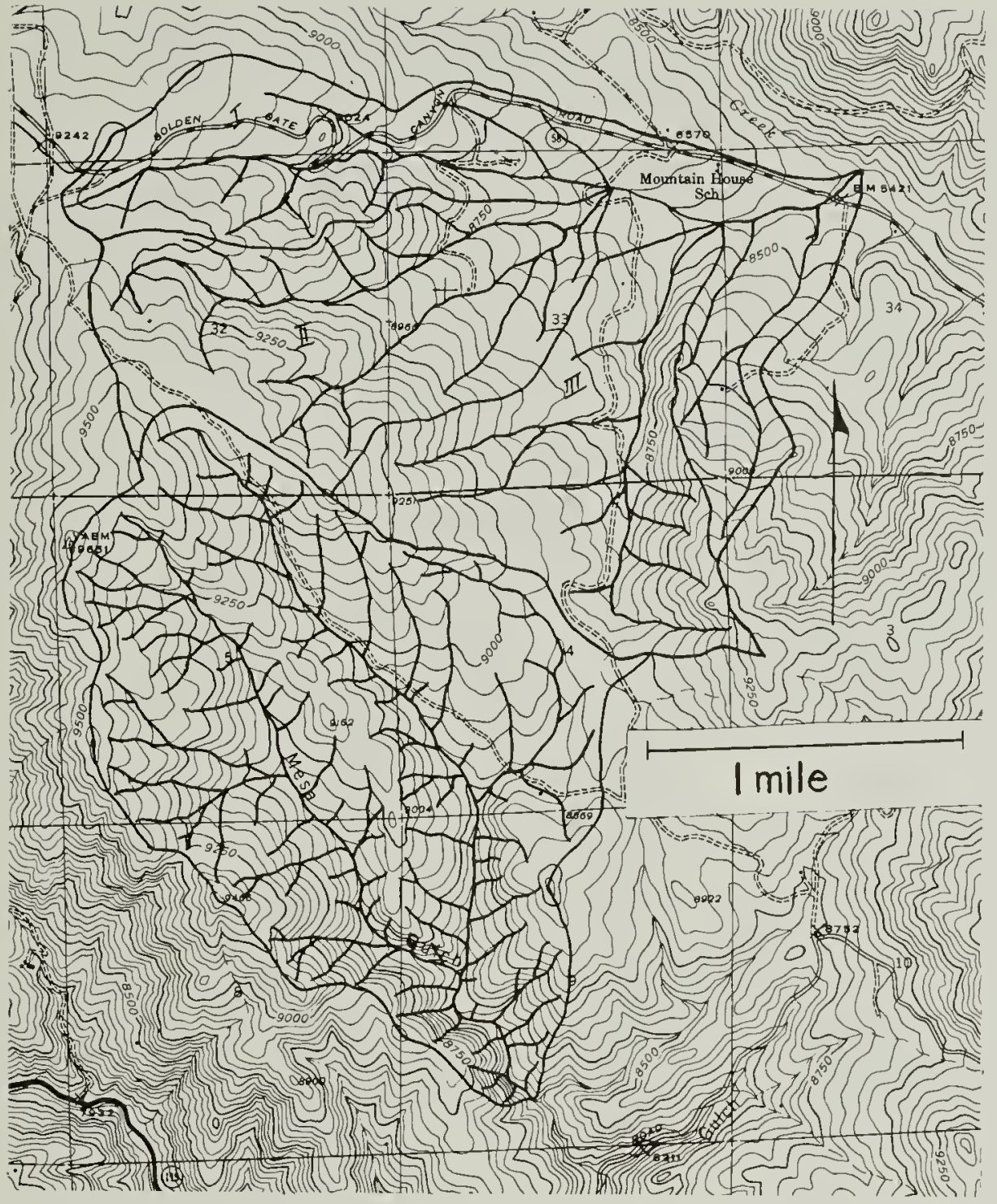

Black Hawk Quadrangle, Colorado

Dory Hill Basin and Mesa Gulch (Fourth order)

Morrison Quadrangle, Colorado

Cabrini Gulch (Third order)

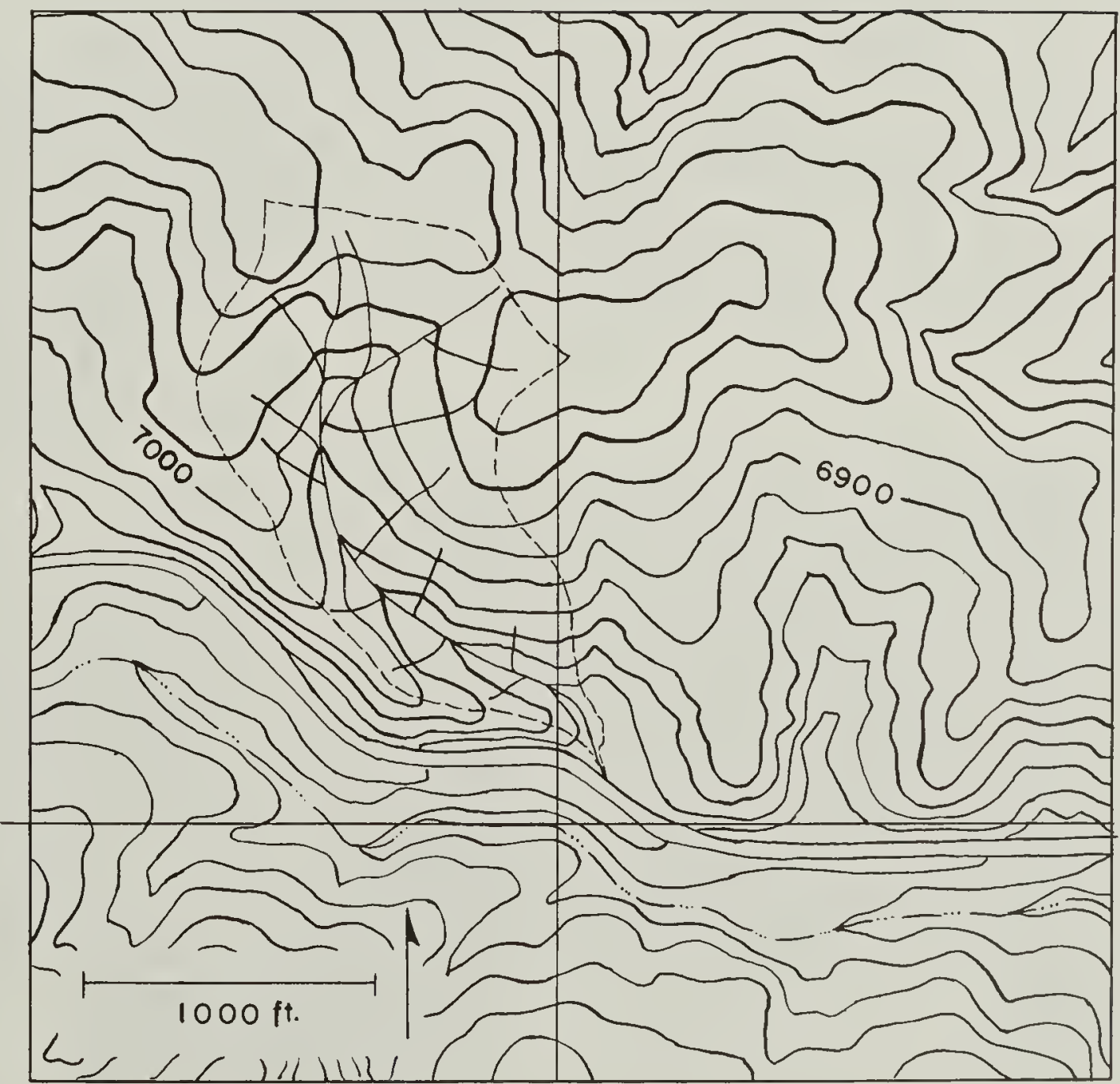


Morrison Quadrangle, Colorado Green Mountain Basin (Third order)
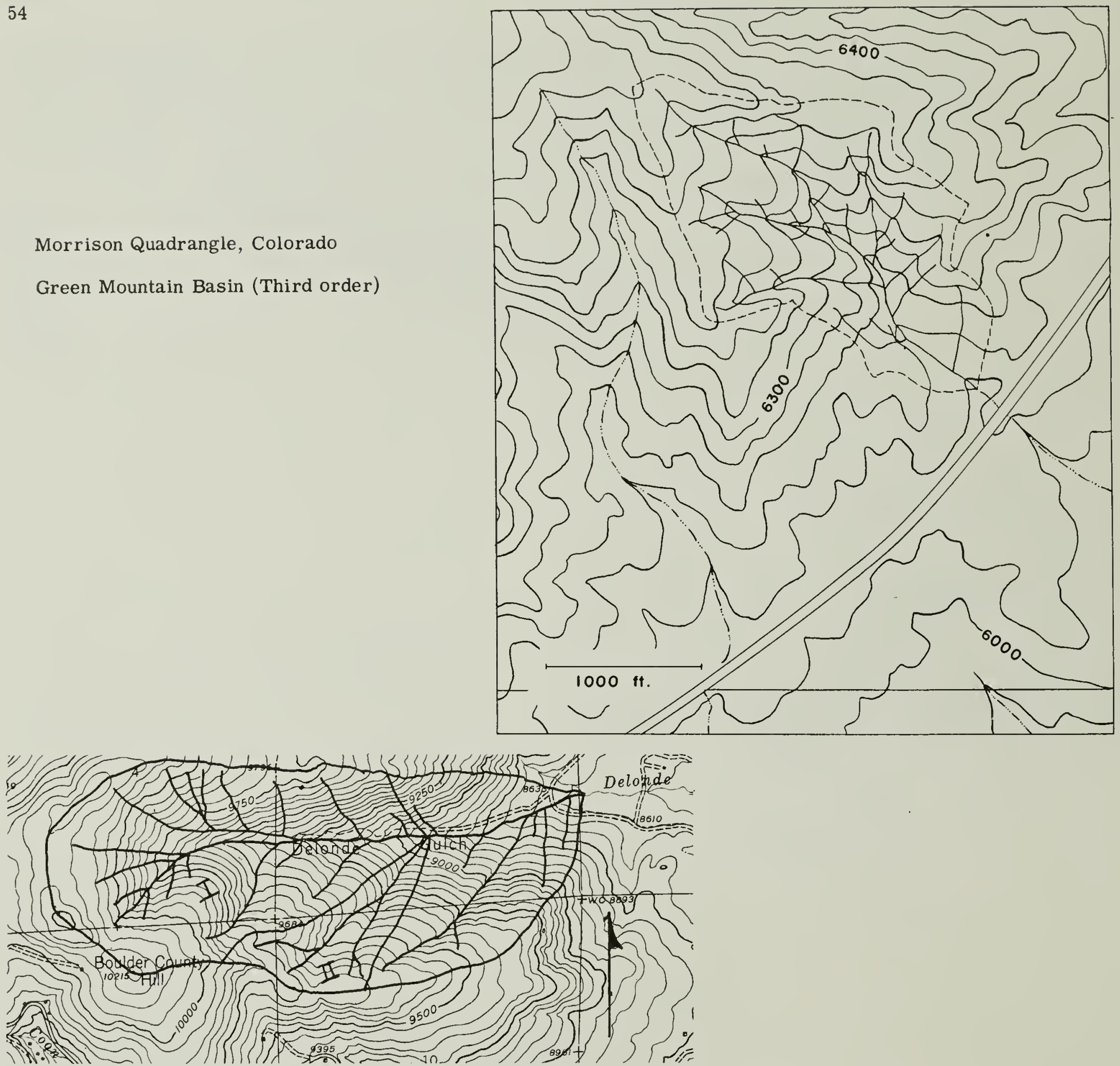

Nederland Quadrangle, Colorado

Above: Delonde Gulch (Fourth order) Right: Hicks Gulch (Fourth order)

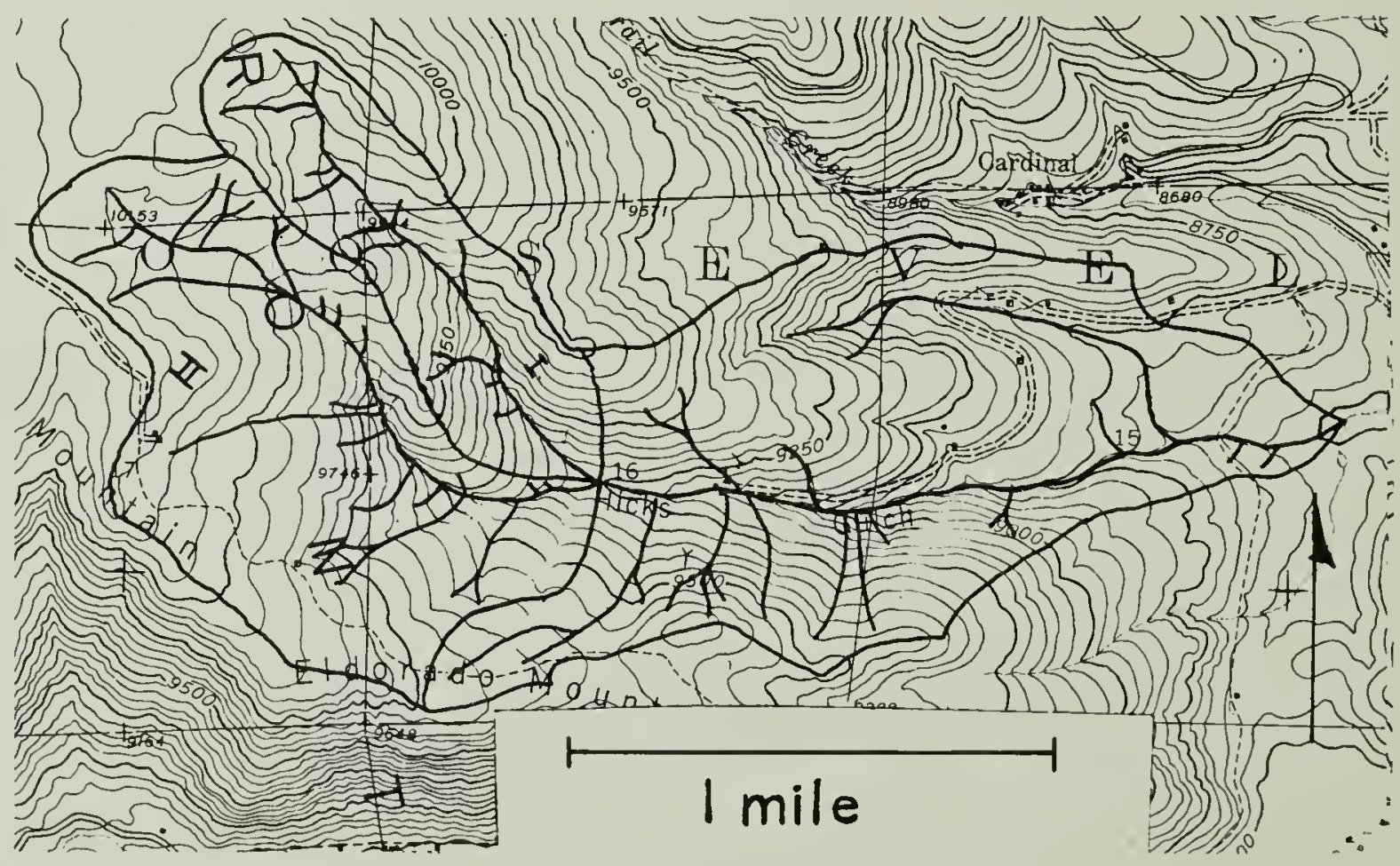




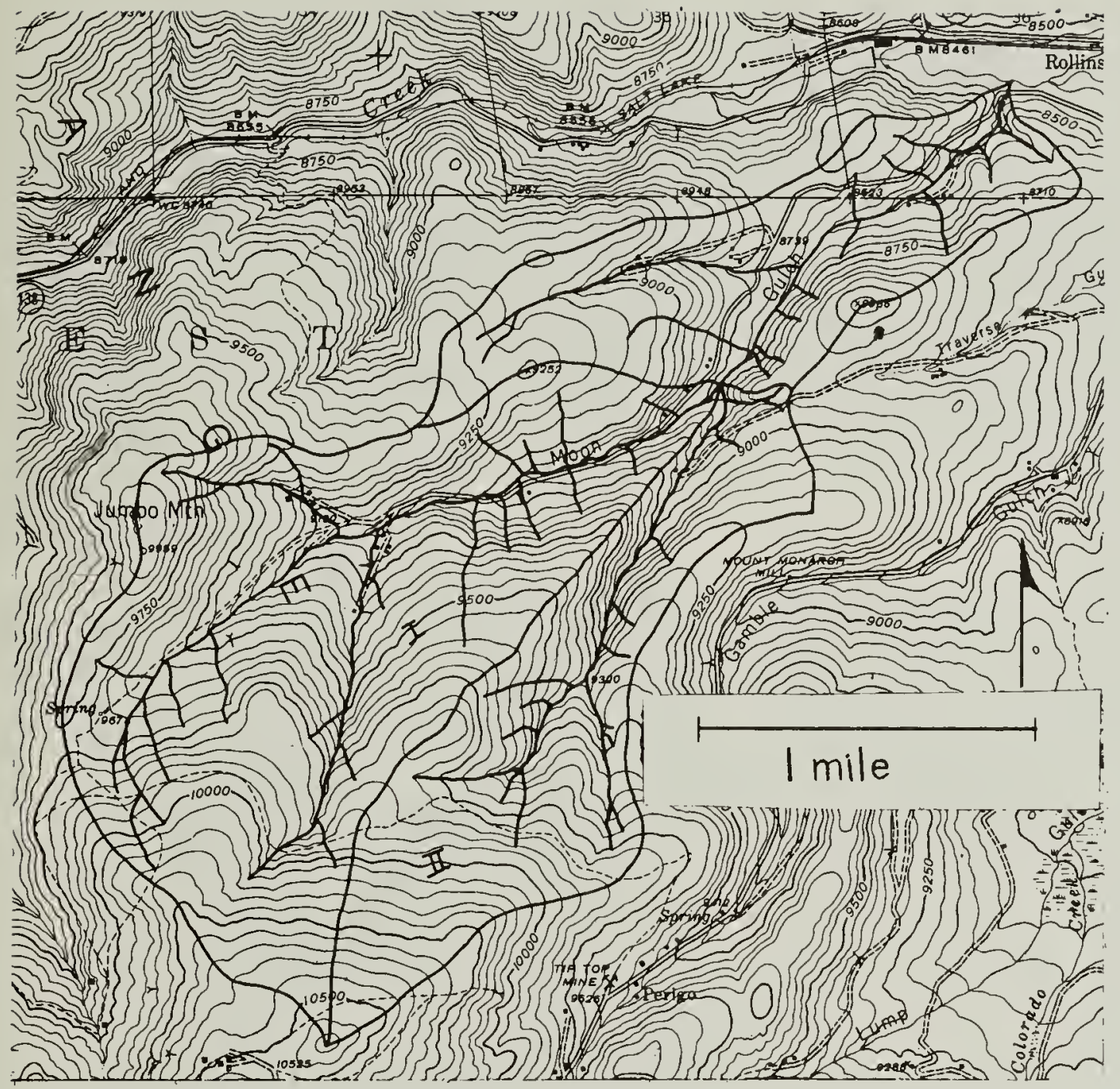

Netherland Quadrangle, Colorado

Moon Gulch (Forth order)

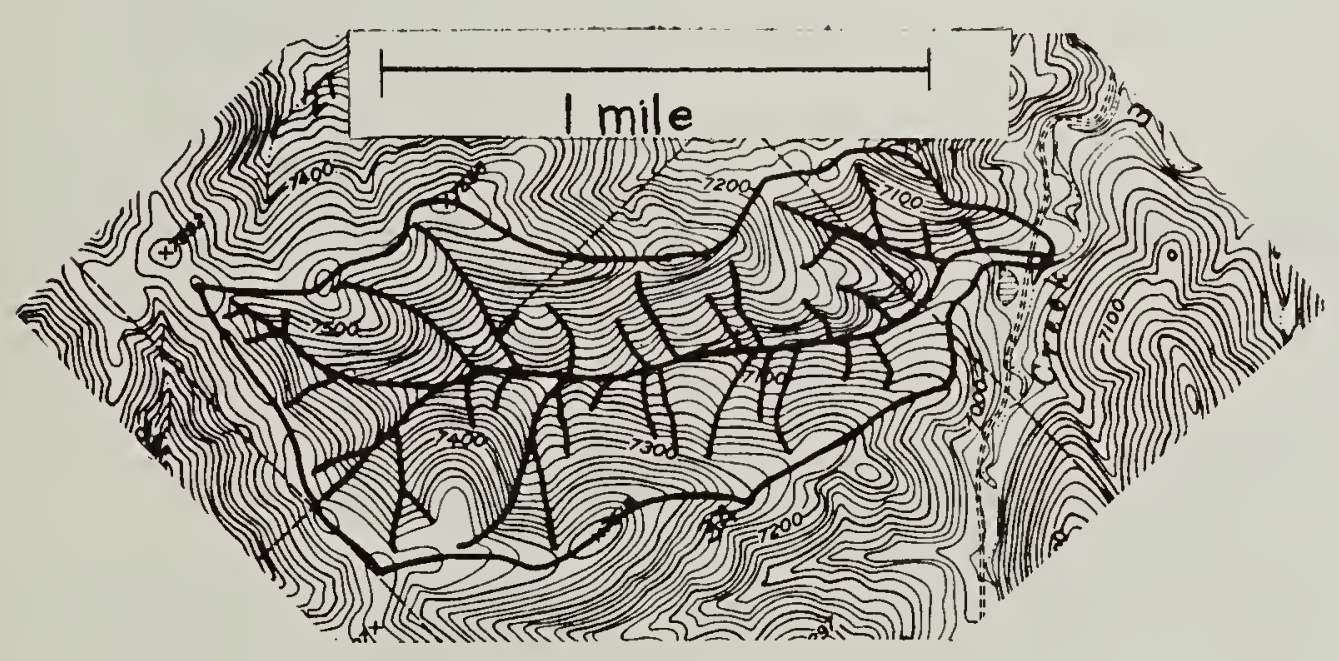

Starkville Quadrangle, Colorado

Above: Tributary to Gallinas Creek (Third order)

Right: Tributary to Saruche Canyon (Fourth order)
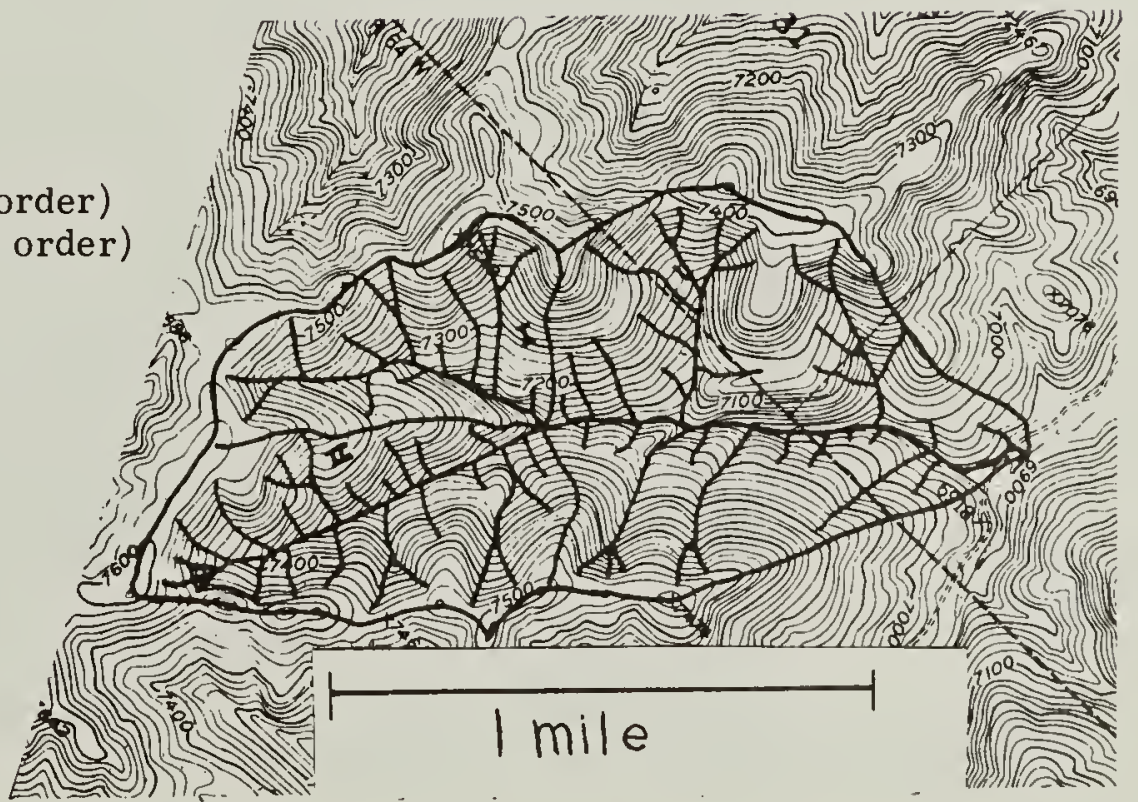


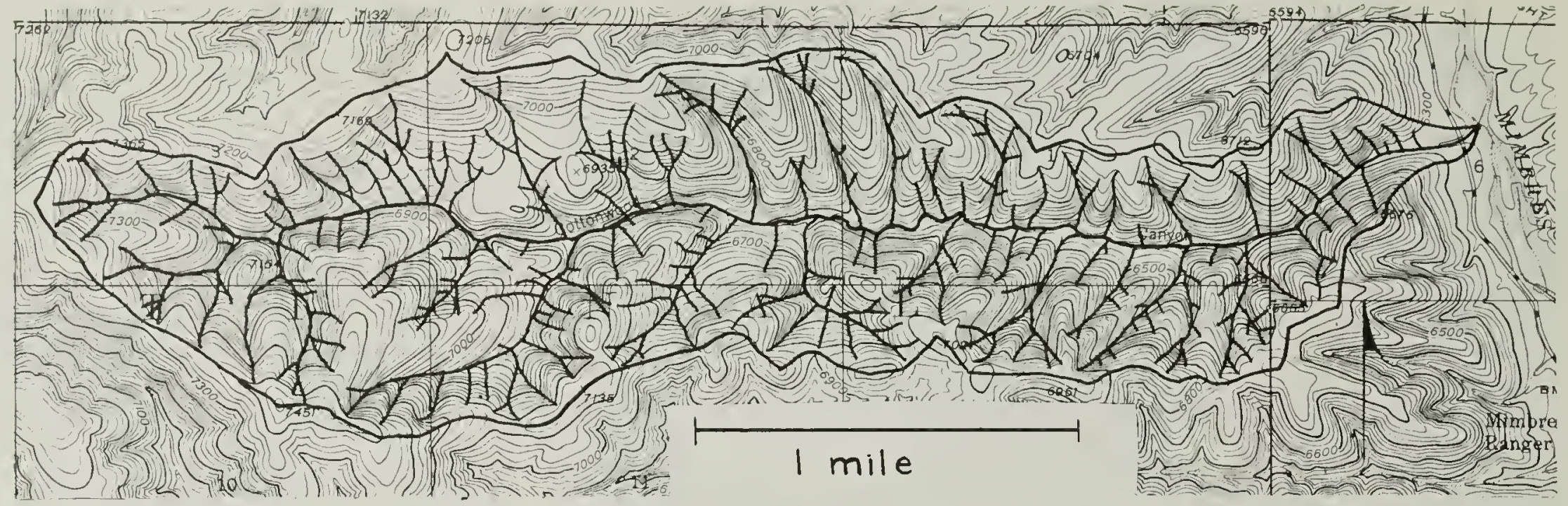

Allie Canyon Quadrangle, N.M.

Above:

Cottonwood Canyon(Fourth order) Right:

Tributaries to Sapillo Creek E 172 20, T 15 S, R. 12 W

(Fourth order)

W $1 / 221$, T $15 \mathrm{~S}, \mathrm{R} 12 \mathrm{~W}$

(Fourth order)

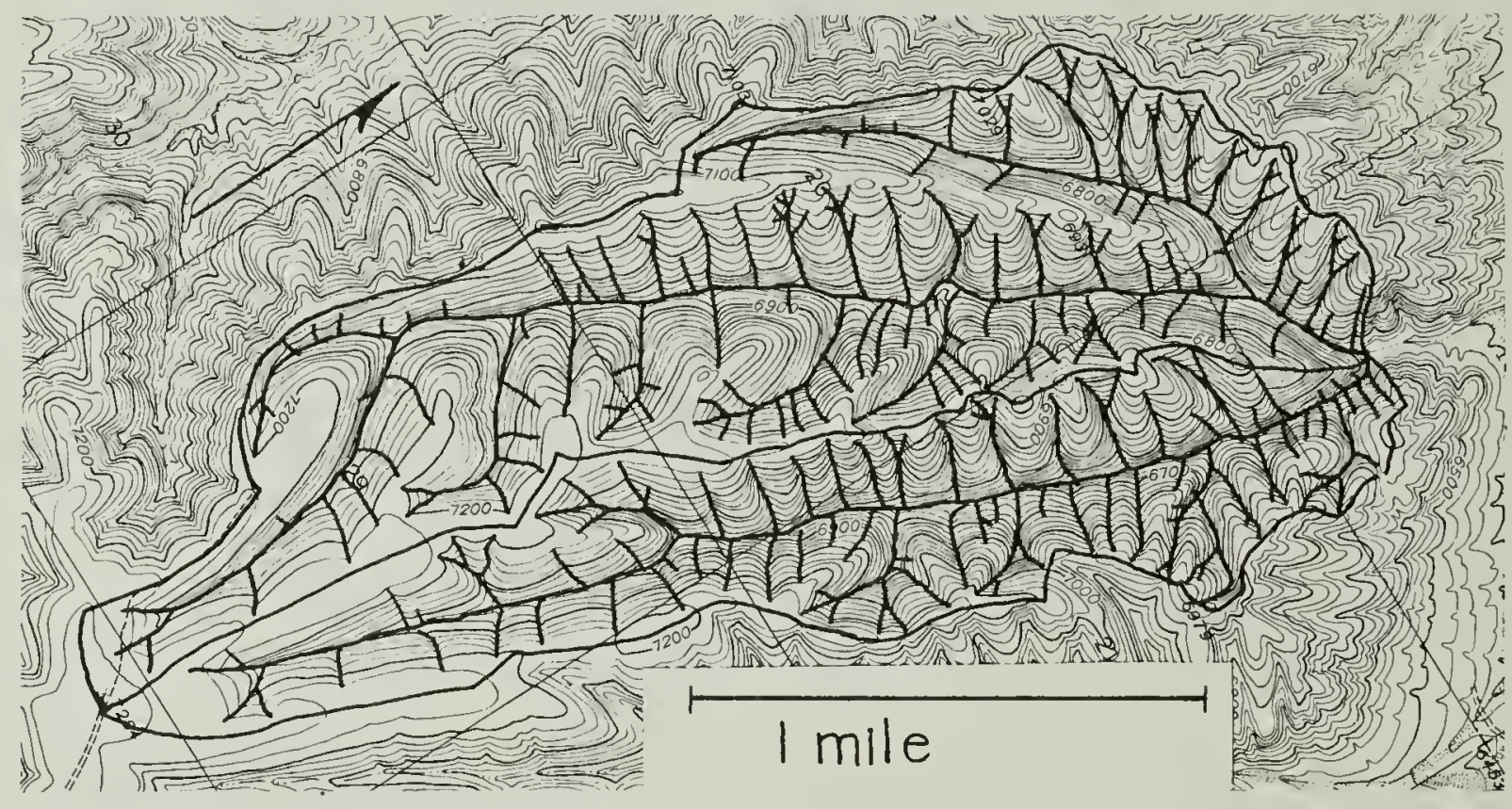

Big Burro Mountains Quadrangle, New Mexico

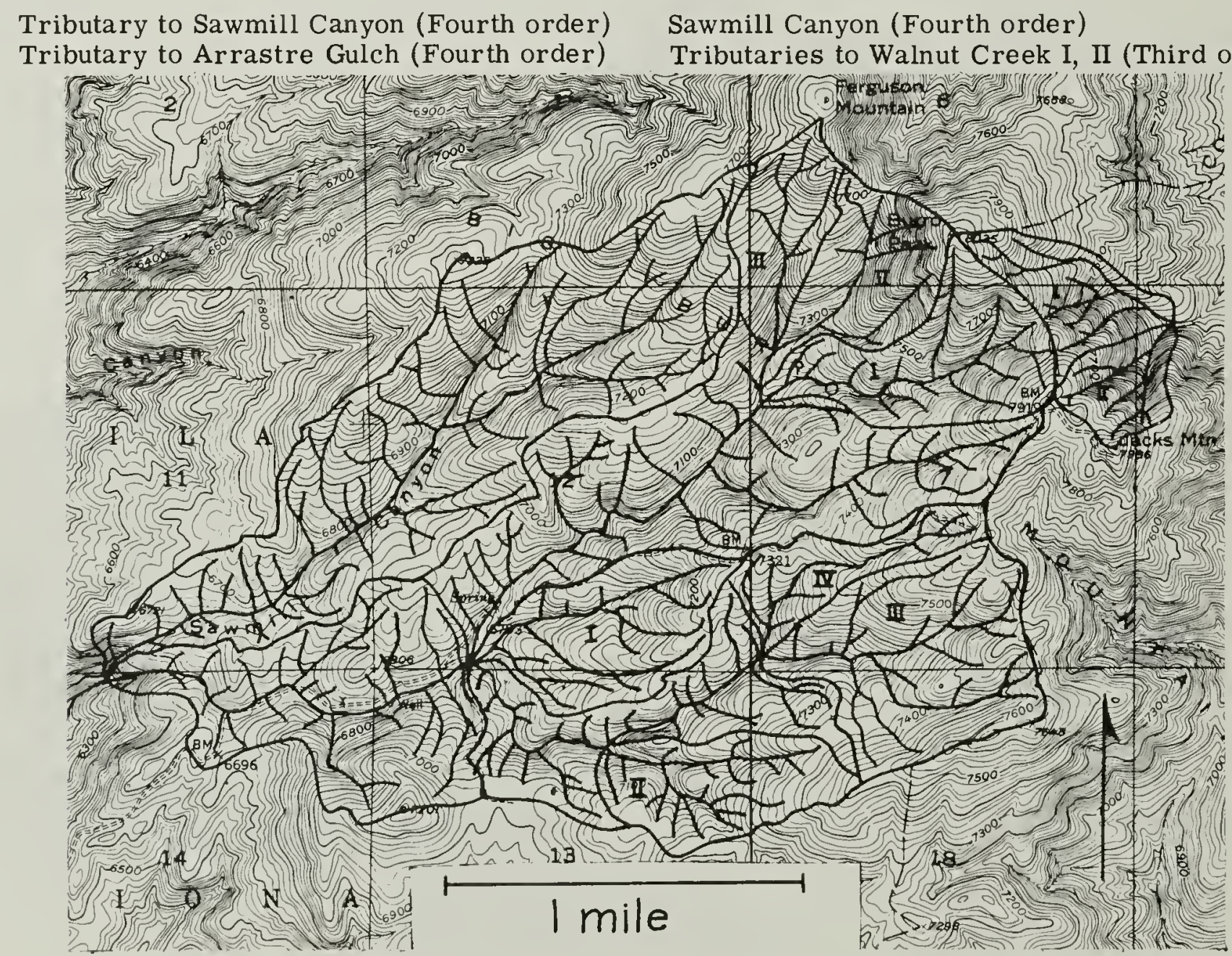




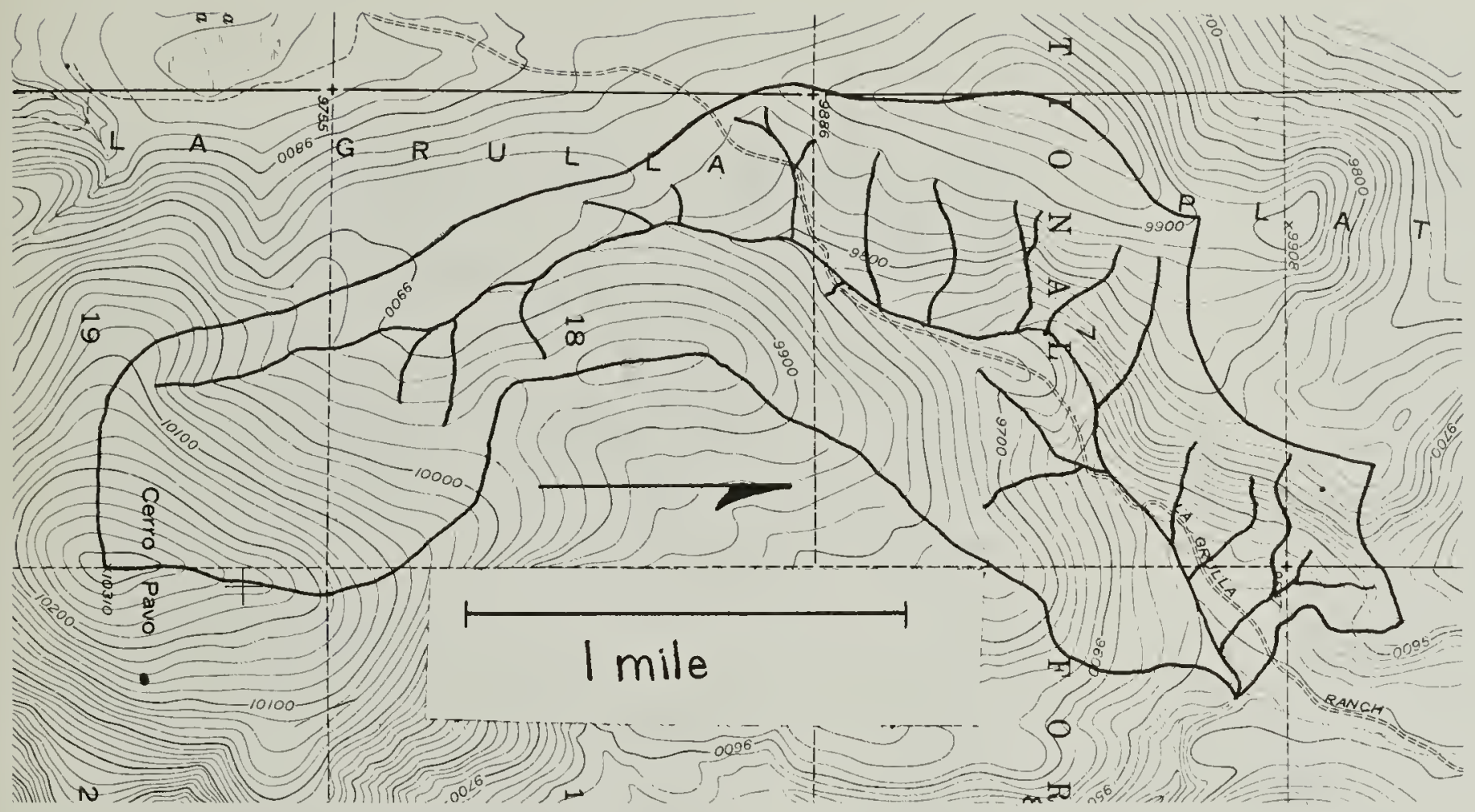

Cerro del Grant Quadrangle, New Mexico

Cerro Pavo Basin (Third order)
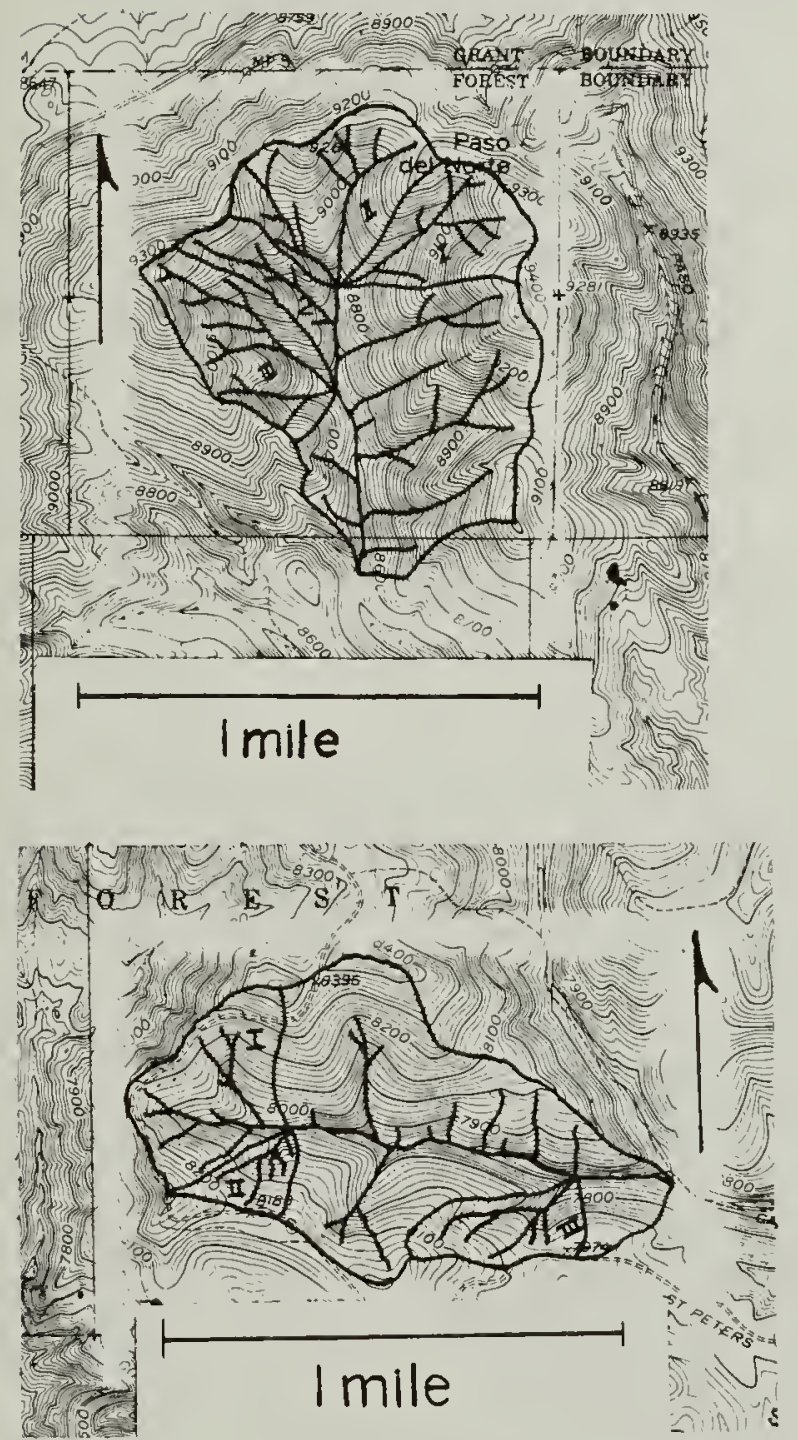

Hurley East Quadrangle, New Mexico

W 1/2 22, T $18 \mathrm{~S}, \mathrm{R} 12 \mathrm{~W}, \mathrm{I}$, II (Third order)

Martin Canyon

$\mathrm{S} 1 / 215, \mathrm{~T} 18 \mathrm{~S}, \mathrm{R} 12 \mathrm{~W}$ (Fourth order)

E $1 / 222, T 18 \mathrm{~N}, \mathrm{R} 12 \mathrm{~W}$ (Third order)

Bland Quadrangle, New Mexico

Above: Paso del Norte Basin (Fourth order) Below: Peters Dome Basin (Fourth order)

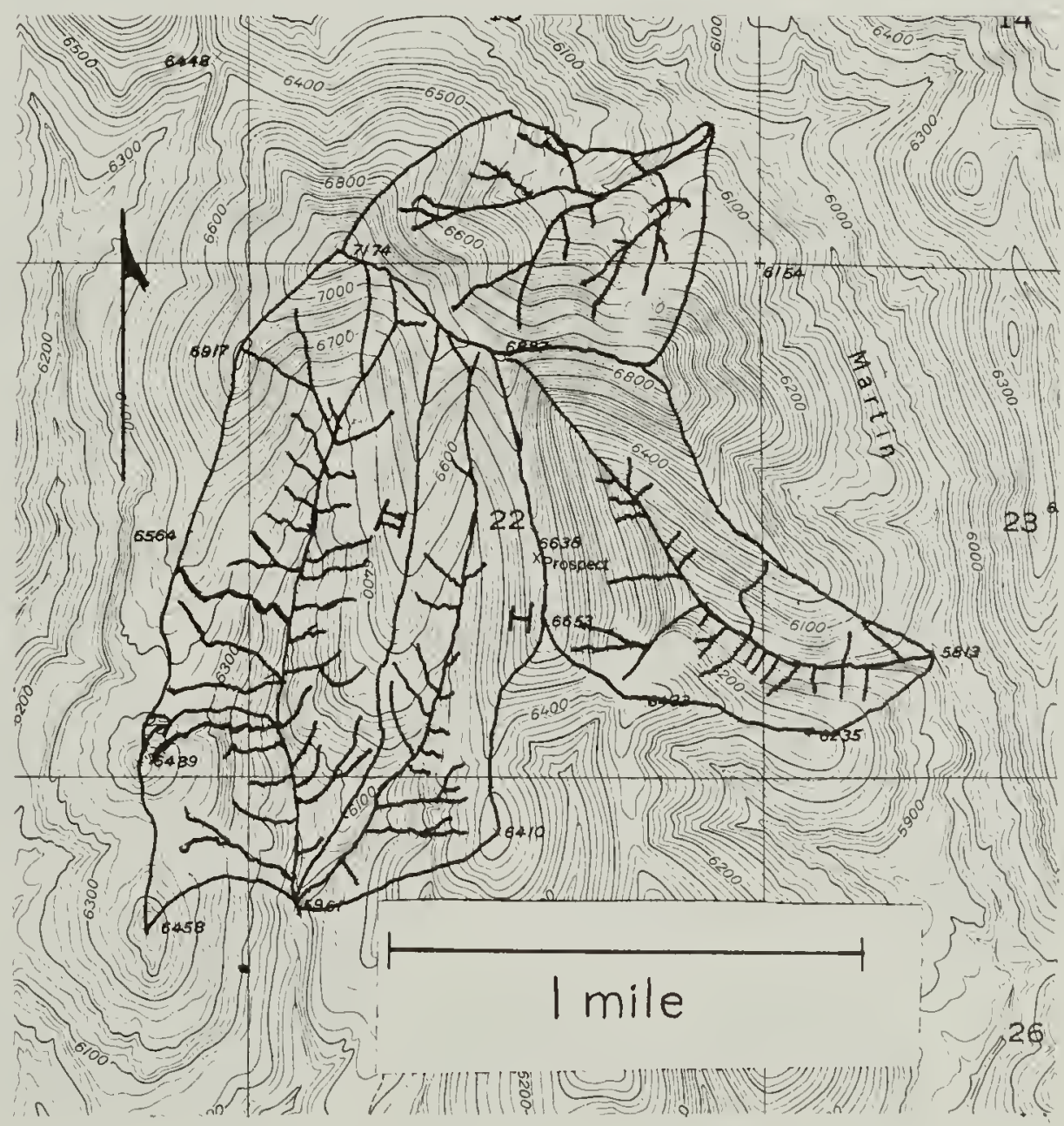




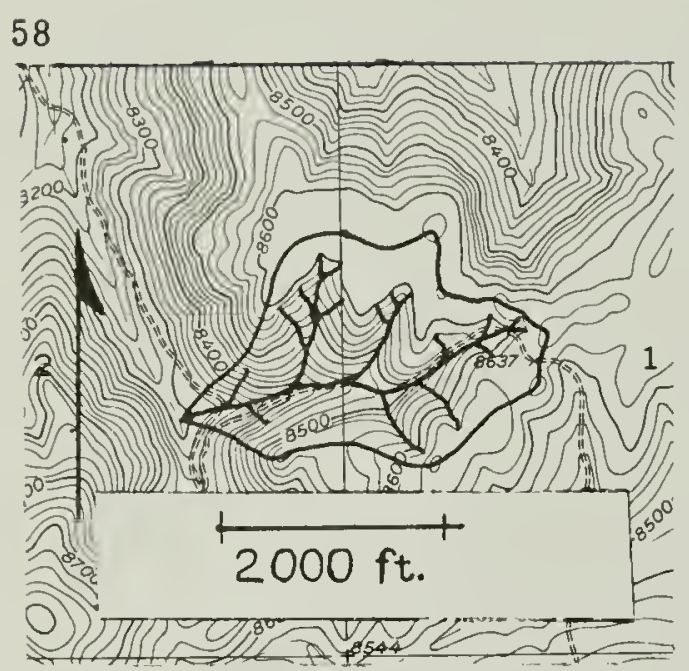

Jarosa Quadrangle, New Mexico

Above: Hairpin Basin (Third order) Below: Poleo Basin (Forth order)
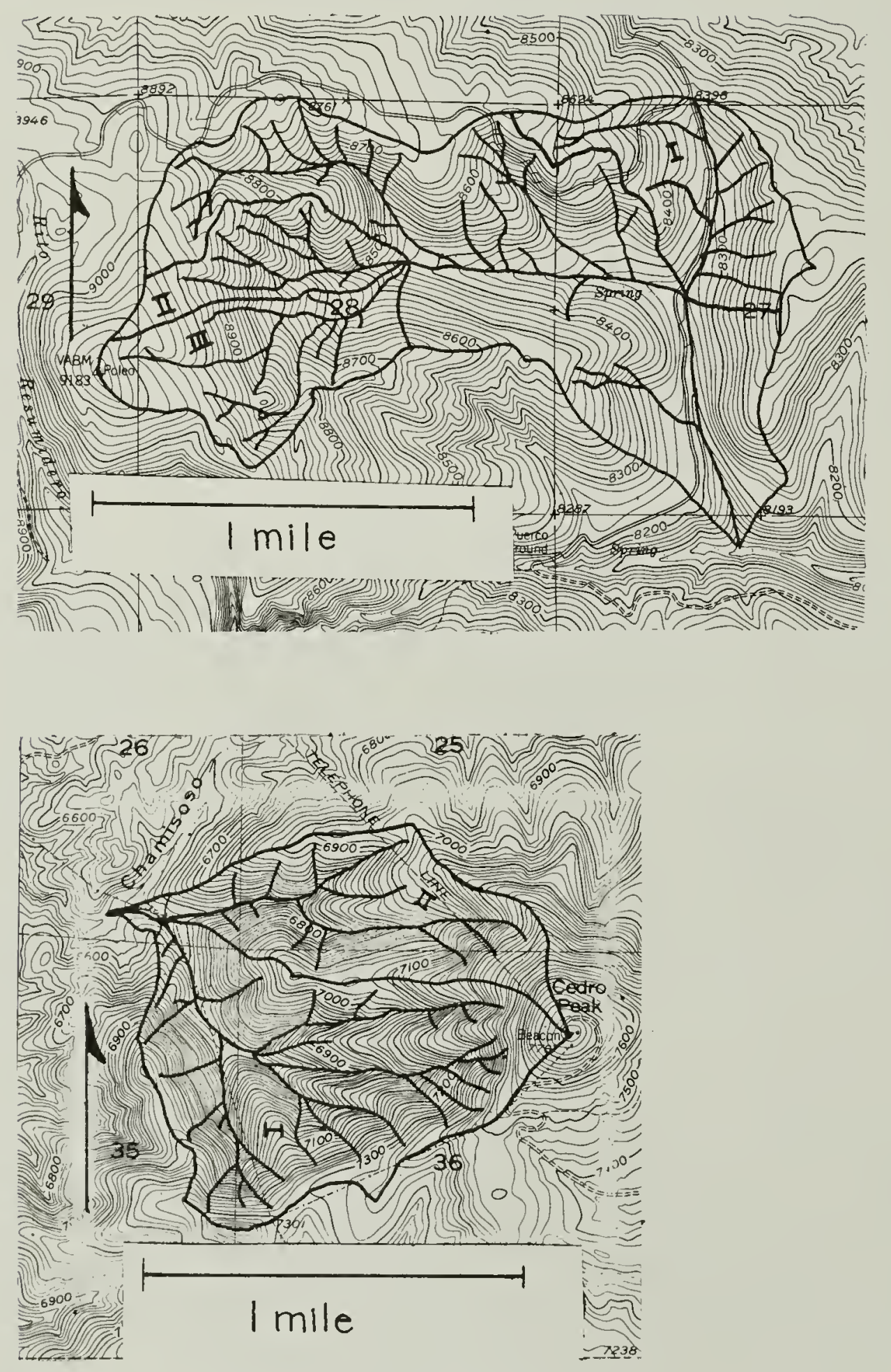

Sedillo Quadrangle, New Mexico

Cedro Peak Basin (Fourth order)

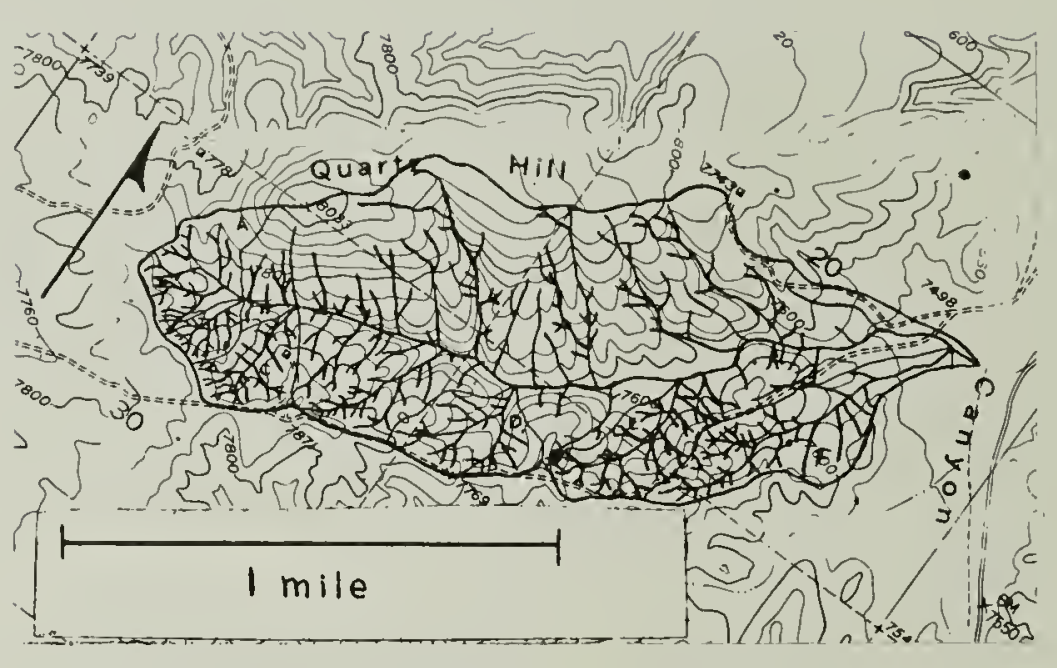

Paxton Springs Quadrangle, New Mexico

Quartz Hill Basin (Fifth order)

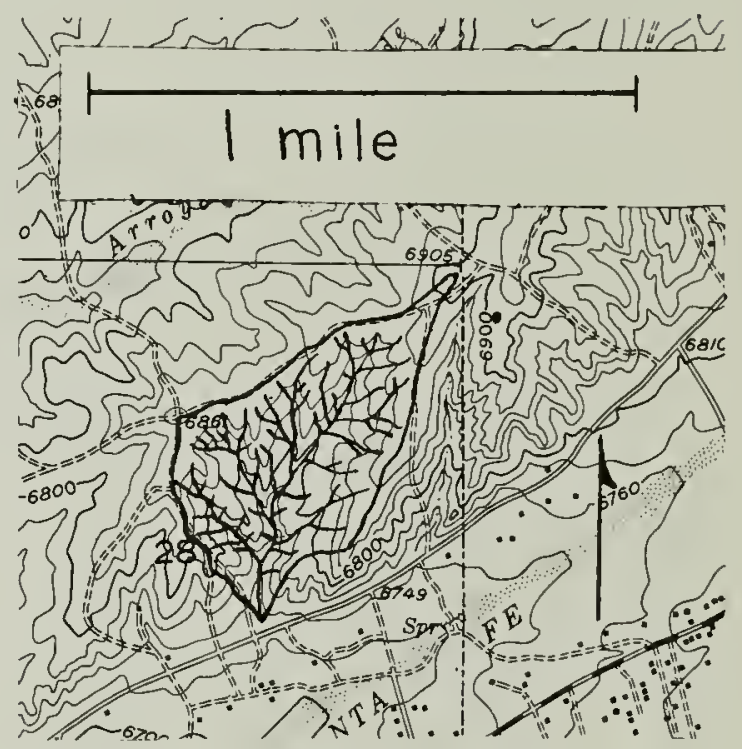

Santa Fe Quadrangle, New Mexico

Above: Camino Basin (Fourth order) Below: Tano Basin (Fourth order)

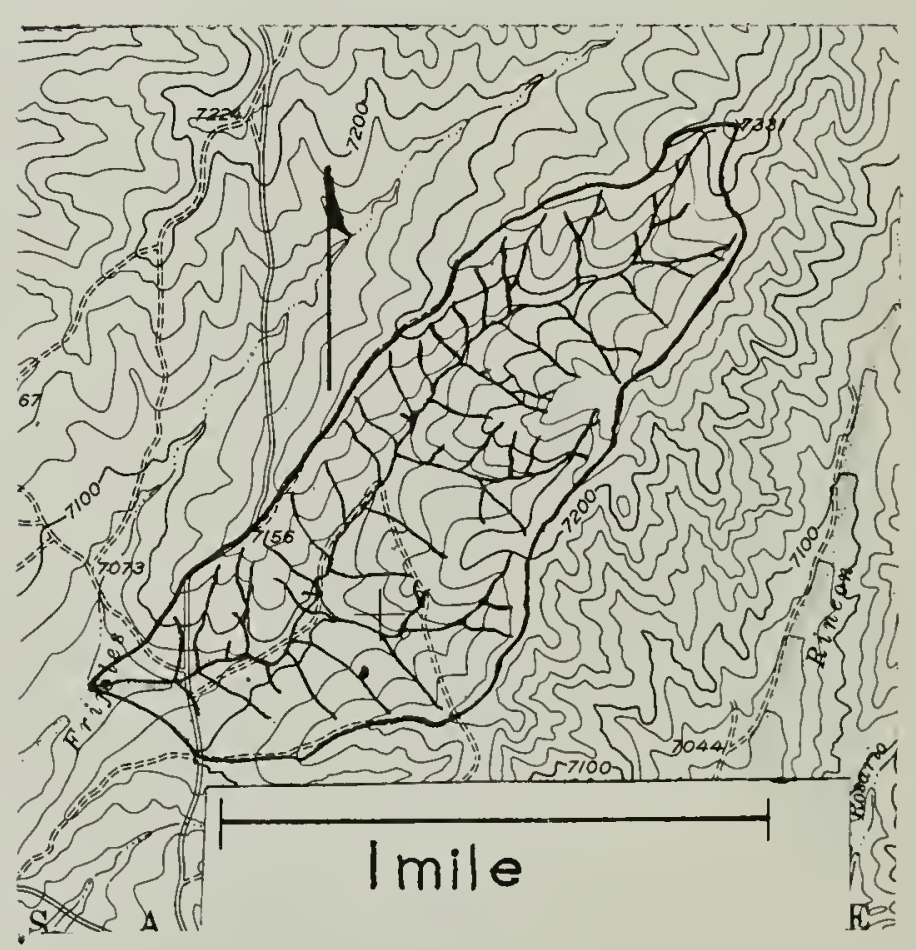




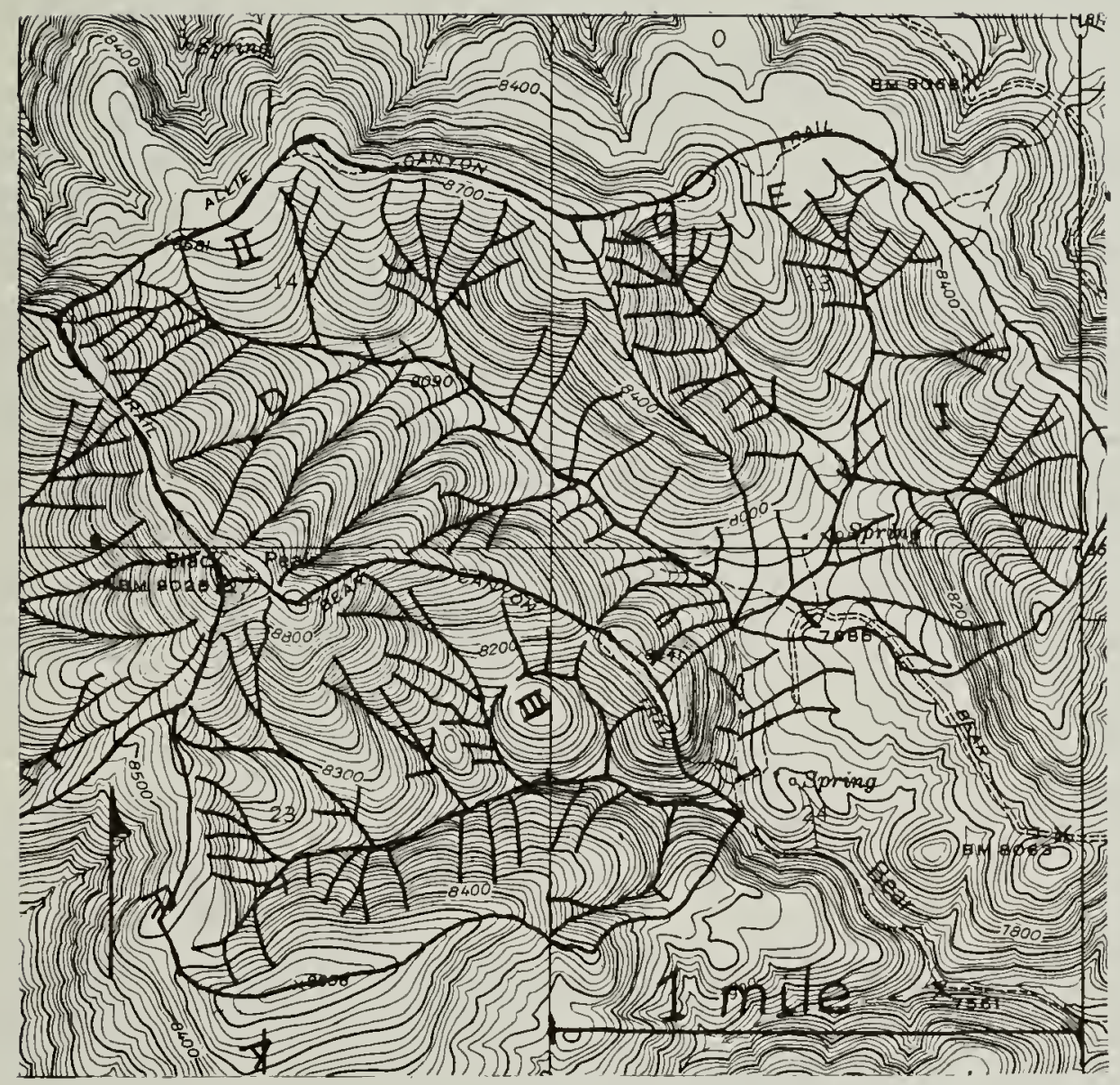

Twin Sisters Quadrangle, New Mexico

Bear Canyon I, II, III, (Fourth order)

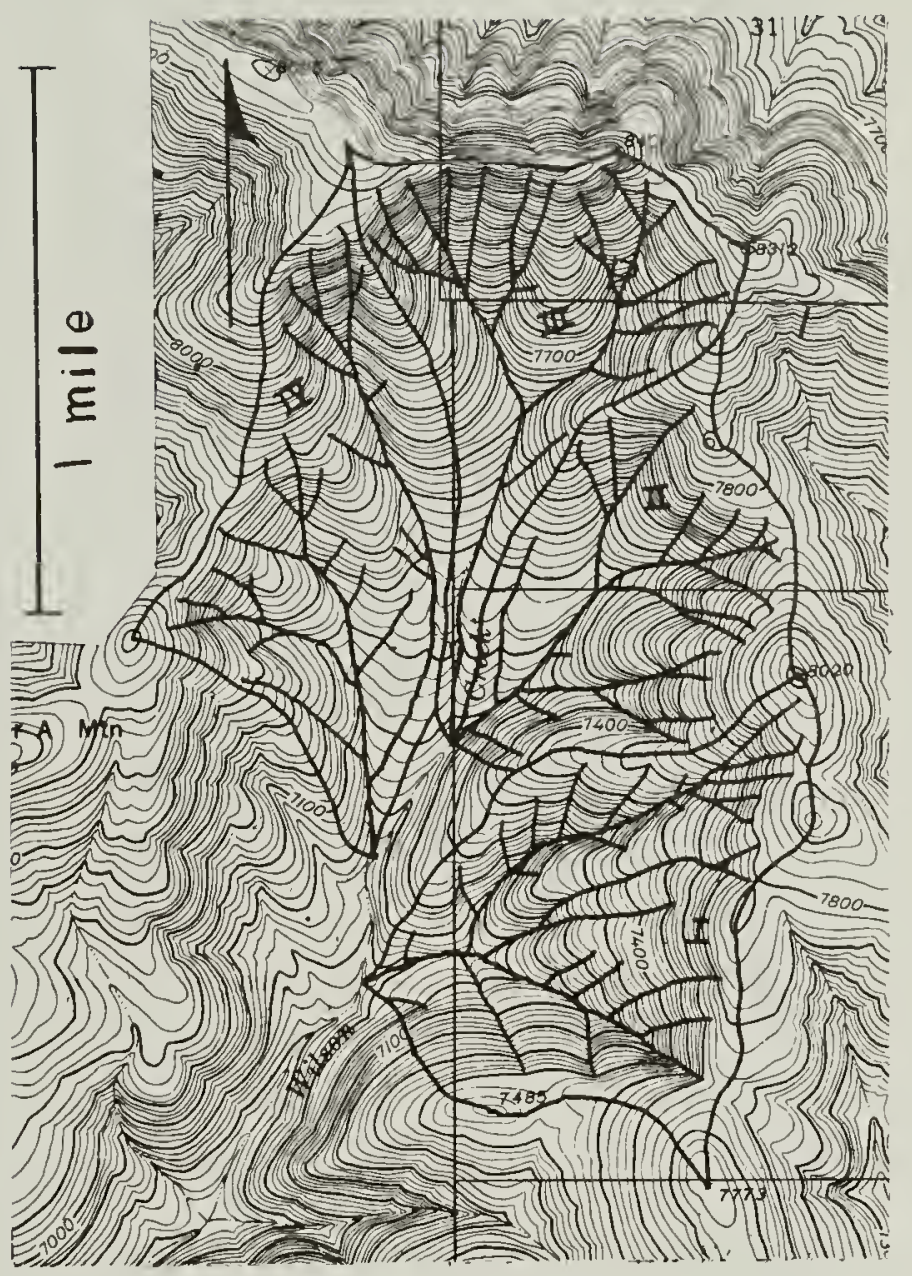

Twin Sisters Quadrangle, New Mexico

Wilson Creek I, II, III, IV (Fourth order)

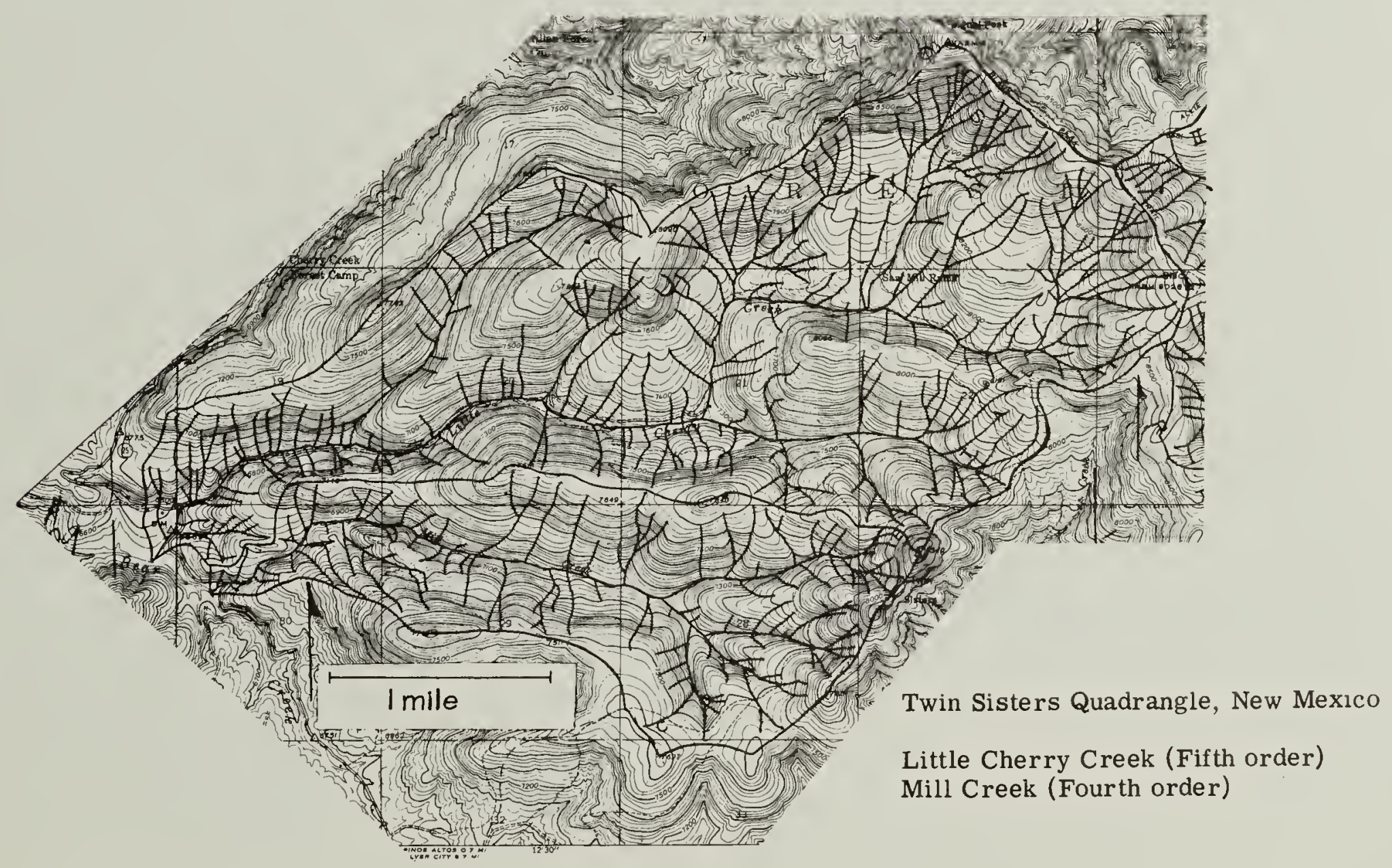




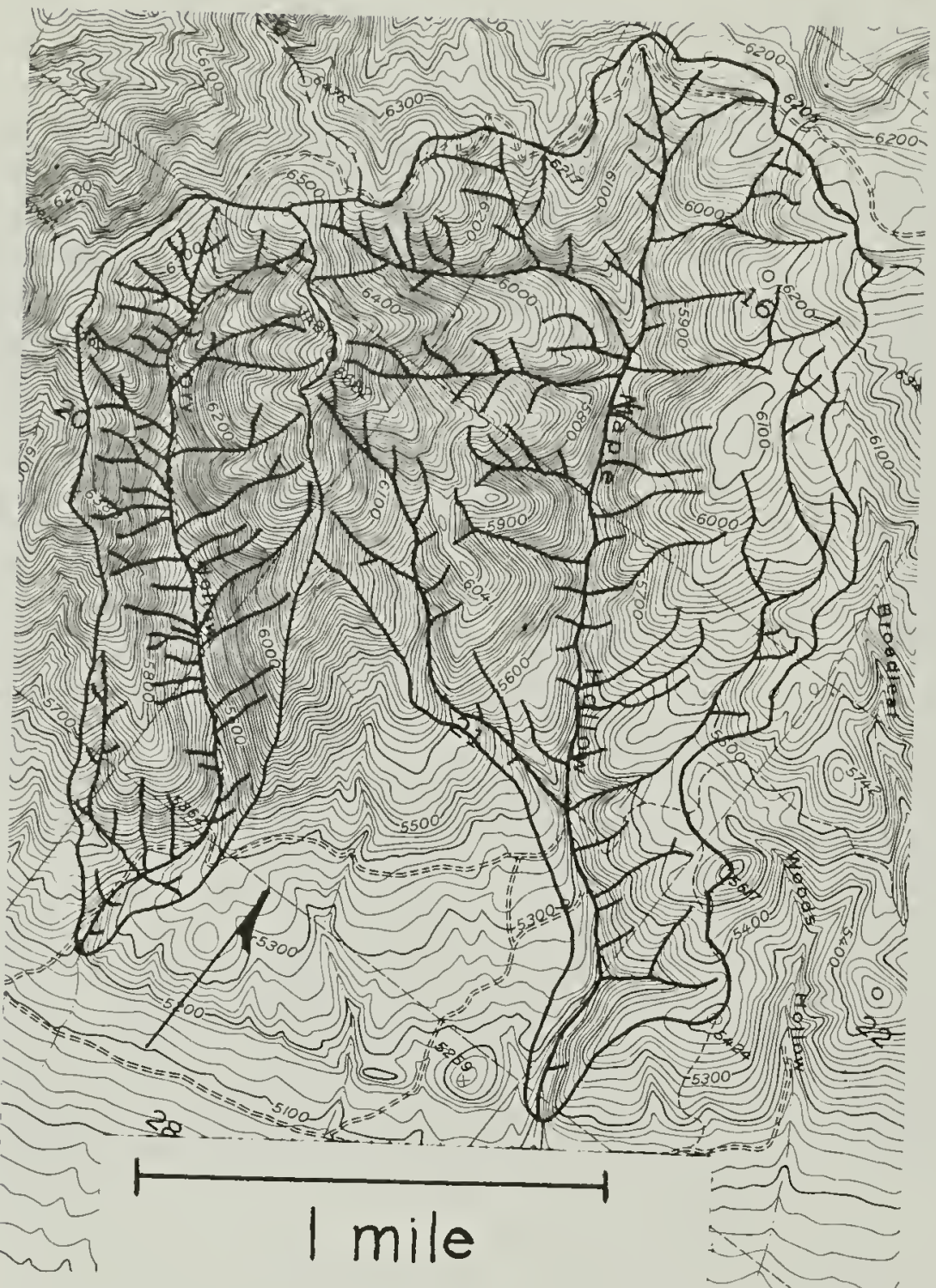

Lehi Quadrangle, Utah

Dry Hollow (Third order)

Maple Hollow (Forth order)

Lehi Quadrangle, Utah

Hog Hollow (Fifth order)

Mercer Hollow (Fourth order)

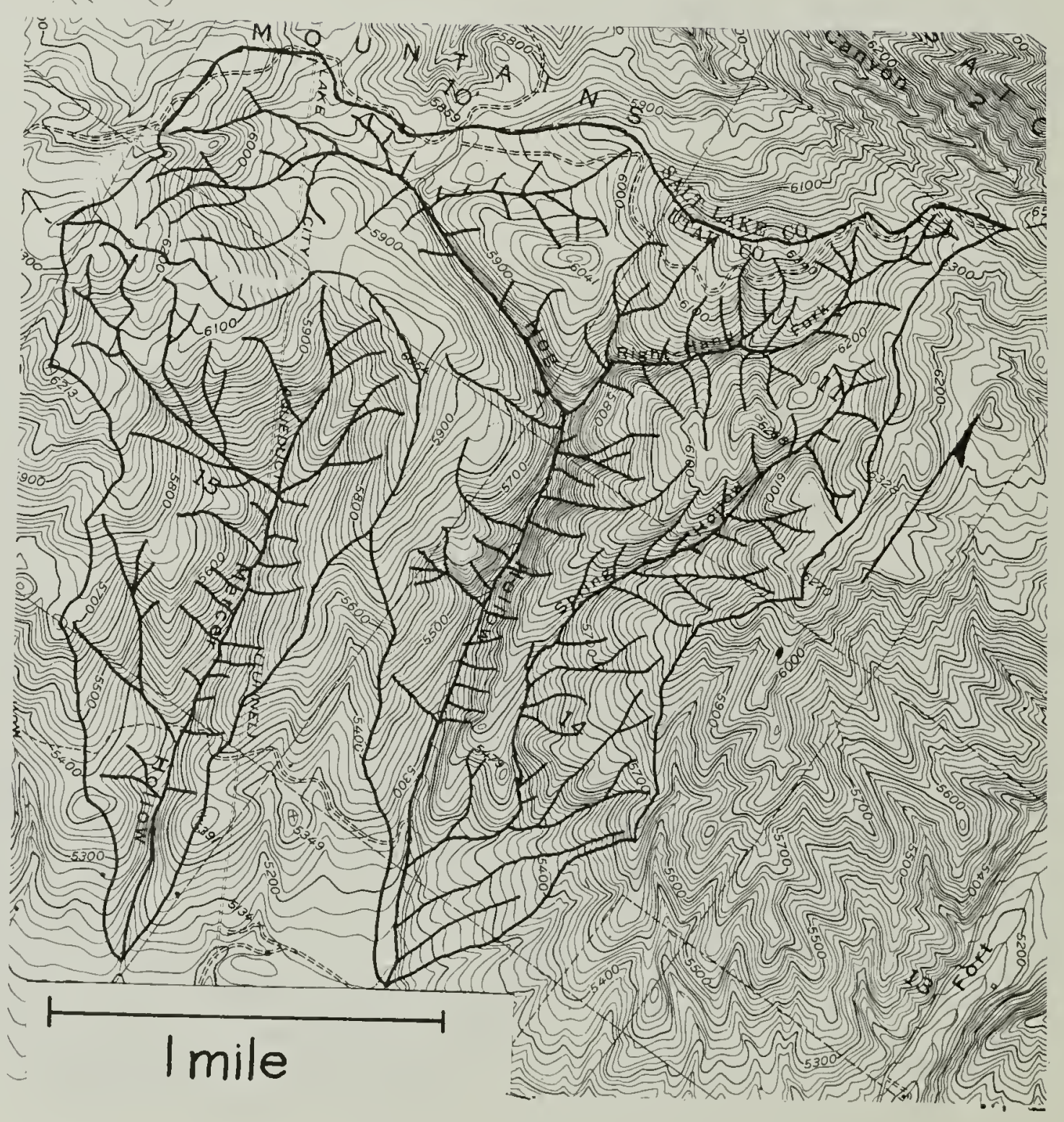




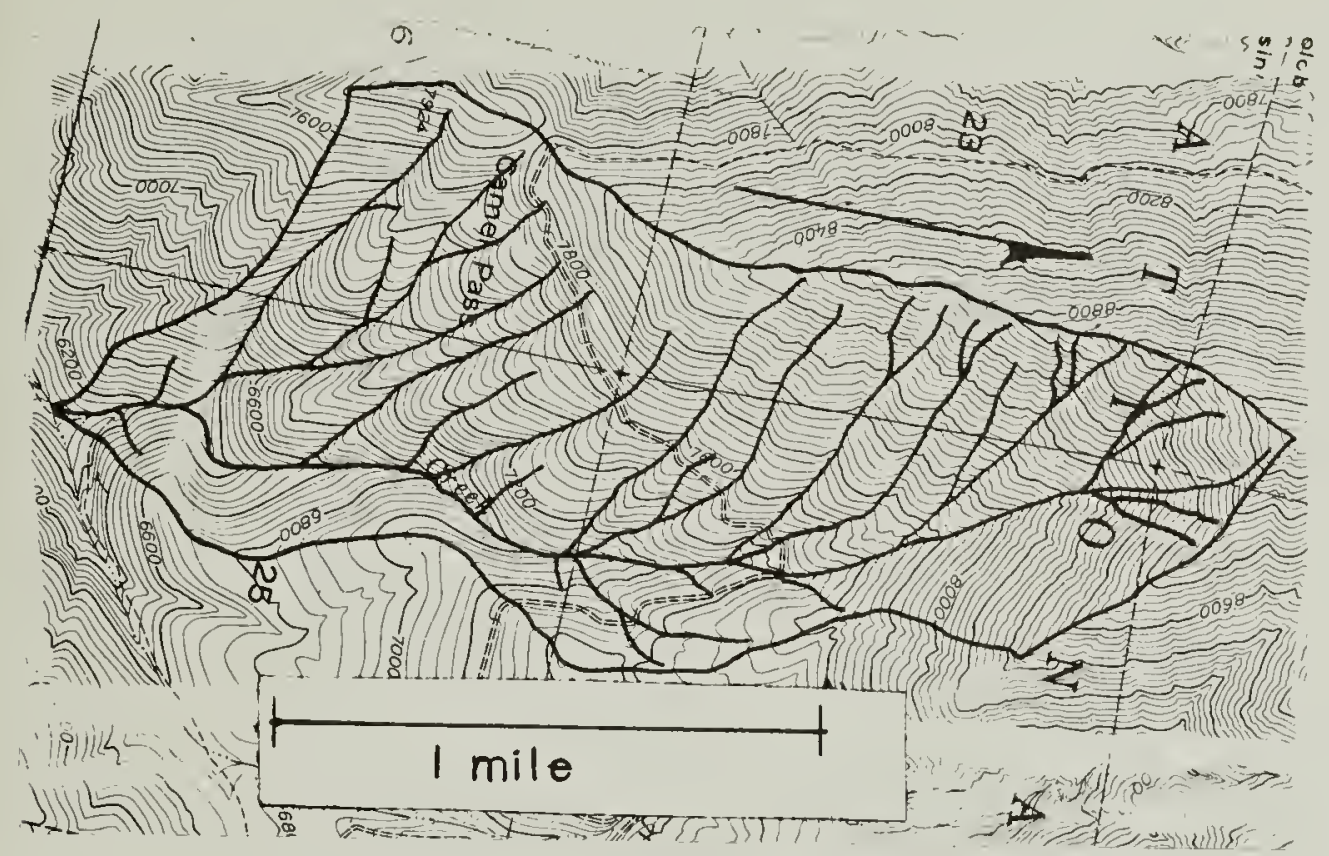

Springville Quadrangle, Utah

Above left: Spring Creek (Fourth order)

Above right: Deadman's Hollow (Third order)

Tributary to Hobble Creek (Third order)

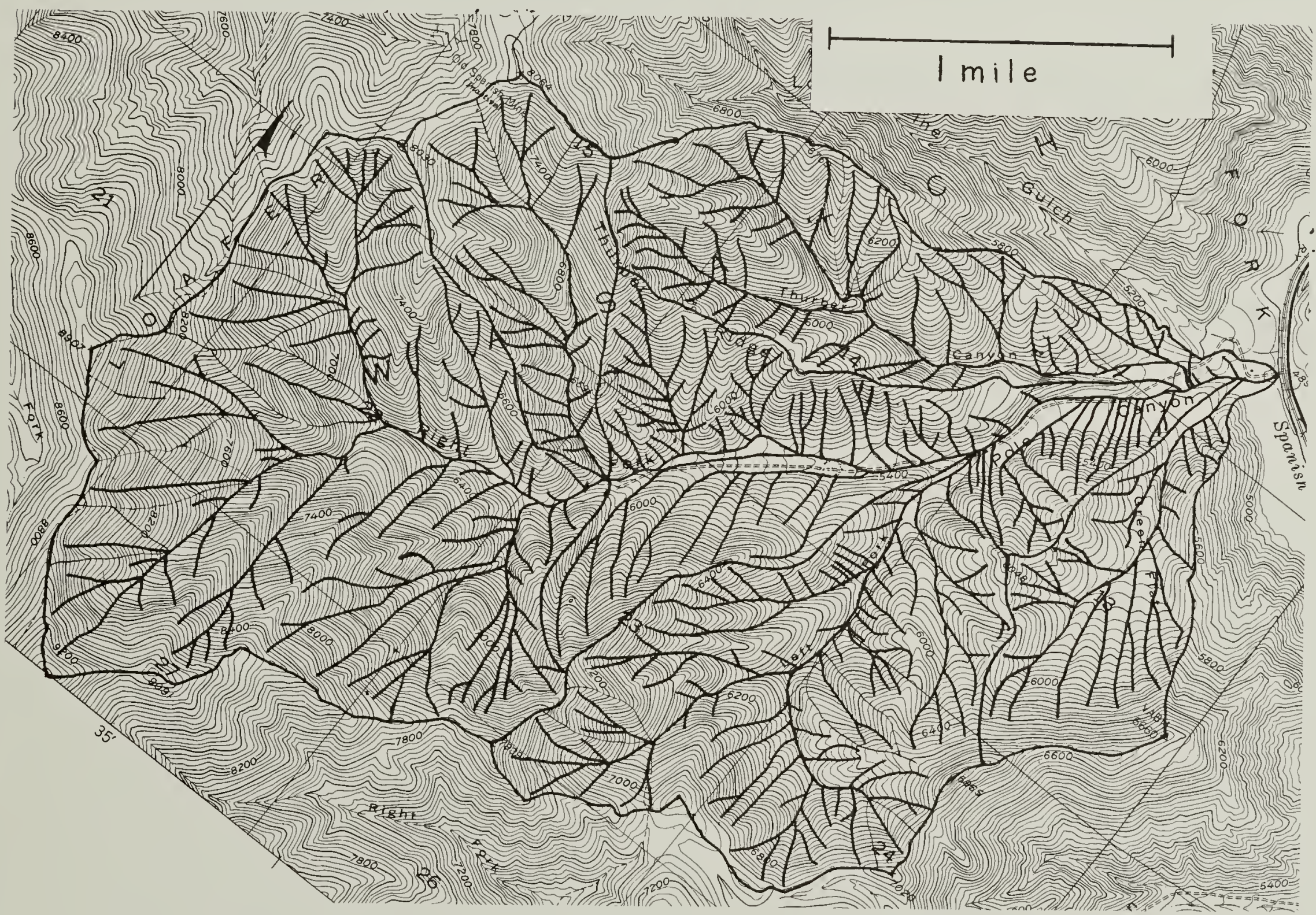

Spanish Fork Peak Quadrangle, Utah

Pole Canyon (Fifth order) 


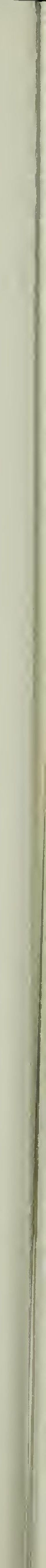




\section{Appendix V}

TWO-VARIABLE CORRELATION AND REGRESSION ANALYSES

A. Correlation tables of relations analyzed by grouped-data methods.

1. $\log _{\mathrm{e}}$ Drainage Density vs. P-E Index.

2. $\log _{e}$ Drainage Density vs. Infiltration Capacity.

3. $\log _{e}$ Drainage Density vs. Percent Bare Area.

4. $\log _{e}$ Drainage Density vs. Valley-side Slope.

5. Log Channel Frequency vs. Infiltration Capacity.

6. Log Channel Frequency vs. P-E Index.

7. Log Channel Frequency vs. Percent Bare Area.

8. Log Channel Frequency vs. Log Wet Soil Strength.

9. Log Relative Relief vs. Log Channel Frequency.

10. Log Frequency of First-order Channels vs. Log Channel Frequency.

11. Log Ruggedness Number Corrected for Order vs. Log Relative Relief.

12. $\log _{e}$ Density of First-order Channels vs. $\log _{e}$ Drainage Density.

13. $\log _{\mathrm{e}}$ Drainage Density vs. Channel Frequency.

14. Valley-side Slope vs. Infiltration Capacity, Fourth-order Basins.

15. Valley-side Slope vs. Log P-E Index.

16. Valley-side Slope vs. Wet Soil Strength.

17. Valley-side Slope vs. Log Channel Frequency.

18. Valley-side Slope vs. Log Ruggedness Number Corrected for Order .

19. Valley-side Slope vs. Log Relative Relief. 


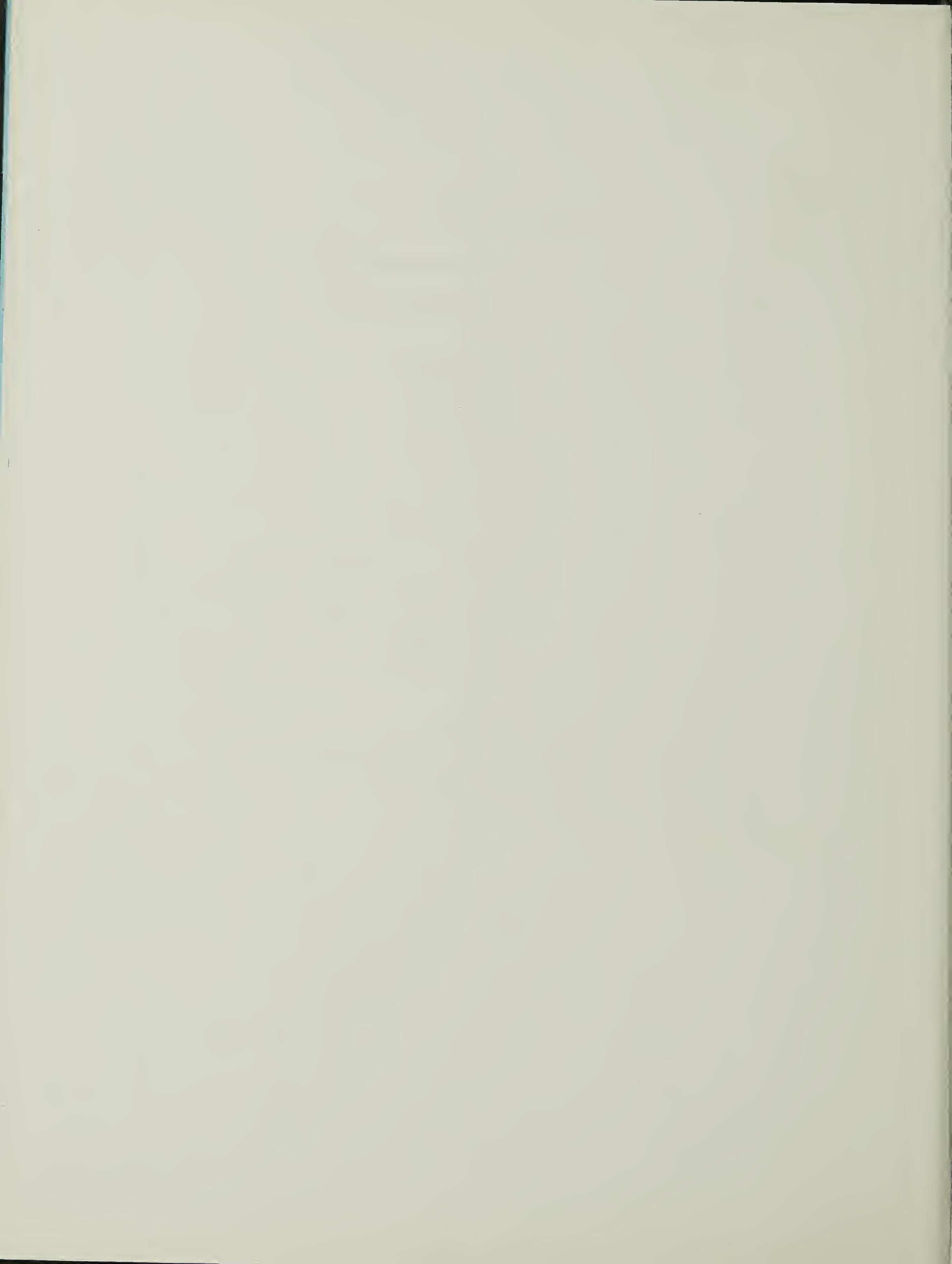




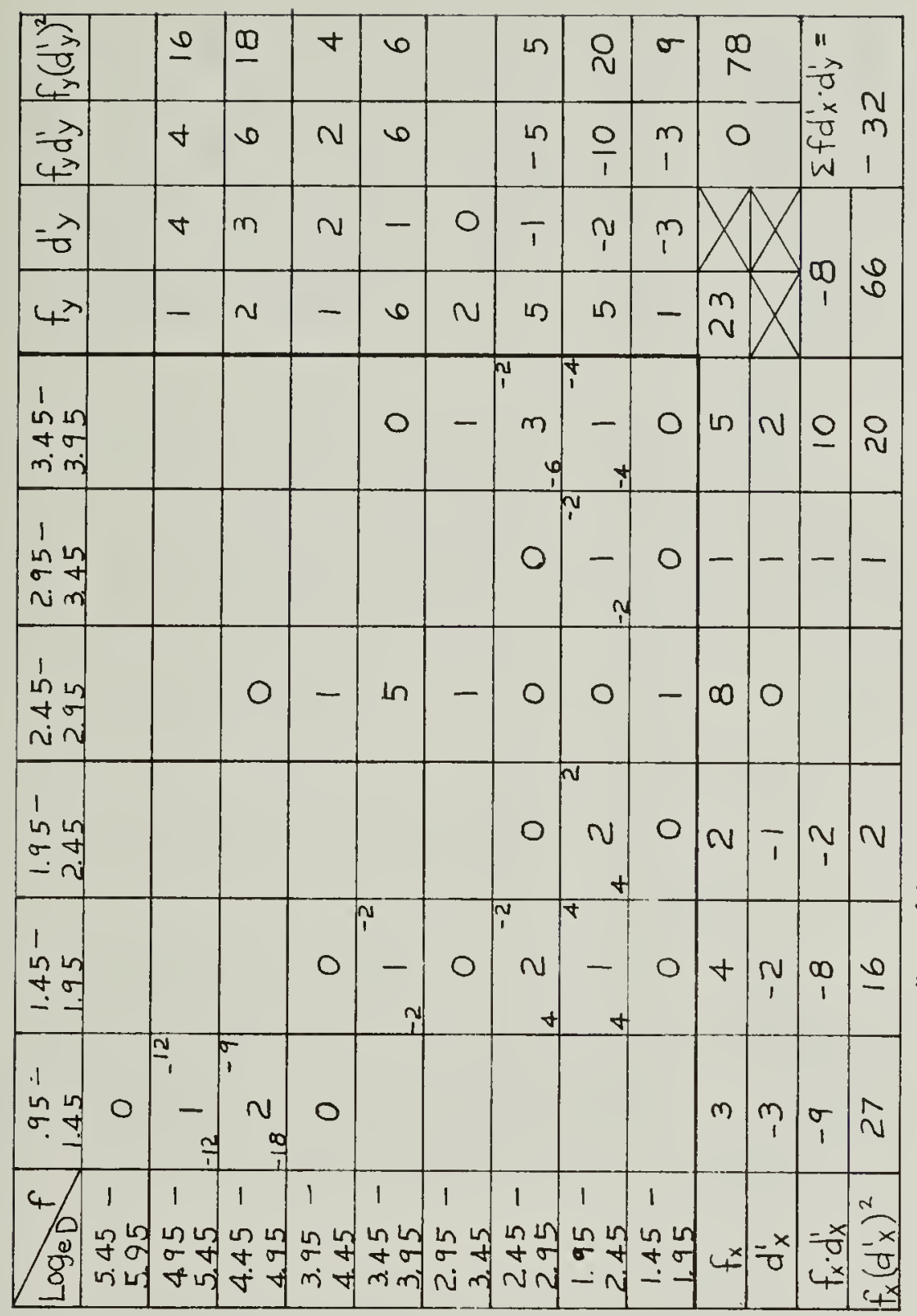

\begin{tabular}{|c|c|c|c|c|c|c|c|c|c|c|c|c|}
\hline 先 & $a$ & $\infty$ & $a$ & & + & $\stackrel{\infty}{\stackrel{N}{\sim}}$ & 2 & t & & $\bar{v}$ & \multirow{2}{*}{\multicolumn{2}{|c|}{ 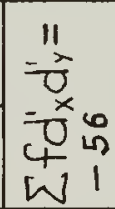 }} \\
\hline $\begin{array}{l}-3 \\
4 \pi\end{array}$ & $m$ & $t$ & $m$ & & $\begin{array}{l}1 \\
1\end{array}$ & $\begin{array}{c}\frac{1}{0} \\
1\end{array}$ & $\begin{array}{c}m \\
m \\
1\end{array}$ & $\frac{6}{1}$ & & $\frac{6}{1}$ & & \\
\hline ते & $m$ & N & - & 0 & $T$ & $\tilde{i}$ & $p$ & $\underset{1}{+}$ & $X$ & $X$ & \multirow{2}{*}{$y_{N}$} & \multirow{2}{*}{$\stackrel{N}{+}$} \\
\hline $4^{\lambda}$ & - & N & $m$ & - & + & $\tilde{m}$ & $=$ & + & $\begin{array}{l}\infty \\
\text { wn }\end{array}$ & $X$ & & \\
\hline ఎ゚ & & & & & - & 6 & & $\begin{array}{l}T \\
m\end{array}$ & 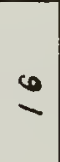 & - & $\underline{-}$ & $\because$ \\
\hline$\stackrel{\infty}{+}$ & & & & & + & $\stackrel{D}{N}$ & 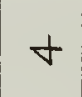 & & $\stackrel{+}{+}$ & 0 & & \\
\hline$\stackrel{+}{\sim}$ & & & & & & & ${ }_{m}^{m}$ & $\begin{array}{l}+ \\
- \\
+\end{array}$ & $\mathrm{N}$ & $\overline{1}$ & $\begin{array}{l}N \\
!\end{array}$ & $N$ \\
\hline$\simeq$ & $\begin{array}{l}4 \\
- \\
\vdots\end{array}$ & 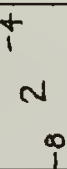 & $m$ & & & & & & 0 & $\mathbb{N}$ & $\frac{N}{1}$ & $\stackrel{+}{\sim}$ \\
\hline $\begin{array}{c}u \\
\vdots \\
\vdots \\
\vdots \\
\vdots \\
\vdots \\
\vdots\end{array}$ & $\begin{array}{l}0 \\
\text { 10 } \\
0^{\circ}\end{array}$ & $\underset{+}{\stackrel{P}{+}}$ & 암 & $\begin{array}{l}R \\
i\end{array}$ & $\stackrel{\circ}{\stackrel{\circ}{\sim}}$ & $\underset{\sim}{\stackrel{R}{N}}$ & $\begin{array}{l}\text { iv } \\
\text { s }\end{array}$ & $\stackrel{R}{\simeq}$ & $4^{x}$ & $\because x$ & $\begin{array}{l}-x \\
0 \\
4 x\end{array}$ & $\frac{-x}{0}$ \\
\hline
\end{tabular}

\begin{tabular}{|c|c|c|c|c|c|c|c|c|c|c|c|c|}
\hline$\frac{3}{4^{2}}$ & $\stackrel{ు}{N}$ & $\tilde{m}$ & $a$ & 志 & $N$ & & $\uparrow$ & $\forall$ & & 3 & \multirow{2}{*}{\multicolumn{2}{|c|}{ 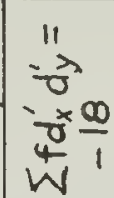 }} \\
\hline $\begin{array}{l}-\lambda \\
\psi^{\lambda} \\
\end{array}$ & in & $\infty$ & $m$ & $\simeq$ & $N$ & & $\hat{\imath}$ & $\mathbb{Y}$ & & $\bar{v}$ & & \\
\hline$-\frac{\lambda}{0}$ & in & + & $m$ & $N$ & - & 0 & $T$ & $N$ & $X$ & $X$ & \multirow{2}{*}{$\stackrel{m}{m}$} & \multirow{2}{*}{$a$} \\
\hline $4 \lambda$ & - & $N$ & - & 0 & $N$ & $\stackrel{m}{N}$ & $\Lambda$ & - & $\stackrel{m}{+}$ & $X$ & & \\
\hline$\stackrel{n}{N}$ & & & & & & & & & & & & \\
\hline $\begin{array}{l}n \\
N \\
n\end{array}$ & & & & & $N$ & $\underline{m}$ & -4 & & $\simeq$ & $N$ & $\stackrel{N}{m}$ & t \\
\hline$\stackrel{n}{\sim}$ & - & & & & & $N$ & + & - & $\underline{m}$ & - & $m$ & $\underline{m}$ \\
\hline $\begin{array}{l}\infty \\
\mathbb{N}\end{array}$ & & & - & $\Omega$ & & $N$ & - & & $a$ & 0 & & \\
\hline$\stackrel{\Perp}{\stackrel{N}{*}}$ & & & & & & & - & & - & $T$ & $\overline{1}$ & - \\
\hline $\begin{array}{l}n \\
\simeq \\
\simeq\end{array}$ & & $N$ & & - & & & & & $m$ & $N$ & $\begin{array}{l}0 \\
1\end{array}$ & $\simeq$ \\
\hline
\end{tabular}

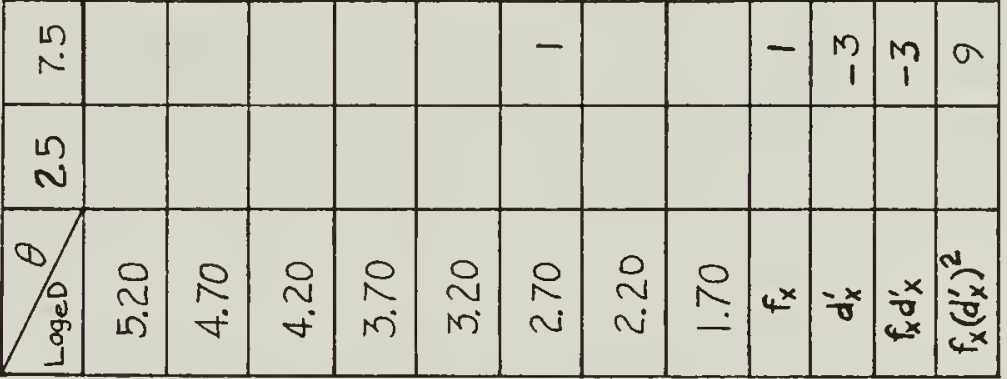

\begin{tabular}{|c|c|c|c|c|c|c|c|c|c|c|c|}
\hline$\frac{\pi}{8}$ & $\sigma$ & $\infty$ & & & $\forall$ & $\stackrel{\searrow}{\text { ก }}$ & $\stackrel{n}{q}$ & $\tilde{m}$ & $\cong$ & \multirow{2}{*}{\multicolumn{2}{|c|}{$\begin{array}{l}11 \\
=-0 \\
-x \\
0 \\
0 \\
w \\
w\end{array}$}} \\
\hline $\begin{array}{l}3 \\
0 \\
4\end{array}$ & $m$ & $\forall$ & 0 & & $\begin{array}{r}4 \\
\end{array}$ & $\frac{0}{1}$ & $\frac{1}{1}$ & $\begin{array}{c}\infty \\
1\end{array}$ & 욤 & & \\
\hline $\overrightarrow{0}$ & $m$ & $N$ & - & 0 & $\overline{1}$ & $\sim_{1}^{N}$ & $?$ & $\underset{1}{+}$ & & \multirow{2}{*}{$M$} & \multirow{2}{*}{$\begin{array}{l}m \\
\text { in }\end{array}$} \\
\hline $4 \lambda$ & - & $N$ & & $\forall$ & $\forall$ & $n$ & Un & $N$ & 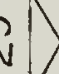 & & \\
\hline
\end{tabular}

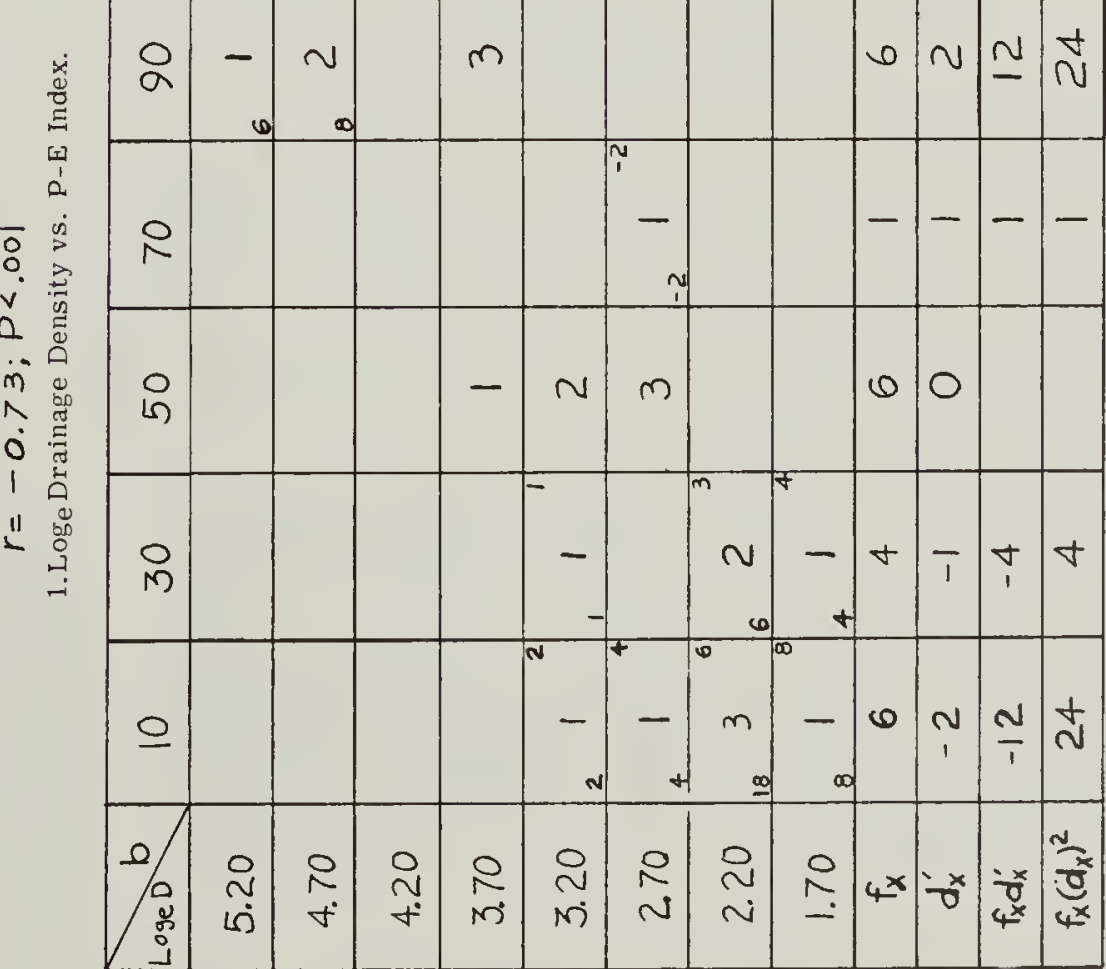




\begin{tabular}{|c|c|c|c|c|c|c|c|c|c|c|}
\hline 氕 & $\stackrel{\infty}{0}$ & $\underline{N}$ & - & & $\stackrel{m}{q}$ & $\tilde{n}$ & & פ? & \multirow{2}{*}{\multicolumn{2}{|c|}{ 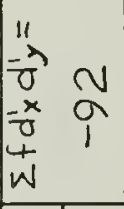 }} \\
\hline $\begin{array}{l}3 \\
\text { ते } \\
4 \overrightarrow{7}\end{array}$ & 6 & 6 & - & & $\stackrel{m}{+}$ & $\frac{1}{1}$ & & $f$ & & \\
\hline$-\lambda$ & $m$ & $N$ & - & 0 & $T$ & $\underset{1}{N}$ & $X$ & $X$ & & 10 \\
\hline $4>$ & $N$ & $m$ & - & 10 & $\stackrel{m}{q}$ & $\infty$ & $\begin{array}{l}N \\
0\end{array}$ & & 0 & 10 \\
\hline$\alpha^{\infty}$ & & & & & $a$ & ${ }^{+} \wedge$ & $\underline{0}$ & $v$ & $\begin{array}{l}\tilde{m} \\
m\end{array}$ & $\mid \begin{array}{l}0 \\
0\end{array}$ \\
\hline 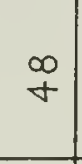 & & & & + & $\bar{m}$ & i & $\stackrel{0}{m}$ & - & $\begin{array}{l}\mathscr{0} \\
m\end{array}$ & $\left|\begin{array}{l}0 \\
m\end{array}\right|$ \\
\hline$\stackrel{+}{\sim}$ & & & & - & $M$ & & $\nabla$ & 0 & & \\
\hline$\simeq$ & $N$ & $m$ & - & & & & 0 & $\overline{1}$ & $\begin{array}{c}0 \\
1\end{array}$ & 0 \\
\hline 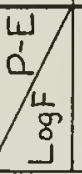 & 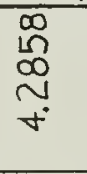 & $\begin{array}{l}\widetilde{\sigma} \\
\stackrel{0}{N} \\
\sim\end{array}$ & $\frac{O}{\frac{O}{I}}$ & $\begin{array}{l}\frac{2}{a} \\
\stackrel{N}{N}\end{array}$ & 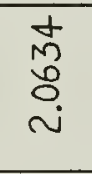 & $\begin{array}{l}\text { 足 } \\
\stackrel{1}{n}\end{array}$ & $4^{x}$ & -x & 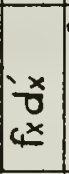 & 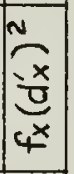 \\
\hline
\end{tabular}

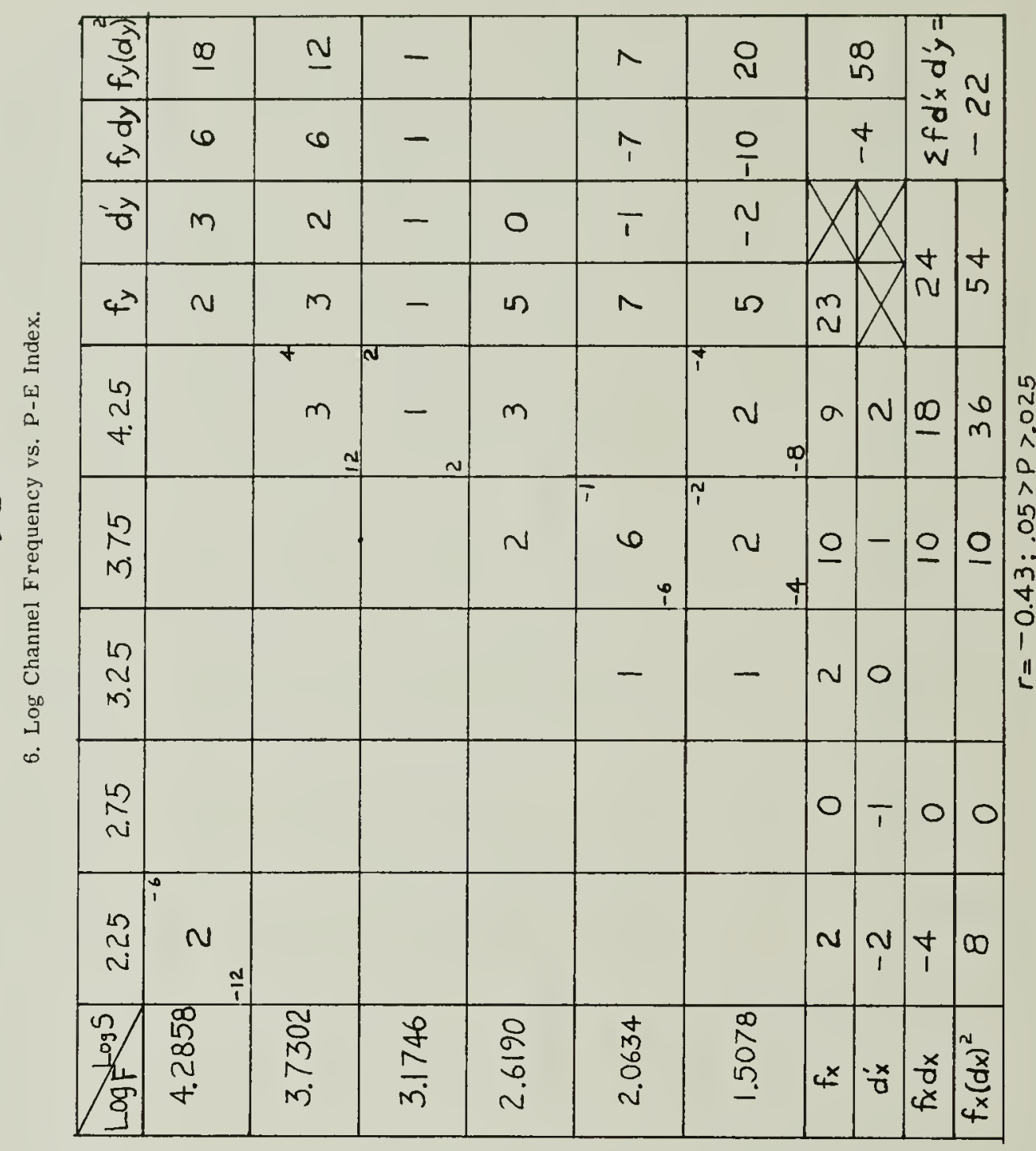

\begin{tabular}{|c|c|c|c|c|c|c|c|c|c|c|c|}
\hline$\frac{\pi}{3}$ & $\alpha$ & $\infty$ & $m$ & & $\infty$ & $\neq$ & $\stackrel{m}{m}$ & 으 & & \multirow{2}{*}{\multicolumn{2}{|c|}{$\begin{array}{c}\infty \\
m \\
1\end{array}$}} \\
\hline 2012 & n & $t$ & $M$ & & $\stackrel{0}{1}$ & $\stackrel{\sim}{\sim}$ & $\frac{N}{T}$ & & in & & \\
\hline${ }^{\lambda}$ & n & $\sim$ & - & 0 & $T$ & $\underset{1}{N}$ & $p$ & $X$ & $y$ & \multirow{2}{*}{\multicolumn{2}{|c|}{\begin{tabular}{c|c}
$\hat{N}$ & $m$ \\
1 & $=$
\end{tabular}}} \\
\hline $4^{\lambda}$ & - & $\sim$ & $m$ & & $\varphi$ & $=$ & + & $\widehat{N}$ & $X$ & & \\
\hline $\begin{array}{l}R \\
i\end{array}$ & & & & & & + & - & in & $N$ & 으 & OO \\
\hline $\begin{array}{c}0 \\
\sim \\
\text { ni }\end{array}$ & & & & & & & - & - & - & -1 & - \\
\hline $\begin{array}{l}R \\
i\end{array}$ & & & & & $\sim$ & & - & $m$ & 0 & & \\
\hline $\begin{array}{l}i \\
i \\
i\end{array}$ & & & & & - & $m$ & - & in & $T$ & $?$ & 10 \\
\hline$\stackrel{?}{i}$ & & & & & $\sim$ & + & & 0 & $\tilde{1}$ & $\frac{N}{T}$ & $\stackrel{\forall}{\sim}$ \\
\hline$\stackrel{\circ}{\cong}$ & - & ${ }^{i}$ & $m$ & & - & & & $r$ & $m$ & $\bar{q}$ & 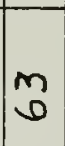 \\
\hline 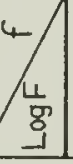 & 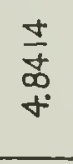 & 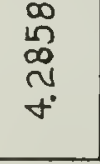 & 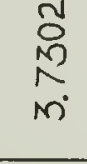 & $\frac{\frac{P}{5}}{m}$ & $\begin{array}{l}\frac{0}{0} \\
\text { i. } \\
\text { ind }\end{array}$ & $\begin{array}{l}\stackrel{+}{0} \\
\stackrel{0}{\circ} \\
\stackrel{0}{v}\end{array}$ & $\begin{array}{l}\infty \\
\stackrel{0}{0} \\
\stackrel{0}{n}\end{array}$ & $4^{x}$ & $\frac{x}{y}$ & $\begin{array}{l}\frac{x}{y} \\
c^{x}\end{array}$ & 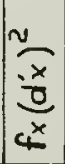 \\
\hline
\end{tabular}

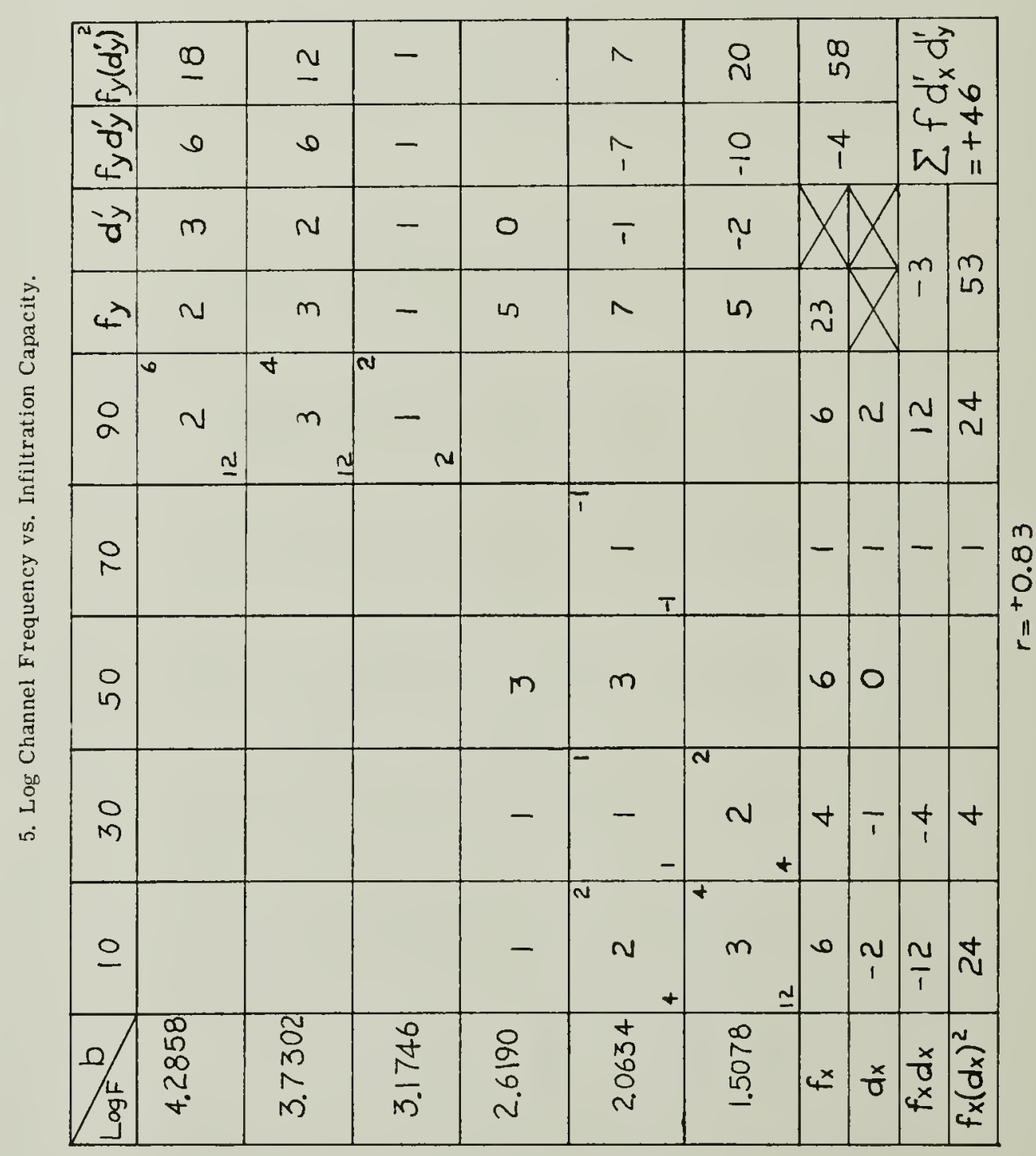




\begin{tabular}{|c|c|c|c|c|c|c|}
\hline$\underline{\square}$ & & & & & i & \\
\hline & $\sim$ & ${ }^{n}$ & & $\frac{d}{p}$ & $\frac{\circ}{i}$ & \\
\hline & $N$ & - & $\circ$ & & ז & \\
\hline & -1 & $\infty$ & $\stackrel{\circ}{\circ}$ & $\frac{8}{0}$ & 10 & \\
\hline & & & & & & \\
\hline & & $-n$ & & & & \\
\hline & & $\sim 0$ & & & & \\
\hline & & - & & & & \\
\hline & & - & $\infty$ & & & \\
\hline & & $\gamma-\gamma$ & $n$ & $i_{n}^{\circ}$ & & \\
\hline & & & & $\theta=$ & & \\
\hline & & & & & & \\
\hline 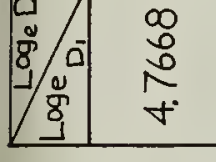 & & 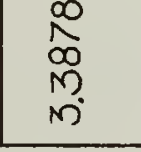 & 总 & $\stackrel{8}{0}$ & $\underline{2}$ & \\
\hline
\end{tabular}

\begin{tabular}{|c|c|c|c|c|c|c|c|c|c|c|c|c|c|}
\hline & 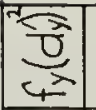 & $\tilde{n}$ & in & $\stackrel{+}{\sim}$ & $\simeq$ & & Ln & $\simeq$ & 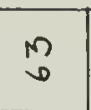 & న్ & & \multirow{2}{*}{\multicolumn{2}{|c|}{ 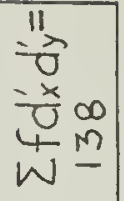 }} \\
\hline & $\begin{array}{c}-3 \\
0 \\
4=2\end{array}$ & $\infty$ & $\dddot{\infty}$ & $\simeq$ & $\simeq$ & & $\begin{array}{l}\text { in } \\
1\end{array}$ & i & $\bar{N}$ & 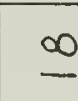 & & & \\
\hline & $=-\lambda$ & + & $m$ & $\sim$ & - & 0 & $T$ & $T$ & $M$ & $X$ & $X$ & & \\
\hline$x^{2}$ & 4 & $N$ & 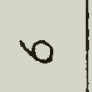 & 6 & $\simeq$ & $\stackrel{\infty}{-}$ & L & $M$ & $r$ & in & $X$ & $\infty$ & $\bar{N}$ \\
\hline$\vec{g}$ & \begin{tabular}{|l|} 
\\
$\infty$ \\
N \\
\end{tabular} & $\stackrel{9}{2}$ & & & & & & & & & + & + & 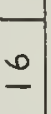 \\
\hline 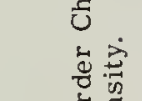 & $\underline{\overline{\bar{m}}}$ & & $m$ & $m$ & & & & & & & $N$ & $\bar{N} !$ & M] \\
\hline 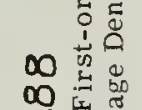 & \begin{tabular}{|l|}
$\infty$ \\
$\tilde{8}$ \\
\end{tabular} & & - & & ${ }^{\top}+$ & $N$ & & & & $r$ & $N$ & \pm & 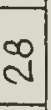 \\
\hline 范 & $\left|\begin{array}{l}2 \\
0 \\
0 \\
0\end{array}\right|$ & + & $n$ & ${ }^{4}-4$ & $N_{N}$ & in & & & & $=$ & - & $=$ & $=$ \\
\hline 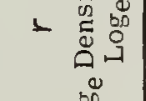 & 高 & & & - & $v$ & + & & $N$ & & $a$ & 0 & & \\
\hline$\stackrel{\text { I }}{ }$ & 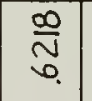 & & & $\pi^{4}$ & $\bar{T}{ }^{\bar{T}}$ & $v$ & $\nabla_{+}$ & - & $m$ & $\underline{m}$ & $T$ & $\frac{m}{1}:$ & $m$ \\
\hline & 紊 & & & & & $m$ & - & & - & in & $T$ & 이 & $\stackrel{\sim}{\sim}$ \\
\hline & $\begin{array}{l}\bar{R} \\
\text { n̊n. }\end{array}$ & & & & 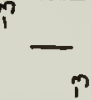 & $\sim$ & & & ${ }^{2}$ & in & $\stackrel{p}{p}$ & $\frac{n}{T}$ & $\begin{array}{l}n \\
+ \\
+\end{array}$ \\
\hline & \begin{tabular}{|l|}
0 \\
$\stackrel{2}{u}$ \\
$\sim$
\end{tabular} & & & & & & & & - & & 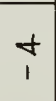 & $\frac{1}{4}$ & $\stackrel{0}{-}$ \\
\hline & 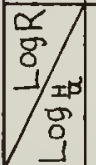 & 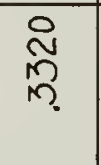 & $\begin{array}{l}8 \\
8 \\
0\end{array}$ & $\begin{array}{l}\overline{0} \\
\text { o. } \\
+\end{array}$ & $\begin{array}{l}\infty \\
\infty \\
0 \\
0 \\
1\end{array}$ & $\begin{array}{l}\stackrel{\infty}{2} \\
\frac{0}{1} \\
\frac{1}{1}\end{array}$ & $\begin{array}{l}\hat{N} \\
\stackrel{N}{N} \\
\vec{p} \\
1\end{array}$ & 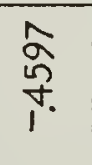 & $\begin{array}{l}\frac{0}{a} \\
\text { n. } \\
i\end{array}$ & & 㓉 & $\begin{array}{l}-x \\
4 \times 1 \\
4 \times 1\end{array}$ & $\frac{0}{4 x}$ \\
\hline
\end{tabular}

\begin{tabular}{|c|c|c|c|c|c|c|c|c|c|c|c|c|c|}
\hline 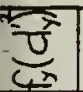 & ㅇำ & $\stackrel{0}{\underline{\Lambda}}$ & $\stackrel{\mathscr{N}}{\simeq}$ & 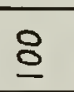 & $\bar{M}$ & & $\simeq$ & ñ & $\hat{N}$ & \multicolumn{2}{|c|}{ 点 } & \multirow{2}{*}{ 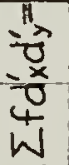 } & \multirow{2}{*}{$\begin{array}{l}0 \\
6 \\
1 \\
1\end{array}$} \\
\hline$\underline{\underline{\underline{x}}}$ & 으 & $\frac{1}{4}$ & $\stackrel{\sim}{+}$ & in & $\bar{m}$ & & $\stackrel{d}{T}$ & $\stackrel{0}{1}$ & $\mathbf{i}$ & $\$$ & & & \\
\hline & ما & + & $m$ & $\sim$ & - & 0 & $T$ & $\uparrow$ & $p$ & 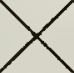 & K & & + \\
\hline & $\sim$ & $=$ & \pm & $\stackrel{\sim}{\sim}$ & $\bar{m}$ & $\stackrel{0}{\sim}$ & $\simeq$ & $\infty$ & $n$ & $\underline{\tilde{n}}$ & $X$ & $\frac{n}{1}$ & $\cong$ \\
\hline & & & & & ${ }^{\infty} \sim$ & & & & & $N$ & $\infty$ & 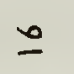 & $\stackrel{\text { న }}{\underline{N}}$ \\
\hline & & & & & & - & & & & - & $r$ & $r$ & $\stackrel{q}{q}$ \\
\hline & & & $=$ & & & - & & & & + & 0 & $\stackrel{ \pm}{\sim}$ & 声 \\
\hline & & & & & & - & & & & - & $n$ & in & $\stackrel{n}{\sim}$ \\
\hline & & & & & & $\sim$ & $-\frac{1}{4}$ & & & $m$ & + & $\simeq$ & $\stackrel{\infty}{+}$ \\
\hline & & & & & m & & & & & $m$ & $n$ & $a$ & $\hat{N}$ \\
\hline & & & & & & $n$ & r- & & & 0 & $N$ & $\cong$ & $\stackrel{+}{\sim}$ \\
\hline & & + & & ${ }^{2}-$ & + & $\sim$ & $\mathrm{s}^{4}$ & & & 으 & - & 음 & 으 \\
\hline & & & & - & $N$ & & $m$ & + & & 은 & 0 & & \\
\hline & & & & & & $d$ & & - & - & $=$ & $T$ & $\bar{T}$ & $=$ \\
\hline & & & & & & + & N & $\mathrm{n}$ & $\stackrel{\sim}{\sim}$ & $\bar{n}$ & $\tau$ & $\underset{\substack{N \\
i}}{\tilde{N}}$ & $\stackrel{ \pm}{\simeq}$ \\
\hline & & $\sim$ & 10 & i으요 & '으 & n & ${ }^{n}$ & & & $\stackrel{+}{m}$ & $?$ & $\stackrel{\widetilde{1}}{1}$ & 茴 \\
\hline & $-\div$ & $\begin{array}{l}P^{2} \\
\sim\end{array}$ & $T^{2}-$ & $i^{\infty} \sim$ & - & & + & & & $\infty$ & + & $\widetilde{p}$ & $\stackrel{\infty}{\simeq}$ \\
\hline & & & & ${ }^{\circ}-$ & 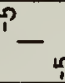 & $m$ & ${ }^{n} v_{0}$ & - & & $\infty$ & 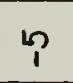 & 웅 & : \\
\hline & $\begin{array}{l}\tilde{N} \\
\underline{\underline{p}}\end{array}$ & $\stackrel{\text { W }}{=}$ & \begin{tabular}{|l}
5 \\
\end{tabular} & $\frac{9}{0}$ & $\frac{m}{0}$ & 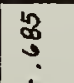 & $i_{n}^{\infty}$ & $\bar{q}$ & 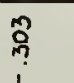 & & & & \\
\hline $\begin{array}{rl}9 & 0 \\
-8 \\
0 \\
0\end{array}$ & $\stackrel{1}{2}$ & . & $\frac{1}{a}$ & 管 & . & 宓 & 亳 & 萮 & ڤે & $4^{x}$ & $y^{-x}$ & $4 x$ & $\frac{\pi}{4 x}$ \\
\hline
\end{tabular}

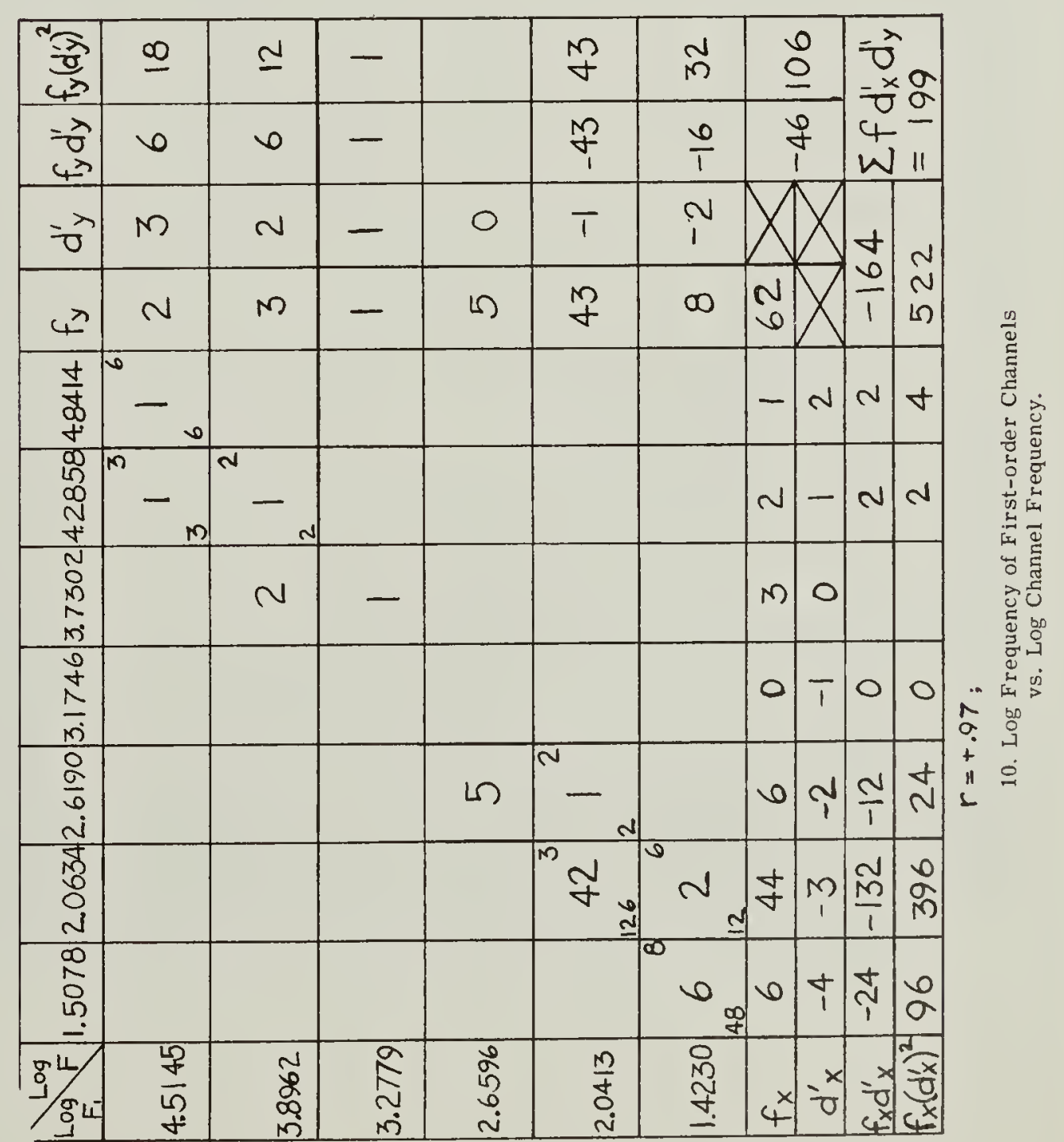



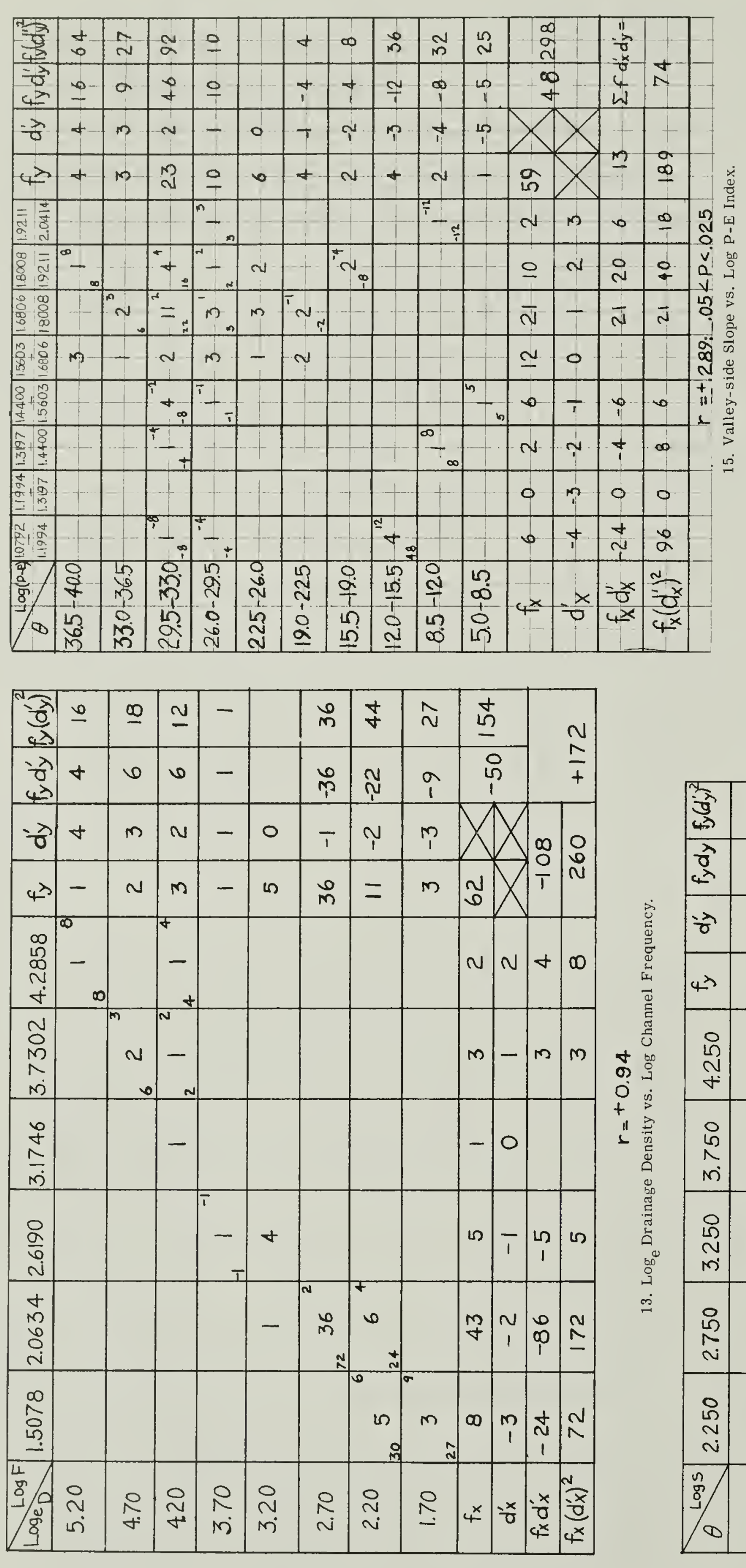

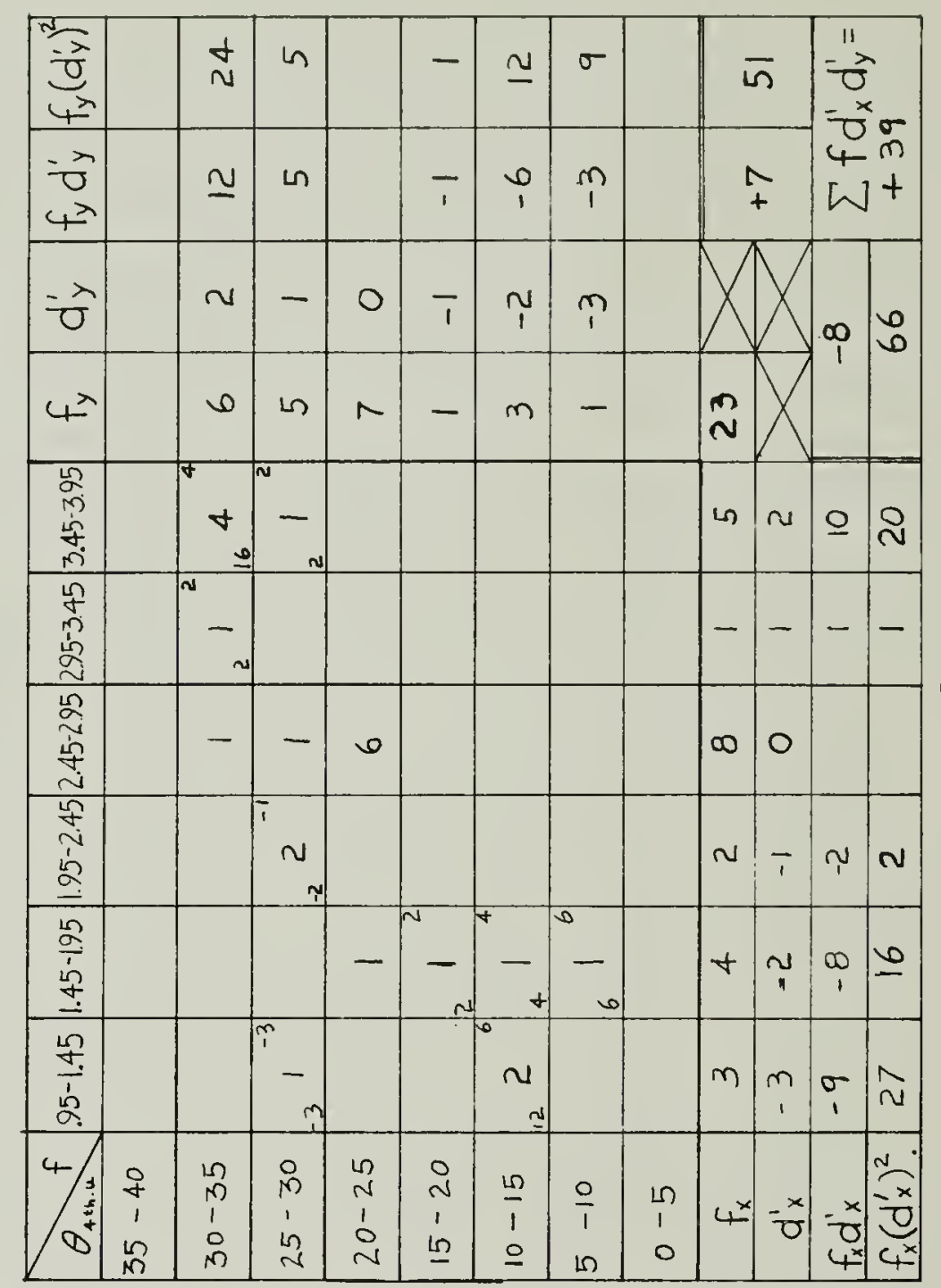

\begin{tabular}{|c|c|c|c|c|c|c|c|c|c|c|c|c|}
\hline 第 & $\stackrel{0}{0}$ & $\stackrel{0}{m}$ & $\stackrel{\infty}{N}$ & $N$ & & 0 & ナ & 0 & & v & \multirow{2}{*}{\multicolumn{2}{|c|}{$\begin{array}{l}11 \\
-0 \\
-0 \\
-x 0 \\
4+\end{array}$}} \\
\hline \begin{tabular}{|l|} 
\\
0 \\
0 \\
4 \\
4
\end{tabular} & + & $\simeq$ & \pm & $\underline{N}$ & & $\varphi_{1}^{0}$ & Y & 0 & & 4 & & \\
\hline तो & $\nabla$ & $M$ & $\sim$ & - & 0 & $T$ & $\underset{1}{\gamma}$ & $p$ & $X$ & & & \\
\hline $4 \lambda$ & - & + & $\wedge$ & $v$ & $\sim$ & 0 & - & 0 & $\stackrel{m}{\sim}$ & $x$ & $\sim$ & in \\
\hline 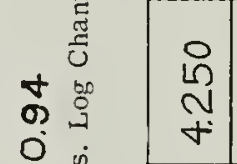 & & - & m & & & n & & & a & $N$ & 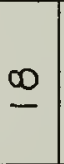 & \\
\hline $\begin{array}{l}i \\
\hat{n} \\
n\end{array}$ & & - & $m$ & $\sim$ & $N$ & - & - & & 이 & - & 으 & 은 \\
\hline $\begin{array}{c}\stackrel{8}{1} \\
\stackrel{2}{*} \\
m^{\prime}\end{array}$ & - & - & & & & & & & $N$ & 0 & & \\
\hline 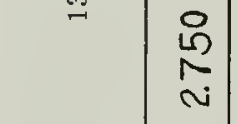 & & & & & & & & & 0 & $T$ & 0 & 10 \\
\hline 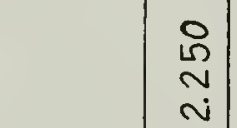 & & - & - & & & & & & $N$ & $N$ & + & $\infty$ \\
\hline $\begin{array}{l}n \\
g \\
9 \\
9\end{array}$ & 耑 & 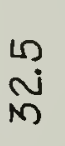 & $\stackrel{n}{\sim}$ & $\stackrel{\sim}{\mathbb{N}}$ & $\stackrel{?}{=}$ & $\stackrel{n}{\simeq}$ & مْ & $\stackrel{n}{v}$ & $4^{*}$ & $\frac{x}{0}$ & $\mid \begin{array}{l}-\frac{x}{0} \\
4 \\
4\end{array}$ & 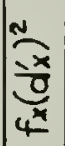 \\
\hline
\end{tabular}




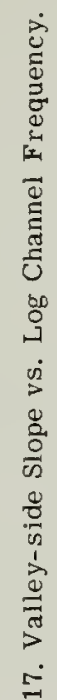

\begin{tabular}{|c|c|c|c|c|c|c|c|c|c|c|c|c|}
\hline$\frac{\sqrt{2}}{c^{2}}$ & fo & $N$ & $N$ & & $m$ & $\stackrel{0}{N}$ & $\sigma$ & 0 & & $\vec{z}$ & \multirow{2}{*}{\multicolumn{2}{|c|}{$\begin{array}{l}11 \\
-\lambda \\
-x \\
-x \\
0 \\
4 \\
w \\
w\end{array}$}} \\
\hline ì & $\ln$ & $\stackrel{0}{m}$ & $\stackrel{\sim}{N}$ & & $m$ & $\frac{0}{1}$ & $\begin{array}{l}m \\
1\end{array}$ & $\begin{array}{l}0 \\
1\end{array}$ & & ת) & & \\
\hline$\frac{-\lambda}{\sigma}$ & $m$ & $N$ & - & 0 & $T$ & $\underset{1}{N}$ & $\stackrel{m}{p}$ & i & $X$ & $1 X$ & & \\
\hline $\bar{\tau}$ & in & $\underline{\infty}$ & $\tilde{N}$ & ما & $m$ & $n$ & - & 0 & is & $X$ & $\begin{array}{l}7 \\
1\end{array}$ & $\sigma$ \\
\hline \begin{tabular}{l}
$\infty$ \\
$\stackrel{\infty}{0}$ \\
$\infty$ \\
$\stackrel{N}{N}$ \\
\multirow{+}{*}{}
\end{tabular} & & $\begin{array}{l}6 \\
- \\
0\end{array}$ & - & & & & & & $N$ & $m$ & 0 & $\underline{\infty}$ \\
\hline $\begin{array}{l}\tilde{O} \\
\stackrel{0}{N} \\
\hat{N}\end{array}$ & & & & & & $m$ & & & $m$ & $N$ & 0 & $N$ \\
\hline$\frac{\stackrel{o}{+}}{\frac{1}{m}}$ & & & & & $\overline{1}$ & & & & - & $1-$ & - & $1-$ \\
\hline $\begin{array}{l}\frac{R}{0} \\
N\end{array}$ & & - & $N$ & - & & - & & & 10 & 10 & & \\
\hline $\begin{array}{l}+ \\
+ \\
0 \\
0 \\
i \\
N\end{array}$ & m) & in & 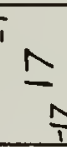 & $m$ & - & & - & & $\stackrel{\sim}{\sigma}$ & $\overline{1}$ & $\begin{array}{l}N \\
1 \\
1\end{array}$ & $\begin{array}{l}V \\
y\end{array}$ \\
\hline $\begin{array}{l}\infty \\
\stackrel{0}{0} \\
\text { n? }\end{array}$ & & - & $N$ & - & - & - & & & 6 & $\Psi$ & $\frac{N}{1}$ & $\stackrel{+}{\sim}$ \\
\hline 0 & $\stackrel{n}{\hat{n}}$ & $\begin{array}{l}0 \\
\stackrel{N}{N}\end{array}$ & $\stackrel{\sim}{\sim}$ & $\begin{array}{l}n \\
\mathbb{N}\end{array}$ & $\stackrel{\sim}{\stackrel{2}{\Sigma}}$ & $\stackrel{1}{N}$ & ?ִ & $\stackrel{10}{\sim}$ & $4^{x}$ & $-\frac{x}{0}$ & $\begin{array}{l}-\frac{x}{0} \\
4\end{array}$ & $\frac{-\frac{\pi}{x}}{\frac{x}{4 x}}$ \\
\hline
\end{tabular}

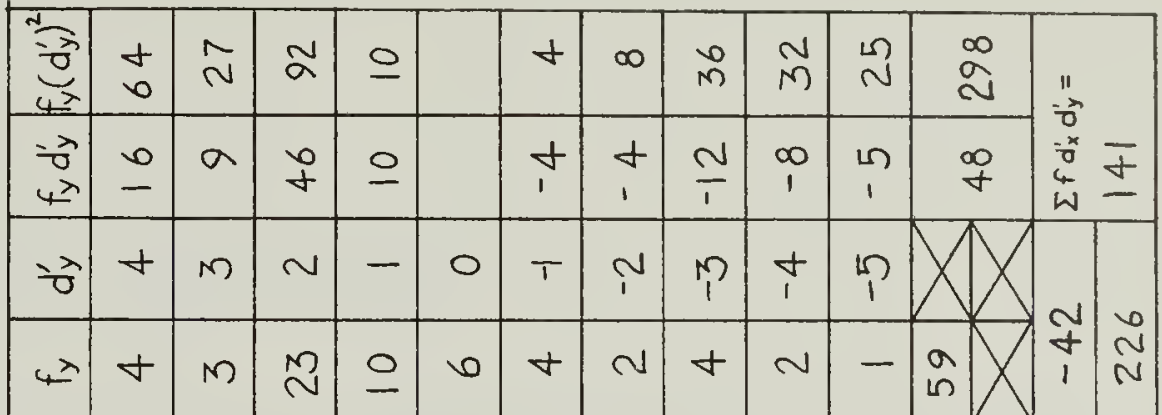

\begin{tabular}{|c|c|c|c|c|c|c|c|c|c|c|c|c|c|}
\hline$\hat{8}$ & $\therefore-$ & & & & & & & & & $N$ & $m$ & & $\stackrel{0}{1}$ \\
\hline & & $m_{f}$ & & & & & & & & 6 & $N$ & & $\stackrel{+}{\sim}$ \\
\hline & & $\sim$ & - & - & & & & & & $\circ$ & - & & 0 \\
\hline & & $\wedge$ & + & & & & & & & $=$ & 0 & & \\
\hline & & $\mathrm{O}_{8}$ & in & + & $=$ & '- & & & & 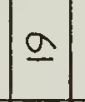 & $T$ & 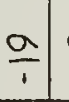 & $\Phi$ \\
\hline & & +7 & - & & $\sim$ & & $\therefore$ & & & in & $\begin{array}{l}1 \\
1\end{array}$ & 은 & 이 \\
\hline & & & & - & & - & D- & & & $\mathrm{m}$ & 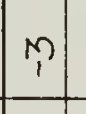 & $\begin{array}{l}a \\
1\end{array}$ & $\hat{N}$ \\
\hline & & & - & & - & & $v$ & & - & 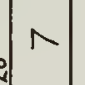 & $\begin{array}{l}4 \\
1\end{array}$ & $\begin{array}{c}\infty \\
\end{array}$ & $\cong$ \\
\hline $\begin{array}{l}8 \\
\text { a } \\
1 \\
i \\
\infty \\
n\end{array}$ & \begin{tabular}{|c|c|c}
0 \\
0 \\
0 \\
1 \\
0 \\
0 \\
$n$ \\
$m$
\end{tabular} & 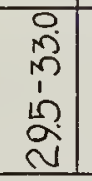 & 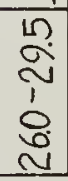 & 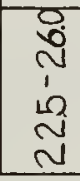 & 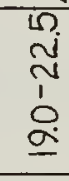 & 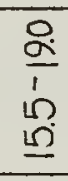 & 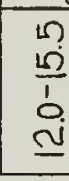 & 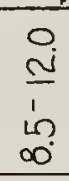 & \begin{tabular}{|l|} 
\\
0 \\
0 \\
0 \\
$n$ \\
$n$
\end{tabular} & & Is & $\mid$ & $\frac{\sqrt{x}}{x^{*}}$ \\
\hline
\end{tabular}
i

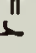

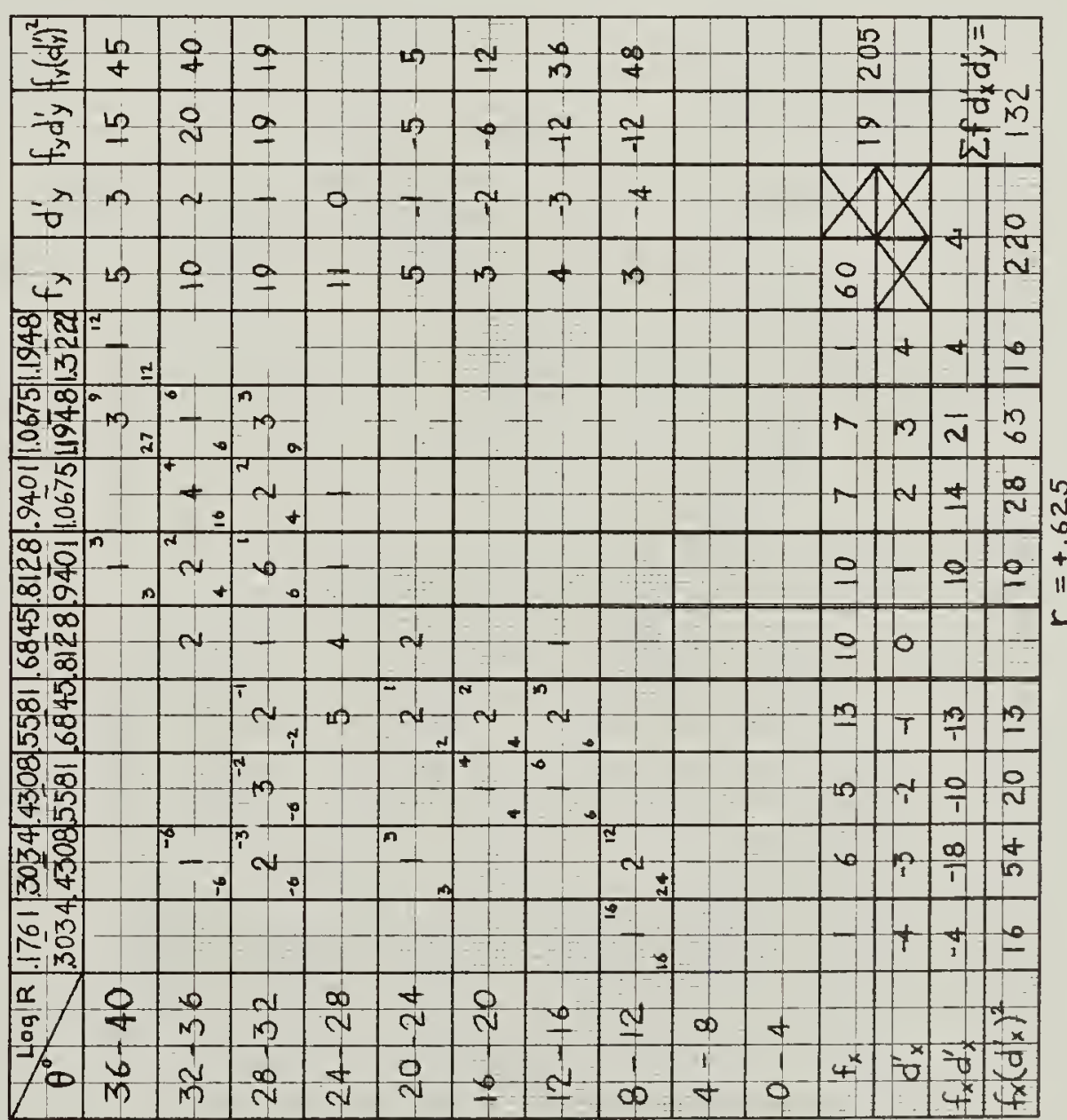




\section{Appendix V (Continued)}

B. Scatter Plots and Regressions of Selected Relations; Ungrouped Data.

1. Drainage Density vs. P-E Index.

2. Drainage Density vs. Runoff Intensity.

3. Channel Frequency vs. Percent Bare Area. Each point represents one major basin.

4. Regression of Channel Frequency on Drainage Density. Each point represents one third-order basin.

5. Regression of Valley-side Slope on Infiltration Capacity.

6. Regression of Valley-side Slope on Runoff Intensity.

7. Regression of Valley-side Slope on Relative Relief.

8. Regression of Valley-side Slope on Ruggedness Number Corrected for Order.

9. Regression of Valley-side Slope on Wet Soil Strength.

10. Regression of Valley-side Slope on Ratio of Mean January Precipitation to 1/12 Mean Annual Precipitation.

11. Regression of Drainage Density on Percent Bare Area. 


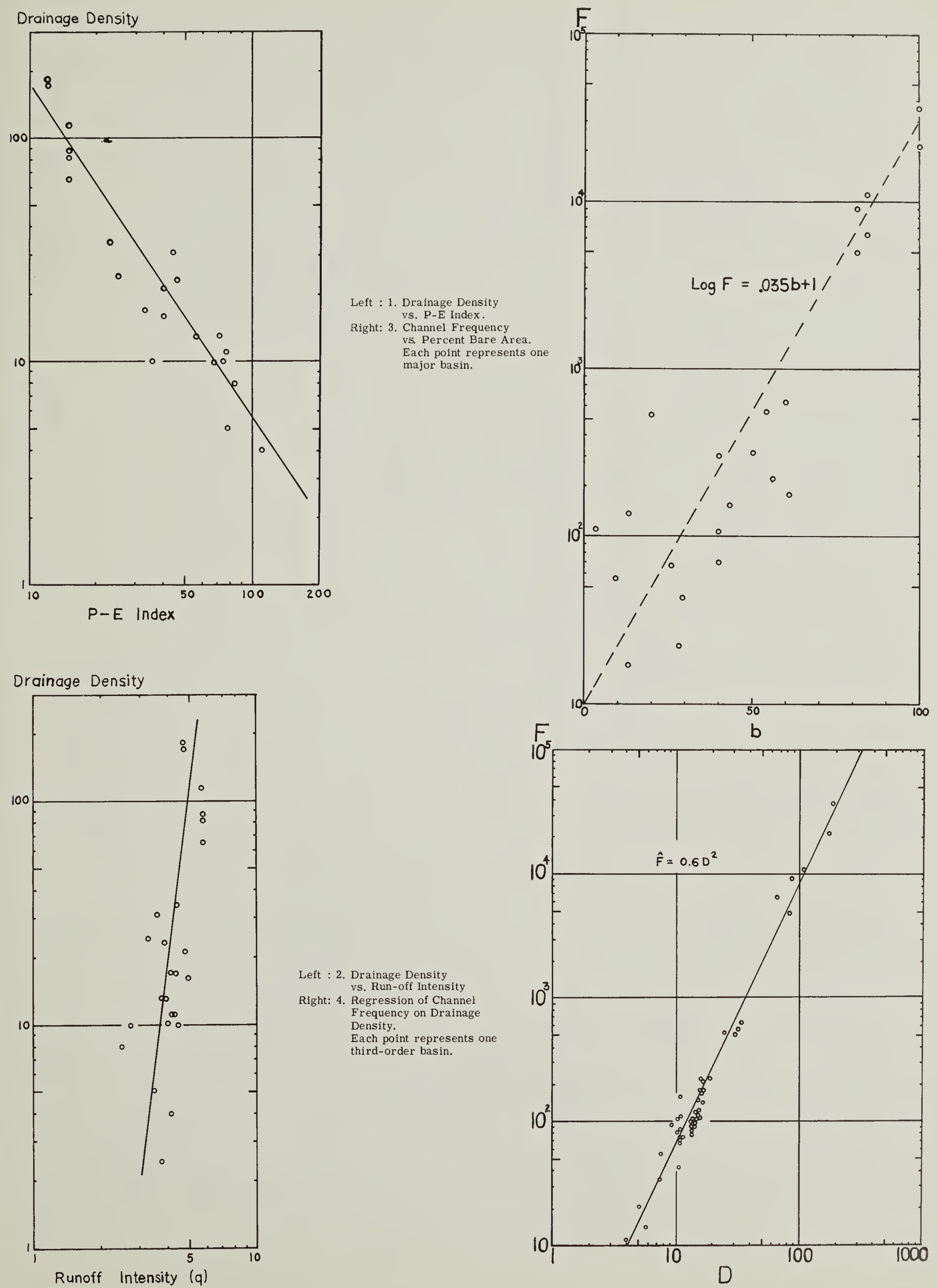

Left : 2. Drainage Density
vs, Run-off Intensity S. Run-off Intensity Frequency on Drainage Density.

Each point represents one third-order basin.

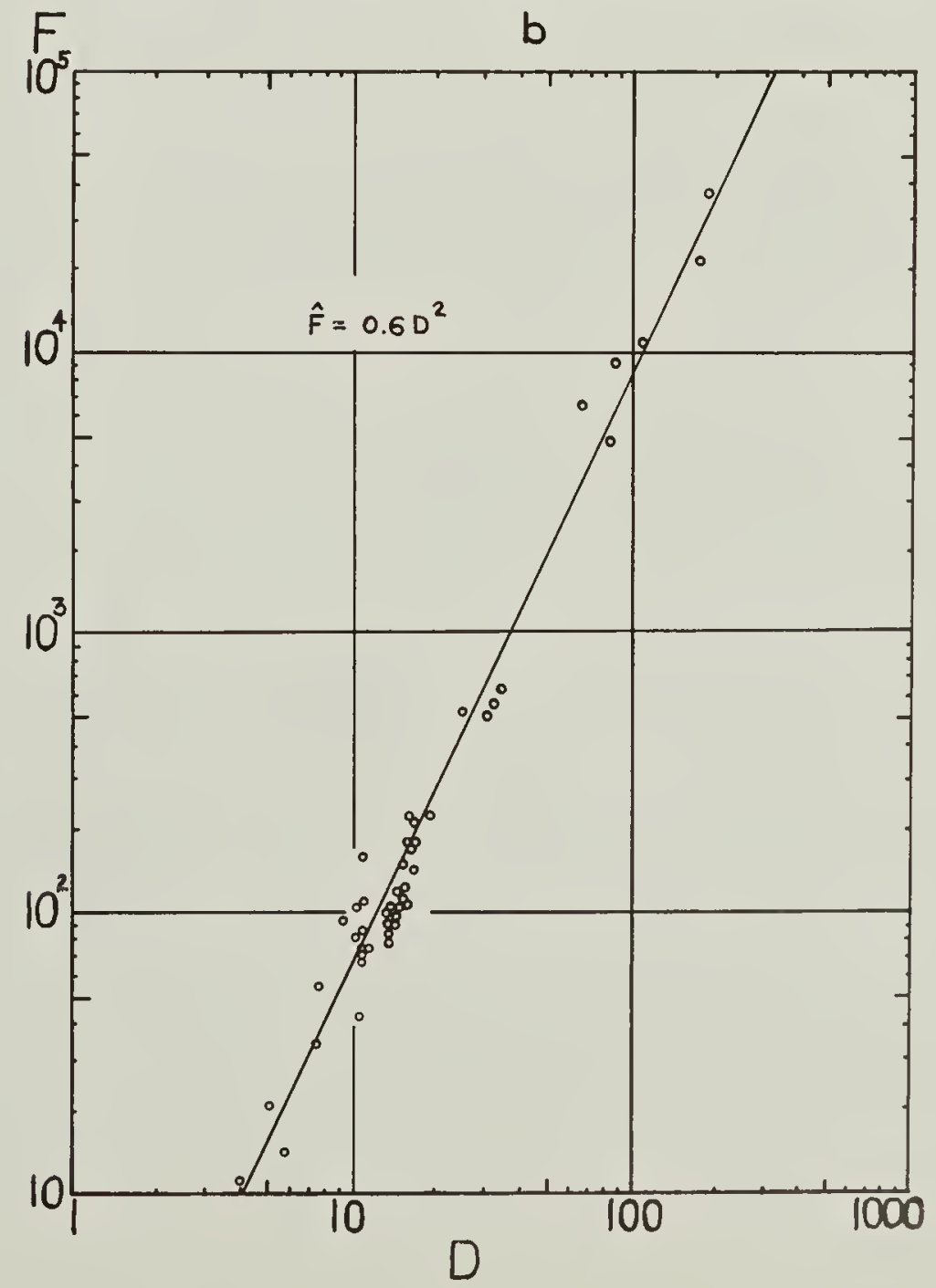



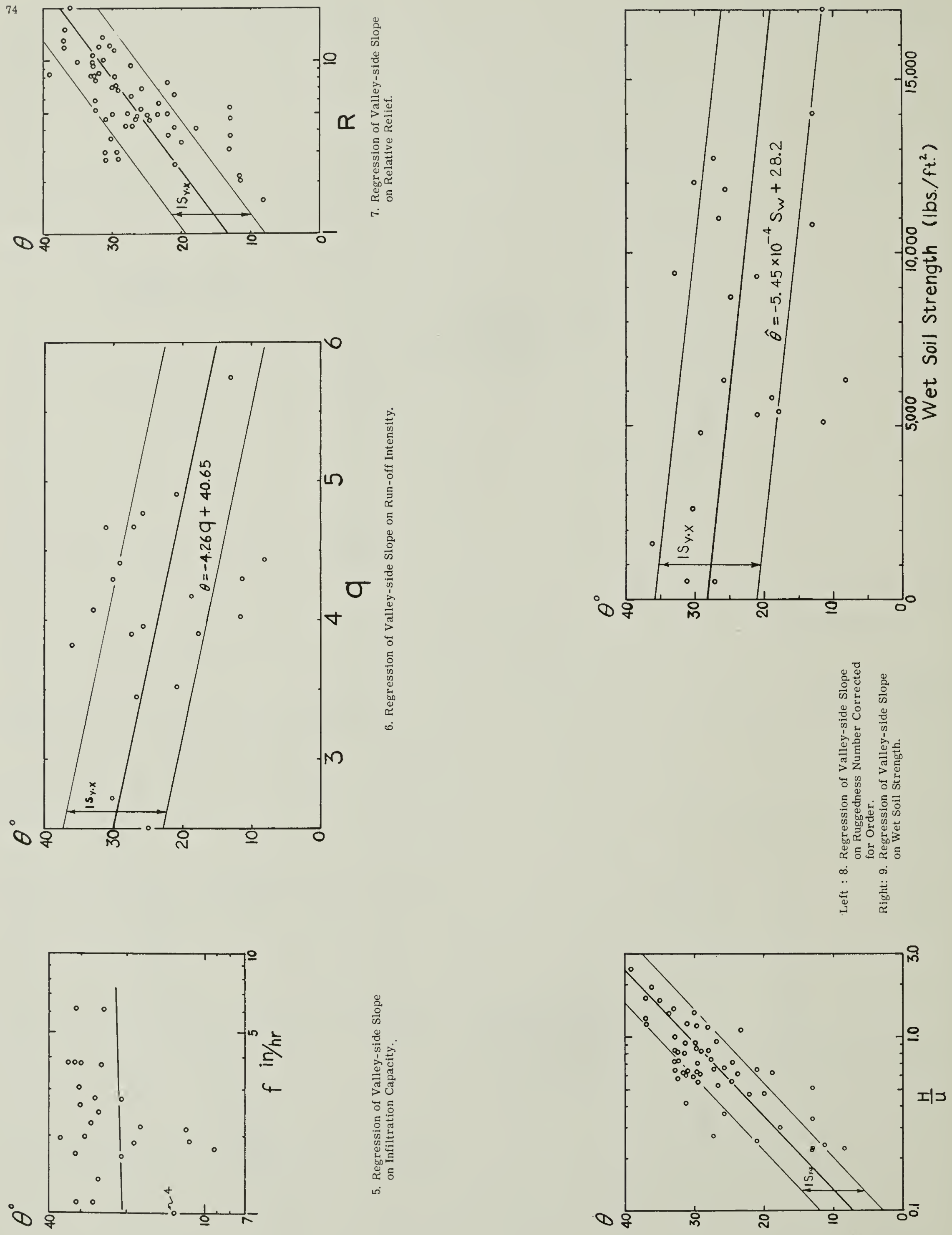


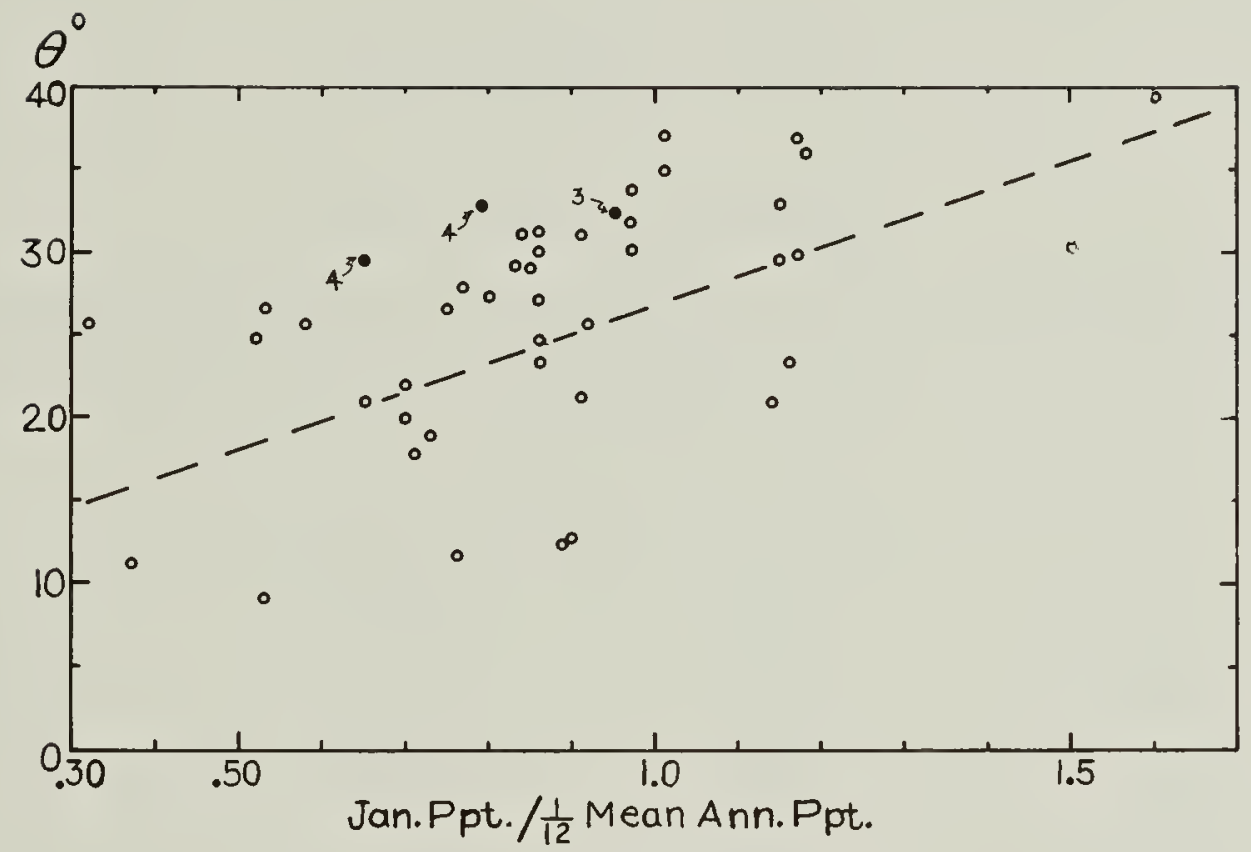

10. Regression of Valley-side Slope on Ratio of Mean January Precipitation to $1 / 12$ Mean Annual Precipitation.

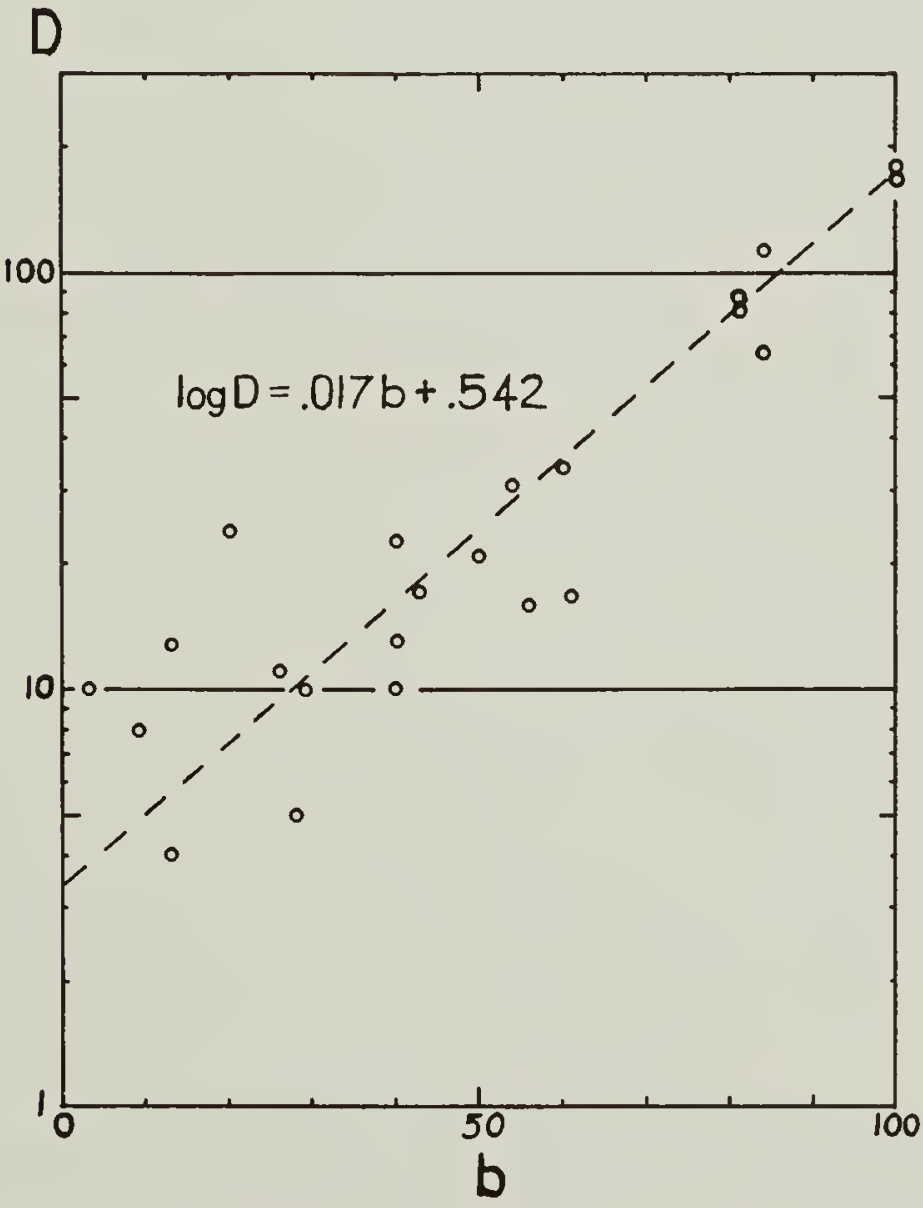

11. Regression of Drainage Density on Percent Bare Area. 


\section{Appendix VI A}

\section{ANALYSES OF VARIANCE}

Effect of lithology on drainage density: All fourth-order basins, and third-order basins if they are not included in a fourth-order basin are sources of data for this study.

\begin{tabular}{|c|c|c|c|c|c|}
\hline & & Drainage $\mathrm{D}$ & ies Groupe & thology & \\
\hline Shale & Clastic & Limestone & Schist & Granitic & Acid Volcanic \\
\hline 179.2 & 24.1 & 14.4 & 80.8 & 17.4 & 15.8 \\
\hline 171.2 & 20.6 & 10.0 & 86.6 & 19.5 & 14.1 \\
\hline 350.1 & 11.2 & $\overline{24.4}$ & 112.7 & 15.2 & 13.8 \\
\hline 350.4 & 13.1 & & 22.9 & 17.5 & 14.9 \\
\hline & 15.1 & $N=2$ & 10.4 & 16.4 & 14.4 \\
\hline $\mathrm{N}=2$ & 16.2 & & $\overline{313.4}$ & 11.0 & 9.9 \\
\hline & 12.8 & $\bar{X}=12.2$ & & 5.7 & 4.4 \\
\hline$X=175.2$ & 11.4 & & $N=5$ & 7.5 & 13.1 \\
\hline & 33.5 & & & 7.5 & 15.0 \\
\hline & 17.1 & & $\overline{\mathrm{X}}=62.7$ & 5.0 & 11.9 \\
\hline & 17.1 & & & 14.8 & 9.2 \\
\hline & 14.7 & & & 13.7 & 13.8 \\
\hline & 12.8 & & & 14.9 & 12.9 \\
\hline & 219.7 & & & 17.1 & 13.2 \\
\hline & 219.7 & & & 15.9 & 12.1 \\
\hline & $N=13$ & & & 36.9 & 11.2 \\
\hline & $N=13$ & & & 58.1 & 13.2 \\
\hline & $\overline{\mathrm{X}}=16.9$ & & & 39.3 & 12.6 \\
\hline & & & & 32.2 & 13.2 \\
\hline & & & & 39.9 & 13.1 \\
\hline & & & & 32.9 & 12.0 \\
\hline & & & & $\overline{438.4}$ & 12.3 \\
\hline & & & & $N=21$ & $\frac{10.4}{286.5}$ \\
\hline & & & & $\bar{X}=20.9$ & $N=23$ \\
\hline & & & & & $\overline{\mathrm{X}}=12.5$ \\
\hline
\end{tabular}




\begin{tabular}{lrrrrrrr} 
& $\mathrm{N}$ & \multicolumn{1}{c}{$\sum \mathrm{x}_{\mathrm{i}}$} & \multicolumn{1}{c}{$\overline{\mathrm{X}}$} & $\overline{\mathrm{X}}-\overline{\mathrm{X}} \ldots$ & $\sum \mathrm{X}_{\mathrm{i}}{ }^{2}$ & \multicolumn{1}{c}{$\left(\sum \mathrm{X}_{\mathrm{i}}\right)^{2} / \mathrm{N}$} & $\mathrm{s} 2$ \\
Shale & 2 & 350.4 & 175.2 & 150.5 & $61,422.08$ & $61,390.08$ & 32.00 \\
Schist & 5 & 313.4 & 62.7 & 37.9 & $27,362.06$ & $19,643.91$ & $1,929.54$ \\
Clastic & 13 & 219.7 & 16.9 & -7.8 & $4,173.47$ & $3,712.93$ & 38.38 \\
Granitic & 21 & 438.4 & 20.9 & -3.9 & $12,947.18$ & $9,152.12$ & 189.75 \\
Limestone & 2 & 24.4 & 12.2 & -12.5 & 307.36 & 297.68 & 9.68 \\
Acid Volcanic & 23 & 286.5 & 12.5 & -12.3 & $3,693.73$ & $3,568.79$ & 5.68 \\
\multicolumn{1}{c}{ Totals } & 66 & $1,632.8$ & -- & 151.9 & $109,905.88$ & $97,765.51$ & ---
\end{tabular}

Analysis-of-Variance Table

\begin{tabular}{lcrrr}
\hline Source of Variation & S. S. & d.f. & M. S. & F \\
\hline Among column means & $57,371.03$ & 5 & $11,474.21$ & 56.7 \\
Within columns & $12,140.37$ & 60 & 202.34 & \\
& & & & \\
\hline \multicolumn{1}{c}{ Total } & $69,511.40$ & 65 & $1,069.41$ & \\
\hline
\end{tabular}

$\mathrm{F} .01(5,60)=3.339$

Therefore, a significant difference among means of drainage density for each lithology exists at the .01 level of significance, and also at the .001 level.

Contrasts* judged significant at the .05 level:

(Granitic, clastic, volcanic, and limestone) vs.

(shale and schist) $(-97.97 \leq \theta \leq-58.85)$

Shale vs. Schist $(71.58 \leq \theta \leq 153.46)$

Contrasts judged not significant at the .05 level:

Clastic vs. granitic. $\quad(-21.24 \leq \Theta \leq 29.20)$

Limestone vs. granitic. $(-44.92 \leq \theta \leq 27.52)$

Limestone vs. volcanic. $(-35.33 \leq \mathrm{O} \leq 36.81)$

Clastic and granitic vs. limestone and volcanic

$(-5.98 \leq \Theta \leq 19.82)$

Effect of lithology on infiltration capacity: Individual measurements of infiltration capacity grouped according to lithology, regardless of basin or climate, are sources of data. (Individual infiltration measurements, grouped by basin, are given in Table 7.)

* A contrast is a difference in means or averages of means of several groups. In Scheffé's notation, the true (population) contrast is denoted by $\Theta$, and the estimated contrast calculated from sample data is denoted by $\hat{\Theta}$. His notation is used in this section, and must not be confused with the identical notation, $\Theta$, used for valley-side slopes in the previous sections. 


\begin{tabular}{|c|c|c|c|c|c|c|c|}
\hline & $\mathrm{N}$ & $\Sigma \mathrm{X}_{\mathrm{i}}$ & $\overline{\mathrm{X}}$ & $\bar{x}-\bar{x} \ldots$ & $\Sigma X_{i}^{2}$ & $\left(\Sigma \mathrm{x}_{\mathrm{i}}\right)^{2} / \mathrm{N}$ & $s^{2}$ \\
\hline Shale & 4 & 4.4 & 1.1 & -1.4 & 4.86 & 4.84 & 0.007 \\
\hline Schist & 7 & 10.7 & 1.5 & -1.0 & 19.53 & 16.36 & 0.53 \\
\hline Clastic & 53 & 106.1 & 2.0 & -0.5 & 257.07 & 212.40 & 0.86 \\
\hline Granitic & 52 & 173.7 & 3.3 & 0.8 & 744.01 & 580.22 & 3.21 \\
\hline Limestone & 8 & 24.4 & 3.0 & 0.5 & 96.00 & 74.42 & 3.08 \\
\hline Acid Volcanic & 17 & 37.8 & 2.2 & -0.3 & 100.22 & 84.05 & 1.01 \\
\hline Totals & 141 & 357.1 & & -1.9 & $1,221.69$ & 972.29 & \\
\hline
\end{tabular}

Analysis-of-Variance Table

\begin{tabular}{lcrrr}
\hline Source of Variation & S. S. & d.f. & M. S. & F \\
\hline Among column means & 67.89 & 5 & 13.58 & 7.43 \\
Within columns & 249.4 & 135 & 1.85 & \\
\hline Total & 317.29 & 140 & & \\
\hline F. $001(5,135)=4.42$. & & & &
\end{tabular}

A significant difference exists among the infiltration means for the various types of lithologies at the .001 level of significance.

The contrast (granitic and limestone) vs. (clastic and volcanic), formed from the groups with highest and intermediate infiltration capacities, was judged significant at the .05 level $(0.450 \leq \Theta \leq 2.042$, in Scheffé's notation). The contrast (clastic and volcanic) vs. (shale and schist), formed from the groups with intermediate and lowest infiltration capacities, was judged not significant at the .05 level $(-0.780 \leq \Theta \leq$ 2.160).

Effect of lithology on valley-side slope: Individual field measurements of slopes, separated according to lithologic type irrespective of basin boundaries, are sources of data.

\begin{tabular}{lrrrrrrr} 
& $\mathrm{N}$ & \multicolumn{1}{c}{$\sum \mathrm{X}_{\mathrm{i}}$} & \multicolumn{1}{c}{} & $\overline{\mathrm{X}}-\overline{\mathrm{X}} .$. & $\sum \mathrm{X}_{\mathrm{i}}{ }^{2}$ & $\left(\Sigma \mathrm{X}_{\mathrm{i}}\right)^{2} / \mathrm{N}$ & $\mathrm{s}^{2}$ \\
Shale & 82 & $2,390.2$ & 29.2 & 7.9 & $74,687.75$ & $69,671.41$ & 61.93 \\
Schist & 113 & $1,898.0$ & 16.8 & -4.4 & $38,135.50$ & $31,879.68$ & 55.85 \\
Clastic & 316 & $7,162.5$ & 22.7 & 1.5 & $193,572.75$ & $162,346.22$ & 99.13 \\
Granitic & 226 & $4,495.0$ & 19.9 & -1.3 & $149,979.00$ & $89,402.76$ & 269.22 \\
Limestone & 20 & 607.0 & 30.4 & 9.1 & $18,594.00$ & $18,422.45$ & 9.02 \\
Acid Volcanic & 123 & $2,128.0$ & 17.3 & -3.9 & $43,868.00$ & $36,816.13$ & 57.80 \\
\multicolumn{1}{c}{ Totals } & 880 & $18,680.7$ & & 8.9 & $518,837.00$ & $408,538.65$ &
\end{tabular}

Analysis-of-Variance Table

\begin{tabular}{crrrr}
\hline Source of Variation & \multicolumn{1}{c}{ S. S. } & d.f. & \multicolumn{1}{c}{ M. S. } & F \\
\hline Among groups & $11,983.48$ & 5 & $2,396.69$ & 18.99 \\
Within groups & $110,298.35$ & 874 & 126.19 & \\
\hline Total & $122,281.83$ & 879 & & \\
\hline F. ${ }_{011}(5, \infty)=4.10$. & & & &
\end{tabular}


A significant difference among the valley-side slope means for each lithology exists at the .001 level.

The contrast obtained from the four lithologies with most nearly similar slopes (granitic and clastic) vs. (schist and volcanic), is significantly different from zero at the .05 level $(1.91 \leq \theta \leq 7.75)$.

\section{Appendix VI B}

\section{DETERMINATION OF THE EFFECT OF GULLYING AND TRENCHING ON DRAINAGE DENSITY, BY THE ANALYSIS OF COVARIANCE}

Source of data: drainage density and mean infiltration capacity for each basin for which data on channel condition are available.

1

Channels trenched

$\begin{array}{cc}\mathrm{X}_{1} & \mathrm{Y}_{1} \\ \mathrm{f} & \log _{\mathrm{e}} \mathrm{D} \\ 3.05 & 2.303 \\ 1.99 & 2.306 \\ 2.23 & 3.131 \\ 1.35 & 3.026 \\ 1.88 & 3.447 \\ 1.90 & 3.512\end{array}$

Slopes gullied

$\begin{array}{cc}\mathrm{X}_{2} & \mathrm{Y}_{2} \\ \mathrm{f} & \log _{\mathrm{e}} \mathrm{D} \\ 2.60 & 3.183 \\ 2.75 & 1.609 \\ 1.65 & 2.798 \\ 1.95 & 2.550 \\ 1.70 & 2.839 \\ 1.00 & 4.392 \\ 1.00 & 4.462 \\ 1.00 & 4.727 \\ 1.00 & 4.180 \\ 1.78 & 2.839 \\ 16.43 & 33.579 \\ 1.64 & 3.358 \\ 10 & 10\end{array}$

3

Unmodified basins

$\begin{array}{cc}\mathrm{X}_{3} & \mathrm{Y}_{3} \\ \mathrm{f} & \log _{\mathrm{e}} \mathrm{D} \\ 2.74 & 3.428 \\ 1.10 & 5.142 \\ 2.44 & 2.292 \\ 3.70 & 2.015 \\ 1.10 & 5.187 \\ 2.15 & 2.550 \\ 2.10 & 1.482 \\ & \\ & \\ 15.33 & 22.096 \\ 2.19 & 3.156 \\ 7 & 7\end{array}$

$\begin{array}{ccccccc}\text { Total } & 12.4 & 17.725 & 16.43 & 33.579 & 15.33 & 22.096 \\ \text { Mean } & 2.07 & 2.954 & 1.64 & 3.358 & 2.19 & 3.156 \\ \mathrm{~N} & 6 & 6 & 10 & 10 & 7 & 7\end{array}$

$\sum \Sigma X_{i j}=44.16, \bar{X}_{. .}=1.92$.

$\sum \sum \mathrm{X}_{\mathrm{ij}}=73.400, \overline{\mathrm{Y}}_{. .}=3.191$.

$\mathrm{N}=23$.

$\Sigma \mathrm{X}_{\mathrm{i} 1}^{2}=27.20,\left(\Sigma \mathrm{X}_{\mathrm{i} 1}\right) \frac{2}{\mathrm{n}_{1}}=25.63, \Sigma \mathrm{X}_{\mathrm{il}} \mathrm{Y}_{\mathrm{il}}=35.83, \Sigma \mathrm{Y}_{\mathrm{il}}^{2}=53.80,\left(\Sigma \mathrm{Y}_{\mathrm{i} 1}\right)^{2} / \mathrm{n}_{1}=52.36$

$\Sigma \mathrm{X}_{\mathrm{i} 2}^{2}=30.91,\left(\Sigma \mathrm{X}_{\mathrm{i} 2}\right)^{2} / \mathrm{n}_{2}=26.99, \Sigma \mathrm{X}_{\mathrm{i} 2} \mathrm{Y}_{\mathrm{i} 2}=49.93, \Sigma \mathrm{Y}_{\mathrm{i} 2}^{2}=122,19,\left(\Sigma \mathrm{Y}_{\mathrm{i} 2}\right)^{2} / \mathrm{n}_{2}=112.75$.

$\Sigma \mathrm{X}_{\mathrm{i} 3}^{2}=38.60,\left(\Sigma \mathrm{X}_{\mathrm{i} 3}\right)^{2} / \mathrm{n}_{3}=33.57, \Sigma \mathrm{X}_{\mathrm{i} 3} \mathrm{Y}_{\mathrm{i} 3}=42.397, \Sigma \mathrm{Y}_{\mathrm{i} 3}^{2}=83.11,\left(\Sigma \mathrm{Y}_{\mathrm{i} 3}\right)^{2} / \mathrm{n}_{3}=69.75$.

$\Sigma \Sigma X_{i j}^{2}=96.71, \Sigma \Sigma Y_{i j}^{2}=259.10, \sum_{j}\left(\left(\sum_{i} X_{i j}\right)^{2} / n_{j}\right)=86.19, \sum_{j}\left(\left(\sum Y_{i j}\right)^{2} / n_{j}=234.86,\left(\sum \Sigma X_{i j}\right)^{2} / N=\right.$ 84.79, $\left(\Sigma \Sigma Y_{i j}\right)^{2} / N=234.24$.

Total sum of products $=-12.77$.

Within-groups sum of products $=-12.03$.

Among-means sum of products $=-0.74$.

Total sum of squares: for X's 11.92, for Y's 24.86.

Among-means sum of squares: for X's 1.4, for Y's 0.42 .

Within-groups sum of squares: for X's 10.52, for Y's 24.44 . 
Sum of squares about the regression line:

$$
\begin{aligned}
& \text { Total S. S. }=24.86-\frac{(-12.77)^{2}}{11.92}=11.18 \\
& \text { Within-groups S. S. }=24.44-\frac{(-12.03)^{2}}{10.52}=10.68 .
\end{aligned}
$$

The dispersion of the $\mathrm{Y}$ values about the regression line with the coefficient $b_{t}$ (total) is therefore 11.18. The dispersion of the $\mathrm{Y}$ values about the regression line with coefficient $\mathrm{b}_{\mathrm{w}}$ (within) is therefore 10.68. The reduction in dispersion is 0.50 , attributable to dispersion of the means. The low value of $\mathrm{F}$ signifies that the reduction is not great enough to be judged significant.

$$
\text { Analysis-of-Covariance Table }
$$

\begin{tabular}{crrrrrrrr}
\hline Source of Variation & d.f. & $\sum \mathrm{x}^{2}$ & $\sum \mathrm{xy}$ & $\sum \mathrm{y}^{2}$ & d.f. & $\sum \mathrm{y}^{\prime 2}$ & M.S. & $\mathrm{F}$ \\
\hline Among means & 2 & 1.4 & -0.74 & 0.42 & 2 & 0.50 & 0.25 & 0.45 \\
Within groups & 20 & 10.5 & -12.03 & 24.44 & 19 & 10.68 & 0.56 & \\
\hline Total & 22 & 11.9 & -12.77 & 24.86 & 21 & 11.18 & & \\
\hline
\end{tabular}




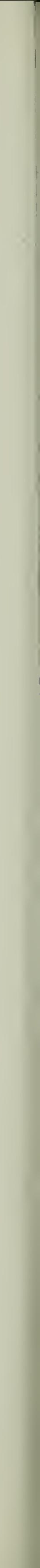




\section{Appendix VII}

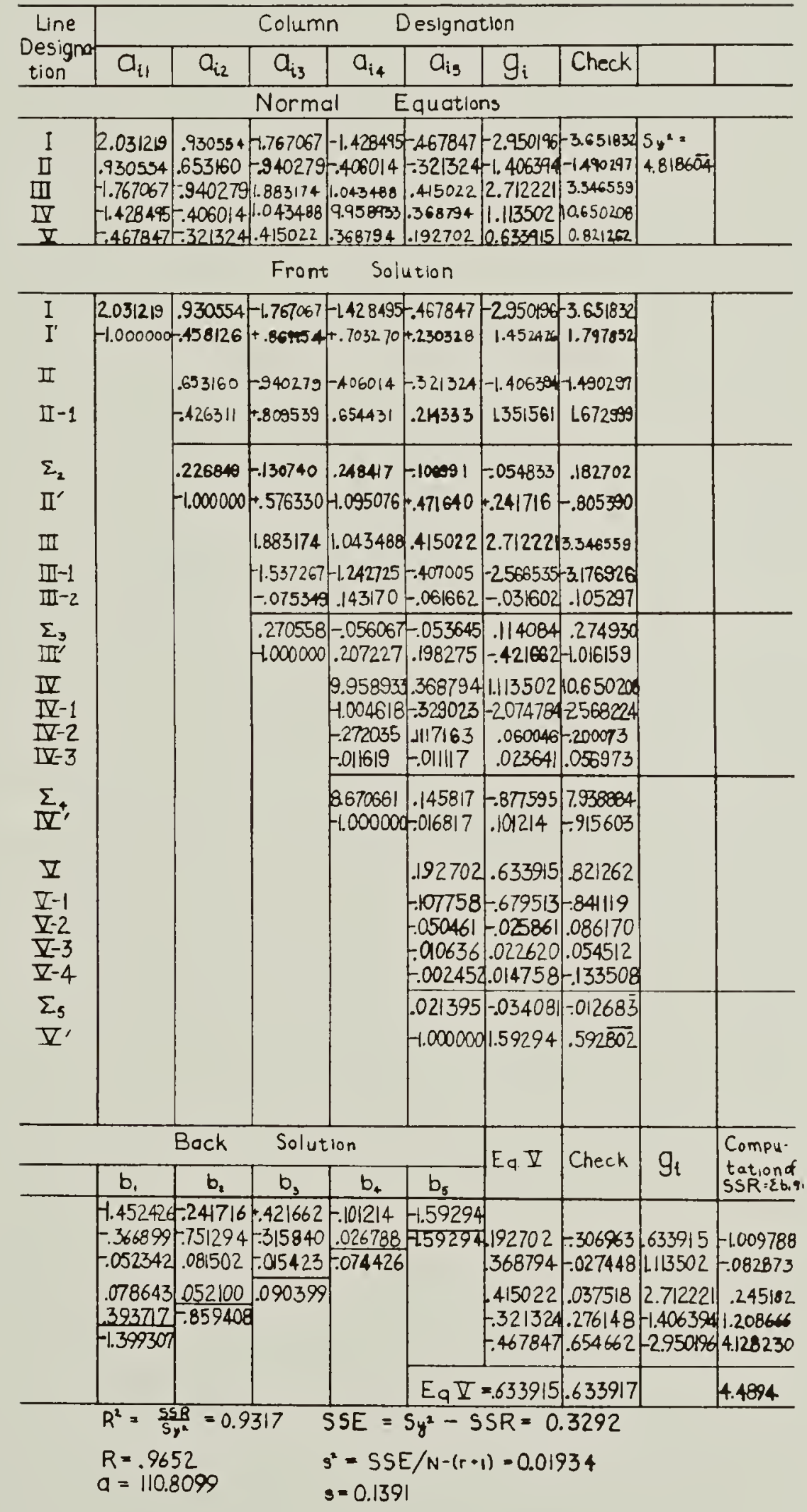

Solution of Normal Equations Relating Drainage Density to Soil Properties and Climate Elements by the Doolittle Method. 

Tables 
TABLE 1

DE FINITIONS OF SYMBOLS

A. Measurements from maps.

Units

Miles

Miles

Miles

Feet

Feet

Square miles

Enumerative

Enumerative

Enumerative

Enumerative

Degrees

Degrees
Dimensions

L

L

$\mathrm{L}$

$\mathrm{L}$

$\mathrm{L}$

$\mathrm{L}^{2}$

0

0

0

0

0

0

B. Quantities derived from map measurements.

D Drainage density, $\frac{\sum l_{\mathrm{u}}}{\mathrm{a}}$;

Miles

$\overline{\text { Sq. miles }}$

$\mathrm{L}^{-1}$

$D_{1}$ Density of first-order channels, $\frac{l_{1}}{a}$;

Miles

Sq. miles

$\mathrm{L}^{-1}$

F Stream frequency, $\frac{\Sigma \mathrm{n}_{u}}{\mathrm{a}}$;

$\frac{\text { Number }}{\text { Sq. miles }}$

$\mathrm{L}^{-2}$

$F_{u}$ Frequency of $u^{\prime}$ th order $\frac{n_{u}}{a}$;

$\frac{\text { Number }}{\text { Sq. miles }}$

$\mathrm{L}^{-2}$

H Ruggedness number, $\frac{D \cdot r}{5280}$;

0

R Relative relief, $\frac{100 \mathrm{r}}{5280 \mathrm{p}}$;

0

P Ratio of channel lengths to perimeter, $\frac{\sum l_{u}}{p}$;

0

C Circularity of basin $\frac{a}{\text { area circle with same } \mathrm{p}}$;

0

$\mathrm{B}_{\mathrm{u}: \mathrm{u}+1}$ Bifurcation ratio, $\frac{\mathrm{n}_{\mathrm{u}}}{\mathrm{n}_{\mathrm{u}+1}}$

0

$\mathrm{L}_{\mathrm{u}: \mathrm{u}-1} \quad$ Length ratio, $\frac{\overline{\mathrm{l}}_{\mathrm{u}}}{\overline{\mathrm{l}}_{\mathrm{u}-1}}$ 
$\Theta \quad$ Maximum valley-side slopes;

$\zeta \quad$ Dihedral angle between valley sides;

$\gamma \quad$ Gradient of stream channel;

C. Field measurements.

f Infiltration capacity of soil;

s Strength of soil under instantaneous impact;

b Percent of area that is bare of all cover;

c Number of rock fragments in a circle of one foot radius;

m Average mid-diameter of rock fragments;

M Roughness number, average of total length of pebble diameters for each one-foot circle in a basin;

$\Theta \quad$ Maximum valley-side slopes;

D. Climatic Data.

P Mean precipitation, either monthly or annual;

$\mathrm{T}$ Monthly average mean daily temperatures;

I Precipitation-Effectiveness index;

q Runoff intensity: 5-year, 1-hour rainfall amountinfiltration capacity +5 ;
Degrees 0

Degrees 0

Degrees 0
Inches $/ \mathrm{hr} . \quad \mathrm{L} \mathrm{T}^{-1}$

Lbs./sq. ft.

Percent

$M \mathrm{~L}^{-1} \mathrm{~T}^{-2}$

0

Enumerative 0

Inches

L

Inches

L

Degrees

0

$\begin{array}{cc}\text { Inches } & \text { L } \\ \text { Degrees } & \theta \\ - & 0\end{array}$

Inches $/ \mathrm{hr}$.
L

$\theta$

0

$\mathrm{LT}^{-1}$ 


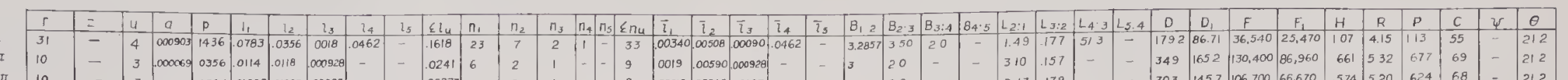

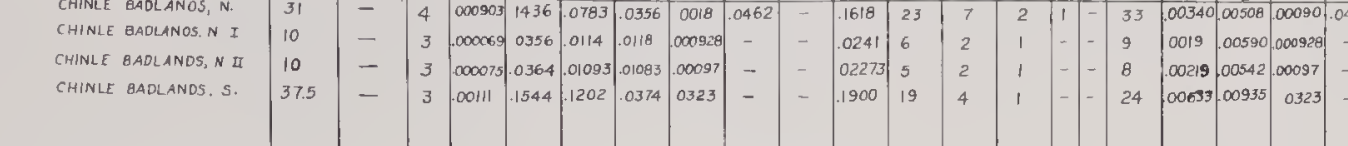

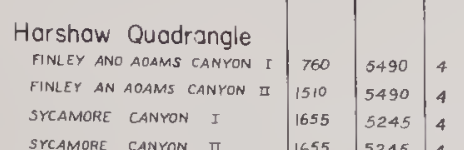

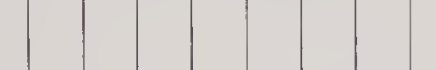

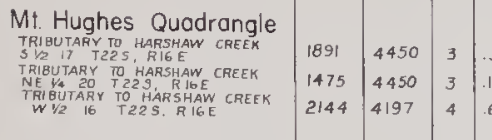

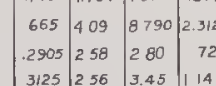

Prescelt oudronge

WHAPPLE BASIN
WHIPPRE
I

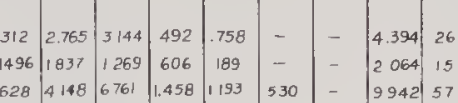

Sanoita Quadrongte

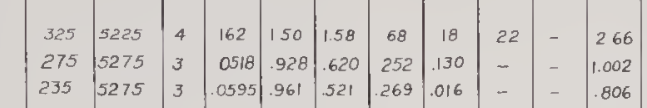

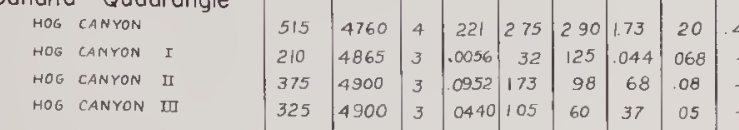

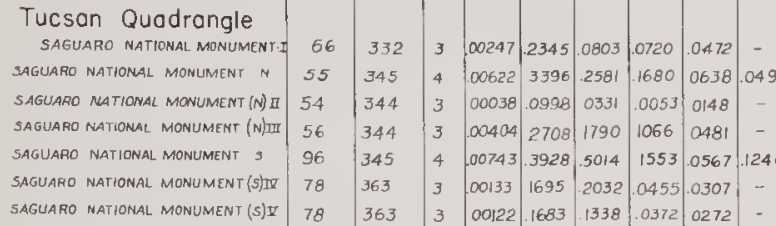

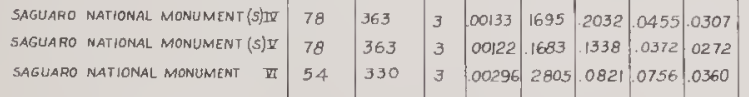

Bilock HaLORADO Quadro

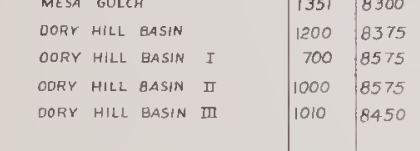

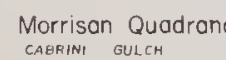

Nederland Quadran

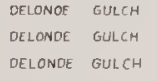

$=$

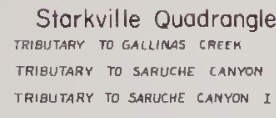

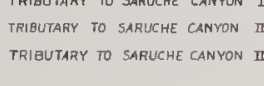

NEW MEXICO

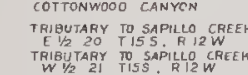

Big Burro Mountioins
Quadrongle

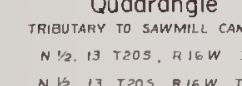

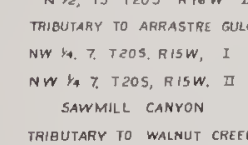

Blond Quadrangle

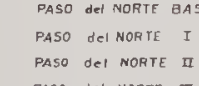

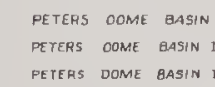

Cerro del Gront Quadrang
GERPo PAvo BAsin

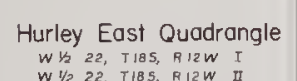

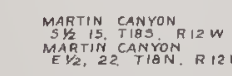

Jarosa Quodrangle

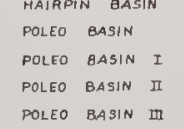

Paxton Springs Quoorangle

$$
\text { 䔩童 }
$$

TANO AASIN
TANO BASIN
Sedillo OWI

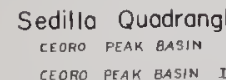

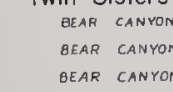

$=$

$\equiv$

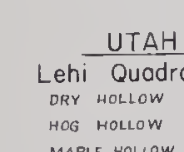
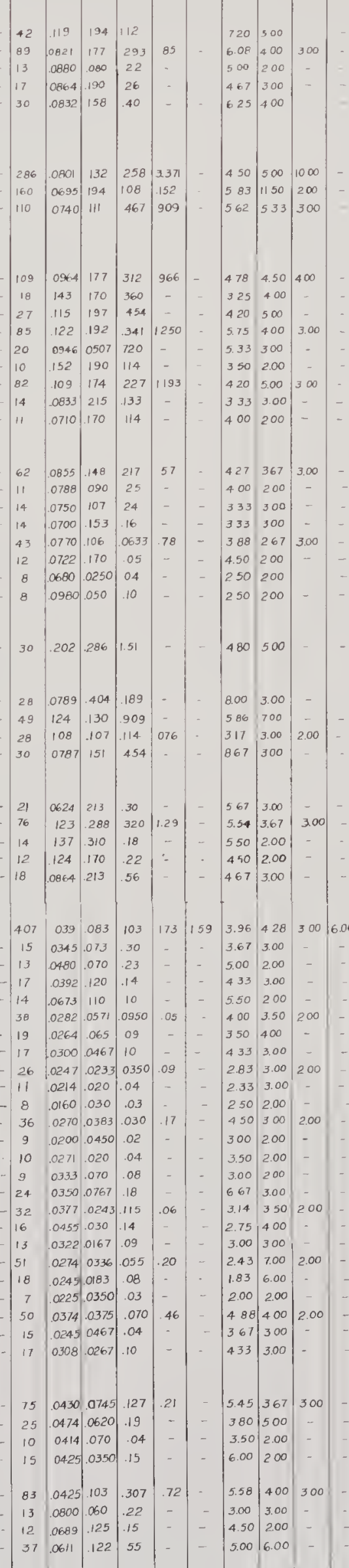

5.86
560
500
600

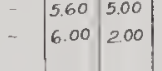

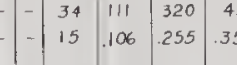

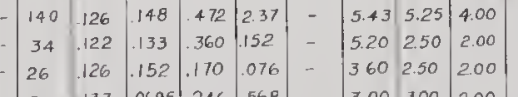

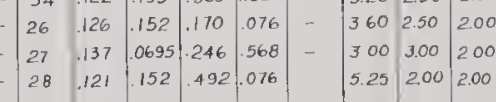

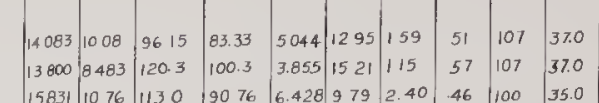

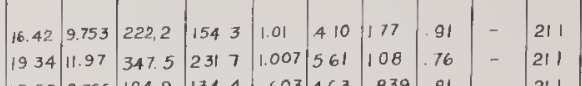

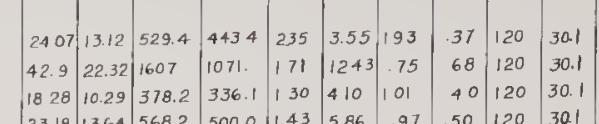

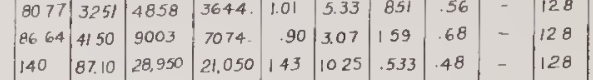

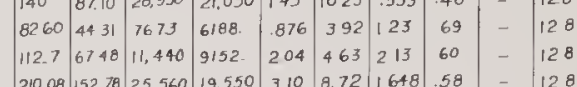

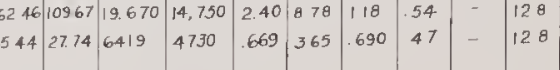

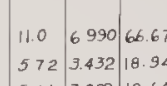

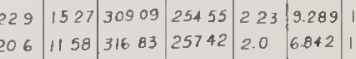

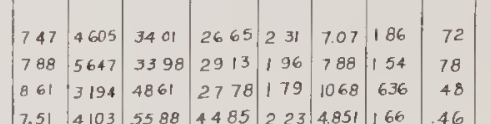

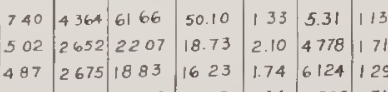

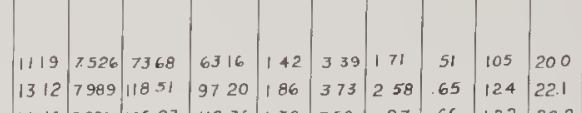

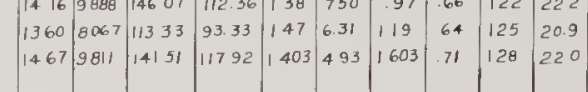

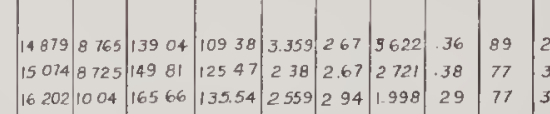

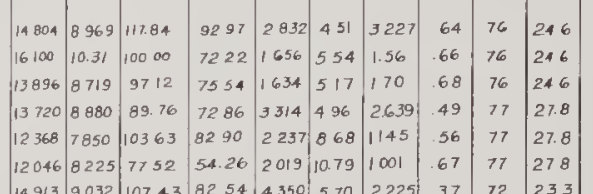

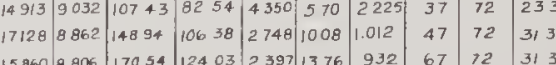

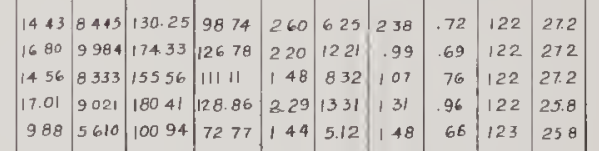

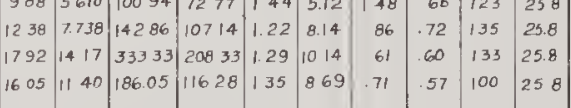

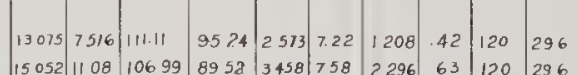
$5 / 187989.14180064120296$

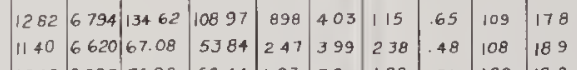

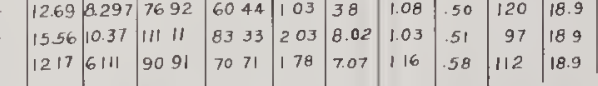

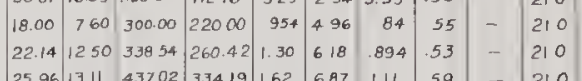

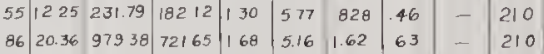

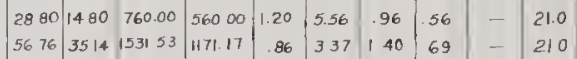

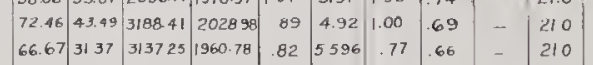

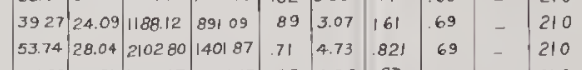

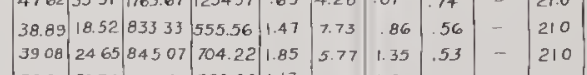

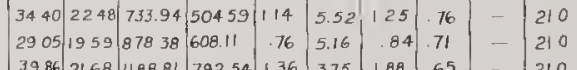

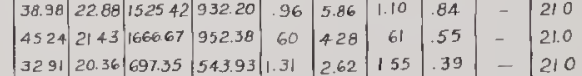

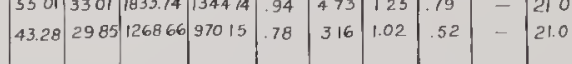

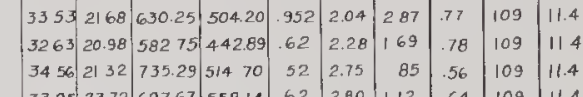

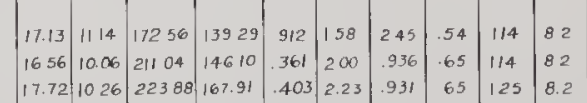

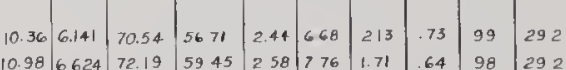

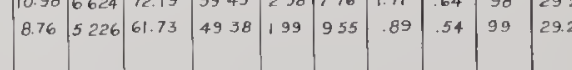

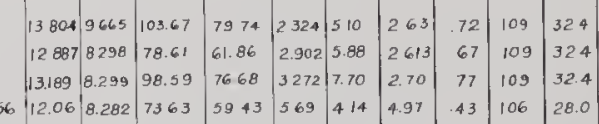

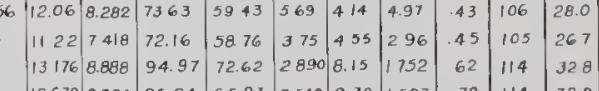

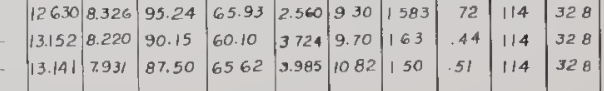



TABLE 3

\section{VEGETATION CHARACTERISTICS}

Quadrangle and Basin Range of Elevation
Measured

Vegetation Species

Bare Area(\%)

Life Zone(s)

ARIZONA

Chinle Badlands about 4000

No vegetation.

100

Upper Sonoran

Harshaw Quadrangle Finley and Adams

Canyon

$7000-5490$

and

Sycamore Canyon 6900-5245

Mt. Hughes Quadrangle

Tributaries to

Harshaw Creek 6341-4200

\section{Prescott Quadrangle Whipple Basin $5550-5225$}

\section{Sonoita Quadrangle \\ Tributary to \\ Hog Canyon $5275-4760$}

Tucson Quadrangle Saguaro National Monument about 2800

\section{COLORADO}

Black Hawk Quadrangle Mesa Gulch and Dory Hill Basin 9651-8300

Morrison Quadrangle Cabrini Gulch $7165-6650$

\section{Green Mountain Basin 6603-6090}

Nederland Quadrangle Delonde Gulch $10215-8580$

South-facing: shrub live oak chaparral, manzanita.

North-facing: emory oak, silverleaf oak, netleaf oak, Arizona white oak, alligator juniper, manzanita, madrone, Mexican pinon, Mexican blue oak, abundant grass.

Below 4800: catclaw acacia.

4800-5800: shrub live oak chaparral, manzanita, ocotilla, yucca.

Above 5800: Mexican blue oak, Arizona white oak, alligator juniper, Mexican pinon.

Arizona white oak, shrub live oak, one-seed juniper, alligator juniper, hairy mountain mahogany, singleleaf pinon, ponderosa pine (small), cliffrose, cholla.

South-facing: mainly grass.

North-facing: emory oak, Arizona white oak, Mexican blue oak, century plant, jumping cholla, manzanita, alligator juniper.

Saguaro, mesquite, paloverde, ocotilla, jumping cholla, staghorn cholla, creosote bush, prickly pear, fishhook barrel cactus, brittle bush, Christmas cactus, sparse bunch grass.

Lodgepole pine, blue spruce, Douglas-fir .

$-$

Canadian

Grass, sage, yucca, poison ivy, wild rose, juniper, prickly pear, chokecherry, hairy mountain mahogany, gooseberry, bigtooth maple, barrel cactus, Russian thistle.

Birchleaf mountain mahogany, prickly pear, grass, sage, yucca, common chokecherry (on north slopes and gullies), barrel cactus, sunflowers, gooseberry.

Aspen, lodgepole pine, ponderosa pine, limber pine, white fir, blue spruce, mountain common juniper, grass, Douglas-fir, willows.

Canadian to Hudsonian
Upper Sonoran

Upper Sonoran

Lower Sonoran Upper Sonoran

Upper Sonoran

Upper Sonoran

Lower Sonoran Upper Sonoran

Lower Sonoran

Upper Sonoran 
TABLE $3(2)$

Quadrangle and Basin

COLORADO

Hicks Gulch
$10210-8640$

Moon Gulch 10625-8415

Starkville Quadrangle

Tributaries to

Gallinas Creek 7590-6920 and

Tributaries to

Saruche Canyon $7625-6875$

\section{NEW MEXICO}

Big Burro Mountains Quadrangle

Tributaries to

Sawmill Canyon $7755-6745$

Tributary to Arrastre Gulch 8035-6745 and

Sawmill Canyon $7820-6280$

Tributaries to

Walnut Creek 8035-7188

Bland Quadrangle

Paso del Norte

Basin $9470-8520$ and

Peters Dome Basin $8460-7690$

\section{Cerro del Grant Quadrangle \\ Cerro Pavo Basin 10310-9460 \\ Jarosa Quadrangle \\ Hairpin Basin $8665-8295$ \\ Poleo Basin 9183-8038}

Aspen, lodgepole pine, ponderosa pine, limber pine, white fir, blue spruce, mountain common juniper, grass, Douglas-fir, willows.

Lodgepole pine, limber pine, white fir, blue spruce, aspen, mountain common juniper, sage, bunch grass, kinnikinnik.

Pinon-juniper woodland.

Shrub live oak, Gambel oak, alligator juniper, ponderosa pine, yucca, barrel cactus, bunch grass, prickly pear, cholla, Douglas-fir. South-facing: shrub live oak chaparral. North-facing: ponderosa-pine forest.

South-facing: shrub live oak chaparral, Gambel oak, alligator juniper, yucca, barrel cactus, bunch grass, prickly pear, cholla.

North-facing: ponderosa pine, Douglas-fir, shrub live oak, Gambel oak, alligator juniper.

Ponderosa pine, shrub live oak, Gambel oak, Douglas-fir, walnut, alligator juniper, prickly pear, bunch grass, cholla.

Ponderosa pine, shrub Gambel oak, white fir, Douglas-fir, aspen, Rocky Mountain juniper, pinon, limber pine, wavy leaf oak, grass.

North-facing: ponderosa-pine and lower Douglasfir forest.

South-facing: ponderosa-pine forest.

Blue spruce, Douglas-fir, white fir, Engelmann spruce, ponderosa pine, mountain common juniper, one-seed juniper, aspen, grass, alpine fir.

Ponderosa pine, shrub Gambel oak, aspen, white fir, birchleaf mountain mahogany, pinon, locust, grass.

Ponderosa pine, shrub Gambel oak, aspen, white fir, Douglas-fir, Rocky Mountain juniper, birchleaf mountain mahogany, mountain common juniper, pinon.
Canadian to Hudsonian

Canadian to Hudsonian

Upper Sonoran

Transition

Upper Sonoran to Transition

Transition

Canadian

Transition to Canadian

13.2

Canadian to Hudsonian

Transition

Transition to Canadian 
TABLE 3 (3)

Quadrangle and Basin

Measured

Range of Elevation

Vegetation Species

Bare Area(\%)

Life Zone(s)

\section{NEW MEXICO}

Paxton Springs Quadrangle

Quartz Hill Basin $8033-7480$

Santa Fe Quadrangle

Camino Basin 6890-6740

Tano Basin 7331-7050

Sedillo Quadrangle Cedro Peak Basin 7767-6525

Twin Sisters Quadrangle

Wilson Creek 8020-6862

\section{UTAH}

Lehi Quadrangle

Dry Hollow
$6682-5340$

Hog Hollow 6350-5135

Maple Hollow 6682-5095

Mercer Hollow 6350-5120

Springville Quadrangle

Deadmans Hollow $6250-4960$

Spring Creek 9325-6050

Tributary to Hobble Creek $7320-4920$

*Indicates estimate
Ponderosa pine, pinon, one-seed juniper, Rocky Mountain juniper, wavy leaf oak, Gambel oak, yucca, grass, mountain mahogany.

Pinon, one-seed juniper, rabbit brush, prickly pear, yucca, cholla, grass.

Pinon, one-seed juniper, prickly pear, grass, rabbit brush, yucca, hairy mountain mahogany.

Pinon, one-seed juniper, wavy leaf oak, Gambel oak (shrubs and small trees), Rocky Mountain juniper, cholla, prickly pear, birchleaf mountain mahogany, rabbit brush, yucca, grass, (small) barrel cactus, Russian thistle.

North-facing: ponderosa pine and alligator juniper.

South-facing: juniper-Gambel oak woodland, bunch grass.

Shrub Gambel oak, sage, bigtooth maple, grass, prickly pear, cliffrose, birchleaf mountain mahogany .

Gambel oak, bigtooth maple.

Gambel oak, bigtooth maple.

Gambel oak, bigtooth maple.

Gambel oak (small trees and shrubs), sparse bunch grass, sage. Northslopes; bigtooth maple, netleaf hackberry.

Gambel oak (trees and shrubs), bigtooth maple (trees and bushes), aspen, common chokecherry, curleaf and birchleaf mountain mahogany, bunch grass, Utah serviceberry.

Gambel oak (small trees and shrubs) sparse bunch grass, sage, Northeast slopes: bigtooth maple, netleaf hackberry.
54.1

Transition

60

Upper Sonoran

60.8

Upper Sonoran

39.6

Upper Sonoran

Transition

Upper Sonoran

Transition

Transition

Transition

Upper Sonoran to Transition

28.9

Transition

$40 *$
Upper Sonoran to Transition 
SOIL AND SURFACE PROPERTIES

\begin{tabular}{|c|c|c|c|c|}
\hline $\begin{array}{c}\text { State, Quadrangle, } \\
\text { Basin }\end{array}$ & $\begin{array}{c}\text { Infiltration } \\
\text { Capacity, } \\
\text { Inches/hr. }\end{array}$ & $\begin{array}{l}\text { Soil Strength, } \\
\text { lbs./sq.ft. } \\
\text { Wet Dry }\end{array}$ & Soil Description ${ }^{a}$ & $\begin{array}{l}\text { Roughness } \\
\text { Number, } \\
\text { Inches }\end{array}$ \\
\hline
\end{tabular}

\section{ARIZONA}

\section{Cameron}

Chinle Badlands

$$
\text { North }
$$

Chinle Badlands South

1.1

500

15,600

1.1

500

16,960

Harshaw Quadrangle

Finley and Adams

Canyon

Prescott Quadrangle

Whipple Basin

1.65

9270

$24,900^{\mathrm{b}}$

$12,000 \quad 46,300$

2.6

Tucson Quadrangle

\section{Saguaro National \\ Monument, North}

Saguaro National

Monument, South

\section{COLORADO}

Morrison Quadrangle

Cabrini Gulch

Green Mountain

Basin
2.23

$12,667 \quad 80,400$

1.35

$11,800 \quad 66,300$
1.0

$14,000 \quad 44,300$

$10,750 \quad 54,300$
Blue-gray silt and clay,

3.99

trace coarse to fine sand;

very plastic.

0

Sieve analysis: $91.1 \%$ sand median at $.373 \mathrm{~mm}$. Coarse to fine $(+)$ sand, little medium to fine $(+)$ gravel, trace (+) silt.

Coarse to fine $(+)$ sand, trace coarse to fine gravel, trace silt. Residual granite soil.

Coarse to fine sand $88 \%$, little(-) fine gravel, trace

45.9 silt.

Angular coarse to fine sand, little $(+)$ medium to fine gravel, trace $(+)$ silt and clay.

Angular coarse to fine sand, little medium to fine gravel, trace $(+)$ silt and clay.

Coarse to fine sand and silt, little medium to fine gravel.

Coarse to fine sand, little silt, trace $(+)$ medium to fine gravel.
16.9

83.5

94.2

${ }^{\text {a }}$ Average soil descriptions for all infiltrometer test plats within each basin.

$\mathrm{b}_{\text {Moist soil. }}$ 
TABLE 4 (2)

State, Quadrangle, Basin

Infiltration

Capacity,

Soil Strength, 1bs./sq.ft.

Inches/hr.

Wet Dry

Soil Description

Roughness

Number, Inches

\section{COLORADO}

Nederland Quadrangle

Hicks Gulch

Moon Gulch

\section{NEW MEXICO}

\section{Bland Quadrangle}

Peters Dome Basin

Cerro del Grant Quadrangle

Cerro Pavo Basin

\section{$\underline{\text { Jarosa Quadrangle }}$}

Hairpin Basin

Poleo Basin

Paxton Springs

Quadrangle

Quartz Hill Basin

\section{Santa Fe Quadrangle}

Camino Basin

1.9

$5,112 \quad 32,500$

1.78

$6,300 \quad 17,000$

Tano Basin

Sedillo Quadrangle

Cedro Peak Basin

3.7

8,700

15,900

$11,000 \quad 27,450$

$6,330 \quad 21,300$

$17,000 \quad 69,800$

$5,420 \quad 30,400$

$5,790 \quad 43,300$

$5,330 \quad 18,600$
Coarse to fine sand, some medium to fine gravel, trace (+) silt and clay. (Residual granite soil.)

Coarse to fine sand and silt, little fine gravel.

16.46 silt, little medium to fine gravel. (Residual soil.)

Coarse to fine sand, little medium to fine gravel, little silt. (Residual soil.)

31.4

Sand and silt, $\operatorname{trace}(+)$ fine

1.29 gravel.

Coarse to fine(+) sand and silt.

Coarse to fine sand, and silt, little medium to fine gravel.

2.90

Coarse to fine sand, little silt, little medium to fine rounded gravel.

Coarse to fine sand, some $(-)$ silt, trace $(+)$ medium to fine gravel.

Coarse to fine sand, little silt and clay, trace (+) med28.4 
TABLE 4 (3)

State, Quadrangle, Basin

Infiltration

Capacity, Inches $/ \mathrm{hr}$.
Soil Strength,

lbs./sq.ft. Wet Dry

Soil Description
Roughness

Number,

Inches

\section{UTAH}

Lehi Quadrangle

Dry Hollow

1.70

$9,400 \quad 30,200$

Fine sand, some silt and

66.3

Springville Quadrangle

Spring Creek

3.05

2,650

26,200

Coarse to fine sand, and silt

Tributary to

Hobble Creek

Fine sand, and silt and clay,

52.48 little(-) medium to fine gravel. 
TABLE 5

\section{SUMMARY OF CLIMATIC DATA}

A: Average number of days per year with rain.

B: $\mathrm{P}-\mathrm{E}$ index.

C: 5-year 1-hour rain, in inches.

D: January precipitation in terms of $1 / 12$ mean annual precipitation.

$\mathrm{E}$ : Average length of growing season.

F: Elevation of station.

* Indicates estimate.

State, Region, Station
Mean Annual Precipitation
Mean Annual

Temperature
A

B
C

D
$\mathrm{E}$

F

\section{ARIZONA}

\section{North Central}

Prescott

Northeast

Tuba City

Wupatki

National Monument

Southeast

Benson

Canelo RS

Crown C Ranch

Ft. Huachuca

Pantano-Vail

Rosemont

Santa Rita

Exp. Range

Tucson Magnetic

Observatory

\section{COLORADO}

\section{North Central}

$\begin{array}{ll}\text { Allenspark } & 22.31 \\ \text { Boulder } & 18.88 \\ \text { Denver } & 13.43 \\ \text { Edgewater } & 16.17 \\ \text { Frances } & 25.02 \\ \text { Golden } & 18.61 \\ \text { Gold Hill } & 25.56 \\ \text { Hawthorne } & 21.21 \\ \text { Idaho Springs } & 15.27 \\ \text { Longs Peak } & 21.51 \\ \text { Morrison } & 18.14 \\ \text { Mt. Morrison } & 15.69 \\ \text { Silver Lake } & 28.17\end{array}$

South Central

Madrid

Mule Shoe Lodge

North Lake

Stonewall

Tercio

Trinidad AP

Trinidad CY
18.61

6.88

7.78

10.63

18.96

16.08

16.96

11.65

17.73

19.73

10.98

16.17

25.02

21.21

15.27

18.14

15.69

28.17

14.75

16.94

21.34

17.97

17.21

14.02

16.20
52.9

55.1

57.5

63.8

58.5

61.4

66.6

$-$

63.8

66.8
39.3

1.57

1.14

143

5700

12.8

11.0

.77

.95

179

4936

$50 *$

.77

.71

180

4908

8

35
71
$55^{*}$
49
26
45
58

-
30.4
$23.6^{*}$
25.6
15.4
-
-

1.40

1.54

1.82

1.54

1.68

1.82

1.96

$50 * \quad 14.6$

1.75

.64
.78

.84

.94

.89

.91

.99

225

180

210

232

286

227

210

$.92 \quad 240$

3500

5000

4775

5100

3300

4800

4300

2526

$\begin{array}{rcccccr}40.3 & 80^{*} & 71.5 & .84 & .67 & 90 & 8500 \\ 50.9 & 74 & - & 1.54 & .48 & 161 & 5404 \\ 50.1 & 85 & 30.0 & 1.19 & .45 & 171 & 5221 \\ 50.0 & 65 & - & 1.26 & .27 & 146 & 5450 \\ 39.9 & 132 & 82.2 & 1.05 & .53 & 108 & 9300 \\ - & 80^{*} & - & 1.26 & .34 & - & 5799 \\ - & 90^{*} & - & 1.26 & .51 & 139 & 8630 \\ - & 78 & - & 1.54 & .49 & 120 & 5923 \\ 43.2 & 78 & - & .98 & .29 & 125 & 7543 \\ 37.6 & 89 & 78.3 & .81 & .48 & 59 & 9000 \\ 47.8^{*} & 52 & 40.3^{*} & 1.33 & .30 & - & 6120 \\ - & - & - & 1.09 & .99 & - & 6000 \\ 29.3^{*} & 94 & 128.0^{*} & .84 & .80 & 30 & 10200 \\ & & & & & & \\ 49.5^{*} & 81 & 27.6 * & 1.54 & .17 & 130 & 6364 \\ - & - & - & 1.33 & 1.24 & 130 & 8800 \\ - & 88 & - & - & .56 & - & 8800 \\ - & 81 & - & 1.40 & .13 & 110 & 8000 \\ - & - & - & 1.26 & .66 & 100 & 8040 \\ 50.8 & 55 & - & 1.65 & .42 & 142 & 5746 \\ 51.4 & 69 & 29.8 & 1.65 & .47 & 167 & 6030\end{array}$


TABLE 5 (2)

\begin{tabular}{|c|c|c|c|c|c|c|c|c|}
\hline $\begin{array}{l}\text { State, Region, } \\
\text { Station }\end{array}$ & $\begin{array}{l}\text { Mean Annual } \\
\text { Precipitation }\end{array}$ & $\begin{array}{l}\text { Mean Annual } \\
\text { Temperature }\end{array}$ & A & $\mathrm{B}$ & $\mathrm{C}$ & $\mathrm{D}$ & $\mathrm{E}$ & $\mathrm{F}$ \\
\hline \multicolumn{9}{|l|}{ COLORADO } \\
\hline $\begin{array}{c}\text { Lake Maloya, } \\
\text { New Mexico }\end{array}$ & 21.77 & 49.16 & - & 52.4 & - & .51 & 140 & 7400 \\
\hline \multicolumn{9}{|l|}{ NEW MEXICO } \\
\hline \multicolumn{9}{|l|}{ Northern Rio Grande } \\
\hline Aspen Grove Ranch & 23.61 & $38.17^{*}$ & 92 & $97.2^{*}$ & - & .85 & 104 & 9500 \\
\hline Bandelier & 15.60 & 50.22 & 45 & 31.2 & 1.40 & .54 & - & 6061 \\
\hline Bland & 19.08 & - & 79 & - & 1.40 & .75 & - & 7050 \\
\hline Capulin RS & 15.94 & 45.96 & - & 31.05 & 1.05 & .31 & 143 & 7200 \\
\hline Edgewood & 11.08 & - & - & - & - & .55 & - & 6800 \\
\hline Lazy Ray Ranch & 18.70 & - & - & - & - & 1.12 & - & 8172 \\
\hline Lee Ranch & 22.45 & 38.9 & 50 & 69.9 & - & .36 & 98 & 9000 \\
\hline Los Alamos & 18.32 & 47.7 & 73 & 78.9 & 1.40 & .59 & 168 & 7324 \\
\hline Otto AP & 11.58 & 49.2 & - & 21.5 & 1.36 & .47 & 120 & 6226 \\
\hline Red River & 22.04 & 39.9 & 94 & 77.5 & - & .71 & 88 & 8956 \\
\hline Sandia Park & 19.20 & 48.9 & - & 43.5 & - & .89 & - & 7011 \\
\hline Santa Fe AP & 10.80 & 50.4 & - & 19.1 & 1.13 & .36 & - & 6312 \\
\hline Santa $\mathrm{Fe} \mathrm{CY}$ & 14.29 & 49.1 & 86 & 26.3 & 1.12 & .53 & 178 & 7045 \\
\hline Tijeras RS & 14.57 & 49.1 & 63 & 32.4 & 1.47 & .83 & 136 & 6300 \\
\hline Wolf Canyon & 22.35 & 39.79 & - & 80.5 & - & .83 & - & 8150 \\
\hline Albuquerque $\mathrm{CY}$ & 9.05 & 55.8 & 47 & 11.3 & .95 & .51 & 198 & 5130 \\
\hline Albuquerque AP & 8.48 & 56.6 & - & - & .98 & .39 & - & 5310 \\
\hline \multicolumn{9}{|l|}{ Zuni Mountains } \\
\hline Bluewater & 10.35 & 47.6 & 44 & 19.3 & .91 & .51 & 122 & 6650 \\
\hline $\begin{array}{l}\text { El Morro National } \\
\text { Monument }\end{array}$ & 13.07 & 47.6 & - & 30.1 & 1.26 & .85 & - & 7218 \\
\hline Grants & 8.46 & 51.5 & - & 13.8 & .98 & .60 & - & 6500 \\
\hline San Rafael & 14.31 & 57.2 & 56 & 26.6 & .98 & .30 & - & 6509 \\
\hline \multicolumn{9}{|l|}{ Gila and Southwest } \\
\hline Bear Creek Ranch & 13.08 & - & - & - & - & 1.14 & - & 5300 \\
\hline Buckhorn & 11.02 & - & - & - & - & 1.14 & 161 & 4900 \\
\hline Cliff & 14.35 & 57.9 & 52 & - & - & .78 & 171 & 4800 \\
\hline Cureton Ranch & 13.11 & - & - & - & - & 1.01 & - & 5200 \\
\hline Ft. Bayard & 16.38 & 55.0 & 68 & 27.1 & 1.4 & .63 & 194 & 6152 \\
\hline Mimbres RS & 17.36 & - & 50 & - & 1.33 & .82 & 162 & 5754 \\
\hline Pinos Altos & 23.08 & $51.42 *$ & 95 & $45.2^{*}$ & 1.54 & .70 & 127 & 7000 \\
\hline Silver City & 16.83 & 53.4 & 67 & 30.7 & 1.54 & .74 & 180 & 6051 \\
\hline Tyrone & 14.98 & - & 49 & - & - & .70 & 190 & 5923 \\
\hline Tyrone Station & 24.28 & 49.99 & - & 54.0 & 1.61 & .86 & 180 & 7986 \\
\hline White Signal & 13.59 & - & - & - & 1.58 & 1.13 & 210 & 6070 \\
\hline Whitewater & 7.32 & - & - & - & - & .33 & - & 5150 \\
\hline
\end{tabular}

UTAH

\section{North Central}

$\begin{array}{ll}\text { Alpine } & 15.94 \\ \text { Alta } & 57.33 \\ \text { Birdseye } & 12.37 \\ \text { Deer Creek Dam } & 22.10 \\ \text { East Portal } & 20.82\end{array}$

15.94
57.33
12.37
22.10
20.82

$\begin{array}{ccc}46.9^{*} & 57 & 48.0^{*} \\ 36.7^{\mathrm{b}} & - & 128.0 \\ - & - & - \\ 43.2 \mathrm{c} & - & 101.9 \\ 46.7^{\mathrm{c}} & - & -\end{array}$

$\begin{array}{llr}.77 & 1.14 & 100 \\ .77 & 1.79 & 90 \\ - & 1.16 & - \\ - & 1.42 & - \\ - & 1.45 * & -\end{array}$

${ }_{b}^{a}$ Borders on south central Colorado area.

No May-June records.

No December-April records. 
TABLE 5 (3)

State, Region, Station

\section{UTAH}

North Central

Lower American Fork

Maplewood

Provo Bench

Provo Radio

Soldier Summit

Spanish Fork

Thistle

Timpanogos Cave

Timpanogos Summit

Utah Lake - Lehi

West Portal
Mean Annual

Precipitation
Mean Annual

Temperature
A

B

C

D

E

F
16.73

20.18

17.33

14.76

14.04

17.55

17.16

24.92

32.92

12.25

28.79

$\begin{array}{lc}- & 42.1 \\ - & - \\ - & 49.6 \\ 66 & 42.1 \\ - & 65.3 \\ 83 & - \\ 69 & 57.0 \\ - & 71.8 \\ - & - \\ - & 33.6 \\ - & -\end{array}$

$\begin{array}{lr}- & 1.22 \\ - & 1.06 \\ .70 & 1.06 \\ .70 & 1.25 \\ .84 & 1.22 \\ .70 & .98 \\ .70 & 1.50 \\ - & 1.10 \\ - & 2.03 \\ .77 & 1.10 \\ - & 1.10\end{array}$

168

5063

- 4890

$140 \quad 5000$

$122 \quad 4650$

$60 \quad 7490$

$162 \quad 4711$

$90 \quad 5050$

9523
$-\quad 5300$

- 8300

$135 \quad 4497$ 


\section{LIST OF WITHIN-GROUPS VARIANCES}

1. Maximum Valley-Side Slope

A. Field measurements*

1) Within basins

$$
\mathrm{N}=880, \mathrm{k}=22, \mathrm{~s}^{2}=19.57, \mathrm{~s}=4.4^{\circ}
$$

2) Within lithologies

$$
\mathrm{N}=880, \mathrm{k}=6, \mathrm{~s}^{2}=126.19, \mathrm{~s}=11.2^{\circ}
$$

B. Map measurements

Within basins

$$
\mathrm{N}=413, \mathrm{k}=24, \mathrm{~s}^{2}=31.44, \mathrm{~s}=5.6^{\circ}
$$

2. Percent Bare Area

Within basins (individual field measurements)

$$
\mathrm{N}=222, \mathrm{k}=21, \mathrm{~s}^{2}=206.65, \mathrm{~s}=14.4 \%
$$

3. Infiltration Capacity

A. Within basins (individual field measurements)

$$
\mathrm{N}=122, \mathrm{k}=22, \mathrm{~s}^{2}=1.16, \mathrm{~s}=1.08 \mathrm{in} / \mathrm{hr} .
$$

B. Within lithologies (individual field measurements)

$$
\mathrm{N}=122, \mathrm{k}=6, \mathrm{~s}^{2}=1.31, \mathrm{~s}=1.14 \mathrm{in} / \mathrm{hr} .
$$

4. Roughness Number

Within lithologies

$$
\mathrm{N}=22, \mathrm{k}=6, \mathrm{~s}^{2}=628.8, \mathrm{~s}=25.08 \text { inches }
$$

5. Drainage Density

A. Within homogeneous, contiguous areas

$$
\mathrm{N}=100, \mathrm{k}=24, \mathrm{~s} 2=68.09, \mathrm{~s}=8.25 \text { per mile }
$$

B. Within lithologies

$$
\mathrm{N}=106, \mathrm{k}=6, \mathrm{~s} 2=407.33, \mathrm{~s}=20.18 \text { per mile }
$$

6. Relative Relief

Similar basins within homogeneous, contiguous areas

$$
\mathrm{N}=106, \mathrm{k}=25, \mathrm{~s}^{2}=3.24, \mathrm{~s}=1.80
$$

7. Ruggedness Number

Similar basins within homogeneous, contiguous areas

$$
\mathrm{N}=108, \mathrm{k}=26, \mathrm{~s}^{2}=0.596, \mathrm{~s}=0.772
$$

*N $=$ Total number of observations

$\mathrm{k}=$ Number of basins, lithologic classes, etc. 
TABLE 7

\section{INDIVIDUAL INFILTRATION-CAPACITY MEASUREMENTS}

BASIN

Arizona

CHINLE BADLANDS SPECIAL MAP
N. Basin
(shale)
S. Basin
"

1.1

1.2

1.1

1.0

PRESCOTT QUADRANGLE

Whipple Basin (Granite, alluvium)

1.6

1.5

1.7

1.8

SAGUARO MON. SPECIAL MAP (schist)

N. Basin

S. Basin

SONOITA QUADRANGLE

Hog Canyon Tributary (alluvium)
NFILT. SLOPE OF

CAP.

PLAT ( $\left.{ }^{\circ}\right)$

TYPE OF SURFACE

Bare, U*

Bare, U

Bare, U

Bare, U

Bare, U

Sparse grass, U

Bare, U

Bare, U

Bare, U

Bare, U

Bare, U

Bare, U

Loose leaves, $\mathrm{R} \dagger$

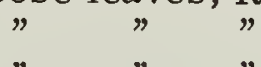

Bare, U

Loose leaves, $\mathrm{R}$ A removed

Loose leaves, $\mathrm{R}$ Sparse grass, U

Bare, U

Bare, U

Loose leaves, $\mathrm{R}$ ?

Bare, U

Grass litter, U

Grass, U

Grass, U

Grass, U

$1 / 2$ grass, $1 / 2$ bare, $U$

Grass, U

Grass, U

Pine litter, U

$" \quad, \mathrm{R}$

Bare, U

Grass, pine litter, U

Pine duff $\left(\mathrm{A}_{\text {oo }}\right), \mathrm{R}$

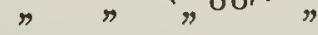

" " $"$

" $" \quad "$

$* \mathrm{U}=$ undisturbed surface 
TABLE 7 (2)

BASIN

Moon Gulch (gneiss, grantte)

INFII
CAP

2.2
1.8
3.1
4.1
2.4
1.2
3.4
3.8

$\underline{\text { New Mexico }}$

BLAND QUADRANGLE

Peters Dome Basin (pumice, rhyolite)

2.9

3.0

2.9

2.3

1.9

1.5

2.6

CERRO DEL GRANT QUADRANGLE

Cerro Pavo Basin (scoria)

JAROSA QUADRANGLE

Hairpin Basin (sandstone)

Poleo Basin (sandstone, limestone)

\section{PAXTON SPRINGS QUADRANGLE}

Quartz Hill Basin (granite)
SLOPE OF PLAT $\left({ }^{\circ}\right)$

8
12
9
14
1
7
3
5

8

2

14

4

4

3.8
TYPE OF SURFACE

$$
\left.\begin{array}{l}
\text { Grass, } \mathrm{U} \\
\text { Pine duff } \\
\operatorname{A}_{\eta} \mathrm{\textrm {c } _ { 0 }}
\end{array}\right), \underset{\eta}{\mathrm{R}}
$$

Bare, U

Pine duff $\left(\mathrm{A}_{\%}\right), \underset{\eta}{\mathrm{R}}$

$" \quad " \quad " \quad$ "

$$
\begin{aligned}
& \text { Pine duff }\left(A_{o o}\right), R \\
& \text { Fir duff, } \mathrm{R} \\
& \text { Pine duff }\left(\mathrm{A}_{o o}\right), \mathrm{R} \\
& \left.n ", A_{n}\right), \\
& \text { " } " \# \\
& \text { " }
\end{aligned}
$$

Fir needles, R

Grass, U

Grass, U

Fir needles, $\mathrm{R}$ Loose leaves, $\mathrm{R}$ Grass, U

Pine duff, $\mathrm{R}$

Grass, U

Leaves, $\mathrm{R}$

Grass, U

Pine duff, $\mathrm{R}$

Grass; leaves $\mathrm{R}$

Grass; U

Pine duff, $\mathrm{R}$

Pine duff, $\mathrm{R}$

$\gg "$

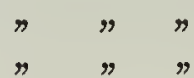

Grass, U

"

$\underset{n}{\text { Pine duff, R }}$

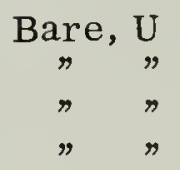

Pine duff, $\mathrm{R}$

Bare, U 
TABLE 7 (3)

\section{BASIN}

SANTA FE QUADRANGLE

Camino Basin (alluvium)

Tano Basin (alluvium)

SEDILLO QUADRANGLE

Cedro Peak Basin (sandstone, shale)
SLOPE OF

PLAT $\left({ }^{\circ}\right)$

CAP.

2.0

1.4

2.3

1.6

2.8

1.4

1.6

1.5

2.1

1.2

2.0

1.4

1.5

2.9

2.5

2.3
TYPE OF SURFACE

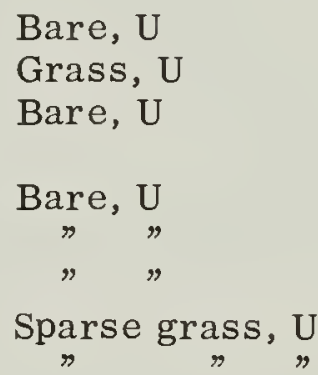

Bare, U

Bare, U

Pine duff, $\mathrm{R}$

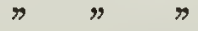

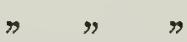

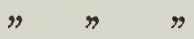

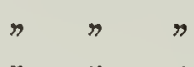

$\underline{\text { Utah }}$

\section{LEHI QUADRANGLE}

Dry Hollow (quartzite, volcanic)

SPRINGVILLE QUADRANGLE

Hobble Cr.Trib. (sandstone)

Bare, U

Spring Creek (limestone)

Grass, U $\underset{\%}{\text { Bare, U }}$

"

Grass, U; oak lit. R

Additional measurements on residual granite soils:

$\underline{\text { Arizona }}$

HARSHAW (PATAGONIA MTNS.) QUAD. (granite) 2.3

IRON SPGS. (SIERRA PRIETA) QUAD. (granite) 2.5

$?$

Bare

Grass, R

Pine duff, $\mathrm{R}$

Bare, U

Pine duff, $R$ ?

Pine duff, $R$

Bare, U

Pine duff, $R$ 
102

TABLE 7 (4)

BASIN

INFILT.

CAP.

Arizona

KIRKLAND (SIERRA PRIETA) QUAD. (granite)

2.3

2.1

New Mexico

BIG BURRO MTNS. QUADRANGLE (granite)

4.0

3.7

$8.3+$

$8.3+$

FORT BAYARD (PINOS ALTOS) QUAD. (granite)

3.5

1.8

1.5

TWIN SISTERS (PINOS ALTOS MTNS.) QUAD. (granite)
2.1

3.5
SLOPE OF

PLAT $\left({ }^{\circ}\right)$

TYPE OF SURFACE

Pine duff, $\mathrm{R}$

Leaves, $\mathrm{R}$

Bare, U

$"$

$"$

Pine duff, $\mathrm{R}$

Bare, U

$"$ "

Bare, U 



